Exploring task-related student peer interactions in physical education

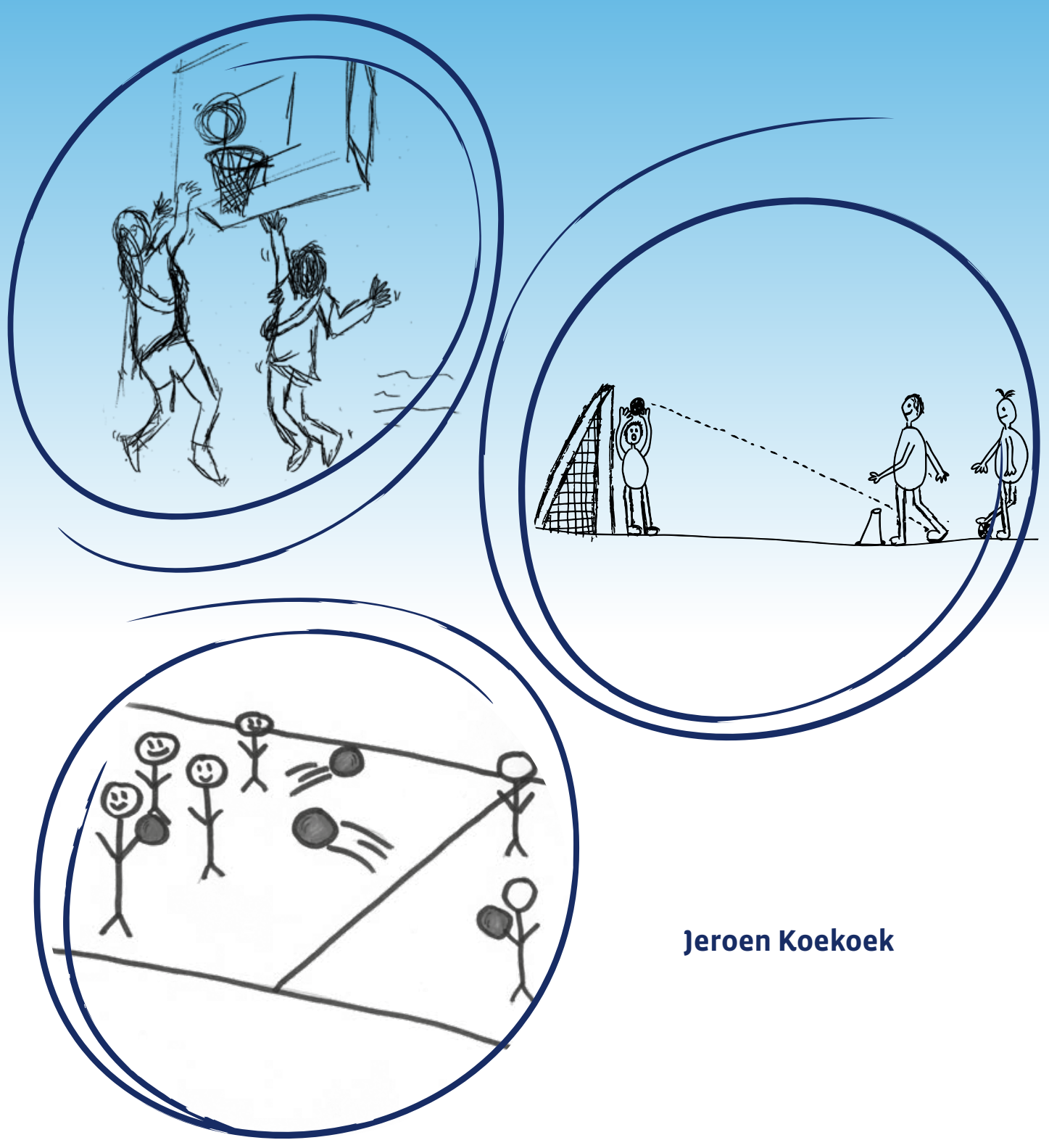





\section{Exploring task-related}

student peer interactions

in physical education
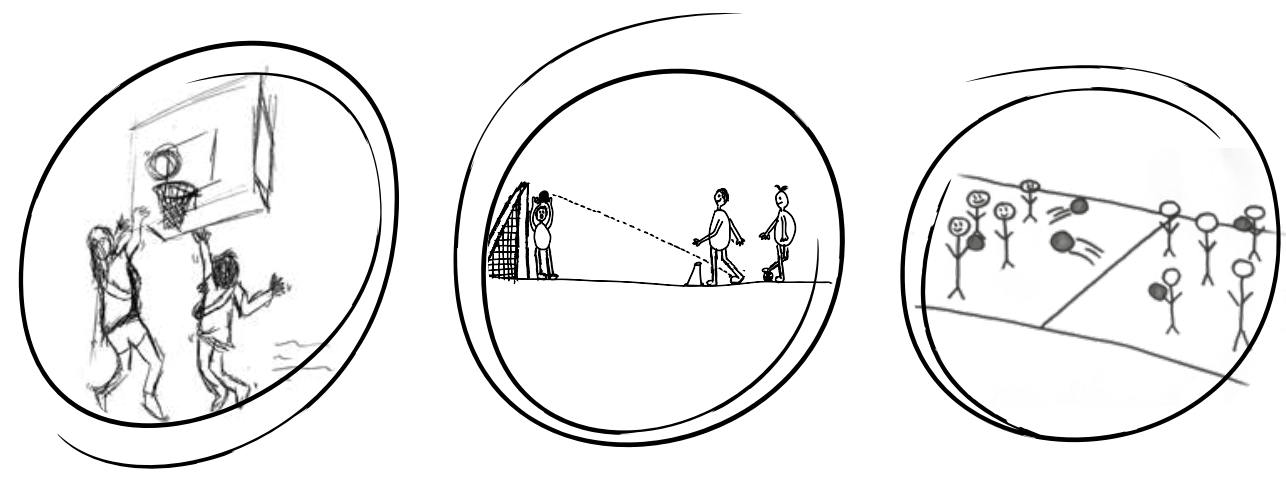



\section{Exploring task-related}

student peer interactions in physical education
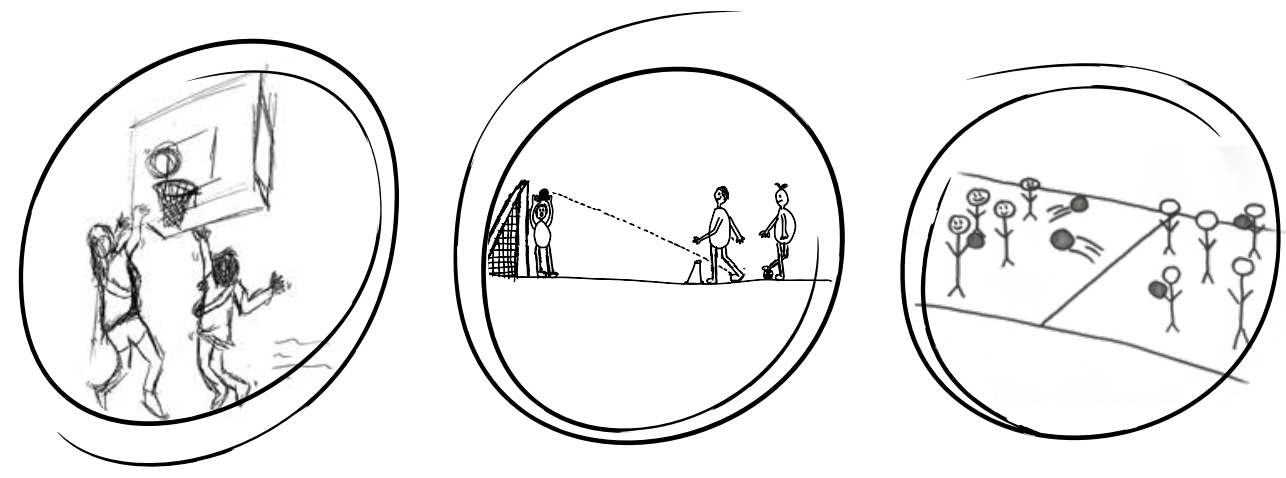

Jeroen Koekoek 


\section{Beoordelingscommissie}

\section{Prof. dr. M. van Bottenburg}

Prof. dr. M. de Haan

Prof. dr. K. De Martelaer

Dr. F.J. Prins

Prof. dr. M. Theeboom

Lay-out \& cover design: Arko Sports Media, Nieuwegein

Drawings cover: Alyke, Babeth, Jenthe, Marrit, Sari

Print: PrintSupport

ISBN 978-90-72335-71-5

NUR 180

With kind permission of Ágora para la Educación Física y el Deporte

With kind permission of Human Kinetics

With kind permission of Routledge

\section{(C) 2020 Jeroen Koekoek}

All rights reserved. Without limiting the rights under copyright reserved above, no part of this book may be reproduced, stored in or introduced into a retrieval system, or transmitted, in any form or by any means (electronic, mechanical, photocopying, recording or otherwise) without the written permission of both the copyright owner and author of the book. 


\title{
Exploring task-related student peer interactions in physical education
}

\author{
Een verkenning van taakgerelateerde \\ interacties tussen leerlingen in het \\ bewegingsonderwijs
}

(met een samenvatting in het Nederlands)

\section{Proefschrift}

ter verkrijging van de graad van doctor aan de

Universiteit Utrecht

op gezag van de

rector magnificus, prof. dr. H.R.B.M. Kummeling, ingevolge het besluit van het college voor promoties in het openbaar te verdedigen op

vrijdag 9 oktober 2020 des ochtends te 11.00 uur

door

Jeroen Henk Koekoek

geboren op 4 juli 1973 te Zwolle 


\section{Promotor:}

Prof. dr. A.E. Knoppers

Copromotoren:

Dr. I.M. van Hilvoorde

Dr. N. van Amsterdam

Dit proefschrift werd (mede) mogelijk gemaakt met financiële steun van Hogeschool Windesheim en Jan Luiting Fonds. 


\section{Table of Contents}

Part I General Introduction and Context

Chapter 1 General introduction .......................................................................................................10

Chapter 2 Perspectives on physical literacy in continental Europe ..............................32

Part II Informal Task-Related Peer Interactions

Chapter 3 How do children think they learn skills in physical education? .............50

Chapter 4 The role of perceptions of friendships and peers in learning skills in physical education

Chapter 5 Gender categorizations during group work in physical education 104

\section{Part III Formal Task-Related Peer Interactions}

Chapter 6 Exploring students' perceptions of video-guided debates in a game-based basketball setting

Chapter 7 Aligning digital video technology with game pedagogy in physical education

\section{Part IV General Discussion}

Chapter 8 Discussion and conclusion.

References .201

Samenvatting in het Nederlands (Summary in Dutch). .216

Dankwoord (Acknowledgements) .223

Curriculum vitae. 230

\section{Appendices}

Appendix $1 \quad$ Dutch elite youth soccer players' perceptions of a

TGfU-modified game practice.

Appendix 2

Co-auteursverklaring hoofdstuk 2.

Appendix 3

Co-auteursverklaring hoofdstuk 3 .276

Appendix 4

Co-auteursverklaring hoofdstuk 4 278

Appendix 5

Co-auteursverklaring hoofdstuk 5

Appendix 6

Co-auteursverklaring hoofdstuk 6

Appendix 7

Co-auteursverklaring hoofdstuk 7 . 


\section{Part I General \\ Introduction and Context}




\section{Chapter 1 General introduction}

Chapter 2

Perspectives on physical literacy in continental Europe 


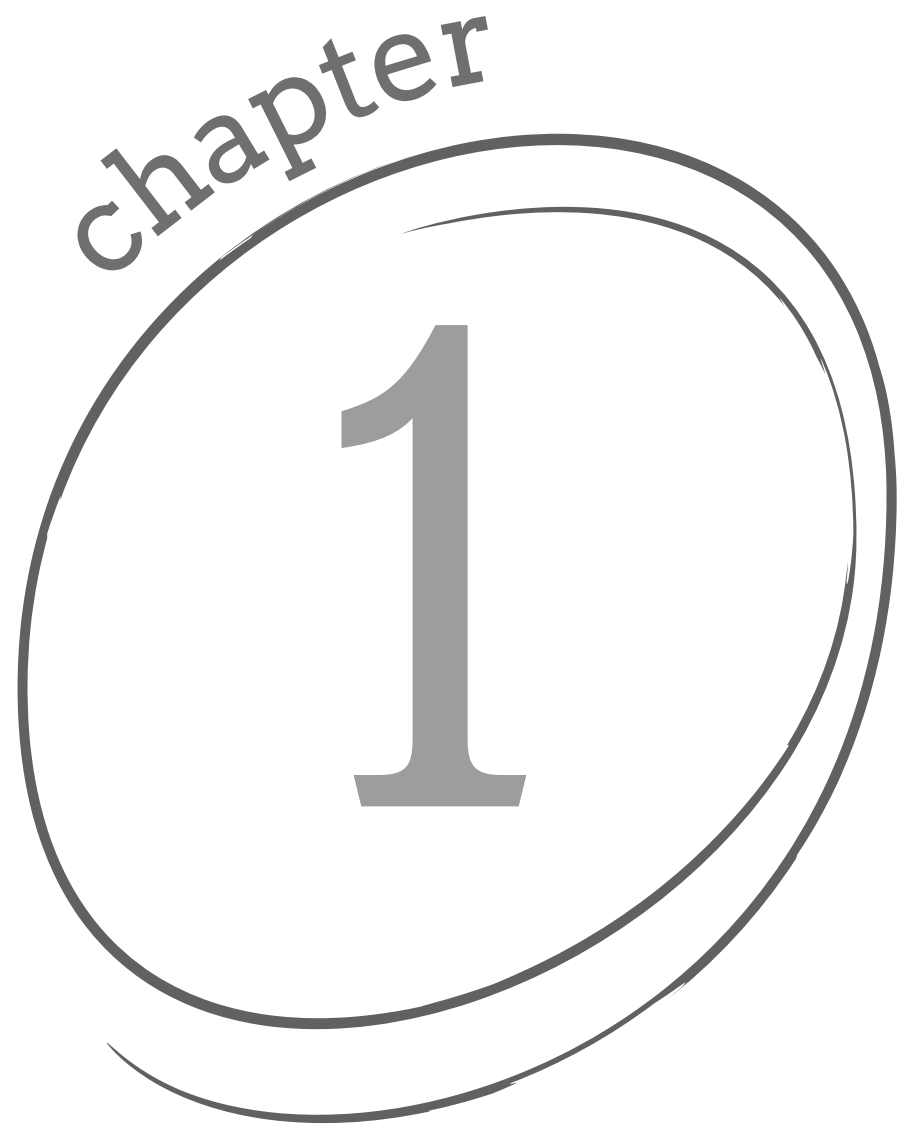




\section{General introduction}

Movement and education are essential for each living human. For that reason, I am very fortunate that I had many opportunities in my youth to be engaged in sports and to be physically active. I enjoyed most of the movement activities during physical education (PE) lessons at school, and I will never forget the exciting time when I learned how to play handball at my sports club. I had many positive experiences in $\mathrm{PE}$ and in most sports activities and sport events that took place during my school period. Looking back, I was particularly attracted to the sports environment and the sports culture in my school, but I also very much appreciated the dedication and positive feedback of my teachers and coaches who taught me the necessary insights and skills. Even more important, I attached great value in learning and playing together with my classmates and friends.

Although I was not specifically aware of why, what or how I learned, my current knowledge makes me realize that I learned much more than I thought. Besides learning movement activities, I learned about what happens during work groups in PE as I was implicitly and explicitly confronted with my classmates' attitudes and expectations. The PE classroom was also frequently the place where I held discussions with my classmates, sometimes accompanied by their affective behaviors and emotions. I currently know that, in contrast to most other school subjects, PE is a site where performances, attitudes, and skills are visible for each student in class. Although I do not remember all details of my PEclasses and what all these experiences in PE meant to me, at present I do realize that my implicit learning experiences in both PE and the sports club made sense for me, for who I was as a child learning the world, and who I am in daily life as well. Now, I also realize that I was not aware that the perceptions of my classmates, and how they experience PE, may have been quite different from my own experience.

My interest in my 'unknown' learning experiences in PE and sports is also one of my main reasons to study the learning experiences of students. I know that I have learned a lot about the struggle of finding solutions for learning problems, and the challenge of learning a new sport. I associated these processes of struggling with having fun and pleasure, in particular when working with others. Last but not least, I felt myself competent and literate and developed a positive sport identity regarding 
PE and sports. Nevertheless, the factors that influenced my route or learning path remains unclear in how I personally learned these skills.

Similar to my experiences, various scholars underscore the assumption that students ${ }^{1}$ benefit from PE because their learning experiences may positively contribute to long-life participation in physical activity (Bailey, 2006; Dudley, Okely, Pearson, \& Cotton, 2011; Kirk, 2005). However, relatively little work has been done to explore underlying mechanisms (Webster, 2017). For instance, the context of PE does not explain why one student learns movement activities in ways that are similar to the experiences I had, and why other students experience learning difficulties. In contrast to possible positive outcomes, several studies also have pointed out that negative learning experiences with $\mathrm{PE}$ can result in alienation from PE classes (Carlson, 1995; Slagt, 2018; Spencer-Cavaliere \& Rintoul, 2012). People who had negative experiences in PE may also develop an aversion to being physically active later in life (Cardinal, Yan, \& Cardinal, 2013). Thus, the way students experience PE seems to be crucial, not only for their learning and participation during lessons, but also for initiatives in sport and physical activities they might take up after graduation from high school.

When I began to work as a PE teacher, I realized that information about how children perceive their learning experiences can be important when I am teaching them movement activities. My interest in this subject remained when I continued as a PE teacher educator and when supervising pre-service student internships. Currently, as a lecturer and researcher, I am in a position to explore possible answers that explain the informal and formal learning that may occur in PE. In line with the development of my professional career, the research in this dissertation is of interest for both scholars and teacher educators, as well as practitioners (teachers and coaches) focusing on physical education pedagogy.

In this dissertation, I explore how students aged 11-13 perceive their learning experiences in PE. This means that the viewpoint and meanings ${ }^{2}$ students assign to learning processes have a central position in this dissertation, instead of me determining what exactly these learning outcomes or performances are. This implies that I neither explicitly define what learning is for students, nor explicate what learning should be for them in physical education. Also, I am not specifically studying the formal content knowledge that has to be learned in physical education. In this dissertation when I refer to what students perceive as learning 
or the learning of tasks, I consider this learning to be personal and contextual (Crotty, 1998; Dyson, 2006; Webster, 2017). This means that student experiences and expectations shape and construct learning processes within their specific context. This perspective positions student learning within a broad possibility of outcomes in physical education (Barker, Quennerstedt, \& Annerstedt, 2015; Casey \& Goodyear, 2015; Quennerstedt et al., 2014). Consequently, I assume that learning in PE contributes to student physical literacy (Whitehead, 2010) that consists of more than the acquisition of (fundamental) skills and movement competencies (Pot, Van Hilvoorde, Afonso, Koekoek, \& Almond, 2017). The learning of assigned tasks in PE may contain relational as well as affective elements. I elaborate on these assumptions in the next paragraphs.

\section{Social interactions in education}

Schools have evolved as sites for learning. Specifically, for students this learning occurs through interactions with humans including adults and children. The teacher-child interaction is shaped by the requirements of the national and school-based curriculum. In this dissertation, I refer to the lessons based on these requirements as the formal curriculum. These lessons are shaped not only by child-object and adult-child interactions, but also by child-child interactions, often called peer interactions. Vygotsky (1978) is one of the founders regarding theories of interactions between peers, and how it contributes to the development of a child's learning. According to Vygotsky, peer interactions are fundamental in how learners construct their knowledge. Vygotsky argued that the essential feature of learning is as follows:

\section{... learning awakens a variety of internal developmental processes that are able to operate only when the child is interacting with people in his [sic] environment and in cooperation with his peers. Once these processes are internalized, they become part of the child's independent developmental achievement. (p. 90)}

The context in which PE takes place means that interactions with others play a central role when teachers want to develop physically literate individuals (e.g., Mandigo, Francis, Lodewyk, \& Lopez, 2009; Society of Health and Physical Educators, 
2014). Whitehead (2010) argued that the embodied dimension (i.e., physical competences and motor abilities), which is a central aspect in $\mathrm{PE},{ }^{\prime \prime}$... lies at the heart of interpersonal relationships" (p. 61). This means that during the development of physical literacy, physical competence and motor abilities play a role during social interactions. These interactions and skills may reciprocally affect children's perceptions of themselves and others.

Peer interactions can be part of the formal curriculum when they are given tasks in which they have to work together. In addition to the transmission of the formal curriculum, teachers and children also are part of informal learning processes during which they encounter messages that may not always be part of the formal curriculum. For example, various scholars (e.g., Flintoff \& Dowling, 2019; Van Amsterdam, Knoppers, Claringbould, \& Jongmans, 2012; Van Doodewaard \& Knoppers, 2018) found that PE teachers may convey a racial/ethnic hierarchy in their interactions with children during PE lessons. Specifically, they may draw on discourses that center white male bodies and marginalize bodies marked as female and/or black.

Similar to physical educators, children may also draw on discourses of ability and gender in their peer interactions (Azzarito, Solmon, \& Harrison Jr, 2006; Hills \& Croston,2012; Wright,1996). For example, Hills (2007) explored girls' understanding of social relationships in $\mathrm{PE}$ settings and found that peer interactions had a positive influence on their enjoyment in participating PE activities. Hills also found that social interactions that occur on the basis of friendships may lead to increased motivation and participation in lessons. The formation of cliques or partnerships can also contribute to the exclusion and marginalization of other girls, however. Although Hills' work emphasized the influence of social interactions and how they may positively influence PE classes, she did not explicitly examine perceptions of collaboration between peers when given assigned PE tasks, nor the interpretations of boys in heterogeneous PE classes. The nature of these interactions may play a role, however, in student involvement and experiences in PE. Recently, Solmon (2017) argued that an evidence-based practice is needed that contributes to understanding of how students learn skills in PE. Solmon pointed out that:

... because students do not always perceive instructional behaviors and class events as the teacher intends, it is an important endeavor for teachers to include checks for understanding in their lessons. (p. 498) 
Solmon underscores the need to explore students' meanings when working on tasks given by the teacher. $\mathrm{PE}$ is often organized in coeducational settings where collaboration between peers is a central aspect of the teaching practice (e.g., Annerstedt, 2008; Hardman, Murphy, Routen, \& Tones, 2013). The interactions that derive from this collaboration influence the learning situation in PE classroom settings. A focus on the way students interact in these learning situations may contribute to an understanding of social skills that need to be addressed by teachers in PE lessons (Barker et al., 2015). A positive facilitation of student-student interactions by teachers could, for example, result in effective classroom practices (Hamre et al.,2013). Student reflections on their own interactions and those of others in the group may therefore provide teachers with insights in how to organize and manage the classroom context. This requires empirical investigation of children's perceptions regarding task-related interactions between peers and how these may occur in the specific and unique site of the subject PE in schools.

Physical education is not the only place, however, where the content of peer interactions in school lessons may play an important role in experiences and collaboration. Other subjects in school may also require children to collaborate and therefore, interact with their peers. For example, music education includes activities and tasks that are congruent with how children must participate and interact publicly during PElessons. Since music is an activity that requires visible and physical public performance, music education also basically draws on collaboration and group processes. Children learn to make music together, so music lessons often include processes of social interactions between peers (Faulkner, 2003; Harrington, 2016). Research with a focus on processes of collaborative learning in music education showed that context plays an important role (Olsson,2007). The quality of 'horizontal interactions' (i.e., those interactions that occur in lessons among peers) in music lessons are highly dependent on relationships. Similar to what Hills (2007) found in the context of $\mathrm{PE}$, friendship relations in music educational contexts have a positive influence on ways children work together and share ideas. For example, Burland and Davidson (2001) found that friendships have a positive effect on how children solve conflict situations during group tasks. Their study indicated that children had a more positive emotional or social experience when working with friends than with others in groups. Harrington (2016) explored how students interact when working in small group music ensembles and discovered positive learning structures. For example, participants created small or subgroups to identify musical problems, they 
used positive and negative peer pressure that provided organic social structures that contributed to team efficacy, and they showed a willingness to work harder toward group goals when empowered with the responsibility for their own learning.

These empirical studies from the field of music education may serve as a valuable source of information for establishing $\mathrm{PE}$ research. The results in music education research suggest that the social context can be characterized as "ongoing reciprocity" (Olsson, 2007). This reciprocal character means that the social context influences individuals' learning on the basis of interactions with others, while the individual also influences the values (beliefs and attitudes) that exist in collaborative work. According to Olsson (2007), music education is a dynamic site that constantly embraces change. The interactions require students to attune to each other through improvisation and negotiation. Since social processes in music education are dynamic, the setting in which they take place is also never a stable or fixed situation. These characteristics of music education regarding collaborative learning (i.e., reciprocity and change) underscore the value of social interactions. Interactions with peers are assigned to educational processes that partly determine the quality of teaching and learning of music in schools. The results from music education studies can contribute to a greater understanding of the complexity, the nature, and the role of horizontal interactions in PE when children work together on tasks. Namely, both subjects demonstrate several parallels that show the unique position they have within school. For instance, students are dependent on the involvement of their peers, they must attune to each other's abilities in order to achieve positive task-related outcomes, and most of what occurs in the classroom is visible and public for others (classmates and teacher).

In this dissertation, I explore what the horizontal interactions within the social context of PE lessons mean for how children think about working on collaborative tasks. Investigating the social context in PE can be valuable in order to understand under what conditions these task-related peer interactions may occur and how they contribute to constructions of learning tasks in the field of physical education lessons in schools.

I assume that both informal and formal aspects can be revealed in these constructions of the learning context. Therefore, I explore student constructions of learning assigned tasks within a context that includes classmates and the teacher. Both teacher and students are part of the curriculum that contains both formal and informal aspects. This means I use a broad definition of curriculum that comprises 
PE lessons with both planned and informal experiences (Cothran, 2017). In addition, I explore student constructions of learning processes when children work together on assigned tasks, but also when fixed pedagogical tools are integrated within a model-based practice (i.e., Teaching Games for Understanding). I then focus on students' constructions of learning when formal teaching methods are used such as observation tools and debate sessions that facilitate verbal exchanges during discussions.

\section{Research questions}

The central research question of this dissertation is: How do formal and informal task-related peer interactions constitute the PE curriculum? This central question will be answered in chapters in Part II and Part III of this dissertation. In the remaining chapter of Part I of this dissertation (Chapter 2), I describe the current state of Dutch physical education and its link with physical literacy. I link physical literacy to the use of a Teaching Games for Understanding (TGfU) curriculum (Doozan \& Bae,2016; Jurbala, 2015). TGfU is a game-based approach that is commonly used for teaching physical education in the Netherlands. I discuss the concept of physical literacy and how it has been integrated within PE. I reflect on developments that may influence processes of collaboration, and I demonstrate similarities of TGfU with social constructivist related PE standards in the Netherlands.

In Part II of this dissertation, I describe several empirical studies regarding informal task-related peer interactions with the following subquestions:

- How do children describe their learning experiences in physical education (Chapter 3)?

- What are children's perceptions of collaboration, group formations and friendships in a modified baseball game (Chapter 4)?

- How do gender constructions shape the way children form groups and how do they think these groups inform their learning (Chapter 5)?

Part III consists of chapters related to formal task-related peer interactions with the following subquestions: 
- How do children perceive tactical elements in a game-based setting with video after a debate of ideas (Chapter 6)?

- How are student perceptions of tactical elements shaped by teacher use of a pedagogical tool that promotes task-related interactions within a game-based curriculum (Chapter 7)?

Part IV of this dissertation contains a general discussion and conclusions with a focus on answers to the central research question (Chapter 8).

In the remaining paragraphs of this chapter, I give an overview of the role that taskrelated interactions play in learning processes in education. First, I point out how interactions can be part of a formal and informal curriculum in PE. I continue with formulating what I mean by formal and informal curriculum. Subsequently, I outline a research framework based on social constructivist learning. This introduction chapter ends with an overview of the methodology I used and of the content of each chapter.

\section{Interactions in the formal PE curriculum}

Since PE is considered a place that enables youth to develop themselves as physically literate individuals, teachers may present a formal curriculum in which task-related interactions are required (see for example, Society of Health and Physical Educators, 2014). Learner-centered models such as Teaching Games for Understanding (TGfU) and Sport Education use a formal curriculum in which students must work together in small groups (Stolz \& Pill, 2014). TGfU approaches can add to an individual's physical literacy because task-related interactions among peers are assumed to stimulate student critical thinking processes (Doozan \& Bae, 2016). Teachers who implement a TGfU approach in lessons should have the knowledge and understanding to manage processes of interactions between peers. Scholarly attention for how these discussions between students occur is relatively scarce, however. Moreover, teachers may find the moderation of student interactions quite challenging. Forrest (2014), for example, explored how pre-service teachers gained an understanding of how they could effectively use a game-based approach, with the use of questioning approaches such as debates. During a debate, children shared meanings that were based on their understanding of the learning situation. Analysis 
of the teachers' self-reflection reports showed that they had difficulties in managing these questioning processes. The study did not, however, investigate what actually occurred during these discussions.

This lack of teacher competency in using questioning and debates seems to be in contrast to the tenets of game-centered pedagogies where peer interactions are stimulated. Task-related interactions play a central role when teachers use a didactical tool called 'debate of ideas'. In a 'debate of ideas' setting, students discuss strategies and exchange tactical ideas in-between play (Gréhaigne et al., 2001; Gréhaigne, Richard, \& Griffin, 2005; Mitchell, Oslin, \& Griffin, 2013; Storey \& Butler, 2010). Through these interactions, students themselves discovered fitting tactical solutions instead of the teacher prescribing an optimal solution. Questions and discussions are supposed to increase the awareness of students of the importance of the dynamics of the game (Harvey, Cope, \& Jones, 2016; Harvey $\&$ Light, 2015). This means that asking questions and stimulating peers to verbally interact about strategies and intentions during time-outs may strengthen students' tactical thinking (Almond,2015). Teachers in turn, must use questions and stimulate discussions when developing students' tactical understanding in games (Gréhaigne, Godbout, \& Bouthier,2001). Although TGfU models may centralize peer interactions in learning processes, teachers may not necessarily have sufficient skills to support these complex processes in game teaching (Forrest, 2014). Relatively little research has been conducted that explores these processes of social interactions in 'debate of ideas' settings. New knowledge is needed regarding these task-related interactions in order to understand what students think they learn during discussion and question sessions in PE.

\section{Task-related interactions within PE}

In the previous paragraphs I stressed the importance of collaborative student interactions in PE as well as in music education. Various PE scholars have pointed to the important role of social processes that shape students' learning experiences (see for example, Bailey, 2006; Darnis \& Lafont, 2015; Dyson, 2005; Jourand, Adé, Sève, Komar, \& Thouvarecq, 2018; Qi \& Wang, 2018). Their research recognizes the importance of collaborative peer interactions in PE. A research project by Beni, Fletcher and Ní Chróinín (2017) is illustrative. They explored several empirical studies regarding meaningful experiences of students in PE and youth sport. Beni 
et al. found sufficient empirical evidence that social interactions in PE lessons are one of the central aspects that contribute to meaningful engagement of students in PE.

$\mathrm{PE}$ is therefore a site where students must work together deliberately or unintentionally. Barker et al. (2015) observed group work during PE and analyzed recorded videos of students' interactions. Barker et al. found that these task-related interactions between students led to unpredictable outcomes. In other words, when students engaged in group work that required collaboration, their learning outcomes were multidimensional (i.e., motoric, interpersonal or in the affective domain) and might not necessarily be a result of a teacher's pedagogical intentions. Although these researchers used interviews in their research, they did not explore student perceptions and motivations of collaboration. Eliciting these could bring deeper understanding of reasons why student interactions may be effective and also sometimes ineffective for quality $\mathrm{PE}$.

Darnis and Lafont (2015) conducted a study that showed a similar methodology to that of Barker et al. (2015). Darnis and Lafont filmed students' verbal interactions during small discussion groups when learning to play basketball. These students held discussions during 'debate of ideas' sessions in a Cooperative Learning model. The researchers used a social constructivist perspective. They found that verbal interactions in group work had positive effects on the development of students' skill level and the tactical choices students made during the games. The study showed the value of having discussions during debates in team teaching situations and that interactions helped the students in becoming more competent in team sports. Darnis and Lafont (2015) did not, however, ask students why these social interactions contributed to positive learning experiences. In other words, student perceptions of these interactions and how they occurred during group work were unknown. This information, however, may help teachers to understand how interactions between peers shape the learning situation in PE.

The foregoing studies (including those from the music education domain) show the relevance and meaning of reciprocal task-related student interactions in applied education settings such as PE. However, the construction of horizontal interactions by students in PE is underexplored (Webster, 2017). Therefore, peer interactions and how students construct these processes in collaborative settings in PE justify a thorough exploration. Such an investigation includes the use of qualitative research approaches to understand these interactions, to clarify underlying perspectives 
of students regarding collaboration. Knowing what students experience in collaborative work in PE may not be similar to getting information about what these processes exactly are, and also may be different than in music education. In PE, the embodied dimension seems to be highly dominant for those involved (Whitehead, 2010). In addition, PE is a unique context due to the emphasis on performance (in particular traditional settings, see Pearson \& Webb, 2009) or through reproducing body norms (Van Amsterdam, 2014). The visibility of individual body performances (such as being physically active in a space together with others) may also be a decisive aspect for shaping ongoing reciprocity. I recognize that researchers often fail to problematize how embodied learning processes in PE may shape student attitudes and expectations of PE. Task-related interactions in the classroom may influence these students' perspectives. The results of the previously mentioned study of Barker et al. (2015) emphasized the notion that task-related interactions during PE classes shape the way students perceive and construct the learning situation.

In line with the original tenets of the work of Vygotsky (1978), I assume that formulations of learning outcomes in PE settings (i.e., outcomes have been formulated in teacher learning objectives), are also socially constructed by the social and situated practice of student interactions (Kirk \& MacDonald, 1998). From this perspective, social interactions are an integral part of student learning in $\mathrm{PE}$, because many learning situations require peer interactions regarding collaboration, communication and negotiation. This is pertinent because PE lessons often consist of situations where informal and formal interactions occur, such as when teachers organize debates and discussions, or when a PE activity requires collaboration and verbal communication. To be more specific, I position $\mathrm{PE}$ as a specific site similar to other subject domains in school such as music education, where task-related interactions between students (i.e., by communicating, negotiating, meaningmaking) may determine the shape of the outcome. The results of an exploration of student viewpoints regarding the role of interactions and meaning-making in the PE context can add to the understanding of how researchers and teachers can align formal pedagogical methods with the needs of students. With this dissertation, I contribute to scholarly work that reveals these perceptions of task-related interactions in PE. These interactions are, however, always situated within a formal curriculum. 


\section{Functional curriculum in physical education}

Planned experiences and outcomes refer to the formal content of a curriculum that is written by teachers or by the government. These experiences can also be understood as the written and the recommended curriculum (Cothran, 2017; Glatthorn, 2000). However, a formal curriculum also contains informal experiences that may include student perceptions of learning processes. Those learning processes in PE, seen through the eyes of students, can provide insights in how they shape the learning context when teachers want to achieve a rich learning climate during classes. I assume that such interactions enable students to create their own curriculum (an informal curriculum) that may differ from the intended curriculum (formal curriculum) presented by the teacher.

A learned curriculum (Glatthorn, 2000), or also called hidden curriculum (Kirk, 1992), refers to unintended informal experiences that occur during lessons ${ }^{3}$. Informal experiences emerge from student beliefs and behaviors that are based on both the prescribed content and the teacher's pedagogical intentions (Cothran, 2017). These implicit processes often remain unexposed but may determine how students think about their competence and performance. The informal experiences that emerge in a formal PE curriculum are partly determined by the way the subject $\mathrm{PE}$ is perceived by students, but also by teachers. Moreover, what students bring to the class (e.g., by having interactions) also contributes to informal learning. Thus, a PE curriculum consists of formal aspects but also includes informal student experiences (Capel,2007; Casey, 2017; Jacobs, Knoppers, \& Webb, 2013).

Various scholars (e.g., Kirk, 1992; Nutt \& Clarke, 2002) specifically addressed the position and recognition of the hidden curriculum ${ }^{4}$. For example, Kirk (1992) argued that studies of the hidden curriculum must include a focus on communication and meaning-making. Kirk stressed that discourses on gender and stereotyping are consciously and unconsciously present in teaching and learning physical education. Specifically, the body and stereotyped or dominant notions of masculinity and femininity that are constructed and challenged during PElessons are often taken for granted but may have a huge impact on teacher and student identities. Kirk's notion of the hidden curriculum stimulated several others to explore it by considering the role of norms, values and ways of behaving during interactions. For example, Rønholt (2002) explored verbal interactions between teachers and students and found that teachers unintentionally created a hidden curriculum by communicating gendered attitudes that also directly shaped the formal PE program. Specifically, the teacher 
assigned boys and girls different tasks and also had gendered expectations of their abilities. Van Doodewaard and Knoppers (2018) also found that physical educators used a hidden curriculum that consisted of a racialized discourse that normalized national (Dutch) norms for all children in class regardless of ethnic background.

Research by Rønholt (2002) and Van Doodewaard and Knoppers (2018) suggest that teachers use implicit norms when interacting with students in PEclasses. Their findings revealed how PE teachers created an informal hidden curriculum. These studies did not, however, problematize how the students themselves contributed to the formal curriculum and created an informal curriculum in their interactions. Recently, Jung, Ressler and Linder (2018) explored Physical Education Teacher Education (PETE) students recall of the hidden curriculum in their formal primary and secondary school physical education experiences. The researchers identified both negative and positive outcomes. Negative outcomes were found regarding the poor accountability of PE and marginalized programs for students in which teachers limited their instructions and expected outcomes to students. In addition, an over-emphasis on competition (thereby marginalizing low skilled students as a result) and biased curriculum offerings (i.e., a curriculum that is mainly based on the preferences of the teacher) were also perceived as negative outcomes of the hidden curriculum. Jung et al. (2018) concluded that peer relationships were perceived by students as a positive outcome. Specifically, students were positive when their teacher enhanced interactions and relationships in the class through strong organization, clear direction for teaching and learning, and appropriately sequencing activities and experiences. These students would then also demonstrate an investment in the class and showed their effort to contribute to goals stated by the group.

Positive peer relationships and interactions in PE classes therefore, seem to be highly dependent on how teachers organize lessons. However, it remains unclear what exactly occurs in task-related interactions and which relationships contribute to creating a positive pedagogy, regardless of the teacher's skills and competencies. For example, specific social groupings that are applied in the context of music education already showed that friendships are positively related to the quality of interactions when working on assigned tasks (Burland \& Davidson, 2001). Casey (2017) suggested that recent insights regarding the role of social interactions in PE inform processes that occur in the hidden curriculum (see for example Barker et al., 2017). Still, relatively little scholarly attention has been paid to this topic. The results 
of my research are also shaped by the theoretical framework in which it is situated. In the next section, I elaborate on social constructivism in order to stress how this framework may help to understand task-related interactions in PE.

\section{Social constructivist framework}

This dissertation is situated within a social constructivist framework. Social constructivist perspectives of learning that focus on the role of interactions have been highly influenced by cognitive psychology theorists Piaget (1964), Vygotsky (1978), and others (e.g., Bandura,1977; Von Glasersfeld,1990). Piaget's (1964) notion of development regarding 'learning through assimilation' played a key role in shifting traditional perspectives that had been described in specifically behavioral stimulus response theories. Piaget defined assimilation as:

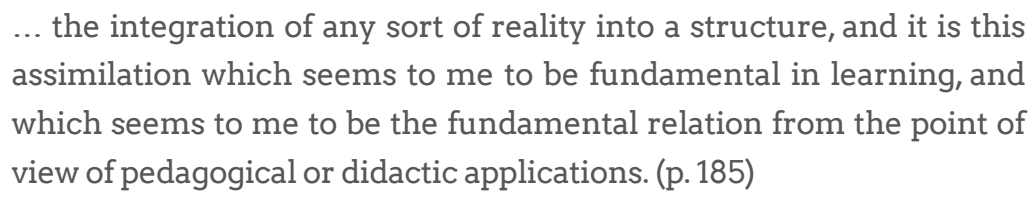

Instead of focusing on the stimulus (i.e., the teaching and instruction aspect), Piaget (1964) centralized the activity of the learner by introducing the idea of self-regulation, what he called equilibrium. According to Piaget (1964), the development of human beings is steered by universal irreversibly fixed stages. Cognitive development from this perspective is based on aspects such as the cognitive structures that determine what information is selected from the environment. Both Piaget and Vygotsky argued therefore, that a relationship exists between the individual and the social (Cole \& Wertsch, 1996).

Vygotsky's (1978) paradigm of knowledge construction assumes that cognitive processes in learning are primarily determined by social and cultural interactions (Davydov \& Kerr, 1995). Social constructivism sees "learning as an active process of constructing knowledge to make sense of the world" (Adams,2006,p. 245). Vygotsky emphasized that social relations are fundamental for the ways learners construct their knowledge. He assumed language emerges from knowledge that is developed through interactions and communications in the world (Davydov \& Kerr, 1995). Learning seen as a language means that the learner constructs knowledge based 
on social interactions, which is the reality of others at the same time. This original work of Vygotsky highlights the role of the social context (e.g., teachers and peers) including interactions that are unavoidable and undeniable in learning processes, in particular for the position of the learner in his or her learning process. A possible way to include a social constructivist framework in conducting research in $\mathrm{PE}$ is to examine student perceptions. These perceptions are assumed to be individual constructions of students' own learning experiences in the classroom setting on the basis of task-related interactions (Azzarito \& Ennis, 2003; Beni et al.,2017). Sun (2017) stressed that a social constructivist perspective suggests "... learning occurs when the learner internalizes the social experience by interacting with others" (p. 631). In other words, social constructivism assumes that learning is considered as an active process in which the learner actively makes sense of the learning situation. I base this dissertation on the assumption that peer interactions need to be studied because they are a site where conditions for learning are created.

\section{Complexity of social constructivist PE research}

Social constructivism is influenced by contemporary theories of learning as described in the previous paragraphs. The development of this perspective has resulted in a variety of theoretical nuances and themes (Rovegno \& Dolly, 2006; Young \& Collin, 2004). Rovegno and Dolly (2006) pointed that most research in physical education settings focuses on multiple aspects of the educational praxis such as teaching, learning, and curriculum. This means that the findings in research based on a social constructivist perspective are often used and interpreted for all three domains. For example, formal PE curriculum models such as Teaching Games for Understanding (Bunker \& Thorpe, 1986; Kirk \& MacPhail,2002; Oslin \& Mitchell, 2006) and Sport Education (Hastie, Siedentop, \& Van der Mars, 2011) are considered to incorporate social constructivist aspects in the teaching and learning processes (Richard \& Wallian, 2005; Rovegno \& Dolly, 2006). This means that constructions of the learning situation by learners emerge through observations of the context in which embodiment and environmental factors play a role. Observations of play behaviors during the learning of games in PE may also stimulate critical thinking processes such as having debates with classmates (Richard \& Wallian, 2005). The incorporation of a constructivist perspective in either the context of teaching or curriculum development does not necessarily mean, however, that the research 
methodology (or the lens) in these studies is congruent with a social constructivist approach. In other words, research methodology can also include a social constructivist approach when researchers explore student constructions with the use of appropriate data collection instruments.

The premise of social constructivism is based on the acquisition of knowledge and does not necessarily explain pedagogies such as curriculum and instruction (Boghossian, 2006). Although Rovegno and Dolly (2006) stressed that social constructivism is a theory about learning, they also argued that studying curriculum work in PE research often includes aspects of teaching and curriculum to theoretical perspectives on learning. Similarly, Harrington (2016) used a social constructivist theoretical framework in the context of music education in particular to study perceptions of participants of their own collaborative learning processes. Harrington explored student collaboration within chamber music ensembles through social interaction and the development of creative rehearsal strategies. Harrington drew on a social constructivist framework, and also provided instructional recommendations such as for the makeup of learning groups. This example shows how a social constructivist framework was used to examine learning, teaching, and curriculum in the same study.

Similar to the work of Harrington, I also draw on the exploration of learning processes based on task-related interactions. I attempt to explain what these social interactions mean for the formal and informal curriculum. Consequently, this dissertation is theoretically framed within social constructivism as a theoretical perspective on learning ${ }^{5}$. However, I also use this framework to explore the consequences of the tenets of social constructivism for the development of formal curriculum tools (such as debates). Moreover, I use this framework to reflect on opportunities and implementation of teachers' pedagogical work and fostering students' physical literacy in settings that purport to produce learning. Such an approach may fit well with many evidence informed practices with respect to understand student learning in PE (Rovegno \& Dolly, 2006).

\section{Methodology}

Since this dissertation is explorative, I used inductive and iterative methodologies that are partly based on the grounded theory approach of Glaser and Strauss (Charmaz,2006; Glaser \& Strauss, 1967). Grounded theory is a step by step approach 
to facilitate the development of theoretical insights when researchers follow specific procedures during the collection and analysis of data. An important aspect of grounded theory is the search for close links with concerns of participants in their life worlds (Charmaz, 2006). A grounded theory approach consists of three repeated steps within an iterative empirical cycle: (1) collecting data based on the formulated research questions, (2) analyzing data and developing concepts and themes, and (3) reflection on the results in light of the research questions with a return to step 1 (Charmaz, 2006). An important aspect of this methodology is that the researcher begins with data collection procedures instead of first developing a theoretical basis that serves the methodology. I use this grounded theory approach in Chapters 3,4, and 5 of this dissertation.

The use of qualitative methods is appropriate when researchers explore student perceptions of collaborative learning in education. Such a qualitative approach is applicable within the context of PE (e.g., Barker et al., 2015), but also in other school subjects such as music education (e.g., Harrington, 2016; Olsson, 2007). I used several methods (e.g., semistructured interviews, focus groups, and drawings) that allow children to express themselves and give meaning to their experiences in physical education settings. The use of both drawings and interviews in obtaining children's perceptions has been a valued methodology within the context of PE (e.g., Bland,2012; Darbyshire et al.,2005; Light, 2006; MacPhail, Kinchin, \& Kirk, 2003; Solmon \& Carter, 1995). Based on the findings of my inductive iterative exploration, I used a draw, write, and tell method in the studies in Chapter 3-5 in order to elicit children's perceptions of learning tasks. Since student constructions may contain both verbal and visual information, a social constructivist perspective is particularly appropriate for this research. The drawing of a picture enables children to talk about their thoughts and feelings and provide realistic, authentic constructions of PE experiences (Matsumoto, 2018). Although the drawings were primarily used as a cue to start conversations about children's learning experiences, I also separately analyzed children's drawings in one study (Chapter 4). In that chapter, I explain in more detail the reasons for analyzing these drawings and how these representations informed student perceptions on learning.

In line with social constructivist ideas, I also searched for other opportunities to elicit student perceptions and to achieve a high degree of representativeness. This means that I collected data describing student perceptions in the PE classroom itself in order to approximate as closely as possible the context of regular PE lessons. 
Consequently, I also used digital observations and single questions to explore students' perceptions and how these contribute to the use of pedagogical tools (see Chapter 6). I furthermore utilized a mixed method approach and collected both quantitative and qualitative data. This use of mixed methods enabled me to make multiple interpretations (Anguera, Camerino, \& Castañer, 2012; Onwuegbuzie \& Leech, 2004). These methods were intended to elicit student perceptions before and directly after debate of ideas sessions regarding their judgements of tactical situations and their perceptions of what they might have learned. Both student observations (by digital tagging) and perceived learning outcomes (by single questioning) required a comprehensive and feasible data collection method due to time constraints during debate sessions and the fixed time schedules of the PE lessons. Moreover, the use of both data collection methods are in line with social constructivist perspectives and provided insights in how debate sessions may influence their perceptions. I evaluate these methods in the discussion (Chapter 8).

\section{Outline of this dissertation}

This dissertation is divided in four parts. After this general introduction chapter in the first part, I address in Chapter 2 the concept of physical literacy. Specifically, I discuss in this chapter how this concept of physical literacy has been integrated into PE and how it has been developed with several countries in Europe. I reflect on developments that influence these processes and I demonstrate similarities with PE standards in the Netherlands that are related to social constructivist learning. A second goal of Chapter 2 is to give context to the current state of Dutch physical education by describing how physical literacy is connected to the use of TGfU as a model-based practice. Therefore, I stress several developments that have influenced its current use in PE.

Part II of this dissertation consists of three empirical studies in which I elicited middle school student perceptions of learning processes in physical education contexts. In Chapter 3, I explore how children were able to express themselves about what they learn in PE. I discuss the implications of these findings for research methodology and quality instruction in physical education. In Chapter 4, I further explore these findings by focusing on the dynamics of one class. I explore children's perceptions of learning processes with respect to collaboration, group formations, and friendships within a TGfU unit baseball. I focus on the role of task-related 
interactions that may play a role in how children perceive learning in the PE class. Specifically, I search for themes that explain how these interactions impact the way children think about their peers and working together. In Chapter 5, I focus on what student perspectives are regarding group work activities in physical education. Therefore, I work with children from different schools to discover how they perceive group work during PE classes. I search for themes that show how the use of gender categorizations by children may play a role in how they select groups for their PE activities and what they learn in these groups. I explore how they assign meanings to group choices for collaborative work and the language they use for doing so. I discuss how gender constructions are based on processes of categorization, in particular the way they form groups and how they think those groups inform their learning.

Part III consists of an exploration regarding formal task-related peer interactions. In Chapter 6, I explore student perspectives of learning tactical situations within a TGfU approach, by comparing two different game pedagogies in the PE classroom. Specifically, I examine student perceptions of a tactical situation in a modified game play situation supported by a social constructivist debate of ideas setting. I determine whether student-controlled video guidance during debates of ideas affects student agreement and accuracy regarding judgements of tactical decisions in shooting at the basket. In addition, I explore to what degree the verbal exchanges and observation tasks affected student perceived learning outcomes.

In Chapter 7, I elaborate the findings in the study of Chapter 6 by describing the practical implications of implementing an innovative pedagogical observation tool such as digital video technology combined with 'debate of ideas' settings. I outline why student perspectives can enhance the practical knowledge of teachers and the potential of these digital resources. In line with the importance of capturing student perceptions in the previous chapters, I provide some recommendations how these perceptions can contribute to insights that stimulate alignment of digital applications with game didactics and vice versa.

Chapters 2-7 in this dissertation are published or accepted (in print) in peerreviewed journals ${ }^{6}$. In the last part of this dissertation, I discuss the implications (Chapter 8) that emerged from the several empirical studies in Parts II and III, and I describe different theoretical and practical recommendations for the physical education teacher education (PETE) faculties and PE contexts. 


\section{Notes Chapter 1}

1. In the several chapters I use the word 'students' as well as 'children'. In both situations I mean children who are participating in an educational context.

2. In this dissertation, I variously use the terms 'meaning-making', 'constructions', or 'sense-making' in different ways. I know that these words include different meanings when used in research as focus or topic. In this dissertation I use these as synonyms.

3. Hereafter I use both the words 'hidden curriculum' and 'informal curriculum' as synonyms.

4. I acknowledge that the hidden curriculum can be considered as unexplained and unexamined routines in teaching methods. However, in this dissertation I focus on the hidden curriculum regarding student interpretations in what they think they learn and experience.

5. Although the term 'social constructivism' with respect to learning is broadly incorporated in educational settings, different explanations and definitions have been used. Young and Collin (2004) described the different positions between constructivism and constructionism. Constructionism considers learning to be a continuous process of making social constructions through meaning-making. Social constructionism is essentially based on meaning-making informed by the way human beings socially interpret the world (e.g., Kim, 2010). A constructionist approach explicitly ignores cognitive development of individuals, but emphasizes processes of making social interpretations. The difference in viewpoint between constructivism and constructionism here mentioned does not necessarily mean that the influence of social interactions is only positioned within a social constructionist perspective. Meaningmaking is also a central aspect that has been recognized in constructivism. However, a critical aspect of constructivist approaches is the dualistic approach that derives from this learning theory (Young \& Collin, 2004). Although social interaction seems to be a pertinent aspect of constructivism, there is a tendency to focus on the individual regarding progression and development. Contextual factors in the learning environment such as relationships and interactions are also manifest in social constructivist learning theories while the emphasis is rather on the cognitive development of the individual.

6. Chapter 2 is published in a book. Chapters 2,3,4,5,6, and 7 are co-authored papers. In Appendix 2 to 7 I clarify my contribution to each specific paper. The chapters in Part II are presented in chronological order. 


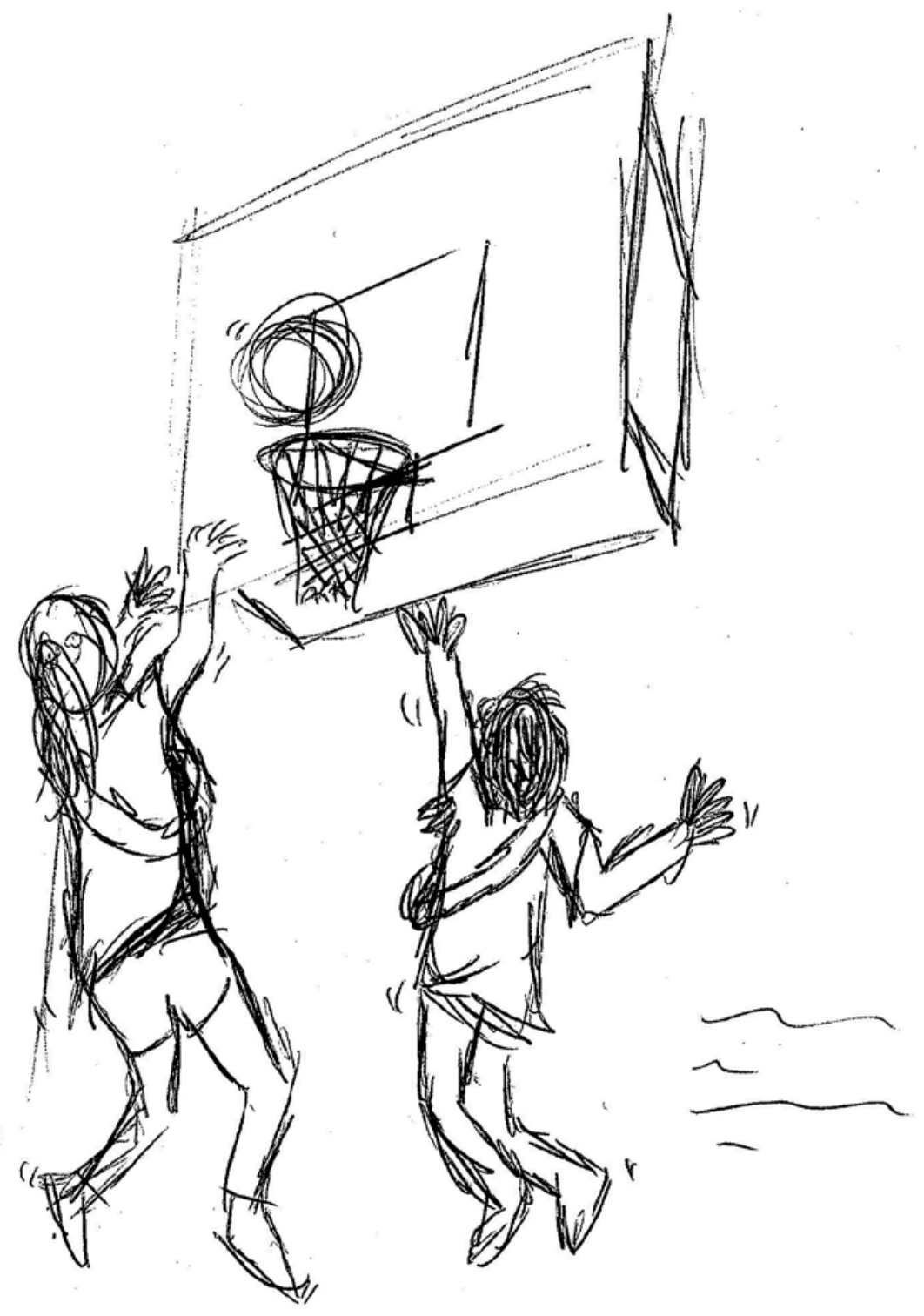

Drawing Babeth. 


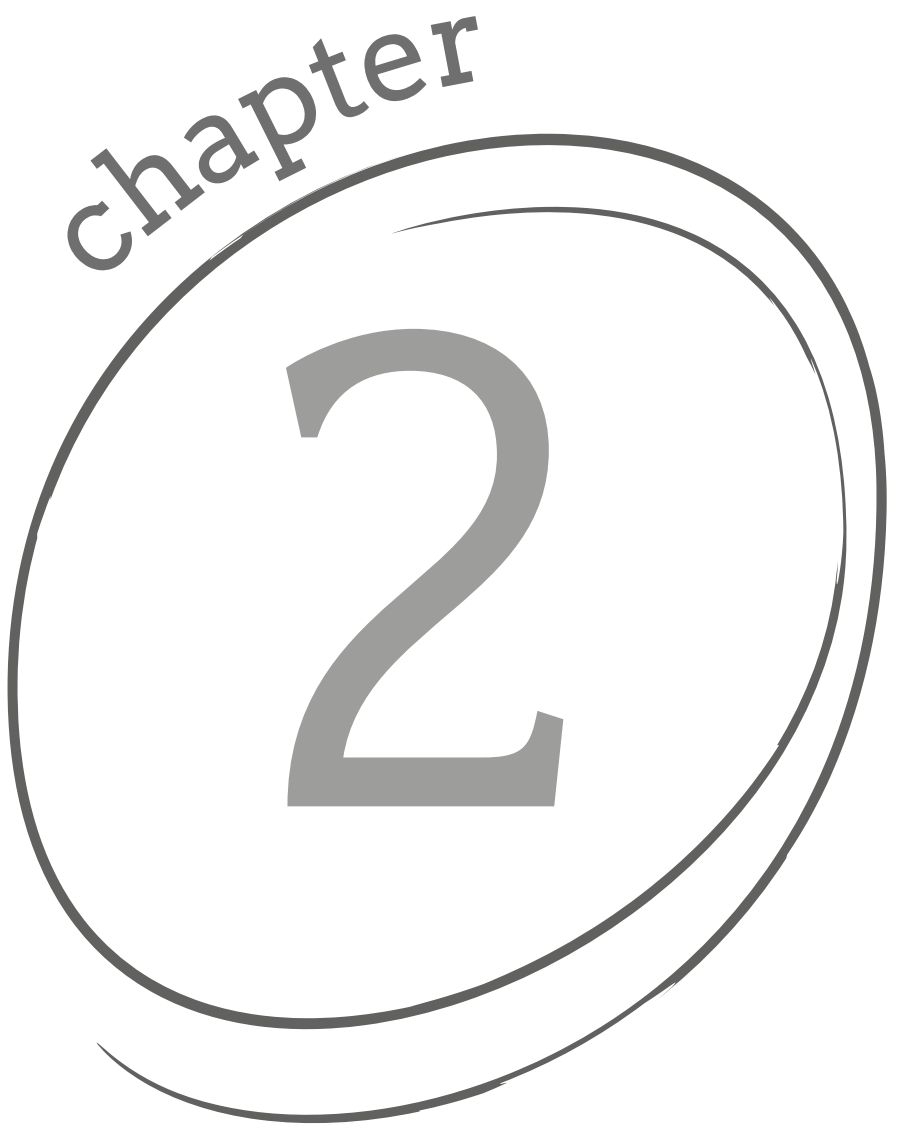

32 


\section{Perspectives on physical literacy in continental Europe}

\section{Abstract}

In this chapter we discuss how the concept of physical literacy has been developed throughout continental Europe. Specifically, this chapter provides an overview of countries (Malta, Czech Republic, Denmark, Norway, Portugal, and the Netherlands) in which physical literacy has been more or less integrated. It shows that the philosophical and pedagogical foundation of physical literacy is strongly integrated within continental European thinking about education, physical education, and sports. The chapter starts by describing the roots of physical literacy. Subsequently, we will expand the discussion about the inherent tension between the ideological orientation and the factual situation in many European countries in which medical, biological and military orientations on physical activity have dominated. It is argued that physical literacy provides a shared and integral framework for thinking about the cultural significance of movement behavior, as opposed to the more instrumental and health-oriented perspectives on human movement. We discuss the use of physical literacy by providing examples within the sports and physical education context.

Published as:

Koekoek, J., Pot, N., Walinga, W., \& Van Hilvoorde, I. (2019). Perspectives on physical literacy in continental Europe. In M. Whitehead (Ed.), Physical literacy across the world (pp. 143-155). London: Routledge. 


\section{Introduction}

In this chapter we discuss physical literacy against the background of the history and ideologies that have shaped and founded the continental European context of physical education. We will address the question of why physical literacy can be considered a concept with strong European, continental roots (hereafter, generally referred to as Europe). We will argue that the philosophical and pedagogical foundation of physical literacy is strongly integrated within European thinking about education and physical education. We will further discuss the inherent tension between the ideological orientation and the factual situation in many European countries in which medical, biological and military orientations on physical activity have dominated.

Before going into detail about the integration of physical literacy in several European countries, we question the current worldwide popularity of the concept. Physical literacy provides a shared and integral framework for thinking about the cultural significance of movement behavior, as opposed to the more instrumental and health-oriented perspectives on human movement. We will touch on this worldwide attraction against the background of a decreasing need to be physically active and also discuss some of the weaknesses of the concept, paradoxically due to its popularity and ease by which it is integrated, even within opposing frameworks. Furthermore, we will discuss the use of physical literacy in the sports and physical education context. The chapter will end with an overview of several European countries in which physical literacy has been more or less integrated.

\section{European roots of physical literacy}

Why do we need physical education? Why do we need to educate youngsters to be able to enjoy movement and sport? Why do we value physical literacy, and what does it mean to be physically literate? Many different answers can be found to these perennial questions. In order to understand the current attraction of physical literacy, we need to stress the origin of physical education as a typically nineteenthcentury phenomenon, in the context of a renewed attention to the healthy body as a response to urbanization, secularization and industrialization. 
The nineteenth century provided a fertile scientific and medical soil in which a general interest in physical culture could be cultivated. Sedentary lifestyles stimulated a concern for "physical compensation", which fostered discourses on degeneracy and prevention (Van Hilvoorde, 2008, p. 1307). European institutes for physical education (PE) were dominated by pedagogical and medical thinking, and were often characterized by their resistance to sport and an overly strong focus on the body-object and competition. Physical education in many European countries is highly influenced by German (J.C. Gutsmuths, 1759-1839; F.L. Jahn, 1778-1852; A. Spiess, 1810-1858), Swedish (P.H. Ling, 1776-1839) and Austrian (K. Gaulhofer, 18851941; M. Streicher, 1891-1985) systems of physical education. The explicit use of gymnastics for the powers of military defense also played an important role in many European countries (Van Hilvoorde, 2008).

During the 1920s and 1930s, a more "relational paradigm" emerged that was adopted by a broad group of scientists and philosophers. This paradigm was highly influenced by "personalist thinking" and shared a critical stance towards Cartesian notions of the human being. Important representatives of this movement were German thinkers such as Arnold Gehlen and Helmuth Plessner and the French philosopher Maurice Merleau-Ponty (1908-1961). Characteristic of these thinkers was their ability to bridge scientific gaps between biology, physiology, psychology and philosophy (Dekkers, 1995). They considered the human being as a unity and strongly opposed mechanistic explanations of human behavior. The body should not be understood as a machine to be trained and disciplined. Instead, the body should be considered, following Merleau-Ponty, as "active as a preconscious disposition of our personal existence" (Dekkers, 1995, p. 24). Entire generations of PE teachers were trained from the 1960s onwards not to use the notion of "physical education" (because of its dualistic connotation), but rather to favor the more personalistic concept of "movement education". In several European countries, this paradigm aided in transforming physical education from a medically and physiologicaloriented practice towards a more pedagogical-oriented, educational practice. In the words of one of the main advocates of this development in the Netherlands, bodies are not trained or educated, but pupils are instead being taught to move and play (Van Hilvoorde et al., 2010). Objectives of PE were formulated in terms of the realization of personal movement competencies and of the developments of the identity of the youngsters. This point will be further explained in the section about physical education. 
Under the influence of strong neo-positivistic tendencies in the social sciences, the importance of the phenomenological approach lost ground in the 1960s and 1970s. Hermeneutical and phenomenological research in the field of sport and PE was marginalized, and empirical and experimental research became dominant. This "scientization of physical education" started to dominate the more pedagogical and phenomenological paradigm.

Interesting, but largely beyond the scope of this chapter, is the explanation for the current popularity of physical literacy. This widespread use of physical literacy does not stand alone, but can be explained in the context of a broader revival of 'personalistic' thinking and value-based and phenomenological approaches within educational science. This change of view arose from several partly opposing developments. Before elaborating more on the content and implications of European concepts of physical literacy, we mention three of these developments:

1. There is a growing resistance, both within education as well as science, to reduce educational systems to "evidence-based education" or the measurement of outcomes (cf. Biesta, 2015). In relation to physical education, this means a critical position towards the reduction of the values and importance of physical education, just in terms of quantifiable outcomes, for example by measuring fundamental movement skills (Pot et al., 2017). Ironically, or some would say its weakness, is the fact that physical literacy is itself being adopted by propagators of a more reductional science. This situation has arisen because those adopting this view have little or no understanding of the philosophical underpinning of the concept (cf. Barnett et al.,2016).

2. The growing dominance of (digital) technology in our society plays a paradoxical role. On the one hand, it facilitates new kinds of measurements of the body, which nurtures ideologies such as the quantified self (e.g., Lupton, 2015). Many of these developments are in conflict with the foundations of physical literacy. However, these kinds of reductions of embodiment to the monitoring of specific parameters can engender support for physical literacy in instigating a renewed focus on meaningful and autonomous movement behavior. When teachers experience that certain measurable outcomes do not reflect the value of their daily work, this could stimulate their wish to revitalize a discourse that is more in line with the educational and pedagogical reality of teaching. There is a clear need for a language that also deals with uncertain outcomes, without implicating 
that this uncertainty is a proxy for lack of quality. Physical literacy offers a broader vocabulary for framing the importance and values of physical activity and PE than more limited concepts, such as fitness or "physical activity", do.

3. There is a growing European interest in "personal learning", stimulated by the propagation of the so-called twenty-first-century skills (e.g., Voogt \& Roblin, 2012). These skills, such as creativity, exploration, communication, discovery and problem-solving,better fit an accent on movementeducation in which the personal goals and self-regulating skills are of more importance than the fulfilment of standardized tests or fitness criteria. Physical literacy pays more attention to the enjoyment of movements and stresses the importance of creativity. The notion of a personal journey towards a "sport identity" conflicts with a strong focus on general goals or generalized levels of fundamental movement skills (FMS). Being physically literate should be considered inherent to human flourishing, instead of being a state of possessing a fixed set of (motor) skills. To be physically literate is, however, more than just a process or personal journey. It can also be considered a value or goal in itself, to be(come) physically literate. The criteria for this mode of literacy are at the same time highly dependent on the context, living circumstances and motivation.

\section{Physical literacy in sport}

As physical literacy originated from a pedagogical and philosophical background, school and physical education is the most obvious context to see it being applied. For instance, in Malta, the Netherlands, Norway, the Czech Republic and Denmark, physical literacy is mainly used in the educational sector. However, the concept also attracts some attention from the world of sport. In most European countries, this can at least partly be explained by the popularity of the long-term athlete development (LTAD) model (Balyi, 2004). This model is used by many European sport federations as a guideline for talent development.

Within the LTAD model, the first three stages are often summarized as 'physical literacy'. However, when taking a closer look at these stages (Active Start, FUNdamentals and Learning to Train), it could be argued that these stages reflect an emphasis on movement skill acquisition. Often a "building block" metaphor has been used in this respect (Abbott et al.,2002; Balyi,2004; NOC*NSF,2011). This means that it is conceived that teaching children certain (fundamental) movement skills 
(building blocks) will lead to more refined movement patterns later in life. Although this is a contested idea (Pot et al.,2017), this reinforces the interpretation of physical literacy as (the learning of) mere movement skills (Pot \& Van Hilvoorde, 2013), and leads to translation of physical literacy in terms of "motor alphabet", "movement ABCs" or "physical grounding".

For instance, in the Netherlands and Denmark, physical literacy is starting to be used as an overarching concept that stimulates intersectoral ways of working, such as common goal-setting of the sport, physical education and health sectors. On the other hand, the Norwegian sport sector is considered to be conservative in its views, and physical literacy is not expected to become a central topic. What can be concluded is that physical literacy is hitherto an educational concept in Europe, and other sectors, such as the sport sector, are only beginning to pick up on the term. Because of the relative novelty of the concept in these sectors, changes in policy and practice are not expected in the short term. The ways in which physical literacy is part of the educational context are described in the next paragraph. We will start with a description of how the concept relates to the educational practice in the Netherlands. After that, we will focus on the similarities and differences compared to other European countries regarding the implementation of the concept in practice.

\section{Physical literacy in Dutch physical education}

In the Netherlands, the backgrounds of physical literacy are most represented - but not equal to - the way the standards of physical education (PE) are structured. In this paragraph, we will discuss practical implications of the conceptual approach in Dutch PE as an example of the European orientations towards physical education and the role of physical literacy. In 2017, the concept of physical literacy received considerable attention in physical education in the Netherlands (Steenbergen, 2017). In spite of the fact that physical literacy itself is not explicitly part of the Dutch standards, there seems to be a large resemblance in the philosophical groundings between physical literacy and the Dutch standards of PE (Mooij et al., 2004). As explained in the first part of this chapter, one physical education teacher education (PETE) faculty and a university of human movement sciences share a history of approaching human movement behavior grounded in existential phenomenological philosophy. This had a major influence on the Dutch standards of physical education in several ways. This was most visible in the appellation 
transition from "physical education" to "human movement education", which was suggested by Gordijn (1961), as an attempt to delete rudimentary attitudes that were based on dualistic approaches. Of course, one could say that in the end, it is not how we name the approach, but how we act according to it. Nevertheless, the discussion initiated a new stimulus to consider a major shift in thinking about physical education in the Netherlands: education is not only about educating or training the physical part, but rather about the meaningful relations a human being encounters while moving. Human movement is about the interaction between the mover and the environment, and should be taught in ways that articulate and understand that significance. Learning to interact is present from birth (and even before). From that moment on, the direction of the development of the human depends on personal, physical, social and cultural constraints.

\section{The curriculum implications}

The pertinent shift in thinking about the undividable and embodied human being - which is fundamentally different from the more dualistic paradigm of "training the physical" (cf. Tamboer, 1992) - influenced the forming of the Dutch curriculum to a practical and meaningful approach (Ten Brinke et al.,2007). For example, in the Dutch standards, the aim is preparing a learner to be part of the (cultural) movement environment. This goal was further developed in four key concepts in which learners could be educated. Besides the responsibility towards health questions, movement education in the Netherlands primarily focuses on teaching children how to "arrange movement activities, improve movement activities, and value movement activities" (Ten Brinke et al., 2007, p. 30). There seems to be a shared thought that $\mathrm{PE}$ is not only an instrumental way of building competencies through the acquisition of skills. A broader development is stressed by focusing on other types of goals, such as increasing skilled competence (and perceived competence), performance, health, enjoyment, and maintaining relationships (i.e., social contact) with the aim of a lifelong commitment to be involved in movement activities (Ten Brinke et al., 2007).

The first mentioned aspect of Dutch PE standards, arranging movement activities, points to the aim of teaching children the aspects of interpersonal constraints in movement activity. In line with social constructivism (Rovegno \& Dolly, 2006), children are introduced to different forms of organized movement 
that necessitate collaboration with others (Koekoek \& Knoppers, 2015). This collaboration is not an isolated goal that is reached through movement education, but rather an essential part of human movement activity. How children tune in to each other, arrange different settings of activities, get acquainted to different forms of organizations, and choose their positions and roles in different group dynamic phases is part of the teacher's focus and guidance in PE at school.

The second aspect of the Dutch standards, improving movement activities, is part of an ongoing discussion and needs some explanation. The key element is how movement skills are defined. Under influence of the current assessment culture (i.e., the tendency to value what we can measure instead of measuring what we value), there is an increased attention for measuring fundamental movement skills. Without denying the importance of a solid foundation for children, we hesitate to embrace this culture. Starting from a relational approach, it is of great importance to further discuss the interpretation of skilled behavior and the effects of its assessment. From our perspective, the metaphor of learning language offers a sufficient analogy to discuss the two approaches towards education of movement activities (Jurbala, 2015; Pot et al., 2017). To avoid the simplification of the metaphor, Jurbala (2015) warns not to interpret the metaphor "physical literacy" only in a parallel to learning to read and write, but rather to linguistic lingual communication. In other words, the question is whether we approach the learning process content as separate building blocks towards an uncertain future, or attempt to find meaningful relations that are tailored to the ability of the learner in which the meaning of the activity is prominently present. This suggestion is reminiscent of the Dutch discussion about assessing "isolated" skills or more holistically following children's embodied interaction with the world. From our perspective, learning to move is comparable to learning to communicate. Thus, learning to move is not the same as the building of separate blocks that in the future will accumulate towards a successful participation in movement activities. Just like learning to communicate, a child is interacting with his or her environment from day one, and, in line with that, learning to move needs guidance from the start in order to become even more meaningful.

Teachers should always try to implement this meaning-making, instead of teaching the children meaningless tricks or isolated skills that perhaps lead to future (unknown) success. In addition, the ability of individuals to choose their preferred environment in which to be active and successful, tailored to their current abilities and interests, might be just as, and perhaps even more, important as the acquisition 
of a set of fundamental skills. The role of fundamental movement skills, and the increasing call for assessing these skills, is a much-debated topic in the Netherlands, and this debate resembles the discussion about physical literacy and fundamental movement skills (Pot et al.,2017). Given the fact that the concept of physical literacy, as introduced by Whitehead (2001), is a holistic approach to human movement that describes participation throughout life, it seems almost logical to presume that motor skills of humans in their earlier years are related to the activity levels throughout life. However, there is very little, and if any poor, evidence that motor skill abilities are related to being active for life. Research that has attempted to show the correlation between the two have encountered methodological difficulties (Giblin et al.,2014).

Knowing that there seems no necessary relationship begs the question regarding what kind of skills should be assessed in PE. Rather than narrowing this to isolated fundamental movement skills that are easy to assess, we aim for development in activities based on their core meaning. In the late 1980s, a categorization of motor activities for PE was developed at the physical education teacher education (PETE) institutes, and is still in use in the Dutch national curriculum standards. Similar to a categorization of game activities (e.g., teaching games for understanding's net and wall,target, invasion and tag games; see Bunker \& Thorpe, 1986), a group of PE teachers at the PETE university tried to cluster activities on criteria of so-called core problems. A core problem represents the meaning of the activity that is independent of the different executional forms or levels. The core problem approach uses a description of activities that are globally described in a sense that the activity is stripped down to the essential meaning. The categorization of activities was used to define learning tracks. A learning track is a group of activities that share the same core problem (e.g., balance activities, target games) structured in a sequence from introductory to complex. Children work in various age groups that match their development. For example, the core problem (aim) of volleyball is to place the playing object in the opponents' field while the opponents are trying to prevent this. Although this is done with specific techniques in the sport context, a (modified) game of volleyball with catch rules shares the same core challenge. Indeed, badminton and tennis share these characteristics, and therefore belong to the same cluster of activities.

Designing activities while retaining the core problem by stripping overly complex techniques and rules is key to providing learners a meaningful and rich 
learning environment (Koekoek et al., 2014). Stripping these sport-like activities to the core meaning also allows teachers to design similar games that retain the core meaning but are tailored to the abilities of the learner. If the activities a teacher offers throughout the years are built in complexity, the teachers will create designs of so-called "learning tracks" (Ten Brinke et al.,2007). Based on analysis of activities, the Dutch curriculum distinguishes categories such as jumping and balancing in gymnastics but also jumping, running and throwing in athletics. Different meaning is attributed to these activities. Jumping in athletics, for example, shares the core problem of citius, altius, fortius (i.e., faster, higher, stronger), but differs in those activities where height is problematized compared to those where distance is problematized. Jumping in gymnastics, on the other hand, shares the same core of using a surface to get airborne and postponing landing, which drastically changes the approach towards the learning of this type of jumping. This is a good example of how meaning-making matters to the behavior. Ways of executing various movements in terms of prescribed 'techniques' are only addressed when they serve to solve the core problem of an activity. Structuring the categories in terms of complexity has resulted in the development of progressive practices and resulted in 12 learning tracks that are now used in Dutch PE in primary school. For example, the global learning track "scoring games" (alongside tag games, aiming and rally games) is divided into three central themes: (1) keeper games; (2) possession games; and (3) small-sided modified invasion games. The keeper games share the same core problem of placing the playing object in the goal while the opponent is trying to prevent this. Various games that build in complexity are suggested for various age groups (such as penalty games). The possession games share the same core meaning of keeping possession of the ball while the opponent wants to take over the possession of the ball. Examples of activities are pass and intercept games, rondo, and end zone ball. The modified invasion games all share the same core meaning of passing the opponent in attempting to score while the opponent wants to prevent this, and vice versa. Modified (small-sided) invasion games are clustered in this theme.

Finally, the third aspect of Dutch movement education is focused on the valuing of movement activities. Through reflection, children are introduced to components of personal involvement in activities such as personal preferences, responsibility, fair play, authenticity or motivation (Ten Brinke et al., 2007). The central theme in this part of physical education is about the experience of individual learners (e.g., by 
questioning the students about how they perceived the PE lessons). This approach leads to reflective questions regarding their perceived abilities but also their preferences. It can be questioned whether or not children should choose their own preferred activity that fits their needs. Therefore, it is necessary to explore the extent to which they are influenced by their peers. For example, are they able to choose with whom they want to play and learn in groups or teams? In addition, what culture of play would be appropriate in that PE setting (e.g., competition, recreation, show)? But also, do they have the ability to estimate the opportunities for active lifestyle in their personal environment? This third goal of Dutch PE also seems to be the least developed. Related to physical literacy, valuing movement activity might, however, be a crucial aspect of PE.

The situation of Dutch physical education as we have described in this section is used as an example of European orientations towards physical education and the role of physical literacy. In addition, the aforementioned existential phenomenological philosophy on PE and its implications for the curriculum can be considered as a starting point for developing future directions, and also for questioning the role of physical literacy in Europe. The Dutch PE context has shown that education should be meaningful and always related to personal developments and goals. Therefore, in the European practice, there might be some key issues to address. For example:

1. How do we protect a broad perspective of physical literacy and PE in a time where measuring details of human movement challenges the implications of a holistic approach?

2. Can we further develop the valuing of movement activities within the PEcontext?

\section{European similarities and differences}

The central purpose of this section is to provide insight into the current status of several European countries in respect of how they are developing the physical literacy concept. To gain this information, some scholars and policymakers who were seen as committed to physical literacy received a questionnaire. Most of these individuals are currently actively advocating physical literacy in their country. In order to obtain information about the development of physical literacy in their particular country, they were asked to respond to a series of questions. 


\section{Main findings of the physical literacy questionnaire}

The questionnaire consisted of 19 questions and explored the status of physical literacy. Six responses were received from continental Europe: Malta, the Czech Republic, Denmark, Norway, Portugal and the Netherlands. In order to give an overview of the initiatives of each country on physical literacy, a few central elements were used to highlight their current status. The following elements contribute to the picture of physical literacy for each country, which will be discussed below: (1) the initial reason to develop the physical literacy concept; (2) the way each country disseminates physical literacy; (3) the sector(s) involved in this process; (4) the impact of physical literacy in several sectors; (5) the opportunities for spreading and developing the concept; (6) perceived barriers to promote physical literacy; and (7) the issues that need to be addressed for adoption of physical literacy.

The most important reason for interest in physical literacy in many countries in continental Europe is the search for a new concept that is related to sport and physical activity. In each country, different starting points were used, but they all considered physical literacy as an important and promising concept. The arguments for exploring physical literacy consisted of expanding the understanding of the definition of physical literacy (by not only focusing on competence or physical activity), linking physical literacy to other concepts (such as LTAD), or searching for the legitimization of current initiatives (i.e., from a health and physical activity perspective).

In all countries, the universities are particularly responsible for disseminating the concept. In addition, there is a tendency to establish project groups (with both policymakers and scholars) or work to secure a degree of governmental influence (the Czech Republic). In Denmark, the National School Sport Association is involved closely in the dissemination of national physical education and sport objectives. Because the universities are particularly involved in disseminating the concept of physical literacy, several articles and chapters are published in national journals and books relevant to the context of physical education, physical activity and sport. Furthermore, seminars and symposia were organized (Malta, the Czech Republic, the Netherlands). A few countries developed courses (Malta, the Czech Republic) and presentations on a university level. In the Netherlands, the status of physical literacy has been explored in a national research project. The findings of this project have resulted in a document setting out a few scenarios to further develop the concept (Steenbergen, 2017). This publication pays attention to physical literacy in relation to new trends, interdisciplinary collaboration, and new perspectives on 
sport and physical activity for all ages. One of the results is that a group of scholars from 10 different institutes developed a white paper that aimed to identify how people can be stimulated for lifelong participation in physical activity and what physical literacy may contribute to this intention (Steenbergen et al.,2018).

Differences between countries were found regarding the impact of the physical literacy concept in several sectors. In the Czech Republic, the physical literacy concept has been discussed in several university discussion groups. More specifically, a few research studies have been conducted that thoroughly explored the value of the concept for the country (Vašíčková,2016). Quantitative and qualitative studies were conducted in order to explore what physical literacy meant for the Czech environment. These studies focused on awareness among students and $\mathrm{PE}$ teachers, for example, by investigating students' motivations to be physically active, their knowledge about health and physical activity, and their attitudes towards PE lessons were mentioned as entry variables to physical literacy. In Malta, several lectures were given for early childhood educators. In Denmark (and in a similar way for Norway), physical literacy in school has been developed by researchers of a PETE university because the term physical literacy is closely related to the Danish understanding of PE and sport. Physical literacy in the Netherlands has been explored only in the educational sector (university level), although other sectors also showed their interest, as illustrated by the White Paper written and signed by 10 different institutes (Steenbergen et al., 2018). Furthermore, in one university in the Netherlands, several critical perspectives were discussed on the use of FMS within physical literacy concepts (Pot et al.,2017).

The researchers and policymakers from the countries who participated in the questionnaire also reflected on both the opportunities of physical literacy as potentially a valuable concept but also stressed the limitations of the concept. For example, Norway noted the potential of physical literacy in order to find alternatives for the physical activity discourse in their country. In Denmark, physical literacy contributed to the Danish school reform from 2014 that promotes physical activity of 45 minutes for all children on a daily basis. This example shows how physical literacy has an important influence on the school curriculum. In Malta also, a new curriculum has been implemented (2012) and new PE learning outcomes were determined (2015). Physical literacy in the Czech Republic and the Netherlands have not yet influenced the (PE) school curriculum. In these countries, (funded) projects and conferences dealing with physical literacy were organized in order to explore 
how the concept could be a valuable approach for schools and children. All countries faced similar barriers when addressing the concept. For example, because of the prevailing culture (e.g., different focus or other priorities), the introduction of new concepts was limited. In the Netherlands, physical literacy was seen as a theoretical approach, with relatively little attention given to the practical consequences. In Denmark, no specific barriers were found, but the term physical literacy was not so much perceived as an innovative concept. Norway reported a significant lack of understanding of the term literacy, specifically because of the lack of an appropriate Norwegian word that accurately represents its meaning. This is also a struggle in the Netherlands, on account of the somewhat dualistic connotations of the concept.

The countries formulated several issues that need to be addressed in order to adopt the physical literacy concept. The most important issue for all countries is the promotion of the concept to key stakeholders with the aim of understanding the nature of physical literacy. Furthermore, sedentary lifestyles and physical inactivity (e.g., Denmark, the Czech Republic, the Netherlands) were seen as decisive developments. In Norway, physical literacy is mainly used for the justification of PE and physical activity as meaning-making processes. The Czech Republic reported the tendency of significant dropout from compulsory PE as an important issue.

\section{Conclusions}

It is delicate to discuss a complex concept such as physical literacy in a generic way, based upon general continental European traditions of PE. It is no problem to stress the common philosophical ground of physical literacy within European, continental philosophy, in particular in the phenomenological and personalistic tradition. When looking in more detail, we do, however, see an enormous variety of understandings and practical translations of physical literacy in different European countries.

In this chapter, we have first used the situation in the Netherlands as a case to understand what the implementation of physical literacy could mean for sport or for the curriculum. The understanding and implementation of the concept in several European countries shows a wide variety of understanding and uses. This variety illustrates both the power and potential of physical literacy, as well as its pitfall. When there is no clear and common understanding, this could lead to diffusion, miscommunication, and use of the concept by sectors with interests other than those that the main stakeholders have in mind. A possible way to develop such common 
understanding is where people from key national organizations or institutes work together on the concept and establish close links with the International Physical Literacy Association (IPLA). In most of the European countries that responded to our questionnaire, the concept has been introduced and investigated by (sport and movement) universities that focused on sport and human movement, as well as faculties for physical education teacher education. It also appeared that the educational context in most countries is the leading context and often the starting point in which physical literacy has been developed. It is a misunderstanding that for developing the concept in a particular country, all national leading (governmental) institutes, sport organizations or universities should be directly involved. We recommend to first bring together those institutes that have a decisive influence in the national educational policies and curriculum reformations. Obviously, in a second tranche, it would be valuable to invite other important stakeholders.

One of the main findings from our exploration among different European countries is that researchers and policymakers use physical literacy to legitimize their national initiatives for purposes that are not always doing justice to the content of the concept. For example, commonly, it is the prevailing culture to establish research projects that are based on general health problems (e.g., obesity, sedentary behaviors), and therefore the focus is often on a single pillar of the concept (i.e., competence, confidence or motivation). Assessing, monitoring and improving motor skill behavior are often taken for granted without including important contextual influences (e.g., the social impact of school, sports club, neighborhood, parents, etc.).

However, we also see an increasing tendency to shift this paradigm by describing physical literacy as a broad, more holistic perspective (e.g.,in the Czech Republic and the Netherlands). Lifelong participation in sport and physical activity should not be used as a decisive reason for isolating the "physical part" of our existence from other domains ("mental", "social", "environmental"). Broad interpretations of physical literacy can be useful for collaboration and provide an impulse for new research and policy with contributions from a variety of stakeholders.

\section{Acknowledgement}

We would like to thank all the colleagues from different continental European countries who helped us by completing the questionnaire. Their insights were a valuable contribution to this chapter. 


\section{Part II Informal Task-Related Peer Interactions}




\section{Chapter 3}

How do children think they learn skills in physical education?

\section{Chapter 4}

The role of perceptions of friendships and peers in learning skills in physical education

\section{Chapter 5}

Gender categorizations during group work in physical education 


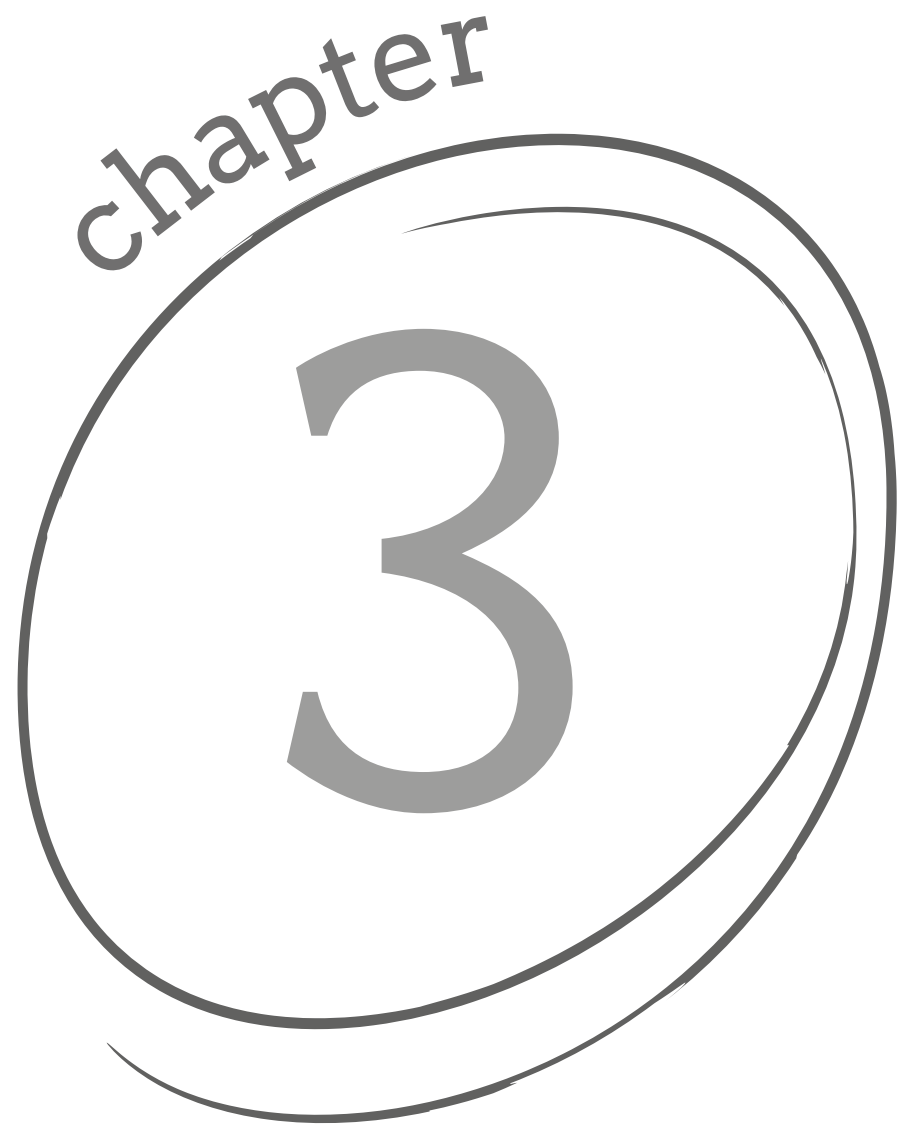




\section{How do children think they learn skills in physical education?}

\section{Abstract}

Relatively little is known about the ways in which children understand and perceive how they learn tasks or skills in physical education classes. The purpose of this study was to use a constructivist framework to explore how children express their experiences, thoughts, and feelings about how they learn in physical education classes. A variety of methods (semistructured interviews, draw and write exercises, and focus groups) were used to examine how 29 children, aged 11-13, perceived assigned tasks. Results indicated that these children could express themselves in a limited way about their learning experiences and that each method yielded similar and different information. We discuss the implications of these findings for research methodology and quality instruction in physical education.

Published as:

Koekoek, J., Knoppers, A., \& Stegeman, H. (2009). How do children think they learn skills in physical education? Journal of Teaching in Physical Education, 28(3), 310-332. 
The recognition of the importance of teaching children the habits and enjoyment of being physically active has been accompanied by an interest in what and how they learn movement skills in physical education (Stegeman, 2004). Curricula may detail the objectives that need to be met but this does not mean that children actually graduate from school with an adequate skill level and understanding of such skills. For example, although the curriculum for elementary schools in the Netherlands is quite specific about basic objectives, the skill level of many children does not meet the stated goals (CITO,2008). This incongruence between goals and achievement requires more attention be paid to what and how children learn in physical education classes (Stegeman,2004). Much research about student learning in physical education has focused primarily on internal cognitive and motivational processes and related outcomes (see for example, Hassandra, Goudas, \& Chroni, 2003; Li, Lee, \& Solmon, 2007; Luke \& Hardy, 1999). Relatively little research focuses on perspectives and experiences of the learner (Rink, 2003). Yet a research focus on children's experiences is crucial (Carlson, 1995; Dyson, 1995; Nugent \& Faucette, 1995; Portman, 1995; Ratliffe, Imwold, \& Conkell, 1994). The instructions of teachers are most likely to enhance student learning if they are based on an understanding of children's thoughts about learning tasks during physical education classes. Dyson (2006) suggests that "listening to students' perspectives can provide valuable new insights into the complexities of teaching and learning that can then be applied to improving the quality of physical education in our schools" (p. 343). There is, however, not only a lack of available research about the perspectives of learners, but there is also little information available about ways these experiences can be expressed.

Research that explores how children construct learning tasks has been grounded in a social constructivist approach (see for example, Dyson, 1995, 2006; Heij, 2006; Rink, 2003; Rovegno \& Dolly, 2006). This approach assumes that knowledge is transferable to other contexts, imbedded with preexisting experiences, that learning occurs in social settings, and that learners of skills play an active role in constructing their own knowledge and competence. Since perspectives of learners are invaluable, the use of this approach requires researchers to explore how children actually experience a learning task and how they (can) articulate those experiences or perceptions. The central position assigned to the learner in this approach necessitates that teachers are attuned to the concerns of children as they learn; that is, teachers need to be able to understand what children think 
and experience before, during, and after a learning situation. For example, a teacher may have assigned a problem that requires children to learn to maintain and regain balance while moving on different surfaces. Children may not necessarily learn this task in a linear manner, however. Their thoughts and/or fears may interfere with or enhance their performance and thus influence their learning. Or they may focus primarily on their own achievement (end product) and therefore move quickly through a task without daring to experiment and explore.

A constructivist viewpoint assumes children's perspectives play an important role in their learning processes (Solmon, 2006). Perceived competence and the ways children interpret instructional behavior are assumed to play a critical role in learner cognition. The assumptions of a social constructivist framework have consequences for pedagogy or teaching methods (didactics). Instruction situated within a constructivist approach allows children to participate in activities on the basis of their own abilities and limitations and does not necessarily require them to meet specific, well-defined standards to be able to solve learning tasks and perform in a specific way. This notion of difference is grounded in respect for and valuing diversity among children (Heij,2006).

Research grounded in social constructivism in physical education has examined relationships between perspectives of teachers and children's about ability and of gender. Grenier (2006), for example, used a social constructivist framework to explore how processes of learning are influenced by the relationship between a child with a severe disability and the teacher. Grenier found a strong relationship between a child's feelings of peer acceptance and a teacher's beliefs of the importance of social skills for all children. Grenier concluded that this strong relationship was essential for learning to occur. However, this learning occurs within the context of a curriculum. Evans and Penney (2008) used a constructivist approach to investigate the social construction of "ability" to determine how the curriculum can facilitate or hinder the ways children and teachers think and interact. Evans and Penney compared two curriculum texts and concluded that a pedagogical relationship between teacher and student based on equivalence and acceptance can influence learning in a different way than when such a relationship is based on differentiation and the creation of ability hierarchies. The first case positions a teacher as a facilitator who helps children discover their potential without prescribing what and how they must learn. In contrast, a curriculum based on differentiation and ability hierarchies clearly defines the boundaries (between teacher and children), 
and children learn their own placement with respect to other children who may be better skilled. These two approaches have different assumptions about how and what children learn.

The social constructivist approach has not only been used to investigate studentteacher relationships within the context of specific curricula, but also to examine social group relations such as gender. Gorely, Holroyd and Kirk (2003) used group and individual interviews of children to investigate the relationship between social constructions of gender and the perceived relevance of physical activities in physical education. The researchers used images of female and male athletes as visual triggers to stimulate group discussions about embodied identities. The individual interviews were used to explore if and how children articulated the gender appropriateness of specific sports. The results indicated that although both girls and boys were aware of female participation in sports usually designated as "male", they easily identified key features of male-appropriate activities. They described male sports as requiring roughness, action, and aggression and used this characterization to argue that these sports were more appropriate for boys. Gorely et al. also noted that these results strengthened current constructions of the sex-differentiation of activities despite the participation of girls in many sports.

Although investigations of the relationship between social constructions of ability and gender and the effectiveness and appropriateness of curricula and physical education are important, there is relatively little research that explores the social construction of learning tasks in physical education classes. Yet a physical education curriculum based on a constructivist approach requires an understanding of what children learn and how they articulate that and should enable children to express or describe their experiences. Solmon (2003) argues that listening to students' views should precede the design and implementation of quality physical education programs. This approach assumes that children are able to express themselves in ways teachers can understand. There is a lack of research available that examines the extent to which children are able to express the ways they experience learning tasks during physical education classes. This study aims to fill this gap.

Dyson (2006) has identified three factors that need to be taken into account in investigations of the experiences of children in physical education classes: access to the voices of children, valid representation and interpretations of the thoughts and ideas of children, and implementation of findings into teaching practice. In this 
study, we focus primarily on the first and second factors. Specifically, the purpose of this study was to gain insight into how children think they learn tasks in physical education classes and therefore to find ways to represent children's thoughts, feelings, and experiences about their learning of skills and tasks and to examine what and how children tell us about their learning experiences. What do children think they can learn in an activity and how can and do they describe what they learn? What do children think about when solving problems that are introduced by a teacher? What language or words do children use to describe their own learning processes? The resulting data should provide insights that help teachers develop teaching activities and curricula that take these thought processes and perceptions into account (cf. Dyson, 2006). An understanding of how children themselves feel about their experiences in learning tasks in physical education could provide important information about how to improve their ability in solving movement tasks or problems. The instructions of teachers are likely to enhance student learning if they are based on an understanding of children's perspectives about learning tasks during physical education classes (Dyson,1995; Ratliffe et al.,1994).

\section{Interviews, focus groups, and 'draw and write'}

Researchers who have investigated children's perceptions about learning have often used qualitative research methods (see for example, Burrows, Eves, \& Cooper, 1999; Carlson, 1995; Sanders \& Graham, 1995). Since observations tend to reflect more how teachers/researchers see/interpret than how children themselves give meaning to learning, we focus primarily on methods that allow children to express themselves, such as semistructured interviews, focus groups, observations, and draw and write/tell techniques. We discuss these methods in the next paragraph.

\section{Semistructured interviews}

Semistructured interviews are a powerful way of gathering rich data (Charmaz, 2006). The interview consists of open conversations based on a list of topics (Baarda, De Goede,\& Van der Meer-Middelburg,2000). The interviewer attempts to obtain as many descriptions of the experiences of the respondents as possible. For example, Carlson (1995) used in-depth interviews, structured interviews, and surveys to elicit the voices of children who felt alienated in physical education. The data gathered 
from these interviews were analyzed by using the constant comparative method of Glaser and Strauss (1967). Carlson used the data to construct an alienationnonalienation model to explain the extrinsic and intrinsic factors that played an important role in the attitudes of these children toward physical education. Although the two in-depth interviews in the first phase influenced the content of the subsequently structured interviews, the effectiveness of the methods used in this study was not evaluated. Similarly, Sanders and Graham (1995) used formal and informal interviews and observations to examine what four young children thought about their participation in physical education lessons. The informal interviews consisted of spontaneous conversations with children during lessons. The formal interviews were conducted with pairs of children and were based on a structured questionnaire. The investigators found that analysis of data from multiple sources was a time-consuming process but resulted in valuable information. But Sanders and Graham focused specifically on children's initial experiences in physical education and their natural desire for play and did not examine their perceptions of "learning". In addition, although both Carlson and Sanders and Graham used oneon-one interviews, we know little about the effectiveness and appropriateness of the techniques that were used in such studies.

\section{Focus groups}

A second way of obtaining specific information from children about a topic is to ask them to share their experiences in a group interview. The use of focus groups assumes that discussions between respondents, often peers, can yield valuable data (Morgan, 1997). Stewart, Shamdasani and Rook (2007) identified a number of advantages of focus groups. Group interviews generate much more data in a short period of time compared with an interview with a single respondent. In addition, since discussions are initiated by a leader or by one of the respondents, a researcher can interact directly with the group by acting as facilitator. A third advantage of the use of focus groups is that they give children more opportunities to respond in their own words to what others, usually their peers, say. The facilitator or leaders can then probe the various points that the children mention. The most significant advantage of focus groups is that they are a particularly appropriate way to obtain information from children since their peers shape much of their social environments (Stewart et al., 2007). A group discussion with other children may be a more natural and, 
often, a more comfortable setting for them than a one-on-one interview with an adult. Accordingly, the presence and contribution of peers may help teachers and researchers better understand what children think and feel about learning a skill (Krueger \& Casey, 2000).

Several researchers have used variations of this technique with children. MacPhail (2001) for example, has suggested the use of a nominal group technique for eliciting information from young school-aged children. This technique is designed to elicit the views of all members in a group. MacPhail, Kirk and Eley (2003) used this nominal group technique to examine the views of older teenagers (14-18 years) about which facilities they needed to be able to participate in various sports and movement activities. Each group of respondents was asked to write their ideas and thoughts, after which each participant presented his or her opinions to the group. Each individual respondent then assessed and evaluated the ideas of the other group members. These assessments were used in the research analysis. Although this approach gives voice to all the children, it may inhibit in-depth discussion and thus influence conclusions that are drawn about their thoughts and feelings since spontaneous discussions/interpersonal interactions were not part of the approach and therefore not analyzed. Consequently, the purpose of the research study should determine how focus groups are used and the type of data that are collected.

\section{Draw and write technique}

A third research instrument that has been used to elicit children's thoughts and opinions within the context of health and physical education is the draw and write (and its variations) technique. This method asks participants to draw something in response to a question and then often, but not always, invites them to write and/ or talk about the drawing. Hume, Salmon and Ball (2005), for example, used both quantitative and qualitative research methods to explore children's perceptions of their direct and indirect environments and thus ascertain their ideas about possible exercise facilities. The qualitative aspect consisted of map drawing and photographic mapping. Although this study did not focus on a physical education setting, the researchers argued that map drawing could provide a realistic impression of the social environments of these children. Since the children were not asked to explain their drawings, however, no information was obtained about how they thought about their drawings. Possibly not the pictures themselves but 
the children's interpretations and explanations of their pictures provide the needed insights. Thus, both drawing and writing/telling are essential components of this method.

The value of this combination of draw and write was evident in Macgregor, Currie and Wotton's study (1998) of the perceptions of a "healthy school" held by children between 8 and 12 years old. The researchers incorporated both drawing and writing techniques. The children were first asked to draw a healthy school. Subsequently, they were asked to write about what their own school could do to become a healthy school that would lead to enhanced health of everyone in the school. The investigators concluded that the draw and write technique was an appropriate way to obtain an indication of the students' perceptions about health. The children were not asked to explain what they wrote or drew, however, so that the researchers, rather than the children, played a key role in interpreting the drawings.

The draw and write technique has been used to elicit ideas children have not only about health, but also about exercise and sport. Burrows et al. (1999) used it to investigate the answers of children to the question "Is there anything you would like to write or draw about exercise?" The purpose of the study was to identify negative perceptions of physical activity. The authors concluded that written comments about a drawing made in response to a single open-ended question could provide a rich source of information. The researchers did not, however, analyze the drawings in this study, nor were the children asked to explain what they wrote or drew. MacPhail, Kinchin and Kirk (2003) also used the draw technique to uncover children's ideas about sport and sport education. They asked fifth-grade children to draw a picture of their experiences with sport education. The researchers conducted interviews with randomly chosen small groups of children upon completion of the draw task. Their analysis was based both on the interview data and the drawings. Although their study did not focus on how children learn tasks in physical education classes, it is a clear methodical example of how researchers can elicit children's perspectives. MacPhail, Kinchin and Kirk did not evaluate the effectiveness and appropriateness of this method.

Although the use of the draw and write technique in health and physical education has elicited much data, a great deal of the accompanying analyses remain anchored in the interpretations of the researchers and/or have ignored the meanings that a drawing may have for a child. Little work has been done that further 
explores the responses of the children in their own words. A drawing not only has value in itself, but it also can provide a way of talking with children about a subject.

\section{Research on children's perspectives in physical education}

Methods that combine interviews and drawings (as well as observations) have also been combined in longitudinal studies that explore the perspectives of children in physical education. For example, Solmon and Carter (1995) used a constructivist approach to focus on the learning situation of children during physical education classes. The researchers observed the lessons of a physical education teacher and four classes for four months. They held short interviews when the children entered or left their classes. Children were asked to draw pictures of their physical education lessons and subsequently to explain their drawings individually to the researchers. Children were asked both what they were learning in class and what they thought the teacher wanted them to learn. Results showed that the children gave global responses to the question of what they had learned. In particular, they primarily tended to describe their activities for the day. Some children associated the concept of learning with the learning of specific rules, whereas others explained that physical education was about learning respect or how to exercise. This study gave children a voice in describing what they learn in physical education classes as a whole. However, their voices were not heard during actual learning situations, particularly when they were fully engaged and actually performing a physical education activity or task. Yet, because physical education classes often consist of learning not one but various tasks, the voices of children need to be heard concerning all their learning tasks. Such information could improve the understanding teachers have about the thoughts and feelings of their students.

Groves and Laws (2000), who examined children's experiences of physical education by also using a multimethod approach, highlighted the importance of eliciting children's voices in the immediate learning situation. The focus of the study was to define and identify the concept of "experience". Various sources were used to elicit information including interviews, field notes, and journals (physical education diaries). The data showed that the experiences of these children were the result of "negotiations" among those who were involved in the learning situation. Groves and Laws also noted that the beliefs held and behaviors shown by these children were affected by the ways the teachers constructed the learning situation. 
Thus, any attempt to give children a voice in physical education research needs to take the influence of the situation/learning tasks and of teachers and peers into account.

In summary, most of the studies that have examined children's perceptions of physical education have adopted a qualitative, multi-methodological approach, using research instruments that include various forms and combinations of observations, drawing, writing, and interviews. Yet, despite these findings, researchers have rarely compared various methods to discern the best ways of eliciting children's perspectives. Further research into the effectiveness and appropriateness of such instruments would be valuable in determining children's views. In the current study, we therefore focused on ways various instruments that are based on eliciting the thoughts of children, such as draw and write, intensive interviewing, and focus groups, may complement each other.

\section{Methodology and results}

\section{Phases of the study}

This investigation of children's perspectives on their performances in learning assigned tasks in physical education had three phases: one-on-one semistructured interviews based on predetermined topics, one-on-one semistructured interviews based on draw and write techniques, and focus group interviews. The interview data were transcribed and coded. Pseudonyms were used to protect the children's identities. The methodology employed in each phase was based on the findings of the previous phase. We therefore report both method and results in this section of the article after we describe the context of the study.

\section{Context/educational setting}

Physicaleducation in the Netherlandsis compulsory till the age of 18 . The compulsory guidelines for curricula are minimal. However, a nationwide curriculum project offers detailed guidelines and plans that, if followed, provide children with a broad introduction to sport and movement culture (Mooij, Van Berkel, \& Hazelebach, 2004). These guidelines and plans are grounded in a social constructivist 
perspective. Children are assumed to learn tasks by working together in groups, imitating and observing, and by giving instructions to each other. Relatively few primary schools employ certified physical education teachers (Stegeman, 2004). The classes in physical education in elementary schools are led by classroom teachers who may divide classes into ability groups that are rarely divided based on gender. The teacher's role is to enable children to learn from and in all situations and to work together effectively. Physical education in primary school consists of activities often containing sport-specific elements but modified to fit a specific situation. During the first two years of secondary education, children become more familiar with sport-specific games like soccer, baseball, volleyball, and handball, and also important elements of athletics, gymnastics, and rhythm and dance. Physical education teachers in secondary schools are certified. In their first two years of high school, students have little choice in their activities. Their involvement in choosing the content of physical education lessons increases in the following years. The extent to which gender segregation occurs depends on school policy and teacher preference.

\section{Participants}

Purposive sampling was used to select participants to ensure that the responses were as diverse as possible with respect to ethnicity, gender, and cognitive levels. Sampling continued in each phase until saturation was attained, that is, until no new information emerged from the data. A certified physical education teacher currently taught all but two of the 29 children. Informed consent was obtained from the parents of children who were interviewed. Participants in this study were Dutch children $(N=29)$, aged 11 to 13 (sixth and seventh grade). The children who participated in the three phases attended different schools. Four boys and four girls were interviewed in the first phase. In Phase 2, the draw and write technique was used to elicit the views of 12 boys and nine girls. Three children from this group were also interviewed in depth after they completed the draw and write assignment. In the third phase, focus group interviews were conducted with two groups of three children who had also used the draw and write method. Thus, each phase was developed based on the results and analysis of the previous phase. 


\section{Data analysis}

We used the constant comparative method (Charmaz, 2006; Glaser \& Strauss, 1967) to analyze the data in each phase. Data were analyzed after every interview, resulting in written memos that described emerging patterns. Subsequently, discussion topics were added or altered after each phase based on the information and descriptions provided by the children when performing a task. The following overlapping themes emerged during the analysis of the three phases as a whole: experience of the learning process, perception of learning based on the input of the teacher, and perception of learning in cooperation with others. In the following sections, we describe these themes and the comments of the children that best illustrate them.

\section{Phase 1: In-depth interviews using a semistructured questionnaire}

The procedure for conducting the interviews consisted of open interviewing (Baarda, De Goede, \& Van der Meer-Middelburg, 2000). This means the interviewer tailors the questions to each individual, allows them to answer in their own words, and bases subsequent questions on these individual answers. Participants have relatively much room to answer questions in their own words. Consequently, although the basic topics covered were similar, each interview was different.

A list of topics grounded in constructivism (Rovegno \& Dolly,2006) and based on the results of the findings of studies cited in the previous section was constructed before the first interviews (see Appendix 8A for a list of the topics and sample questions). Several sample questions were developed for each topic, in case children did not understand it.

Two interview sessions were used as a pilot and recorded on video. This enabled the three interviewers to explore effective ways of asking children questions about learning. The content of these pilot interviews helped the researchers to refine the list of topics and to develop tips for effective interviewing. The interviews were conducted in regular schoolrooms and recorded with a voice recorder. Interviews lasted about 30 to 45 minutes. Analysis and interpretation of the data focused particularly on the information obtained from the children about their perceptions of performing a physical education activity or task. 


\section{Results: Phase 1}

Experience of the learning process. The descriptions these children gave of the learning activity tended to reflect specific learning outcomes. They thought that achieving the stated goals was much more important than the learning process that the activity actually represented. For example, Vincent (12 years) talked about juggling plates:

I couldn't do that. I am not sure why, but I thought it was just very difficult. I saw that others could do it. And when I looked at myself, I thought: 'I want to be like them.' And everything went wrong all the time. Then, I threw away the plate and played with a ball. It [juggling] is no use to me.

Vincent's experience of his own lack of ability was not replaced by a positive perception of either the learning process or the possible challenge of improving his juggling skills. The visible success of others also played an important role in constructing the experiences of these children. In contrast, a group performance encouraged some of the children to participate. Jim describes his participation in acrobatics:

First, I thought it would be boring. Later, I understood it a little. Then, other children created a large pyramid. Then I thought: 'I would like to do something like that. I'm going to do that and will participate.'

Each of these children had thoughts or feelings before or during learning a task about how they could be successful. An analysis of their answers to what they had learned revealed that they associated the idea of "learning" with new activities or with new tasks embedded in familiar activities. Apparently, these children defined learning as the acquisition of something new in physical education. Sam described how learning occurs:

... well, with an unknown game, the teacher will give an instruction and you will imagine it, OK? So, I did not know that [game] and I am now learning it. I have to pay attention; otherwise I learn nothing and get it wrong. 
In this case, Sam perceived his learning to be based on understanding an activity and, specifically, understanding the rules or the performance of a specific task within an activity. We also noted that the perceptions of these children were mainly focused on the introduction provided by the teacher. The active cognitive understanding in a learning situation could be defined as a child's perception of what learning entails. Sally, for example, said that a new game would be easier to learn "when the explanation is good and if the teacher talks clearly and if we get examples". According to these children, their learning often occurred in a solid, logical sequence. They perceived this learning as "natural". This linear understanding was apparent when they described learning a game. For example, Jenny explained that "every time I am supposed to pass, the ball goes in the wrong direction. I asked where I had to throw it. Then it was explained, and now I can do it." In this example, Jenny saw the learning process as uncomplicated. In general, the children's answers lacked details of their learning perspectives. They tended to talk only about the differences between what they saw (an example or an introduction by the teacher) and what they did (actual performance). Mary's comments reflect this view of "learning" a new activity:

\section{How do I know [if I have learned something]? Well, I wait and see. Possibly, there is something new [I need] to learn. And when I watch the introduction of the activity by the teacher and it looks easy, it will be easy. Then when I really try to do it by myself and it seems to be very hard, I will go ask someone for help. So, then I am learning.}

These children rarely described the actual intervention of a teacher. When they were asked to comment on an intervention and how it was (not) helpful, their responses were limited to a few words about how they individually tried to solve problems in a learning situation: "He [teacher] explains it all briefly. Most of the time, I understand what to do. Then I try it out. I often succeed in it and then I know how the game works." Their answers to questions about what they have learned pertained primarily to the learning of rules or of specific functions:

Interviewer: Could you tell me why learning that game is so difficult? Mary: It is very complicated to be an offensive player for two teams. First, I play with the first team and when the other team has possession of the ball, I play with them. 
These children did not see learning as experimentation or as finding various solutions to movement problems. "Learning" for them most often pertained to solving and understanding the difficulties and complexity of rules in games.

Interviews based on a semistructured questionnaire were specifically tailored to elicit the views of the children about learning. Yet the responses were mostly limited to what was specifically asked and did not go beyond that. They seemed to be unable to express their thoughts and/or the researchers experienced difficulties in understanding them. Possibly children may be limited when it comes to expressing their individual learning processes in ways that can be understood by teachers and researchers.

Perceptions of learning based on the input of the teacher. Some of the interview responses provided information about the children's ideas regarding the position and contributions of the teacher. The children stated that their "learning" was "better" when teachers were skilled enough to be able to explain activities clearly. For example, when Marrit was asked if the teacher made a considerable contribution to their learning processes, she responded by comparing the effectiveness of two teachers:

\section{This teacher [John] is actually better, I think. He explains briefly and clearly. The other teacher [Sam] takes a long time before he finishes his explanation. It is difficult to understand [his explanation] and he reads a whole list of rules.}

In this case, the teachers' explanations of activities seemed to be very important to the children. A good explanation of activities is assumed to aid learning. If children do not specifically understand what they could learn (the end result) in an activity, the teacher may not be attuned to the children's concerns during their learning processes. For example, Susan describes: "I was juggling and I still could not do it. He [teacher] had already explained how I should do it. After that, I still did not understand. Then I did not feel like learning it anymore and I chose something else." This concern may be related to the social nature of physical education classes.

Perceptions of learning through cooperation with others. When asked about what they learn from others, these children revealed that they are influenced by 
their peers and their attitudes to physical education. Consistent with findings by Dyson (1995) and Ratliffe et al. (1994), the children's responses in the current study indicated that group composition in physical education classes was important to the way they felt about the lessons and that these group compositions made a significant contribution to or detracted from their learning specific tasks. Their experiences of physical education were partly shaped by the ways in which other children participated. Classmates who did not participate in a group or who limited their efforts were seen negatively by other children and as an obstacle to their learning. Working with friends was constructed as fun and appealing. Linda described how working with friends was a major factor in encouraging her to participate in learning situations:

\section{$\mathrm{PE}$ is fun when I can be with my girlfriend [in an activity]. It is not fun if I'm not with my girlfriend and only with boys. A lesson should be fun and I want to participate in fun groups. When I do not have fun, then I do not feel like participating.}

These children found physical education classes boring when they were placed with classmates who failed to comply with rules, who were not liked, or who only wanted to argue. Group composition therefore played a crucial role in the ways children evaluated their learning experiences.

Finally, the results of this phase revealed that these children found it difficult to describe their experiences of learning when the interviewers used a list of topics. Therefore, the sample questions that had been created for each topic had to be used. Yet the use of a large number of questions allowed the interviewers little time for indepth probing, and several issues remained under-explored. Questions based on the topics may have both enhanced and limited children's abilities to put words to their personal thoughts and feelings. Thus, we wanted to explore the viability of other available methods to obtain insight into how these children experienced learning.

\section{Phase 2: Draw, write, and tell}

During Phase 2, the number of topics used in Phase 1 was reduced and the remaining topics were augmented with the draw and write technique. The (redundant) topics "motivation in physical education classes" and "the perceived importance of PE" 
were eliminated; related items were merged into the topic "experience of the learning process". Similar to the methods employed by Macgregor et al. (1998) and Burrows et al. (1999), the children in the current study were instructed to draw something about learning in their physical education class. Specifically, they were presented with the following scenario:

\section{During classes, you usually play all kinds of games or undertake different physical activities. We would like to know what your thoughts, feelings, or experiences are about these activities. We are especially interested in your personal opinion. Is there anything you could write or draw about learning in physical education classes?}

The day after the children had completed the above assignment, we conducted indepth interviews with three children who were randomly selected by the teacher. We assumed that the experiences highlighted in their drawings were still relevant. The interview sessions were organized around four questions/topics. The conversations started with asking the children to comment about their drawings: "What can you tell us about what you have drawn about your classes?" Subsequently, we explored their perceptions of learning with the question "How do your drawings show you are learning?" Depending upon the children's responses, two other topics were introduced by the interviewer, namely, how they thought their learning had been influenced by teacher's input and by working with others. We used semistructured questions to encourage an open discussion about their drawings. We did not, however, analyze the drawings because the purpose of the study was to give the children (rather than the researchers) a tool to talk about their experiences, feelings, and thoughts.

\section{Results: Phase 2}

Experience of the learning process. This phase included the use of children's drawings in combination with the aforementioned interview technique. Most of their drawings depicted a new game or activity that had been introduced by the teacher. Most of the children also provided descriptions of these games and their rules. Similar to the results obtained in Phase1, the children participating in this phase of the investigation seemed to be limited in their ability to express their experiences. 
For example, in her responses to what is meant by "fun" in an activity, Cindy, who plays handball, explained that she likes to learn a new activity: "Well, because I like throwing and I play handball. I liked that at once, so..." She actually is responding to what she likes to learn. But she could not clearly explain what she meant by "learning something new". To the question about which activities she disliked learning, she answered "playing tag, because games of tag are won by cheating". This argument seemed to be rather unrelated to learning, and it is, of course, possible that children also cheat when playing handball. Cindy's explanation about why she enjoyed a game could be qualified as one-dimensional. This type of response was typical in that these children tended not to provide details when talking about their own skill levels, regardless of their levels. Doreen was able to distinguish between her own lack of ability and having fun: "I am not very good in basketball. I also don't think it is fun. However, it depends... You could still enjoy this game even if you are not very skilled." She was an exception, however. It seemed that drawing and explaining what they drew enabled these children to focus on their underlying intentions and experiences. Furthermore, the children seemed to give more authentic responses when the interviewer continued to probe. Specifically, these children were able to talk more explicitly about their learning difficulties or barriers. For example, Peter had drawn a child who was doing a handstand and explained:

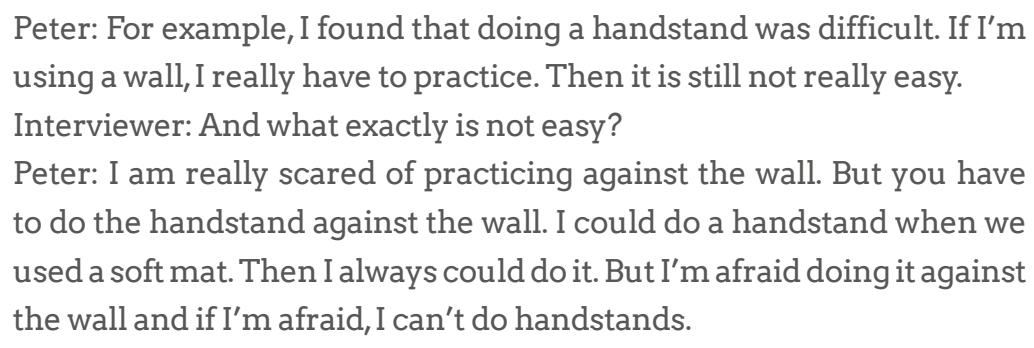

In this example, the child used the drawing to describe his feelings about the learning situation and its role in the process of learning tasks.

Perceptions of learning based on the input of the teacher. The children did not give supplementary comments about their teachers' input into their learning processes during Phase 2. 
Perceptions of learning through cooperation with others. The draw, write, and tell method revealed a variation in results about the ways in which children speak about working with others in a learning situation. Some of them explained that willingness to enforce the rules is necessary if they are to work together effectively. Otherwise, "problems" will occur: "For example, when playing a game of tag, we have to decide who is 'it'. But not many players want to get a turn at being 'it'. Most of the time we have an argument." Not only was the composition of groups of major importance to children's learning experiences, but also the reactions of their classmates. Ruben explained how this works:

\section{Ruben: Some classmates said: "You can't really do it. You cannot join the team." But if they let someone join the team, he becomes more confident. He will also be more successful. \\ Interviewer: When did you feel good about yourself? \\ Ruben: When I was a goalkeeper. When I stopped the ball [from entering the goal], other classmates said: "Yes, excellent!" Then I thought: 'Yes, I have to do that again.' \\ Interviewer: You think that what other children say is important? \\ Ruben: Yes, because then I feel that others also believe that I can do it. Then I feel this success again.}

These children were able to talk in more detail about what they had learned when they used the draw, write, and tell method. The depth of the results still depended, however, on the ability of each child to explain this to an adult. This may have resulted in great variation in the data and may have limited the results as well. The results in Phase 2 suggest that not only draw and tell, but also the input of classmates may yield additional information about children's perspectives of learning tasks.

\section{Phase 3: Focus group interviews in combination with the draw, write, and tell method}

Because discussions with classmates may provide the children with support, and enable them to talk in greater depth about their own learning experiences (Morgan, 1997; Krueger \& Casey, 2000; Stewart et al., 2007), Phase 3 consisted of two 
focus groups interviews $(N=3)$ that were also based on children's drawings using similar procedures as described in Phase 2 (cf. MacPhail,Kinchin, \& Kirk,2003). The interviews lasted between 60 and 75 minutes.

The drawings and five topics culled from Phases 1 and 2 were used to guide the conversations (see Appendix 8B for an example). Each child first answered the question "What do you think about physical education classes?" and subsequently was asked to explain her or his drawings in answer to the question "Could you explain what you have drawn?" Then the children talked with each other about their perceptions using the following topics: "learning based on what children have drawn", "learning in cooperation with others", and "perceptions of learning based on the input of the teacher". The interviewers moderated the discussions. The use of these topics was limited to the amount of time the children needed to express their experiences.

\section{Results: Phase 3}

Experience of the learning process. The focus group interviews provided new and additional information about the children's perspectives and thoughts about learning tasks. The group discussions were frequently spontaneous and meant that the children, instead of the moderator, determined the topics that were discussed. In these circumstances, the children made important contributions to the input of a conversation. For example, during a conversation about the high jump (athletics), the children gave their reactions to a classmate's drawing of the high jump:

Nick: Well, that's really boring.

Interviewer: What do you mean when you say the high jump is boring?

Nick: Because, I always think that I won't make it. Then I will not make it.

Interviewer: Because?

Nick: Well, I am just afraid that I can't make it... That my feet will hit the bar and I look like a fool.

Interviewer: I understand. You can't make it because of what others think?

Nick: Yes, because I just get a strange feeling. Interviewer: What kind of feeling? 
Nick: [I get] a stomachache.

Interviewer: Do you have this feeling only with the high jump?

Nick: Ehmm, also with other things. If I have stress or something.

Interviewer: When do you feel stress?

Nick: Well, when I think I'm too late for school... [he continues talking about the high jump]. Yes, I stop. I'm just around the cones and then I stop just before I have to jump. I just stop running and have to do it again.

Robert: Yes, I have this also a couple of times. Then it is quite scary to jump.

Lyn: Yes, I feel that too.

Nick: Yes, I run and just think during the last meters that I can't make it. It seems so high when I get closer to the bar.

In this example, the responses to a classmate's drawing and his experiences of the activity provoked various reactions in the children. During this conversation, they were able to express their experiences clearly about what they see as a difficult task. Some children described "learning processes" in their own sport. The children all agreed on the need for repetition of the tasks being learned: "Learning too many different aspects at once is very difficult and doesn't work." Lieke (age 11) explains:

Lieke: I play handball. We had to make a running shot, a jumping shot, close-ups, and I had to throw right. I also had to learn to throw a lob. Also, I had to throw with my legs in the right position, all at the same time. During a match I could no longer do this.

Interviewer: And now?

Lieke: Now we are practicing one thing throughout the lesson. I understand it a little bit.

The children could articulate an evaluation of their ability, yet they did not show an understanding of the components of their performance. They also found it quite difficult to specify what they needed to learn to improve their skills. This finding was similar to the results obtained in Phases 1 and 2. Yet focus group interviews yielded more information since this method gave the children the opportunity to focus much longer on just one topic. The following discussion exemplifies this. The 
children talked about learning to play soccer during physical education classes and how they believed that they could at least learn something in this game:

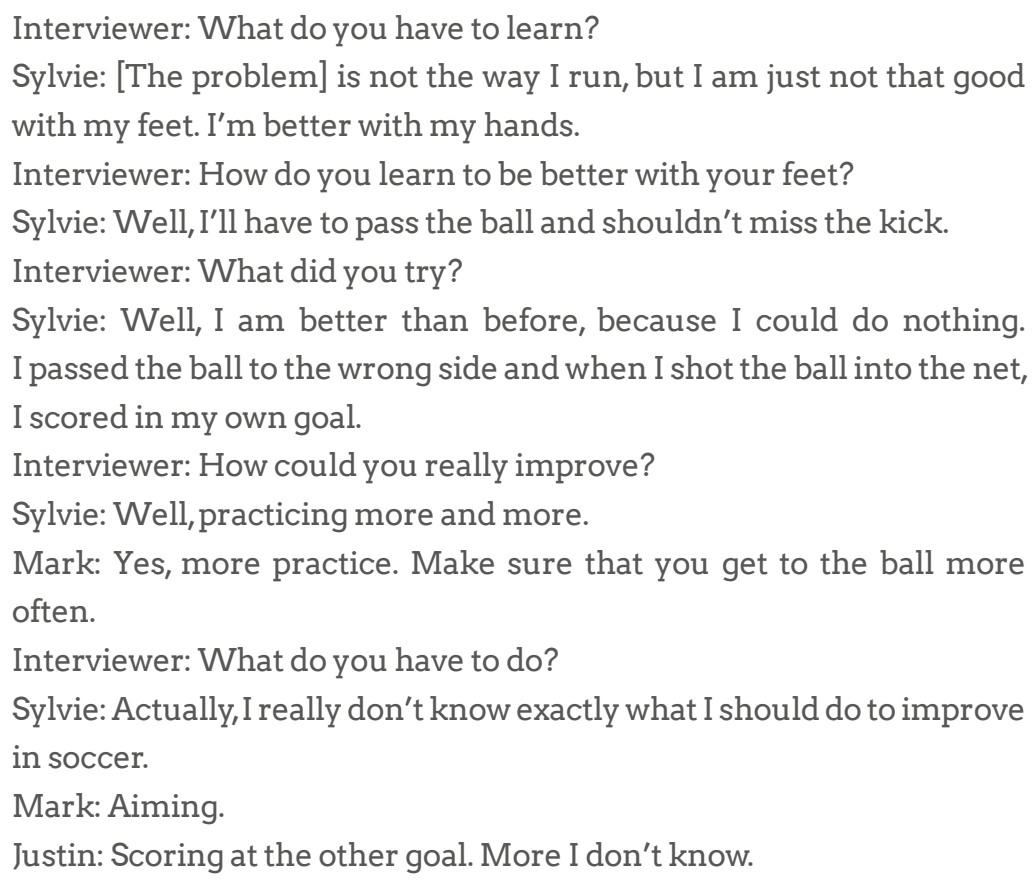

The children could not clearly explain what they learned during a game like soccer, even though they realized that they have difficulty executing the skills. Nevertheless, they were confident in their capacity to learn the skills as long as they practiced enough. Their experiences of problem solving or learning a task were expressed with words like "practicing", "training", or "do one's best". During the same conversation, these children found it strange or funny that their own attempts at change did not have any positive effects:

Sylvie: When I trained in and practiced athletics, I became better skilled. But, with soccer, it doesn't work that way.

Mark: Yes, I have the same thing. Because the more often I do [athletics], the better I become. I play soccer quite often, but I don't improve. Justin: Perhaps, you don't practice enough. 


\section{Mark: Well, I play soccer almost every day. \\ Justin: I used to play soccer every day. \\ Sylvie: Me too.}

Perceptions of learning based on the input of the teacher. During the focus group interviews, the children had difficulties in expressing what they could learn from their teachers. In particular, they had problems in articulating what they thought the teacher's ideas or intentions were. One child noted that the teacher's input "makes sense", but is "actually invisible". Apparently, the children do not actually visualize the instructions of their teachers. They regard their teachers as being skilled, although the children could not say exactly how the skills of the teacher contributed to the learning experiences of the children. Moreover, the children rarely discussed teacher interventions. They did not construct a link between interventions or instructions of teachers and their own views of their learning processes: "... if [the teacher] tells us something, I think, 'yes, I'm going to do that.' But I don't know if that means I learn something."

Perceptions of learning through cooperation with others. The children gave more details than they did in Phases 1 and 2 about how they work with others during classes. Although they prefer to work with friends in physical education classes, the children also realized that it would be impossible for the teacher to organize each class in this way. Moreover, they agreed that children with "not many friends" would have fewer opportunities to work with friends if classes were organized on the basis of friendships. A few children indicated that they can learn skills even if they have to accept the group composition organized by the teacher:

\section{Justin: You have to learn to work with children you don't like. Perhaps your friend will not go to the same high school [after you have graduated from elementary school]. \\ Sylvie: Yes, you have to learn to live with disappointments.}

These comments suggest that the perspectives of learning articulated by these children were both external and future oriented. Secondly, they seemed to regard learning to work with different group compositions during physical education classes as a necessary learning process. 


\section{Discussion}

The current study explored how children talk about learning tasks. The results illustrate that children's views can be examined by using a phased qualitative investigation and show that an exploration of the perspectives of learners in physical education classes requires that attention be paid to methodology. In addition, these results reflect how these children constructed their learning of specific tasks during physical education classes. We reflect on the use of several instruments followed by a discussion of what the children said about their experiences.

\section{Methodical reflections}

In-depth interviews based on semistructured topics and questions and the use of the draw and write/tell technique elicited relevant information about the topics "experience of the learning process", "perception of learning based on the input of the teacher", and "perceptions of learning through cooperation with others". Similar to Krueger and Casey (2000) and Stewart et al. (2007), our results revealed that the use of focus group interviews in combination with draw and write/tell were more successful in obtaining information about children's perceptions than individual interviews or draw and write techniques alone. Relatively speaking, the discussions in the focus groups seemed to minimize the importance of the teacher's input into the children's learning. Possibly the presence of an adult as moderator and the children's loyalty to their own teachers may have prevented them from speaking out publicly. They may have dared to do this during an individual interview more so than in a public group perhaps because of their sensitivity to their classmates' individual relationships with a teacher. This finding corroborates Stewart et al. (2007) contention that a very dominant or opinionated member can affect the discussion, that children's responses during group discussions are interdependent, and that results obtained in a focus group restrict the ability to generalize the results. Yet the focus group interviews in the current study elicited information that had not emerged during the other techniques. Further research is needed to explore these dynamics. 


\section{What do children really say? Implications}

The purpose of this study was to find ways to elicit children's thoughts, feelings, and experiences about and in learning situations. The results of the draw and write/ tell techniques revealed that these children viewed learning as a concrete activity such as gaining an understanding of rules and not of as a process of exploration. This result is similar to that of Solmon and Carter (1995), who discovered that when children were asked to draw pictures of their physical education class, they often drew physical education activities and equipment. This finding suggests that children wanted to understand how activities really work instead of exploring new challenges.

The results of the current study revealed that children equated physical education learning with concrete results and that these children used similar words and expressions to describe how they participated in a learning situation. They seemed to be limited by their vocabularies when trying to express their experiences of their learning. For example, children responded to questions about learning activities with diffuse phrases such as "I like that game" or "I think it was really good". Others (Laws \& Fisher, 1999; Groves \& Laws, 2000) have noted the limited vocabularies of children in describing their physical education experiences as well. The findings suggest that children either have little idea of how they negotiate a learning situation or solve problems during the learning process and/or do not have the vocabulary to describe this. As a result, the children in this study only talked about the use of repetition ("continue practicing") or trying ("try to do your best") as the best way to learn skills. These responses suggest that they created few of their own descriptions or phrases. They may have verbally mirrored the words used by their teachers, who may not have provided verbal tools that these children could have used to express their perceptions in more varied and concrete ways. Possibly then, teachers play a decisive role in constructing children's use of language and their ability to articulate their learning processes. Teachers may be more focused on the learning outcome and pay less attention to children's perceptions during the actual learning process. Further research is needed to determine how this language limitation of children influences their learning outcomes and how teachers could expand the vocabulary of children so that they can articulate their ideas and opinions about learning situations.

The results of this study also indicate that these children thought that peers and the composition of work groups significantly influenced their learning. Executing 
tasks with friends during physical education classes was very important to them. New tasks were seen as more appealing,less difficult to learn, and more fun ("without quarrels") in such circumstances. This finding is not unique (see for example, Laws \& Fisher,1999). Yet little is known about exactly how this works in a personal learning situation. For example, does a positive peer group situation compensate for perceived failure and possibly loss of face in learning a task? A further examination of these influences on children's perspectives and feelings could provide more information about how teachers can use group compositions effectively.

Constructivism assumes that children's experiences and their subsequent construction (and accumulation) of these experiences into knowledge occur in an active way and that teachers should elicit children's perceptions (Rovegno \& Dolly, 2006). The veracity of this assumption was reflected in our data. The results showed that what these children thought and how they gave meaning to their experiences played a critical role in their own learning. They decided whether to listen to what teachers are saying, whether to put effort into learning, and whether they wanted to be engaged even before a task even began (cf. Rink, 2003). Consequently, these results indicate that teachers face complex challenges if they wish to take individual learning processes into account. These challenges are compounded by an increasing diversity among children and their skill levels in physical education classes. In a sense, a social constructivist approach is best suited for dealing with diversity in a classroom since it sees each child as a constructor of meanings (cf. Solmon, 2006). At the same time, the results of the current study indicate that eliciting the thoughts of children is a complex process for which few of the necessary tools are available. Further research is needed to explore how children's perceptions can be elicited and be incorporated into lesson plans so that the chosen didactical and pedagogical methods can be based on an understanding of what exactly children experience when learning tasks. The quality of physical education could be enhanced if teachers incorporate this understanding in their didactic and pedagogical repertoire. If used, it could help enhance the skill level, and possibly enjoyment as well, of children in physical education classes and thus contribute to quality instruction. 


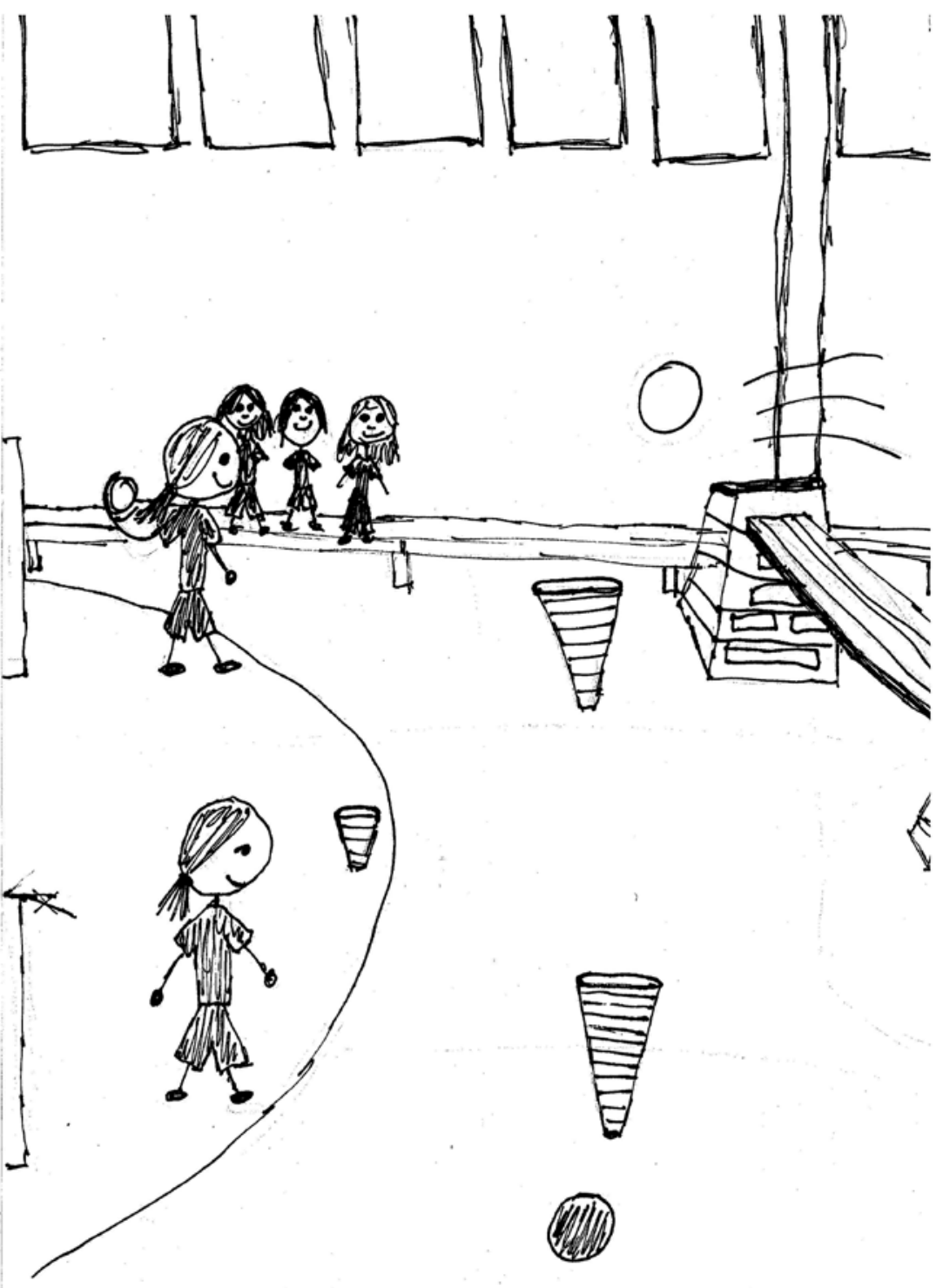

Drawing Sari. 


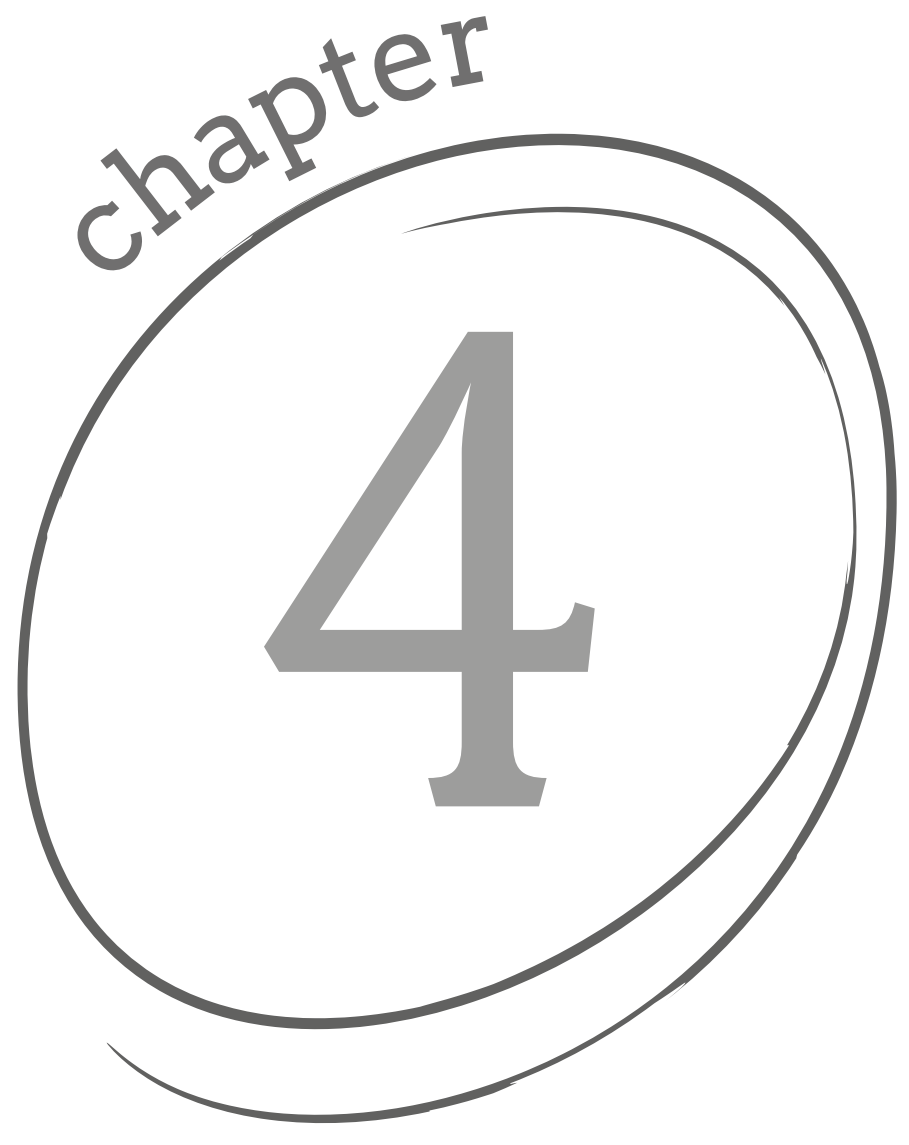




\section{The role of perceptions of friendships and peers in learning skills in physical education}

\section{Abstract}

Background: Most research on how children learn when using the Teaching Games for Understanding (TGFU) approach has focused on cognitive dimensions in teaching games models. A social constructivist perspective suggests, however, that learning also takes place during social interactions. Since the process of learning game skills tends to have a relational dimension, researchers need to understand children's affective responses and how they situate their skill learning in games in relationship to their classmates.

Purpose: To explore children's perceptions of collaboration, group formations, and friendships while learning a modified baseball game situated in social constructivist learning. Specifically, we focused on how children perceived the role that the social context, especially friends and classmates, plays in learning skills and strategies.

Participants and setting: The children $(N=25)$, aged $12-13$, were in their first year of secondary school and were taught in a TGfU baseball unit. They participated in eight small focus groups to talk about their experiences in a modified baseball game.

Data analysis: The constant comparative method was used to collect data in which drawings were used as cues for focus group discussions about interactions with peers during their learning of skills. 
Findings: Three themes emerged from the analysis: peers as necessary collaborators, friends as supporters and distractors, and peers as perceived critics. The results indicated that the presence of peers shaped the experiences of these children in contradictory ways. Findings were situated within social constructivism and compared with other research focusing on game-centered approaches and the role of the affective domain in learning.

Published as:

Koekoek, J., \& Knoppers, A. (2015). The role of perceptions of friendships and peers in learning skills in physical education. Physical Education and Sport Pedagogy, 20(3), 231-249. 
The use of Teaching Games for Understanding (TGfU) is in part based on the assumption that collaboration to find solutions and to solve tactical problems is essential to enhance the learning of games (Light, 2009). However, based on their review of studies of game-centered approaches, Oslin and Mitchell (2006) showed that most of these investigations focused on the performance results of children while the nonverbal ways of learning that occur in the PE class have received relatively little attention. Much of the research within game-centered approaches such as TGfU has focused on cognition and thought processes. With a focus on verbalization, that is considered to be a key element in these approaches, several researchers have explored how children give meaning to their feelings and thoughts and how these might influence learning (Chow et al., 2007; Dyson, 2005; Light \& Fawns, 2003; Ward \& Lee,2005).

Gréhaigne, Godbout and Bouthier (2001) contend that decision-making is an important component of learning tactics in team sports in physical education. These researchers argued that decision-making is not only an individual action but also is influenced by collective experiences. For example, how children experience and think about relationships has an indirect influence on their actions and behavior. The authors characterized these interactions as forms of implicit affection. The question is then how these relations can be made explicit. An understanding of children's perceptions about the dynamics of these collective influences in learning tactical knowledge may contribute to ways to enhance children decision-making skills.

Pope (2005) has argued that researchers need to pay attention to the role of affective responses such as feelings and emotions in children's decision-making processes while learning physical skills. He suggested that such research could contribute to a more holistic understanding of how children learn games since their learning strategies and decisions are not guided by cognitive interpretations and thoughts alone. Pope's findings showed that collective understandings such as perceptions of team involvement and beliefs about other players' input make a significant contribution to how children learn games in PE contexts. It is not surprising therefore that researchers (e.g., Dyson, Griffin, \& Hastie, 2004; Koekoek, Knoppers, \& Stegeman, 2009; MacPhail, Kirk, \& Kinchin, 2004; Taylor, Ntoumanis, \& Smith,2009; Weiss \& Stuntz,2004) argue that peer influence plays an important role in how children learn skills and strategies in physical education and sport. Weiss and Stuntz (2004) noted that "experiencing positive friendship and perceiving social 
support are strong predictors of positive self-evaluations, affective responses, and motivational processes" (p. 183) of participants in youth sport. Most of this research on peer influence focuses on the sport context, however. Such competitive settings are characterized by high and homogeneous skill levels. Children's skill levels (but also other factors such as interest) in physical education classes tend to be heterogeneous. In addition, activities are selected by the PE teacher and vary greatly encompassing many sports and games. Research that focuses on the sport setting may therefore not necessarily be applicable to the PEcontext. A better understanding that the role perceptions of friendships play in a PE setting in the learning of games may be helpful to teachers as they plan their lessons and subsequently benefit children in their classes.

Bunker and Thorpe (1986) conceptualized games teaching and learning with the notion of TGfU.This approach seeks to enhance learning through the use of modified team games that emphasize the development of tactical learning. TGfU assumes children must learn to make appropriate decisions in what they have to do and how they can solve a problem before they attain the next phase of skill execution. This means that children should be fully engaged in solving tactical problems instead of focusing only on learning skills. TGfU settings require children to exchange and assimilate interpretations of strategic intentions and ideas of others through debates. The debate of ideas can be defined as an explicit way to share reflections on action through discussion assumed to improve tactical knowledge (Richard \& Wallian, 2005). The research that focuses on peer influence and interactions described earlier, however, does not inform teachers and researchers in a PE context how potential nonverbal and underlying interpretations of interactions may influence children's learning (Dyson, 2005). Affective elements such as feelings and emotions may contribute to the ways children construct their interpretations and as such shape the process of decision-making (Pope, 2005). The purpose of our study is to explore dynamics that determine children's perceptions of collaboration, group formations, and friendships while learning a modified baseball game in a physical education setting.

\section{Participation and learning through social interactions}

Several researchers have tried to gain insight into the ways children construct and assign meanings to social interactions in physical education and sport. For example, 
Mulvihill, Rivers and Aggleton (2000) explored factors that influence children's involvement in physical activity. They used the draw and tell technique to uncover perceptions that children aged five to eleven had of physical activity. One of the five themes that emerged from the data indicated children enjoyed interacting socially with friends and engaging in competition, and had an overwhelming preference for group activities such as team sports. Mulvihill et al. (2000) concluded that social interactions motivated children to succeed in the assigned tasks. Though these findings were not situated within a PE context, the study suggests that friendships can play a decisive role in children's involvement in physical activity. Carr and Weigand (2001) found that, as well as teachers and parents, peers also influence children's goal orientations and subsequently their behavior and participation in PE lessons. These children showed effort and perseverance when their peers focused on self-improvement and personal progress. In contrast, when peers valued making comparisons and demonstrating ability, these children tended to avoid challenging tasks and competition and showed low levels of effort. Understanding how children learn in physical education therefore needs to include a focus on these complex dynamics of social interactions between peers.

Light (2006) is one of the few researchers who explored the role of affective dimensions in social interactions and interpersonal relationships in games learning. He used interviews, drawings, and observations to investigate the first experiences of children playing within a Game Sense approach (a variation of TGfU). Drawings of cricket and softball lessons were used to generate discussion in individual interviews with sixth graders. The results indicated that the use of Game Sense not only improved relationships between peers but also contributed to individual learning. Light concluded that social interactions between children influence how they learn games. This finding, as well as the results of the study conducted by Mulvihill et al. (2000), suggests a greater in-depth analysis is needed of how children construct learning in the context of friendships.

\section{Learning and friendship relations in TGfU}

This relationship between learning and friendship has not been totally ignored in research on TGfU. Cothran and Hodges Kulinna (2006) explored the impact of three teaching strategies on the relationship between friendship and learning of children, aged 11-14. They used semistructured interviews to explore the influence of direct 
instruction (the teacher shows how children must execute a skill or technique), peer instruction (choosing a partner to learn a task with different roles), and inquiry instruction (questioning by the teacher to encourage children to try different solutions). Children perceived peer instruction from friends as fun because it provided an opportunity to chat with each other. Furthermore, although children had less fun during the direct instruction method, they thought it provided more opportunities to concentrate or focus on the task. Cothran and Hodges Kulinna focused, however, on reactions to instructions by friends only. They did not ask the children the perceived advantages and/or disadvantages in learning and performing skills. However, knowledge about these perceptions may add to theorizing about how children learn within the context of TGfU and help teachers think about how their teaching methods and class organization can best facilitate the learning of skills and strategies.

\section{Theoretical framework}

We framed our research within a social constructivist perspective that emphasizes the role of the social context in learning (Vygotsky, 1978). Vygotsky claims that interaction between individuals and the social context results in learning. This interaction forms the theoretical basis of learning (Davydov \& Kerr,1995).Specifically, collaboration and collective activities serve as a social bridge enabling children to learn. These interactions shape language use in the classroom (Powell \& Kalina, 2009). A social constructivist perspective therefore suggests that communication is a key factor in learning and requires the development of language skills.

Liu and Matthews (2005) drew on Vygotsky's approach to situate the concept of interconnectivity within the context of collective subjectivity. They argued that change during learning processes are based on collective participation and collaboration. These interactions provide realities for learners that go beyond their individual learning experiences. Specifically, what individual children learn is influenced by social interactions that simultaneously shape collective output. For example, research in $\mathrm{PE}$ that focuses on this relationship indicates that teachers can teach children to negotiate decisions and share responsibility in relation with others. In this manner they contribute to the group as a whole (Azzarito \& Ennis, 2003). This constructivist perspective suggests therefore that children construct reality of affective aspects during learning through interaction and contextual dialogue such as their chats and conversations. Since such social processes produce 
knowledge, children's talks are therefore a necessary social activity that can shape their learning and need attention from researchers.

Rubin, Bukowski and Parker (2006) contended that the use of a multilevel perspective can provide information about how children differ and act in relation with others. These researchers made a distinction between interactions, relationships, and groups. While interactions can be defined as social exchange between individuals, relationships represent a higher order of complexity because they involve meanings, expectations, and emotions. A group, as highest order in peer experiences, is embedded within patterns that occur in relationships based on interactions among children.

The TGfUmodel reflects a learner centered approach. TGfUencourages children to construct meanings and to use them to make decisions in game situations. These decisions are commonly made in small groups where social skills can be developed such as negotiating opinions and listening to others (Butler, 2006; Kirk \& MacPhail, 2002). The focus is not the learning of techniques per se as occurs in direct teaching methods but on children's discovery of acting and playing games together (Wallian \& Chang, 2007). These assumptions of how use of the TGfU model engages children and their experiences with peers, however, need to be corroborated (Griffin, Brooker, \& Patton, 2005).

Several researchers (Kirk \& MacPhail, 2002; Light, 2009; Wallian \& Chang, 2007) who have explored the use of TGfU have emphasized the congruency between the model and social constructivism. Kirk and MacPhail (2002), for example, revised the TGfU model situating it within a situated learning perspective. Strategic thinking plays an important role in this model. An emphasis on strategic thinking assumes a process of intentional and relational goal- and action orientations of the learner. Therefore, knowledge production within TGfU is assumed to include the learner's adaptation to environmental influences. Wallian and Chang (2007) contended that TGfU is conflated with a semio-constructivist approach. They emphasized the situated, social context that serves as a key for constructions of meanings by the (implicit) sharing of interpretations. Social constructivism also assumes that learning is an active process in which children use social interactions to reflect on or to analyze information that is critical to their learning (see for example, Adams, 2008; Barker \& Rossi, 2011; Davis \& Sumara,2002; Light,2008; Rovegno \& Dolly,2006; Singleton, 2009). Children's understanding occurs through a process of discussing these interpretations with other players. Light (2009) noted that verbal interactions 
are a central characteristic of TGfU where children learn from the social experience even without influences of the teacher.

Light and Fawns (2003) argued that the use of an approach such as TGfU to learning enhances social interactions that help children acquire physical skills. Children need peers to define and assign meanings to how they must use rules, tactical knowledge, and make decisions. MacPhail, Kirk and Griffin (2008) found that even skills that seem to be de-contextualized such as throwing and catching a ball also contain a relational character. They explored how fifth grade children learned to play a 12-lesson unit invasion game within a TGfU approach. MacPhail et al. (2008) used written narratives of lessons recorded on video, semistructured interviews with both the teacher and children during game play, and evaluations of children's skill levels as the result of a game performance assessment instrument (GPAI). They found that learning to catch and to throw was not an individual learning process since players had to deal with capacities and off-the-ball actions of other players, and to take shifting physical spaces continually into account. Furthermore, they also discovered that the learning and performance of these children was dependent on the abilities, motivation, interpretations, and contributions of other children. This finding underscores the crucial role of team members and their influence in individual learning and the need for researchers to pay attention to the affective domain. MacPhail et al. (2008), however, limited their research focus to children's perspectives on what they considered to be a good pass. In light of what has been argued, additional information is needed about perceptions of friendships that may have had a role in these constructions of ability.

The use of critical thinking processes requires children to develop verbal skills by replying to open-ended questions posed by the teacher to help them to find tactical solutions (e.g., Chow et al., 2007; Richard \& Wallian, 2005). Since the vocabulary of some children may limit their descriptions and explanations of their learning experiences, special methodological attention needs to be given to ways to incorporate their experiences and thoughts (Light, 2006; Mulvihill et al., 2000). As such, any research study on TGfU that invites children to express their thoughts on social interactions and peer influence could also simultaneously be an intervention and play a role in that development (e.g., Koekoek, Knoppers, \& Stegeman, 2009). The focus of this investigation is rather on data of children's perceptions of peers than evaluating their thoughts to enhance teacher instructions. 


\section{Methodology}

\section{Draw, write, and tell}

The content of interactions and subsequent meaning-making can be represented in verbal and visual ways. Several researchers have explored this learning using variations of draw/photograph and tell approaches (e.g., Bland, 2012; Darbyshire, MagDougall, \& Schiller, 2005; Lomax, 2012). This visual information can reveal meanings that are created through interactions as well. A combination of both verbal and visual information may reveal the influence of social interactions in learning and is especially suited for use in research with a social constructivist perspective.

The use of both drawings and interviews in obtaining children's perceptions has been a valued methodology within the context of PE (e.g., Light, 2006; MacPhail, Kinchin, \& Kirk, 2003; Solmon \& Carter, 1995) and health education (e.g., Burrows, Eves, \& Cooper, 1999; Macgregor, Currie, \& Wetton, 1998). Gathering information about the social context requires a social setting such as focus groups (Krueger \& Casey, 2000; Stewart, Shamdasani, \& Rook,2007). We therefore combined the use of these groups with a draw and write task (Koekoek,Knoppers, \& Stegeman,2009). The purpose of the drawing task was to serve as a cue to enable children to express their thoughts and feelings. The drawing of a picture may enable children to talk about their thoughts and feelings more so than solely being interviewed by a researcher (Koekoek et al., 2009). A combination of drawings, written explanations, and conversations provided a rich source of information about children's perceptions during learning (Bland, 2012; Darbyshire et al., 2005).

After the first PE lesson that consisted of a modified baseball game, children were invited to draw pictures about an activity in their PE lessons and to write an explanation of their drawings. We used a regular classroom in order to give the children clear instructions in a comfortable facility to enable them to concentrate on drawing and writing. Subsequently we used focus groups to ask them to explain what they drew/wrote. The use of focus groups allowed the researchers to obtain a rich amount of data since the children could use their own words to talk about their drawings and their (shared) experiences in the class (Stewart et al., 2007).

Since the focus of the study was on the social context of learning games, we used an intact class of 12-13-year olds to gather the data. These children were in their first year of high school and therefore they may have seen their peers, friends, and 
their own skills with 'fresh' eyes. The newness of the high school and of many peers meant that these children may have noticed more than they would if they had been together for many years. We assumed that children at this age also have sufficient verbal skills to enable them to describe their thoughts with the use of drawings.

\section{Focus groups}

A moderator who was also a member of the research team facilitated the eight focus groups. The moderator observed the PE lessons before the data collection started. These observations of classroom dynamics, collaboration, and interaction provide the moderator a way to tune into the children's worlds and facilitate the discussions. The observations were not intended to be object of analysis but used to prepare the researcher for the focus group sessions.

To elicit the greatest variety of possible responses about what children learned from peers, we organized four same sex focus groups while the other four focus groups consisted of girls and boys. With the exception of one group with four children, each focus group consisted of three children. Aside from selection based on gender, children were randomly assigned to a focus group. The small group size, and the facilitation of the moderator enabled all children to contribute to the conversations. The children were given the opportunity to explain their drawings and what they wrote about these drawings. Each focus group session began with a question to each child: "Would you explain your drawing and your written explanation?" Subsequently the moderator began a group discussion using questions to explore deeper meanings of what was said.

All eight focus group sessions began directly after or during PEclasses and lasted between 60 and 75 minutes. This enabled the children to focus on the experiences that occurred during this lesson. The researcher asked children to come to a room located close to the outdoor playing field. After the draw and write task had been completed, the researcher needed four lesson days to conduct all eight focus groups with a frequency of two focus groups per lesson.

\section{Participants}

The children $(N=25)$ aged 12 to 13 were in their first year at City High School (pseudonym). The class consisted of eight boys and 17 girls. Informed consent for 
the children to participate in the study was obtained from all parents. Pseudonyms are used to protect children's identities.

\section{Context of the study}

City High School is located in a middle-sized city in the center of the Netherlands. The school was selected because its PE curriculum and teaching methods are based on a social constructivist approach and include an emphasis on TGfU (Ten Brinke et al., 2007). This approach informs the teacher education curriculum at the PE academy from which the teacher had graduated. During his pre-service education the PE teacher had followed several courses in which he learned how to incorporate a student-centered approach with the use of TGfU pedagogical principles such as game sampling, representation, exaggeration, and the learner's tactical complexity (Griffin \& Patton, 2005). Before the data collection phase, we discussed with the teacher how he tries to use these principles in his game lessons. This discussion led us to conclude that he used the TGfU approach in his lessons.

In their first year of high school, Dutch children have three PE lessons per week of 45 minutes each. Lessons consist of units with many different activities and games. Games are modified so that children with different skill levels can play together.

Baseball is taught extensively in the first two years of City High School and includes features such as collaboration and tactical decision-making that allow teachers to elicit thoughts and feelings about competition and cooperation. In addition, baseball is a sport that requires children to focus on group interactions and relationships while executing skills to enhance their learning and subsequent performance. In this six week unit children played different modified baseball games in order to learn specific skills such as throwing, catching, and batting (see Table 4.1).

One of these games was a modified baseball game called hit and run that was developed to teach a specific problem that had to be solved using these skills (see also Koekoek, Walinga, \& Dokman, 2009). In this simplified fielding game, children have many opportunities to bat. The game emphasizes the role of children as learners in a social context since they constantly need to take the actions of other players into consideration in order to make decisions. The modified baseball game was also assumed to develop children's tactical knowledge by providing them with an abundance of practice time (at least 30 minutes) and many opportunities to make tactical decisions. Not only do the batter and pitcher have to work together 
but members of the fielding team also need to communicate with each other about position, placement, and tagging.

Children play the game in small groups of six players. The teacher creates new group compositions for each lesson using different methods such as assigning a group number for each child or by assigning children directly together to a group. This meant the children had to interact with almost all their classmates during the unit and could draw and talk in the focus groups about their experiences in playing with a variety of peers and friends.

Table 4.1 Lesson plan of a six week unit baseball (first year) at City High School.

\begin{tabular}{|c|c|c|c|c|c|c|}
\hline CATEGORY & WEEK 1 & WEEK 2 & WEEK 3 & WEEK 4 & WEEK 5 & WEEK 6 \\
\hline GAME & $\begin{array}{l}\text { Hit and run } \\
\text { (basic) }\end{array}$ & $\begin{array}{l}\text { Hit and run } \\
\text { (basic) }\end{array}$ & $\begin{array}{l}\text { Hit and run } \\
\text { (basic) }\end{array}$ & $\begin{array}{l}\text { Hit and run } \\
\text { (basic) }\end{array}$ & $\begin{array}{l}\text { Hit and run } \\
\text { (advanced) }\end{array}$ & $\begin{array}{l}\text { Hit and run } \\
\text { (advanced) }\end{array}$ \\
\hline $\begin{array}{l}\text { SUPPORTING } \\
\text { SKILLS/ACTIVITIES }\end{array}$ & $\begin{array}{l}\text { Warming-up } \\
\text { Throwing balls }\end{array}$ & $\begin{array}{l}\text { Warming-up } \\
\text { Catching balls } \\
\text { with a glove }\end{array}$ & $\begin{array}{l}\text { Batting balls } \\
\text { Fielding 1-1 with } \\
\text { two goals }\end{array}$ & $\begin{array}{l}\text { Pitching and } \\
\text { batting balls }\end{array}$ & $\begin{array}{l}\text { Fielding } \\
\text { Run down game } \\
\text { (Pickle) }\end{array}$ & $\begin{array}{l}\text { Run down game } \\
\text { (Pickle) }\end{array}$ \\
\hline $\begin{array}{l}\text { LEARNING } \\
\text { OBJECTIVES }\end{array}$ & $\begin{array}{l}\text { Learning how to } \\
\text { throws balls: } \\
\text { - To other } \\
\text { players } \\
\text { - To a player } \\
\text { positioned on } \\
\text { a base }\end{array}$ & $\begin{array}{l}\text { Learning how to } \\
\text { catch balls: } \\
\text { - Use of a glove } \\
\text { - Estimating the } \\
\text { line of a ball } \\
\text { - Catching } \\
\text { groundballs } \\
\text { - High speed } \\
\text { balls } \\
\text { - Catching fly } \\
\text { balls }\end{array}$ & $\begin{array}{l}\text { Learning } \\
\text { to make } \\
\text { appropriate } \\
\text { decisions: } \\
\text { - Estimate } \\
\text { players' own } \\
\text { skill level } \\
\text { - Estimate the } \\
\text { base choice } \\
\text { on the basis } \\
\text { of fielders' } \\
\text { positions } \\
\text { - Estimate the } \\
\text { base choice in } \\
\text { relation with } \\
\text { fielding skill } \\
\text { levels }\end{array}$ & $\begin{array}{l}\text { Learning to: } \\
\text { - Enhance } \\
\text { adaptation and } \\
\text { cooperation } \\
\text { between batter } \\
\text { and pitcher } \\
\text { - Estimate pitch } \\
\text { execution in } \\
\text { relation with } \\
\text { the batter's skill } \\
\text { level } \\
\text { - Use } \\
\text { conversations } \\
\text { to identify the } \\
\text { batter's needs }\end{array}$ & $\begin{array}{l}\text { Learning to } \\
\text { field: } \\
\text { - Catching fast } \\
\text { ground balls } \\
\text { - Recognizing } \\
\text { different tasks } \\
\text { between } \\
\text { fielders } \\
\text { - Recognize } \\
\text { different } \\
\text { throwing } \\
\text { skills between } \\
\text { outfield and } \\
\text { infield }\end{array}$ & $\begin{array}{l}\text { Learning to: } \\
\text { - Force the } \\
\text { base runner } \\
\text { to reverse } \\
\text { direction to the } \\
\text { previous base } \\
\text { - Take an } \\
\text { appropriate } \\
\text { position to } \\
\text { catch balls or } \\
\text { tag the runner } \\
\text { - Attempt } \\
\text { (the runner) to } \\
\text { advance to a } \\
\text { next base }\end{array}$ \\
\hline $\begin{array}{l}\text { TEACHING } \\
\text { INTERVENTIONS }\end{array}$ & Experiencing & $\begin{array}{l}\text { Using tactical } \\
\text { interventions }\end{array}$ & Questioning & Questioning & Debate of ideas & Debate of ideas \\
\hline
\end{tabular}

\section{Data analysis}

Our use of discourse analysis was based on the assumption that what the children drew, wrote, and said, represented their interpretations of their realities (Barker \& Rossi,2011).Although the drawingswere primarily used as a cue to start conversations about children's thoughts and feelings, we initially analyzed the baseball pictures 
to enable us to get a first impression of children's representations of the game. We therefore selected the baseball drawings on the basis of the frequency they illustrated particular features (e.g.,Hume,Salmon, \& Ball,2005). These features were categorized into emergent themes with the use of constant comparative analysis, to give us insight into the consistency between the drawings, the written explanations, and what the children explained during the focus group (Bland,2012; Braun \& Clarke, 2006; Charmaz, 2006).

The focus group discussions were recorded and transcribed. We selected the topics in the transcriptions that highlighted the conversations about learning modified baseball games for further analysis. We paid special attention to what children said in the focus groups about their experiences in the baseball games. Discussions concerning other activities or subjects were not the focus of our analysis. Subsequently we coded what was said pertaining to perceptions of learning in cooperation with classmates during the baseball unit. We also used the constant comparative method and a thematic analytical approach to analyze verbal data (Braun \& Clarke,2006; Charmaz,2006). Codes were combined into themes that were refined during an iterative process that included looking for counterevidence. After each focus group we performed a tentative analysis of the data. Subsequently we conducted another focus group and refined the themes. Three robust themes emerged after eight focus groups had been held. The three themes consisted of: (a) peers as necessary collaborators; (b) friends as supporters and distractors; and (c) peers as perceived critics. The robustness of themes led us to conclude that saturation had occurred (see also Guest, Bunce, \& Johnson, 2006).

\section{Results}

In this study, we focused on children's perceptions of several aspects that may influence their learning in physical education. We explicitly followed their ways of talking in the analysis. The results provide a snapshot of children's thoughts and feelings about playing and learning a baseball unit. The children did not distinguish between learning and performing when talking about PE class. They tended to describe learning as an activity in which they show their ability by doing or executing something or in which they come to understand different rules or tactics. As we show below, their perceptions revealed a great deal of variability in their meaning-making. 


\section{Using drawings to enable children's talk about baseball}

Although the children were asked to draw something about what they experienced in PE lessons, the drawings and accompanying explanations by the children described primarily various facets of baseball. $16(66 \%)$ of the drawings consisted of baseball pictures. The other drawings depicted soccer (3), illustrations of both sports (4), and a different activity (1). All the pictures depicted activities that had been played during the last weeks of PE lessons. The baseball pictures depicted equipment, playing areas, and children who were batting and/or throwing a ball (see Figure 4.1).

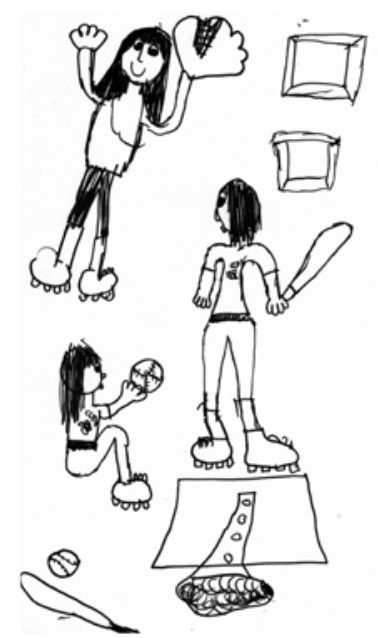

(a)

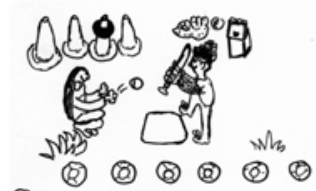

(2)

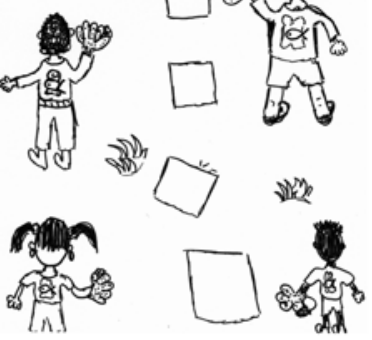

(b)

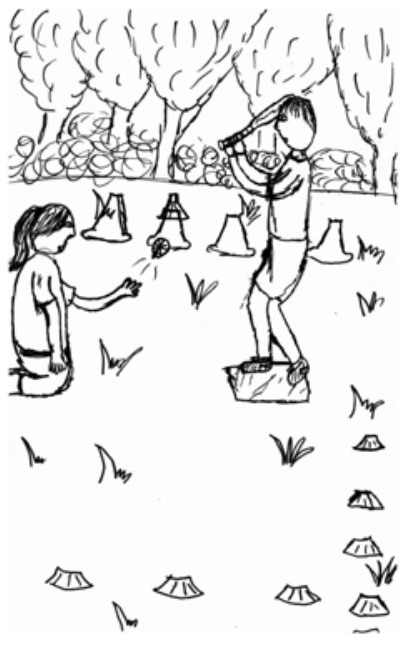

(c)

Figure 4.1 Examples of baseball pictures that can be divided into three categories: (a) equipment, (b) playing $\overline{\text { areas, and }}(\mathrm{c})$ players hitting or throwing a ball.

The written comments were quite diverse and frequently did not match what the researchers thought the children had drawn. For example, Martin drew three players without marking their position in relation to the four bases and wrote: "We learned how to throw and catch balls. That's why I want to practice the game." William, who drew a picture of only two players (the batting team), wrote: "I like baseball, especially matches." Both examples suggest there is a difference between how these children experienced and described the game and how they visualized 
it. Most of the baseball pictures noticeably depicted players, teammates, or other classmates instead of the child her/himself. This suggests these children assumed that playing baseball or practicing related skills includes the presence of others.

Equipment such as bats, gloves, or bases needed to play the game played a central role in some pictures, perhaps to illustrate what the game hit and run means or how it is played. For example,Caroline wrote how the game works: "I am the batter. First, I have to indicate which base I want to go to. Therefore, I put a marker on the traffic cone. Then I hit the ball and start running to the first base." The written comments that accompanied these pictures of equipment showed a great deal of variety and often did not support the content of the picture. For example, Vincent drew and wrote: "I don't like ball sports, but this baseball game is fun", and Stan had written that "unfortunately the game is not played by counting strikes".

Other pictures showed playing areas to explain how the game is constructed and organized in the field. Furthermore, the drawings seemed to describe what the team goals were, the amount of players needed, and which base they could choose to run to in the field. These children supported their drawings with comments about their experiences of enjoyment and how they could learn or play the game. For example, Steve wrote: "I drew a baseball area because I like baseball. [Baseball] was new for me and I learn a lot." Similarly, Simon explained in the focus group:

\section{I drew a picture of baseball because I like the game very much. First, I have to choose the base where I want to run to but I can't hit the ball so far. I was lucky that I reached base one.}

Some children attached importance to the task of the pitcher who must throw well if the game is to succeed. They pictured children who were batting or/and throwing the ball. The written comments suggest that these children constructed baseball as a team game in which a batter must run to a base or that a fielder must tag a runner. Children supported their drawings with comments about their experiences of being a member of a team. Mary wrote, for example, that she likes baseball "because we have to play this game in a team". The conversations in the focus groups corroborate this finding as we discuss in the next section. 


\section{Peers as necessary collaborators}

The discussions that took place after children individually explained their drawings, suggest that these children constructed baseball as a team game and that they realized players have different roles in the game such as pitcher, batters, and fielders. Jessica wanted to learn more about the game and explained to the group: "We have to work together as a team. In this game I must think a lot. I have to think about choosing the best strategy." She emphasized that players must take the proper field positions if they want to tag a runner out with the ball.

During the discussions children showed awareness that they needed others to play. Additionally, they realized they were dependent on teamwork. For example, Jim explained:

\section{Some children pitch a difficult ball. It's not easy to hit the ball when, for example, he throws the ball in the direction of my chest. I tell him he must throw the ball in a better way.}

Another group discussion about the same subject showed a similar perspective. Tim said: "Throwing the ball is more important than hitting. If you throw the ball too far it is impossible to hit the ball well." These quotes suggest that children know that two players in a team need to adapt to each other's skills in order to have a positive result. Vera's answer is illustrative of how these children explained that they could learn things from others:

\section{[Hitting the ball improves] when I ask other children how I must hold the bat. Then at every turn I can tell the pitcher how they must throw. In this way I can hit the ball further every time.}

Such explanations indicate these children had a common understanding about the game and the contribution of other children in the game. Children constructed the game as a place of interaction that requires equipment, understanding of the rules, tactical strategies, and teamwork. Apparently, these elements were considered as conditional or necessary in defining the game as a game. This finding is congruent with a TGfU perspective that assumes that the focus of children in learning a new game begins with an appreciation for the game and with the development of an understanding of game modifications (rules, boundaries, equipment). The 
explanations of the children about the specific role of friends and peers suggest that the development of this appreciation and understandings played an important role in the learning that occurs during such a unit. These children therefore took the composition of teams very seriously as the next section indicates.

\section{Friends as supporters and distractors}

All the children indicated they preferred to collaborate and practice with friends. They could clearly articulate the role friends play in their learning process of playing baseball although their reasons for choosing friends varied. Simon said for example: "[When I play] with my friends I have a better chance to perform well because I know them and also their abilities." He also liked it because: "[I meet] other children when I have to practice with others." Simon's comments suggest he preferred to play with friends but also wanted to get to know other children. Some children indicated they wanted to practice with friends because they could chat. For example, Monica said: "It is important to play with a friend because of the [opportunities we have to] talk with each other. [If there are no friends in my group] I cannot have conversations when we have time to do so." Other comments made in the focus groups reveal the perceived supporting role of friends when failure occurred in learning situations. For example, Michael said: "Friends will help me but not others." These children were sensitive to negative reactions of peers to their performance and therefore they wanted and needed friends to support them.

The children were not always consistent in their preference for practicing or playing with friends, however. The children were aware that friends could have a disruptive influence on their learning. Friends can "tease" or "laugh in your face". A discussion between Justin and Paul illustrates how they thought friends influenced them:

\section{Justin: It is better for me to work without my friends because they joke around a lot. They are annoying and do not listen anymore. \\ Paul: Yes, that happens many times.}

Linda explained that she tried to anticipate how the teacher would create the groups. She and her friend wanted to be in the same group and yet she was also aware that her performance could be negatively influenced by the presence of her friends: 


\begin{abstract}
Linda: My girlfriend and I handle this [desire to play together] by standing at the end of the row. And if the teacher counts $1,2,3 \ldots$, we make sure there are two children between us.

Moderator: But why do you want to play with your girlfriend?

Linda: Actually, it is not important for me. My girlfriend talks too much and disturbs the lesson. And when I work with classmates who are not close friends, I try harder to do well.
\end{abstract}

Naomi reacted similarly, and said: "I just do my best; when I'm not in the same team as my girlfriend, then I show more commitment and just want to show that I'm an excellent player." The comments suggest that these children wished to select their own groups in physical education lessons but at the same time they had a preference for groups that did not necessarily always include friends. Linda said: "It is good that you not always play with just one friend, you must also learn to work with others." In the foregoing examples, children articulated negative consequences of playing with friends on the same team. The desire to comply with assignments and the presence of friends interfered with the desire of some of these children to participate effectively in a game.

The children also gave examples that showed just the opposite. For example, Mandy explained that "when teamwork is needed, I want to play together with my friend [because] then I will do my best instead of playing with classmates who I don't like". The data suggest that these children felt a tension between working with friends and working hard/seriously. Children indicated they preferred to play with classmates who were serious about learning and playing the game since a lack of motivation of others, according to Paul, "reduced skill performance and also increases levels of irritation".

In summary, friends seemed to play an important role in these children's preferences for team and group selection. Their friends provided a comfort zone when they played baseball in PE lessons but also served as a distracting factor when these children wanted to learn something or perform well. Thus, friends and those who are not defined as friends played a role in whether children felt they could attain the perceived learning outcomes. Their comments indicated a tension existed between having fun and working to reach a performance goal.

Although they were clear about the supportive and distracting roles friends played, their descriptions of attitudes of classmates indicated these children also 
had expectations about how classmates must work together. These expectations were based on their liking of the game as well as their focus or their attitude towards the game or physical education in general. Justin's comment is illustrative: "It's hard for me to do my best if others do nothing." In other words, they wanted other children to take the game or task seriously.

\section{Peers as perceived critics}

Not only did reactions from friends or classmates seem to influence how and what children learn, but also their perceptions of what other children may be thinking. For example, Bjorn explained his drawing as follows: "I have drawn pictures of me missing balls while batting. It took a long time [to hit one] and the other players became impatient." Apparently, he needed a picture to explain how his classmates' impatience affected him. However, Karin explained how batting works and what she thought:

\section{Karin: The first time in baseball I had to use a bat I wanted to hit the ball but constantly missed it. Then I felt or thought: "The other field players are standing and waiting and I am constantly missing the ball.' \\ Moderator: And what did you think then? \\ Karin: I thought: 'I really have to hit the ball.' And then I thought: 'I'm really being stupid.' I also thought that the other players think: 'Please, let someone else hit the ball.' \\ Moderator: But it doesn't have to be true, does it? \\ Karin: I want to be better than that player. If you constantly miss the ball, then I think I need to be better than someone else.}

The examples of Bjorn and Karin illustrate how these children thought and worried about the attitudes of their peers. Though the presence of peers at times served to motivate these children, their performance was influenced by possible meanings others may have assigned to their ability.

Another discussion showed how children try to develop a strategy to deal with this feeling. Anna explained: "I am not good at hitting the ball. I don't like that, but now I think: 'I must practice as much as possible. Then I will become a better player.'" The children attached great importance to what their classmates thought about 
their ability and also how they may construct team performance, work attitude, and fair play behavior. Peter explained:

\begin{abstract}
I think there are some children who only want to win, definitely. And if they lose a game they are going to cheat. I don't like that. Also, some children don't want to play [baseball] anymore because they think they are not skilled enough. Then they stop playing and hang out. If you play in a team you have to work together and for example throw balls to others. If a player does not concentrate during a game, he could drop the ball. Then I feel alone because I belong to a team and I am the only one who is motivated. The other players don't try to do their best. I want to play [baseball]. Yes, they ruin the atmosphere.
\end{abstract}

Peter's example shows these children had implicit ideas and expectations about the work attitude in teams and that their constructions of the game were also based on what other classmates might think about collaboration within a team. This study may have been the first time these children had tried to explicitly explain their thoughts and expectations to other peers. Perceptions about work attitude may possibly shift in a positive manner if the children become more experienced in expressing their feelings to others. Their thoughts about playing baseball together influenced their satisfaction and how they participated in class. These feelings shaped children's expectations about the need for collaboration and about peers in game play.

\title{
Discussion
}

The purpose of this study was to explore the dynamics of children's thoughts and feelings about collaboration, interactions, and their relationships. We used drawings, written comments, and conversations in focus groups to explore children's perceptions of the game, peers, and the role of friends when learning baseball skills in a TGfU unit. The drawings and written comments provided cues that enabled the moderator to construct questions for children to elicit their motives and feelings. There was little overlap between the content of the drawings and written and verbal comments about these drawings. This lack of similarity between drawing and 
writing suggests that children initially may have drawn part of a game because it was a place where they learned something new or difficult. However, their explanations changed when they had to explain their thoughts or feelings about the picture. These differences in results suggest that different data sources complement each other and are needed to provide insight into the ways that children give meaning to their experiences. The foregoing results showed that a significant part of these children's constructions of learning in a baseball game could be attributed to how they constructed the game, their relationships with friends and classmates, and what they may be thinking.

\section{The social construction of learning with others}

Their thoughts about collaboration showed how these children understood and perceived working together with others. The children began talking about the game by giving their personal reflections on the game itself. However, when children exchanged meanings with their classmates, they constructed a broader perspective that allowed more opportunities for them to be influenced by peers. Mulvihill et al. (2000) found that children prefer to work in teams especially in interaction with friends. The current study, however, indicates their meanings are susceptible to different influences. These children's perspectives about team play and working together on PE tasks can best be described as variable due to influencing factors such as their team preference, team composition, and estimated team performance outcomes. This finding suggests that children may take peers' input into account while learning skills and games (MacPhail et al., 2008). Though their methods differ in terms of age and the TGfU unit used, MacPhail et al. (2008) found that opportunities to learn are also dependent on other players' contributions and interpretations of the game.

By focusing on the dynamics of children's perceptions we tried to capture their meanings and the role peers and, in particular, friends play. Children in our study were aware that interactions influenced how a game is played and their enjoyment of it. Their perceptions of friendships and their preferences for working with friends or peers suggest that they primarily associated PE classes and playing games with having fun. Similar to the children in Mulvihill et al.'s (2000) study, they described an enjoyable learning environment as one where they can work with peers with whom they like to work. Similarly, Weiss, Smith and Theeboom (1996) found that 
children want to engage in sport and PE with their friends because they want to have fun. Children seem to attach a great deal of value to friendships by spending time, doing things or hanging out together (Weiss \& Stuntz, 2004). A PE lesson therefore should not only be constituted as a place of learning skills and strategies. PE may also be an activity where it is possible to "hang out together" or to "have fun". In addition, children's constructions of the way they want to participate and learn in PE may strengthen or develop a positive attitude towards PE or physical activity. However, the contradictions found in the discussions indicate the situation is more complicated than this seems.

The theme, friends as supporters and distractors, suggests these findings may vary by perceptions of goals. Friendships were perceived to have both a positive and a negative effect in a PE class when skills were taught within a modified game setting. These children did not always want to play with friends in this context. Our conversations with children revealed that as these children gained more information about the demands and goals of the game and improved their skills, they changed their preference for teammates. They then wanted to play with classmates who were perceived to be able to contribute positively to the performance of others through their skill and commitment to the task. A game-like baseball situation such as hit and run with specific goals and tasks for both fielders and batters shaped these children's constructions of desired team composition. In this situation they preferred to play with highly skilled and motivated players.

\section{The fluidity of children's perceptions}

These findings suggest that the ways children make sense of the role of friendships in PE is not static but contextual, that is, it is dependent on whether the emphasis in the task is on learning and/or performing, and as individual or as team. Thus, these children constructed PE not only as a place for enjoyment and fun but also as a place where they wanted to perform well. Children may therefore initially prefer friends for enjoyment but as the nature and goal of an activity change, so may their preferences. This finding is congruent with the notion that children frequently use instrumental motives such as complementarity in talent to seek friends (Rubin et al., 2006). Research by Hills (2007) about the dynamic of friendships in girls' physical education, partially support this finding of complexity and contextual influence. Hills found that friendships can serve as a filter for social interactions and thus 
influence girls' experiences. For example, children influence peer relations through inclusion (passing a ball) or exclusion (not passing). Such findings suggest that within the context of games learning such as in target, net/wall, or territorial games, research needs to be conducted to help teachers and researchers gain insight into contextual dynamics and how children assign meanings to the different roles they play during a game in combination with the defensive or offensive strategies they choose to use.

Other contradictory factors played a role in the learning and performance of the children in the current study as well. The third theme, peers as perceived critics, indicated that the children were able to explain in a straightforward way how they perceived social relationships in teams. Their descriptions about how they engaged in decision-making during game play were more complex, however. They attached a great deal of importance to their own perceptions about how their peers might think about or judge the skill levels of others. They did not want to be seen as the weakest player or as the least skilled member of a team. Perceived levels of skills therefore also played a role in how these children thought others saw them. Thus a tension existed between the choice for the comfort of being with friends when these children lacked confidence in their skill level, and at the same time, wanting to be with high skilled players to ensure what they saw as a good performance. Consequently, friendships can be therefore a limiting factor for children in PE but may also provide comfort and enjoyment during the learning of skills. Cothran and Hodges Kulinna (2006) also found that children preferred not to show their skills in public but felt more opportunity to make mistakes while working with friends. This preference for a 'comfort zone' supports Rink's (2003) notion that learning is not only facilitated but also could be disturbed by the presence of others. The results of our study also suggest that children do not want to play only with friends. Their motives may be influenced by a variety of factors rather than the possibility to chat or hang out only (Weiss et al.,1996).

Our results reflect assumptions of social constructivism that suggest learning is influenced by contextual factors. Powell and Kalina (2009) expanded Vygotsky's notion that children in particular learn through critical thinking in relationships and when they are able to chat and discuss with others to construct meaning. Vygotsky's (1978) emphasis on interactions and their influence on learning are reflected in our findings about the fluid and dynamic nature of these interactions. Children's interpretations are shaped by dominant societal and contextual meanings and their 
previous experiences. This assumption about the role of previous experiences in the sense-making of a current situation means physical education teachers who use a TGfU approach must challenge children to utilize their prior knowledge to solve technical and tactical problems in modified games (Singleton, 2009). Additionally, the results show that cognitive thought processes are not just confined to information acquisition but also involve learning factors such as relationships, interactions, the public nature of performance, and grouping (Rovegno \& Dolly, 2006). The findings contribute to research about the influence of meaning-making between peer relations. Our study indicates these processes are divers and show patterns of variability that is depended on children's reciprocal interpretations of peers and their expectations, ability, and motivation. Such a development adds to TGfU research findings that incorporate constructivist aspects of learning with children's verbal productions (e.g., Griffin, Brooker, \& Patton, 2005; Wallian \& Chang, 2007). Therefore, the construction of tactical knowledge (e.g., decisionmaking skills) should not be seen as an individual activity but rather as a process of exchanging perspectives between players (Gréhaigne, Wallian, \& Godbout, 2005). Possibly then meaning-making may influence the learning of tactical knowledge. Further research should explore if the dynamic patterns in perceptions and meanings of children directly influence decision-making skills. In addition, it also can be suggested to take into account the possible fluctuations or clarifications in children's perceptions that revealed after each lesson separately (Darbyshire et al., 2005).

\section{Conclusion}

The three themes that emerged from the data suggest that social interactions play an important role when children learn skills or tactical tasks. In addition, their (previous) experiences with skill learning may be related to their preferences for classmates in PE. This depended on whether they placed the learning challenges inside or outside of their comfort zone. Rubin et al. (2006) pointed that children vary their behavior on the basis of their short-term and long-term personal goals and also on feelings and thoughts about their peers, and whether they are present or not. Teachers may assume students are learning a task while children may be constantly negotiating their preferences to work with peers and friends. The public performance of skills signifies a unique aspect of PE. Unlike they do in many 
other school subjects, participants in PE always have to deal with the presence and perceived thoughts of others and interactions among them. Research that focuses on enhancing children's tactical awareness within TGfU practices should further explore their feelings about performing skills in front of others and the ways they think about players and teams while learning games. 


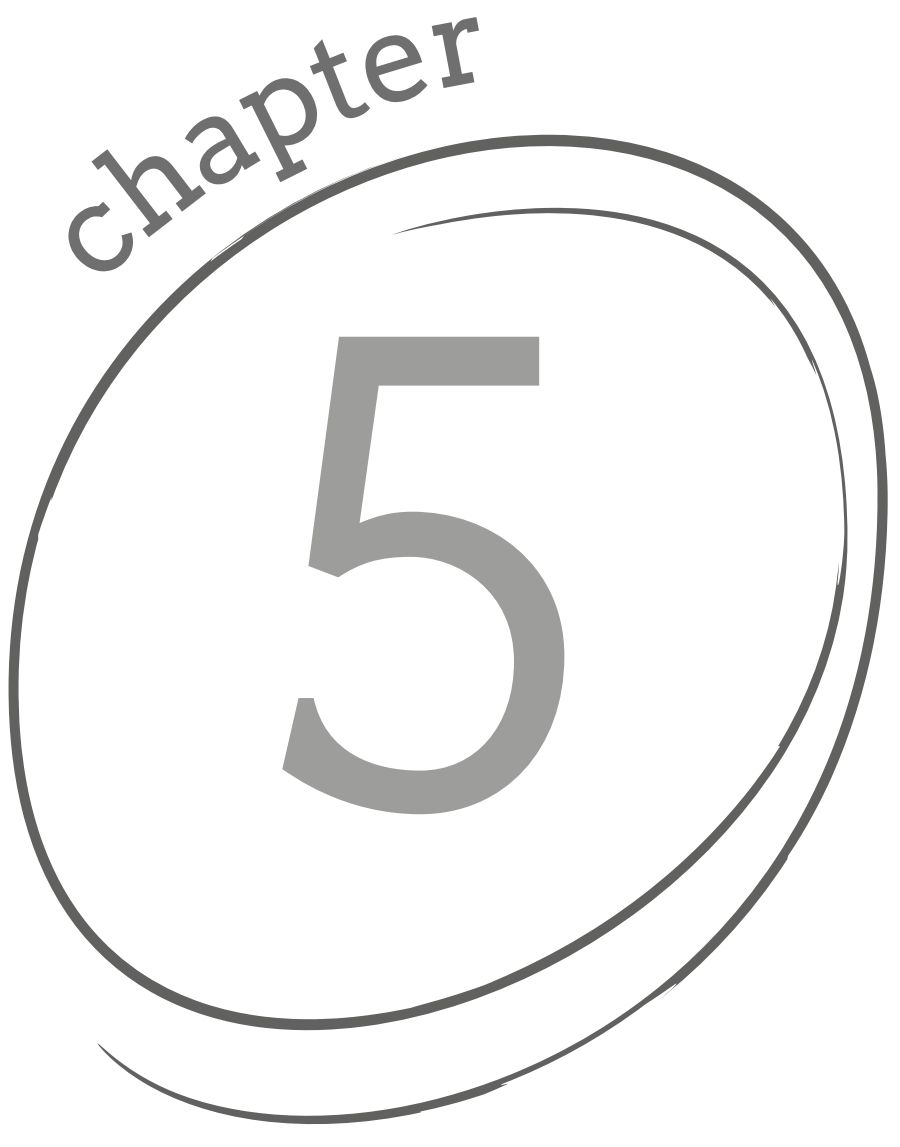

104 


\section{Gender categorizations during group work in physical education}

\section{Abstract}

Purpose: To explore how the use of gender categorizations inform children's preferences of working with others in physical education.

Method: Draw, write, and tell procedures were used to elicit the thoughts and feelings of 42 children, across four schools, about their peers and working together in groups. The children, aged between 11 and 13 years, were distributed across 14 focus groups to talk about conditions in group work that they thought facilitated and inhibited their learning.

Results: Two meta-themes - (a) classmates and friendships; and (b) work intention and trust - emerged from the interview data about their preferences for the ways groups were constituted. The results indicated that these children created or constructed categories of their peers based on gender but using gender-neutral words.

Conclusion: Their constructions of working with others in PE contributed to an implicit curriculum consisting of different expectations for the same gender and for other gender groups.

\section{Published as:}

Koekoek, J., \& Knoppers, A. (2019). Gender categorizations during group work in physical education. Journal of Teaching in Physical Education,39(2),196-205. 
Working in groups is often an integral part of physical education (PE) lessons, regardless of teaching and/or educational philosophies. Learning through group work is a multi-dimensional practice that generates a variety of ways in what and how children learn (Barker, Quennersted, \& Annerstedt, 2015). In order to develop students' skills in cooperation, teamwork, negotiation, strategic thinking and involvement, PE teachers often include a focus on learning to work together with others in their lessons. Learning to work in groups is also a specific objective of various models-based practices such as Teaching Games for Understanding (TGfU), Sport Education, and Cooperative Learning. These models assume that children need to constantly work together in order to perform well in group activities and to develop strategies for their team during game play (Dyson, Griffin, \& Hastie, 2004; Harvey \& Jarret,2014). This approach to group activities implies that children develop more than only fundamental motor skills in PE. The social interactions involved in learning in a group also contain relational or affective elements (Barker et al.,2015). The nature of these interactions suggest that children construct relationships and expectations in PE (Williams \& Bedward,2002). For example, Koekoek and Knoppers (2015) found that children paid a great deal of attention to the composition of groups that were formed for activities in PE. These children preferred to work with others who were willing to cooperate and perform well. Specifically, they wanted to work with classmates who were serious about group work, who were assumed to be safe and who could be trusted. Working on tasks in groups therefore may not automatically be productive for children. They may, for example, differ in the expectations they have for their peers and the (gendered) meanings they assign to collaborative work (Barker et al., 2013).

Research that focuses on the effects of group work suggests that social interactions in PE have a significant influence on how children perceive their learning during classes (Barker, Wallhead, \& Quennerstedt, 2017; Beni, Fletcher, \& Ní Chróinín, 2017). This suggests that the composition of groups matters. This research also suggests that children often use gendered expectations to decide who can be part of their group for certain activities. This categorization of their peers based on gender means that children not only make sense of what they experience but that they also distinguish between behaviors of boys and girls (Baron,Schmader, Cvencek, \& Meltzoff, 2014; Flintoff, Fitzgerald, \& Scraton, 2008). As we argue in the following section, although a large body of literature exists that focuses on the role gender plays in PE, relatively little is known on how the use of gender categories 
may shape children's preferences for peers when working together in PE and how they think these preferences influence their learning. The purpose of this study is to explore how gender constructions based on processes of categorization used by children shape the way they form groups and how they think those groups inform their learning.

\section{Gender constructions in PE}

West and Zimmerman (1987) have defined the construction of gender differences as a process of "doing gender". This means individuals, including children, create differences to support their gendered perspectives. The preferences and the meanings children give to participation in particular activities within PElessons also tend to be based on gender constructions, often called stereotypes (Constantinou, Manson, \& Silverman, 2009; Solmon, 2014). These stereotypes extend to meanings children give to perceived gender differences during group work. These meanings may reflect the motivation and participation of children in PE classes. For example, Constantinou et al. (2009) found that girls said they felt much safer when they participate in teams with only girls. These feelings seemed to be based on expectations they had about working in teams. Hence, the constructions of and about gender that children make in PE activities are shaped in part by the presence and expectations they have of their classmates.

The categorization of children as boys and as girls in PE classes is a way of "doing gender" that assumes that groups of boys and girls differ from each other and that boys and girls will assign themselves to one group or the other (West \& Zimmerman, 1987). Those scholars who have explored the process by which children create these categories have primarily focused on differences and similarities between groups of boys and girls, and how these produce inequalities (e.g., Azzarito \& Solmon, 2009; Clément-Guillotin et al., 2013; Hills \& Croston, 2012; Flintoff \& Fitzgerald, 2012). However, these studies in particular focused on how teachers engage in categorization by gender and their emphasis on differences that they saw between groups (boys and girls). Relatively few scholars have searched for explanations of why and how children construct gender categories during PE. Grahn and Torell (2015) explored the views of Swedish children participating in a co-ed sports initiative regarding their thoughts about participating in soccer. The researchers found that children expressed stereotypical views pertaining to abilities, for example, that 
boys have more ball sense, are better skilled and are much tougher than girls. The children used these gender constructions to decide whether or not they wanted to play soccer together. Grahn and Torell also questioned how these assumptions played in other contexts. Children may therefore negotiate their choices based on the expectations and views of others in the group in a specific context.

\section{Theoretical framework}

We place these negotiations of choices that underlie children's constructions of others within a social constructivist learning perspective. Principles of social constructivism are based on meaningful learning through deep and durable understanding of school content that emerges in the presence of pre-existing knowledge and experiences (Azzarito \& Ennis, 2003; Davydov, 1995; Vygotsky, 1978). Social constructivism assumes individual learning occurs through the influence, examples, and the presence of others during collaboration/interactions and the learning of tasks within a social context (Rovegno \& Dolly, 2006). A social constructivist framework for research means, therefore, that we explored the meaning-making of children about their preferences for working with others (Beni et al., 2017). This exploration is in particular with the aim to inform teachers how to create, facilitate, and stimulate a student-directed (instead of a teacher-directed) learning environment to encourage cooperative and collaborative behaviors by students when they practice skills (Darnis \& Lafont, 2015).

The constructivist lens that we use in this paper is based on Kirkand Macdonald's (1998) notion of "situated learning". This assumes learning is an active process that includes the interaction of the learner with his environment. Situated learning does not refer to children's individual (cognitive) learning but learning that occurs on the basis of a "social practice in social settings" (p. 380). This means that learning is not an isolated process but will always be influenced by the presence of others. Knowledge construction or meaning-making emerges from the ways individuals position themselves and their group interactions.

\section{Children's expectations of group work across gender}

Processes of doing gender in group work consists of children's meaning-making or constructions of how and with whom they want to collaborate, and how they want to 
form groups. With-Nielsen and Pfister (2011) found that Danish high school youth understood that the organization of PE was based on the expectations and interests of boys. Activities associated with males such as basketball and Thai-boxing, their interests, and their performances were valued more highly by these children than those associated with females such as dance and gymnastics. Girls thought they were expected to integrate elements they associated with boys such as competition and performance into their participation. Since many girls did not want to be labeled as boys, they avoided performing well and exerted minimal effort in PE. Boys who did not meet the dominant boys' norms disengaged from PE and engaged in behaviors similar to those of girls. The expectations of both boys and girls showed how the different demands they encountered in PE reproduced gender differences during PE classes. With-Nielsen and Pfister's findings illustrate how children may 'do' gender in PE and how this process of meaning-making is influenced by their experiences. These researchers did not, however, focus on perceived learning and how the children thought this might influence their behavior during group work.

Children's expectations for learning in groups not only reflect differences in interests but also the process of skill acquisition such as throwing and passing a basketball in school settings. For example, Chen and Darst (2002) found that successful learning outcomes and achievements had a positive influence on children's individual and situational interests, that is, the degree to which they were attracted to an activity. Boys and girls were similarly motivated to participate in activities they liked. Chen and Darst suggested that individual differences across gender in meaning-making could be explained by the stereotypical environment that is constructed in PE settings. Consequently, these constructed differences may contribute to the degree of attractiveness of an activity or skill.

The use of gender categorizations by children may play a role in how children select groups for their PE activities and what they learn in these groups. An exploration of how children assign meanings to group choices for collaborative work and the language they use for doing so may provide insight into how they experience learning tasks in PE lessons. We explored how gender constructions based on processes of categorization by children inform the way they form groups and how they think those groups inform their learning. 


\section{Method}

\section{Participants and context}

$\mathrm{PE}$ in the Netherlands is compulsory until age 18. Children follow a nationwide curriculum based on a comprehensive classification system (Ten Brinke et al.,2007). Assigned group work during PE is required and serves as an important element of the curriculum. Due to the nationwide use of this national curriculum we therefore assumed that all the children participating in the study had a history of participating in group work in PE.

In this study 42 Dutch children aged 11 to 13 were involved (see Table 5.1). These children were from one primary $(A)$ and three secondary schools $(B, C, D)$. Children from primary school (grade 6) had two PE lessons of 45 minutes a week each. Children from the secondary schools (grade 7) had three lessons of 45 minutes per week. Although PE teachers in the Netherlands may arrange their lessons with individual preferences, both grades had similar content regarding the curriculum, the goals, and the units. These curricula consisted of a broad variety of modified activities within the domains gymnastics, dance, track and field, and games, and take into account children's needs and abilities. The four schools in this study have incorporated TGFU as the prevailing models-based practice for games teaching (Kirk \& MacPhail,2002).

Table 5.1 Summary of schools, participants, and different types of focus groups.

\begin{tabular}{|c|c|c|c|c|c|}
\hline SCHOOL & $\begin{array}{l}\text { TOTAL CLASS } \\
\text { SIZE }\end{array}$ & $\begin{array}{l}\text { SELECTED } \\
\text { CHILDREN }\end{array}$ & $\begin{array}{l}\text { FOCUS } \\
\text { GROUPS }\end{array}$ & $\begin{array}{l}\text { COMPOSITION BY } \\
\text { GROUP }\end{array}$ & RATIO BOYS VERSUS GIRLS \\
\hline A & 31 & 6 & 2 & Mixed gender & Two mixed groups (two girls, one boy) \\
\hline B & 25 & 6 & 2 & Same gender & $\begin{array}{l}\text { One boys group }(n=3) \\
\text { One girls group }(n=3)\end{array}$ \\
\hline C & 20 & 9 & 3 & Mixed gender & $\begin{array}{l}\text { Two mixed groups (one girl, two boys) } \\
\text { One mixed group (two girls, one boy) }\end{array}$ \\
\hline D & 25 & 21 & 7 & Mixed gender & $\begin{array}{l}\text { Two boys groups ( } n=6) \\
\text { Three girls groups ( } n=9) \\
\text { Two mixed groups (two girls, one boy) }\end{array}$ \\
\hline TOTAL & & $N=42$ & 14 & & \\
\hline
\end{tabular}


All four participating schools were located in the eastern part of the Netherlands. The majority of the children at these schools can be described as White and were assumed to be from middle class homes, based on the neighborhood in which these schools are located (Knol, 2012). The schools were selected on the basis of similarities in the formal co-educational PE curriculum content ensuring to some degree that the children had comparable educational experiences during PEclasses. The primary school data were collected at the end of the school year whereas the secondary school data were collected at the beginning of the following school year. All of the PE teachers involved had graduated from the same Physical Education Teacher Education (PETE) program.

The children were asked by their PE teacher to participate in this investigation. They received information about the content of the study in general, and more specifically the procedures of the drawing task and for the focus groups. Informed consent for the children was obtained from all parents as well as the children.

\section{Draw, write, and tell procedure}

In order to elicit thoughts and feelings of these children about working in groups, we used a draw, write, and tell procedure (Angell,Alexander, \& Hunt, 2015; Koekoek, Knoppers, \& Stegeman, 2009; Kendrick \& McKay, 2004).

\section{Draw and write task}

All children from the four classes were invited to draw pictures about an activity in their PE lessons and to write an explanation of their drawings. Children made these drawings in a regular classroom on the day they had PE lessons so that they had 'fresh' thoughts and experiences of working together in groups. The purpose of the drawings was to stimulate conversations in which children could explain why they drew what they did and talk about learning, particularly about topics such as their peers, social interactions, and working together (Koekoek \& Knoppers, 2015). The following question was used to introduce the assignment: "Could/would you draw something about what you learned in physical education classes during the last lessons?" Subsequently, children were asked to write an explanation of their picture to stimulate them to think about their intentions. 


\section{Focus groups}

Children from each class were randomly selected for the focus groups. We asked the PE teachers to randomly select children without making any judgment about possible relationships or their gendered meanings as they assigned them to same gender or mixed gender groups. The involvement of the PE teachers during this stage was important because they facilitated the selection processes by also supporting the moderators during the necessary communications with the selected children. Immediately, if possible, after completing the draw and write task (and thus after the PE lesson), the selected children participated in focus groups in order to discuss their drawings (Koekoek \& Knoppers, 2015; Krueger \& Casey, 2000). We assumed that this temporal sequence improved the children's ability to focus on the experiences that had occurred during this lesson. Since the writing and drawing abilities of some children may have been limited, the use of focus groups seemed to be especially appropriate and enabled them to react and build on meanings and responses of others (Stewart, Shamdasani, \& Rook, 2007). Furthermore, the use of focus groups yielded a rich amount of data. In conducting focus groups, we followed the procedures of Krueger and Casey (2000). This means that instead of using a set of standard questions, moderators asked open ended questions that facilitated focus group discussions.

Each focus group consisted of no more than three children to enable children to participate sufficiently during the group discussions (Koekoeketal.,2009). Each focus group session began with asking each child: "Would you explain your drawing and your written explanation?" Subsequently, the moderator began a group discussion using questions to explore deeper meanings of what was said. The moderator encouraged the children to react to what was said by their peers. To this end, the conversations were guided in a way that explanations of the drawings regarding the learning of assigned tasks in PE were seamlessly integrated with topics about group work. Since we aimed to keep the discussions as authentic as possible children were not prompted in the focus groups. Instead, the moderator steered the discussions by keeping the subject close to the perceptions and experiences of the children.

Discussions and interactions were stimulated by the moderator asking open ended questions on the topics 'peers' and 'working together.' The topic 'peers' referred to questions or probes regarding different relationships, classmates' attitudes, and the expectations they have of others in a work group. The topic 'working together' referred to probes about how they perceived collaboration and specifically, 
the contribution and efforts of themselves and those of others. We conducted the focus groups in Dutch and audio recorded them.

We conducted two focus groups in schools A and B, three focus groups in school C, and seven focus groups in school D (see Table 5.1). The talk in the focus groups about the drawings in the current study acted as a cue that enabled children to explain their drawings and what they wrote about these drawings in their own words. We only analyzed data about what was said during the focus groups because our focus was on the 'tell' aspect of this method (Angell et al.,2015). This ensured that these conversations consisted of the children's own meaning-making and not our interpretation of their drawings.

We conducted as many focus groups (14) as needed until thematic saturation occurred. Focus groups were used with different gender compositions to allow for diversity in gender constructions. Based on methodology guidelines of Guest, Namey and McKenna (2017) about sample sizes, and data saturation, seven same gender focus groups were conducted that consisted of four groups of girls and three groups of boys. In addition, seven mixed focus groups participated in the study, each consisting of different gender ratios. This method of creating focus groups was assumed to increase the diversity of each group in friendship relations, ability, and cognitive levels. The focus group discussions lasted between 60 and 75 minutes.

The first author, an experienced moderator, managed the data collection processes during all the focus groups. Three interviewers, who were pre-service PE teachers interning with the various schools, and who therefore knew the children, were involved as moderators in the focus groups. These moderators were trained to conduct these focus groups using identical procedures. The audio recordings from the focus groups were transcribed (in Dutch) and coded. A native speaker translated the focus group data, especially the quotes that were used in the analysis from Dutch to English. Pseudonyms were used to protect children's identities in the description of the results.

\section{Data analysis}

\section{Trustworthiness}

We used a categorical-form method to analyze the data (Smith \& Sparkes,2005). The use of this method means we focused on the diversity of meanings in the data looking 
also for contradictions. The analysis focused on language use and meaning-making. Discussions that focused on the topics 'peers' and 'working together' were selected for further analysis for this paper. We especially looked at those conversations where children explicitly and/or implicitly referred to gender. By 'implicitly' we mean that children's use of language contained underlying assumptions about gender. We did not analyze by categorical gender (i.e., boys versus girls), but focused on what was said and how that had gendered meanings.

\section{Constant comparison analysis}

A constant comparative method was used to analyze the interview data (Charmaz, 2006). Themes were discovered through the iterative process of line-by-line coding of the interviews in order to make a tentative analysis of subcategories. We mainly followed the step by step approach of constant comparison. This approach consisted of comparisons (a) within a single interview; (b) between interviews within the same school; and (c) of interviews between schools. We repeated this analysis and applied a cycle of comparisons by using 'old' and adding new interview data. We also determined a fixed sequence of analyzing the data as follows: we first coded the data from schools with two and three focus groups respectively, then followed an analysis of data from the school with seven focus groups. Since interactions play a role in focus groups and in constructions of gender (Martin,2003; 2006), we present several conversations as well as individual responses in the 'Results' section.

\section{Results}

Two meta-themes emerged from the data: (a) classmates and friendships; and (b) work intention and trust. Very few consistent differences in constructions of categorical gender emerged between same gender and mixed gender groups. We also did not find any differences in gendered perceptions between the various compositions of mixed gender groups (e.g., groups with either two girls or two boys). We indicated the instances where they did occur.

An initial analysis of the data revealed that many of the choices for group work seemed to be based on gender-neutral choices with use of words such as friends or classmates. However, a closer look at the data indicated these children were actually referring to same gender children. In our subsequent analysis, we paid 
special attention to their description of friends, classmates, and group preferences. We found that although in their initial answers they seemed to use gender-neutral words, the ensuing dialogue revealed these words were not gender-neutral but were synonymous for same gender friends and/or classmates. We begin by describing how they coded gender in their wish to work with friends and classmates. Subsequently we show how they did this in their preferences for group work.

\section{Classmates and friendships}

Children's ideas about group work seemed driven by an implicitly formulated question that seemed to underlie much of the focus group discussions: "Who is going to play with me in the PE class?" These children's perspectives about group formation and team compositions in PEshowed a variety of preferences. Classmates who supported them in their learning were described as friends and vice versa. For example, Jennifer said: "It is easier for me to work with others if I know who they are or when they are my friends." Lotte explained her preference for same gender classmates and compared it to the idea of playing with friends: "Mostly girls play with girls and boys with boys. I think it's because we are friends. And that makes PE more enjoyable." This conversation showed that she constructed the desire to play with the same gender as 'natural'. She constructed her friends as being synonymous with girls.

The interview data showed that children consistently coded informal words based on categorical gender to describe their interactions with classmates. The presence of friends was seen as influencing learning. To explain how their learning was influenced by interactions and the contributions of others, they used words like "friends" and "classmates" that turned out to be code words for categorical gender. For example, the word 'friends' seemed to be defined as children playing with other children of the same gender. Tim for example, coded the concept 'friends' as meaning boys, described as follows:

Tim: Most of the times we play with boys in group work. A boy plays with boys, a girl plays with girls.

Moderator: Why do you think this?

Tim: Well, I think it is because we are friends. That makes playing together more fun. 
A conversation during a focus group consisting of three girls is also illustrative, described as follows:

\author{
Cindy: Playing with friends? Yes, together we have much more fun \\ than when we have boys in our team. [She pauses and then says] It's \\ nice to have a friend in my team. \\ Moderator: Tell me why? \\ Cindy: I think you are real buddies with your best friends. \\ Moderator: What do these buddies mean for you? \\ Cindy: I think it means friendship.
}

The word 'friendship' may seem to be gender-neutral but was not, as the above fragments show. Jeffrey explained that he likes to work with friends because it increases the fun-factor of physical education lessons: "[I like to] work with friends because we know each other better than when I play with children I don't know. With friends I have so much more fun." In this example, Jeffrey implicitly suggested that he likes to work with friends who are peers who have a positive attitude towards the task at hand and he wants to have fun. This need to practice with friends was tied to their explanations of how classmates should behave and which unwritten rules are needed in order to feel safe and confident during a class. Girls and boys explained how the assumed intentions and attitudes of friends could contribute to learning. For example, Linda and Barbara explained the following:

\title{
Linda: It is nice to work with friends especially when other children laugh at you, for example, when you cannot perform a task. Everyone makes mistakes. \\ Barbara: Yes, I think laughing is not a good idea. If you cannot perform then children laugh at you. It is never good to laugh at other children.
}

In this example, taking a task seriously was associated with feelings of safety and trust, and included an implicit rule that children should not laugh at each other while performing in PE. This unwritten rule seemed to be important. Similar concepts of 'working seriously' and 'friends' emerged from a boys' focus group. 
Ron and Simon explained this rule as follows:

\author{
Ron: I feel better [playing] with friends instead of children who I don't \\ like. \\ Simon: It is really annoying when children are laughing. Friends don't \\ do this. \\ Ron: Yes, friends are kind, and do not laugh [at you].
}

These examples suggest that these children needed their classmates to support their efforts to learn something and also to be supportive in their possible failure. At the same time, their dependence on feedback of others demonstrates the influence of the presence of peers on learning of both physical and verbal actions. The implementation of this 'do not laugh at mistakes' guideline may support the learning processes of children since they do not want to practice with others who may observe and judge their skills negatively. Classmates or 'peers' were constructed as playing an important role in learning and performing and were categorically gendered as the fragments above also indicated.

Receiving feedback from classmates was seen as essential to successful learning. This success was based on 'special relationships' described as 'friends' who were implicitly coded as 'same gender.' In a discussion about physical ability, three boys explained that friends have information about each other and therefore can provide them with positive feedback in group work, as follows:

\footnotetext{
Fin: I think children think the same way when they like each other. When you are good friends, then you know each other's strengths and weaknesses. For example, if you play with someone who is not your friend and you say to him: "You are not good enough to do that", I think that he wouldn't like to hear something like that.

Jeffrey: It is not a problem if you say this to your friends, they know it already. We know each other better and we know what we can do.

Robin: I think compliments given to friends are different than [what you say] to children you don't know or you don't like.
}

Here again, 'friends' are a code word for other boys. The content of this and similar conversations suggest that these children have constructed ideas about how 
reactions from classmates influence their learning. They wanted to work with children who they see as trustworthy, who do not laugh or make fun of them, who give positive feedback and who are able to judge their ability realistically. They valued the presence of classmates to help them to solve problems in PE.

The category 'friends' or 'classmates' was, therefore, gender differentiated for both boys and girls although all used the same words. When boys said "friends" or "classmates", they meant other boys and girls meant other girls. In other words, although these children did not always explicitly use categorical gender, they did assume and reproduce it in their meaning-making. This finding points to possible criteria children may use to choose with whom they want to practice skills in PE. They want to work with friends or children who can be relied on to provide pleasure and comfort. In the following section we show the implications this same gender preference had for the formation of groups.

\section{Work intention and trust}

The focus groups conversations also indicated that an important part of children's comments about what went on in PE was based on their preferences for the composition of groups and teams. These preferences were based on their doing gender by constructing gender differences in ability and their feelings of what and how boys and girls contribute to the atmosphere in the group. This was also related to their friendships and their preferences for working with classmates.

Children in both same and mixed gender focus groups assumed they would learn more, have fun in and enjoy PE more if they could interact with preferred peers. These preferences were based on the peers' expected ability and performance in PE class. Children frequently stated that they wanted to learn from other children in a team activity. They attached importance to their gender preferences. For example, Stan explained how girls and boys might think about grouping and that he preferred to play on a team that does well:

The teacher asks what we want to do: "Do you want to play in mixed groups or boys and girls [play] separately?" Then we say: "Boys and girls separate." Then he [the teacher] says: "The girls may choose." But the girls think: 'Boys want to play by themselves.' 
Stan then explained what he thinks about working with other boys, as follows:

For boys it is important [that they play together] because they always want to play in the best team. I want to play with children who are good in PE, they will help me win and do well in activities.

This quote shows how Stan merged his ideas about groups for learning/performing with constructions of gender. Stan assumed performance to be related to gender. He assumed that the performance of girls would be lower than that of boys. Since he wanted to do well, he did not want girls in his group/team. The explanation Stan gave suggests that he assumed the best possible ways of learning and performing occurs in homosocial group compositions based on categorical gender. Similarly, Mary explained why a group consisting of both boys and girls limits what she can learn/achieve. The limitations she describes differed from those given by Stan, and are as follows:

In that game you always must throw the ball. Most of the times you have to pass the ball to other players, but when the boys have the ball, they only pass to other boys. It's impossible for a girl to get the ball! That irritates me that others can't get the ball.

These "others" seem to be girls who also want to have ball possession. According to Mary, boys think that they are better than girls and that the presence of girls limits the learning of boys. She thinks everyone should be able to play the ball, i.e., have learning opportunities. She assumed girls had fewer learning opportunities in mixed gender groups than in all girl groups.

In contrast, Marley thought mixed gender groups resulted in more learning opportunities and wanted a voice in the composition of a group, as follows:

I prefer to play in a group with both boys and girls. I learn from boys and they can learn from me. And if I can select the group, I choose children whom I don't know very well. I don't like it when girls sit together in the classroom. 
Marley had a clear preference for mixed gender groups and wanted to work with children with whom she did not have a relationship. She thought that was where she could learn the most. She was one of the few who had a preference for working in mixed gender groups. Still, in general the preference of children was for same gender groups. One girl felt most comfortable when she played with only girls in a team, as follows: "There are all girls on my team. I feel safe when there are only girls in our team." She could not exactly make sense of and explain how her feelings of safety contributed to positive learning experiences. She said the following: "I like soccer because we play in a team and then I feel more confident." Here too, "we" refers to girls.

The foregoing suggests that how these boys and girls assigned meanings to the work/learn climate depended on which gender was represented in a group. The results from several (both mixed and same gender) focus groups indicated however, that children also understood that if they wanted to learn and/or do well that their gender preference could at times, interfere with that objective. They realized that chatting or doing something else during PE classes might not always be beneficial for their learning. For example, three boys discussed the following differences in participation between boys and girls:

Jim: It is more fun to work with only boys than with girls.

Moderator: Can you tell me why?

Jim: We have less fun when we work with them [girls].

Moderator: But can you explain why?

Simon: I also don't have fun if I play with girls.

Jim: I have more fun if there is at least one boy in the group.

Simon: Mostly they [girls] have little energy (laughing).

Jim: Sometimes there are girls who do not want to play. They don't participate anymore and that irritates me. They often ask the teacher: "What time is it and when will this lesson end?" They also sit on the bench and give me angry looks. 
This discussion showed how boys had expectations about their classmates' behavior related to both 'working hard' and having fun. Some girls, however, saw working together in a team situation differently. Valerie explained the following about her drawing of a soccer practice:

\begin{abstract}
[In this drawing] you can see we were supposed to play [soccer] in a mixed team. I could see [because of the situation] that boys needed to pass the ball to girls, because too many players were standing in front of the goal. Although they [boys] think girls cannot play soccer, [in this game] they really must pass [the ball] to girls.
\end{abstract}

The conversation provides insight into how these children created meaning around working together and gender differences. Their perceptions show a pattern that consists of constructing static and homogenous gender categories of boys and of girls instead of differentiating among children's attitudes and chats and boys or girls. They seem to assume that all boys like PE and are active during class. Such assumptions create expectations about cooperation during team play and how classmates ideally should work together. These expectations refer to assumed behavior or work attitude and are based on constructions of working hard and being serious.

It is not surprising then that dissatisfaction about playing together occurred when these children perceived large differences between each other's working attitudes and skill levels based on gender. Simon and Jim, for example, argued that too many girls in one group is unacceptable because of their inability and lack of willingness to cooperate in a baseball game:

They [girls] tell us that we are not allowed to throw or hit the ball too hard. They get angry when your throw is inaccurate. And when the ball goes into the bushes, they won't retrieve it.

The conversations revealed a tendency for boys to construct girls as a group of children who do not want to work together to achieve a goal. They are assumed to lack interest and are seen as not being able or willing to participate in a serious manner in PE. This disdain for what they associated with girls also meant that boys played a large role in determining the curriculum when they had the opportunity to do so. 


\section{Discussion}

The purpose of this study was to explore how gender constructions based on categorizations inform children's preferences of working with others and how these may influence their learning in the Dutch PE context. We analyzed children's verbal conversations regarding their use of categorical gender. These children understood and defined learning in PE as a place where they have fun but also must perform or learn skills by practicing them. They constructed PE as a public activity where everyone views, sees, and judges performance. Consequently, these children wanted to work with classmates who work hard and do not laugh or mess things up. These children expected others to be willing to cooperate; conversely, they disliked 'bad' attitudes and excluded classmates whom they judged not to be serious enough. Specifically, the children constructed what they thought would be a positive learning situation for themselves. These constructions were based on the meanings they gave to working in same and mixed gender work groups.

The two themes that emerged from the data suggest that these children created their own invisible or hidden curriculum for PE that might be different from the formal curriculum with its specific objectives envisioned by their teachers. The results showed that social interactions played a significant role in this hidden curriculum with different expectations for same and for other gender groups. These interactions were shaped by stereotypical gendered meanings they assigned to ability, attitudes, and expectations. The main finding from the two themes that emerged from the data is that children implicitly used gender codes when they had to work in groups. Gender coding refers to the process of constructing gender categories such as 'boys', 'girls', 'peers', 'friends', and 'classmates'. Teachers may think they are presenting a gender-neutral or gender-positive curriculum, but the children may have their own ideas, that is, their own curriculum, about with whom the required skills should be learned and practiced. They constructed implicit same gender preferences by coding same gender 'friends' as peers who contribute to collaboration with positive attitudes and feelings of safety and confidence. This finding suggests that friendship groups could be used in PE to stimulate children to participate in PE because they feel they belong to an appropriate group that is supportive (Mitchell, Gray, \& Inchley, 2015). In other words, children may engage in practices of gender in ways similar to how adults do gender (Martin,2003; 2006). 
These children's gendered constructions of groups not only influenced this implicit curriculum but the meanings they used to describe these groups also provide insight into how they used social constructions in their learning. The results of our study suggest the constructions of 'peers' and the implicit gender coding of words like 'classmates' and 'friends' played a decisive role in these children's perceptions of their ability to learn. The language or words such as 'friends' and 'classmates' that children used may seem to be gender-neutral to an outsider, however, these words represented gender specific preferences. This process of categorizing seemed to be a result of the implicit categorical meanings these children assigned to boys and girls (Zosuls et al., 2011). Boys and girls constructed the concept 'boys' or 'girls' as a binary. Boys and girls were constructed as 'active/inactive', 'interested/not interested', or 'willing to share/not to share' respectively.

Social interactions in a PE class are, however, multidimensional and complex. Teachers may play a role in constructing this hidden curriculum. These children created their own climate for achievement by constructing an implicit curriculum that may have been reinforced by teachers. For instance, Van Doodewaard and Knoppers (2018) described how PE teachers did gender by endorsing practices of masculinity such as describing boys as "sporty" and "macho". Teachers may not always explicitly use gender categorizations to group their students, but their methods may implicitly result in such groupings. For example, Rønholt (2002) found that explicit gender categorizations used by teachers shaped the rewards for boys and the use of negative remarks about girls. Rønholt's study showed that teachers unconsciously also created a hidden curriculum in communicating their gendered attitudes and values within the official PE program. Rønholt's findings as well as those of the current study suggest that teachers need to critically reflect on the ways their instructions may do gender and how they perpetuate the gendering of PE often in unintended and implicit ways. Both teachers and children may be part of their own invisible curriculum.

Not only the contribution of these teachers but also the activities that were offered in the formal national co-educational PE curriculum could be part of the hidden curriculum (Kirk, 1992). Because the children in our study participated in lessons that consisted of activities that are based on Dutch national standards and pedagogical approaches such as TGfU and cooperative learning, we presumed that they followed a curriculum that created opportunities for all in the classes. However, despite the implementation of a models-based practice that could stimulate gender 
equity, not all children involved in the study may have perceived they had equal opportunities to learn the requisite skills. Teachers may have chosen traditional and male dominated sports and activities (O'Sullivan, Bush, \& Gehring, 2002). Hence, in order to reduce the use of possible gendered stereotypical constructions by teachers and students about PE content, teachers need to consider how they structure the learning environment.

A recurring issue that also emerged from the data was how children constructed working together in groups. Children's constructions of what they called "friends" or "working seriously" consisted of implicit meanings about working and learning together in PE and how those are related to gender categories. The findings in this study suggest that gender hierarchies were embedded in children's choices when they verbally expressed their preferences for group atmosphere, cooperation, and classmates' behavior. The meanings children assigned to preferred peers in group work were also dependent on factors such as a classmate's perceived ability, the expected behaviors of the other gender, and the children's feelings of comfort with others in groups. Children saw same gender peers as being more supportive than children from the other gender. However, the results do not reveal why they thought same gender groupings were safer. The results do reflect recent studies that indicate that feelings and fear of embarrassment girls may experience in the $\mathrm{PE} /$ sport context seem to determine their interest and enjoyment especially when they think they are judged in a game or activity (e.g., Casey, Hill, \& Goodyear, 2014). Fisette (2013) explored how girls in high school attempted to save themselves from embarrassment in physical education classes. These girls thought they were expected to do 'girly' things, felt embarrassed when they failed in front of the whole class, felt incompetent and ignored in PE class, and wanted to prove themselves to boys. Their interest in PE was related to and was dependent on contextual influences such as nature of the task, the student-teacher relationship, and their relationship with other students. Their underlying reasons for the children in our study doing gender was influenced by their expectation of the behaviors of others in groups.

In contrast to their desire to avoid possible feelings of embarrassment associated with learning, children also constructed $\mathrm{PE}$ as a place to have fun. This construction can be interpreted as the desire to be together with friends that may guarantee inclusiveness and acceptance. The other gender group may have been seen as unable to supply that and therefore needed to be avoided. Being with friends and having fun in PE seemed to contribute to children's feelings of safety and trust. It 
enabled them to participate within a comfort zone, so they felt they could publicly show their skills or attempts without feeling embarrassed. Both boys and girls preferred to be with friends/same gender teammates because they wanted support, enjoyment and above all, not to be laughed at (see also Hills \& Croston, 2012).

These insights regarding children's small group demands can be useful for teachers who incorporate a models-based practice. In models that emphasize cooperative learning strategies children are assumed to learn movement activities by developing positive interdependence and individual accountability (Dyson \& Casey, 2012). Interdependence refers to feelings of being a group member and the need to trust each other as a condition for having success. Individual accountability refers to the responsibility given to children to complete a substantial part of an assigned task in group work. Our study suggests that implementation of these principles of cooperative learning in PE requires teachers (and researchers) to pay attention to children's wishes and demands about group work.

The use of a social constructivist, situated learning perspective with respect to children's constructions of group work was helpful since the results showed that according to the children, their learning was influenced by the context (Barker et al., 2016; Kirk \& Macdonald, 1998). More specifically, we found that expectations for learning were shaped by the way these children articulated expectations for others in group work. This suggests that teachers and researchers need to consider that group work processes may be informed by preferences for collaboration and their affective responses within the group. The use of a social constructivist lens also suggests that the meanings these children assigned to comfort and safety overlapped with the meanings they assigned to conditions for learning movement skills. They constructed learning as an activity that requires the support of those they construct as friends. They did not construct the assigned activities as opportunities where they learn to work together.

Working in small groups can also be considered as learning in communities of practice. Such communities assume that children learn from each other through their interactions while finding solutions or solving problems (Kirk \& Macdonald, 1998). Learning is then assumed to emerge from participation (Quennerstedt, Öhman, \& Armour, 2014). The results of this study can contribute to theory building about situated learning within such communities. Quennerstedt et al. called this "knowledge as doing" (instead of knowledge as having). Knowledge as doing assumes learning is shaped by relations and contexts in which the learner is situated. To this 
end, the learner is always an actor in a dynamic situation because the context in PE constantly changes due to the possibility of changes in relationships, interactions and expectations depending on the activity (Fitzpatrick \& Enright,2017).

The findings in this study can also add to understandings of how social interactions and gender work and shape how learning is perceived by children (Barker et al., 2016; Wright, 1997). The children in this study were Dutch. However, Spencer-Cavaliere and Rintoul (2012) found in their exploratory study of Canadian children that social interactions impacted their alienation in PE. Feelings of being rejected by a group were associated with lower perceived competences or disappointment in not belonging. Spencer-Cavaliere and Rintoul therefore recommended that PE teachers help children to develop and support peer relationships. The findings in our study support these recommendations but also suggest teachers consider the gendered constructions that occur within the context of these relationships to prevent children from having an unpleasant experience that is publicly visible. Children's desire to learn in a climate in which they feel comfortable in the group in PE without being laughed at or ridiculed suggests that such a climate enhances their ability to learn and providing it should be a priority for teachers. This does not mean that gendered constructions should be taken as fixed (Azzarito, Solmon, \& Harrison Jr, 2006). Teachers could also explore them with their pupils and look for ways to bring about shifts in the ways these children do gender.

Barker et al. (2015) have argued that interpersonal relationships and learning are directly connected to each other in group work. More specifically, the use and development of social skills and the ability to communicate seem to be as important to learning in PE as the development of technical and physical skills. Social constructivism assumes that social interactions are fluid and temporary (Koekoek \& Knoppers,2015; Azzarito \& Ennis, 2003). This means the meanings children assign to an activity or skills may differ or change over time and across contexts depending on their attitudes and expectations (Williams, Bedward, \& Woodhouse, 2000). The development of these gendered expectations is not an isolated process, but may also be influenced by experiences in other contexts, such as the constructions of gender by teachers, parents, or in sports clubs. These children engaged in gender categorizations; both boys and girls showed similarities in their constructions of preferences in working with others. This suggests teachers need to be sensitive and listen to what they say about collaboration in groups and what the use of certain 
words actually means to those involved, and that they may need to deconstruct them. These words may vary by context, including the role of ability plays in the objectives of physical education. Future research is needed to explore how gendered constructions children may bring to PE could be altered or redone where needed. The current study suggests that these children's implicit gendered expectations of others played an important role in their PE group work and seemed to influence their interactions and their perceptions of their learning outcome.

The limitations of the study pertain to the contextuality of doing gender; we did not know the athletic background of the children and if they were used to mixed or single sex competition outside of PE. Further research needs to explore how consistent these children are in their categorizations. They might be specific to the PE setting or perhaps similar to the way they group themselves in group work in other settings, such as group assignments in the classroom. Since we explored how children make gendered categories about group work from a social constructivist perspective the focus on learning can be limited.

\section{Conclusions}

Understanding the implicit meaning of constructions children bring to class can inform teachers about the ways children interact in PE and their hidden curriculum. This understanding is especially useful when teachers incorporate instructional models that require children to cooperate with each other. Teachers can draw on children's constructions about group work to compose groups that may enhance the possibility of having successful learning experiences. In addition, teachers can look at ways to reduce constructed differences so that gender can be undone or 'redone' in PE. 


\section{Part III Formal \\ Task-Related \\ Peer Interactions}




\section{Chapter 6}

Exploring students' perceptions of video-guided debates in a game-based basketball setting

\section{Chapter 7}

Aligning digital video technology with game pedagogy in physical education 


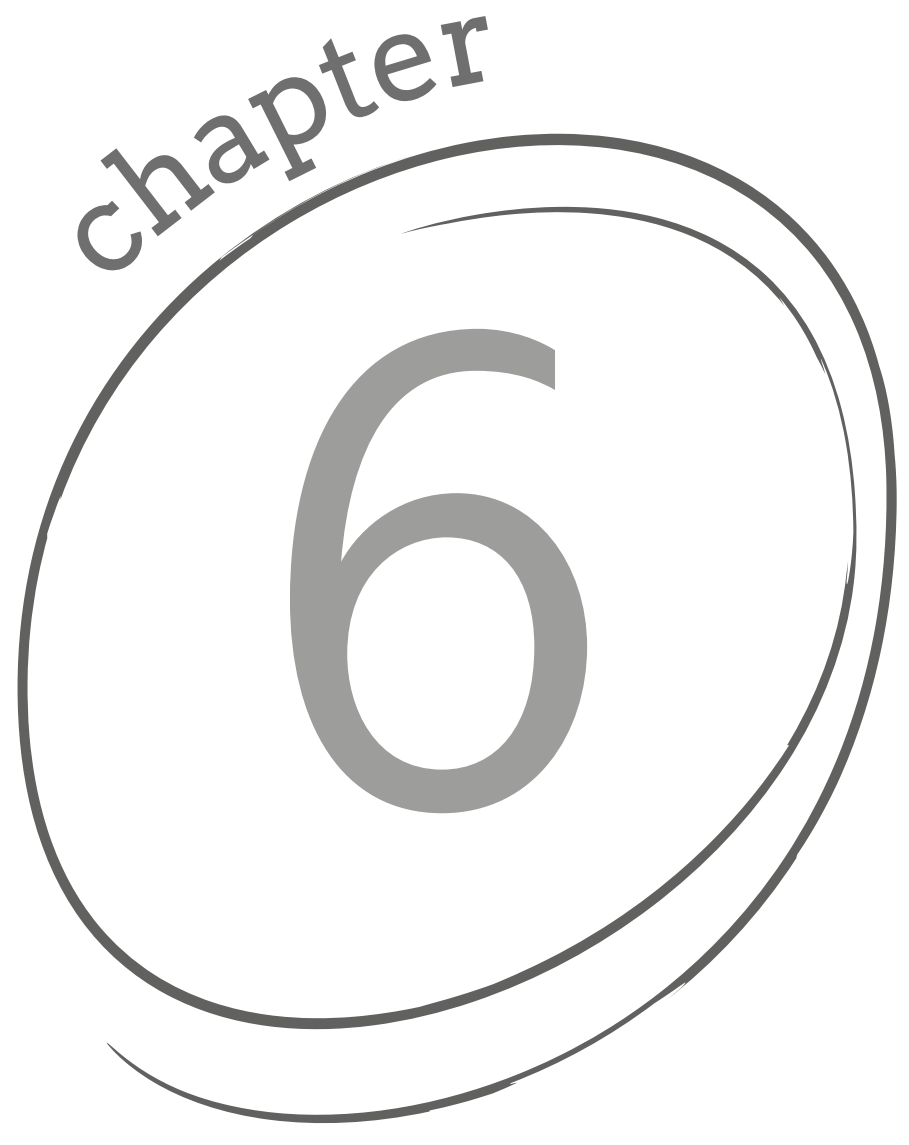

130 


\section{Exploring students' perceptions of video- guided debates in a game-based basketball setting}

\section{Abstract}

Background: Digital video has been increasingly adopted as a pedagogical tool in physical education. One implementation is in teaching student tactical understanding in games, in which it can promote student perceptions and shared understanding in learning tactical situations within a game-based approach.

Purpose: The central aim of this study was to explore how mutual agreement and accuracy of student perceptions of tactical aspects of a basketball game situation and student perceived learning outcomes are influenced by using a debate of ideas (DI) setting that is enriched with video footage from digital tagging the foregoing game play.

Participants and setting: Two groups of secondary school students $(N=20,11-13$ years) judged the tactical appropriateness of 'shooting at the basket' in modified basketball games during three lessons. A debate of ideas session was organized between two matches. One group of students introduced video-tagged video clips into the debate, while the second group debated without video clips. Mutual agreements in identifying and judging a shot on basket was assessed, as well as the accuracy of judgements of shots during the games. In addition, student perceived learning outcomes were determined after each lesson.

Findings: The results of the study revealed for both groups relatively low percentages of agreement among students with respect to identifying and judging 
a shot on basket. This shows that students perceived the situations that were debated differently. Similarly, both groups showed low accuracy in their judgements regarding the appropriateness of the shot. No group differences were revealed. However, students of the video-guided group had increased shared understanding regarding their perceived learning outcomes in comparison to students that debated without video.

Conclusion: The debate of ideas in a pedagogical game-setting generated a variety of meanings about tactical situations among students, which were weakly dependent on the debate being enriched by digital video. Student-centered debates supplemented with video clips can support teachers in promoting students' shared understanding of tactical learning objectives of games.

Published as:

Koekoek, J., Van der Kamp, J., Walinga, W., \& Van Hilvoorde, I. (2019). Exploring students' perceptions of video-guided debates in a game-based basketball setting. Physical Education and Sport Pedagogy,24(5), 519-533. 


\section{Introduction}

In physical education (PE), an important pedagogical tool for teachers for developing student tactical understanding in games is to ask questions and stimulate discussions (Gréhaigne, Godbout, \& Bouthier, 2001; Harvey \& Light, 2015). Questions and discussions invite students to become aware of the importance of the dynamics of the game (e.g., the changes in players' relative positions on the field) and for deciding about (appropriate) actions, while also increasing students' active involvement and engagement in games (Harvey, Cope, \& Jones, 2016). Accordingly, research has shown that asking questions and stimulating discussions about strategies and intentions during time-outs appeals to tactical thinking of students (Almond, 2015; Light \& Fawns, 2003; Richard \& Wallian, 2005).

However, there is a dearth of research addressing what students actually think and discuss during questioning and discussions. This is pertinent because it is not unlikely that students are not always in agreement (i.e.,either implicitly or explicitly) about what situation is discussed. For example, in basketball games, whether or not a certain position at court affords shooting at the basket not only depends on the distance to the basket, but also on the student's throwing capabilities. For example, a skilled student would consider an undefended position from a far distance as an opportunity for shooting, while a less skilled student needs to be significantly closer to the basket before throwing is afforded. Given these individual differences, it cannot be presumed that students' perceptions and understanding of the situation of interest are identical. Consequently, posing questions and stimulating discussion may not inevitably lead to a rich learning environment. SueSee, Pill and Edwards (2016) noted that:

\section{$\ldots$ it is a combination of the question and the knowledge which student does or does not possess before the question is asked. It is this difference in knowledge between learners which makes it difficult to determine if all learners are discovering new knowledge and whether everyone or anyone is discovering at all. (p. 81)}

In fact, if students perceive different situations or perceive situations differently, then this may also increase the differences (and/or misunderstandings) in what appropriate tactical decisions are. 
One prominent example of stimulating discussions is creating a "debate of ideas" (DI), in which students discuss strategies and exchange tactical ideas inbetween play (Gréhaigne et al., 2001; Gréhaigne, Richard, \& Griffin, 2005; Mitchell, Oslin, \& Griffin, 2013; Storey \& Butler, 2010). Proponents of DI have argued that a debate can foster students' tactical understanding and decision-making (e.g., Chang, Wallian, Nachon, \& Gréhaigne, 2006; Darnis \& Lafont, 2015). With the DI, Gréhaigne and colleagues $(2001,2005)$ aimed to develop a setting that matches with a pedagogy that centralizes social interactions between students in the learning process. Through these interactions, students themselves discover fitting tactical solutions instead of the teacher prescribing the optimal solution. Since a particular game situation affords different solutions for individual students and because they differ in action capabilities (i.e., their ability to achieve meaningful action outcomes), there is no one optimal solution or strategic decision for the teacher to be taught. DI can bring these differences in students' perception to the fore and fosters the exchange of tactical solutions by promoting interactive discussions. DI is grounded in the students' perceptions of game play. It typically unfolds through a series of didactical steps: observing and describing the relevant situations in the game (Richard \& Wallian, 2005), identifying and interpreting the tactical problems of the situation (e.g., Wright \& Forrest, 2007), and verbalizing the tactical strategies for the situation (e.g., Zerai, 2018). Finally, after the debate, students try to bring the newly formulated tactical intention and strategies into practice with the resumption of game play. Experiences during game play will feed into the next debate, and so on.

DI is consistent with social constructivist learning methods in which the teacher facilitates learning in groups (Richard \& Wallian, 2005). The social context of a DI fosters students' learning and skills in perceiving what game situations afford and stimulates students' autonomy in making choices (Harvey \& Light,2015). Organizing DI provides PE teachers many opportunities before, after or in-between game play for promoting discussions and interactions on tactical issues; yet, the unfolding of these sessions has largely remained unclear. For instance, researchers have not often addressed how students (mutually) influence each other's perceptions and performances during game play following a debate. In one study, Koekoek and Knoppers (2015) examined 13-year-old students' perceptions of how they learned in a modified baseball game, based on principles from Teaching Games for Understanding (TGfU). They suggested that social interactions, particularly regarding collaboration and communication, may also adversely influence learning. 
Classmates, who worked together in groups, sometimes had negative ideas of their peers, which resulted in ineffective collaboration and/or negative thoughts about others' performances. Although the study of Koekoek and Knoppers (2015) did not specifically focus on DI, it underlines the presence and impact of differences in student perceptions. In DI, differences in student perceptions likely influence student agreements and may even lead to confusion of what a situation affords and what decisions are appropriate. Nonetheless, differences in perception may also introduce new situational perspectives on the tactical situation into the debate. It is pertinent to establish the impact of differences in student perceptions, because it can inform teachers whether they should try to reduce or encourage them. In other words, the effective implementation of a DI warrants that the necessary conditions for a pedagogical debate are addressed (e.g., Light, 2013). Hence, the current study addresses the mutual agreement and the accuracy of student perceptions of the shot on the basket within the context of a DI setting.

\section{Digital video and debates in game-based settings}

A didactical tool that may support the mutual agreement and accuracy of students' perceptions during DI is reviewing video footage from students' actual game play. In general, researchers have claimed beneficial effects of digital video in PE and sports, especially when used for video-modeling (Amara, Mkaouer, Nassib, Chaaben, Hachana, \& Salah, 2015; Sani \& Khan, 2017) and assessment for learning such as feedback (O'Loughlin, Chróinín, \& O'Grady, 2013; Palao, Hastie, Cruz, \& Ortega, 2015; Van der Kamp, Duivenvoorden, Kok, \& Van Hilvoorde, 2015; Weir \& Connor, 2009). This research has largely focused on supporting the learning of motor skills or techniques, and only few studies have investigated the use of digital video to enhance game understanding (e.g., Blomqvist, Luhtanen, \& Laakso, 2001; Ningthoujam, 2016).

Video-based analysis can be a useful teaching strategy within game-based approaches to enhance game understanding, because it creates a student-centered PE learning situation. Yousef, Chatti and Schroeder (2014) argued that in a studentcentered learning setting digital video can provide "... space for students to be active participants in their learning environment, interact to build and construct knowledge, and get mutual support to make decisions using reflection and critical judgement" (p. 115). Nevertheless, studies that have examined the effects of digital video in student-centered learning settings are scarce (Gainsburg, 2009; Smyth, 
2011). An exception is the study by Harvey and Gittins (2014) that compared two groups of 13-14-year-old students involved in DI with and without video-based tactical feedback. Video footage of game play was recorded and selected by the researchers, who also planned and controlled when the footage was fed into the student discussions. It was found that student game performances (e.g., conquering and receiving balls, successful shots) significantly improved in students who participated in the DI with video feedback compared to those who discussed without video footage. Harvey and Gittins (2014) argued that looking back on game situations may increase the agreement of student perceptions, and thus make questioning and discussions more effective. However, the study did neither assess the agreement between student perceptions nor report the accuracy of their perceptions. It did not examine either what students thought they had learned from the discussions. Finally, although the students in Harvey and Gittins' study participated in the discussions, the DI sessions were not fully student-centered. A student-centered DI means that it would allow the student to control input of video footage, rather than having it provided by the researcher (or teacher).

In this respect, recent developments in PE regarding digital video-tagging allow students to record and select game situations of interest (Koekoek, Walinga, \& Van Hilvoorde, 2017; Koekoek, Van der Mars, Van der Kamp, Walinga, \& Van Hilvoorde, 2018). Video-tagging is an annotation tool (Rich \& Hannafin, 2009) that can be used in PE settings for observational purposes in which events are marked during 'real time' video recording (Koekoek et al., 2018). If students do the video-tagging, they can learn to recognize key events during game play. Moreover, the use of videotagging makes the tagged game situations directly available as input for DI, and students can bring them into the discussion. Student-controlled video-tagging may therefore not only benefit self-regulatory processes and motivational beliefs (Koekoek \& Knoppers, 2015; Van Maarseveen, Oudejans, \& Savelsbergh, 2018), but potentially also affects the mutual agreement and accuracy of students' perception of what actions a game situation affords.

The central aim of the current study is to explore how mutual agreement and accuracy of students' perceptions of tactical aspects of a basketball game situation and students' perceived learning outcomes are influenced by using a debate of ideas (DI) setting that is enriched with video footage from digital tagging. Across three lessons, this study gauges the constructions of two groups of students involved in debate of ideas (DI) settings that were either enriched with self-selected video footage 
or entirely based on students' verbal input. The mutual agreement and accuracy of these 'real-time' perceptions before and following the DI were compared between the two groups across the three lessons. To this end, during game play in each group three students (i.e., observers) used video-tagging to identify shots on basket and to judge the appropriateness of the decision to shoot. Additionally, after each lesson, the students were interviewed to assess their perceived learning outcomes. It was expected that video would promote situational perspectives about shot on basket situations (i.e., by stimulating dialogue, negotiation and critical thinking, students may learn to value others' perspectives). Accordingly, it was hypothesized that DI enriched with student-controlled video footage would increase the mutual agreement as well as the accuracy of students' perceptions of shot on basket situations. In addition, it was hypothesized that the perceived learning outcomes of shot on basket situations would be more similar for video enriched DI, reflecting a larger shared understanding among students.

\section{Methodology}

\section{Participants and context}

20 students (10 boys, 10 girls), aged between 11 and 13 years, volunteered to participate. These students were randomly chosen from two year one classes at a secondary school located in a medium sized city in the Netherlands. The two groups were not matched for motor skill or otherwise. In the Dutch school curriculum, PE is compulsory. In the participating school, students have three PE lessons each week, and PE teachers design the lessons from a social constructivist learning perspective, in which they emphasize group work, collaboration and communication. The study was conducted in accordance with the ethical guidelines of National Organization of Dutch Universities of Applied Sciences (Netherlands Code of Conduct for Research Integrity, 2018). The director and PE teachers provided written informed consent for the study prior to recruiting student participants. Next and prior to the study, written informed consent was obtained from the parents, while students gave verbal informed consent.

An important aim for the present study was to achieve a high degree of representativeness. This means that the study design followed as closely as 
possible the normal proceedings of PE lessons, with one important exception: the roles students took (i.e., player, video-tagger, observer) were kept the same across games. This allowed us to collect both quantitative and qualitative data. Such a mixed method approach provides the opportunity to make layered interpretations (Anguera, Camerino, \& Castañer, 2012; Onwuegbuzie \& Leech, 2004). In this respect, however, it is pertinent to acknowledge that the study is exploratory as the use of qualitative data constrained the sample size (i.e., the number of student-observers that could be used for the quantitative analyses).

\section{Material and equipment}

The study took place on one half of a basketball court (10 x 14 meters) in the school's regular PE hall. The basket ring height was adjusted to 2.60 meters. A video recorder (Sony, HDR CX115) placed on a tripod at the center of the court was used to record the games. In total, four iPads (i.e., 4th generation) were used. One of these iPads was used by one student (i.e., the student video-tagger) to record and select video clips for reviewing during debate of ideas. To this end, VideoTagger (Robinson, 2014) was installed on the iPad. VideoTagger was used for tagging and recording shots on basket. After tagging, it processes the tagged event into a video clip. AppleTV (version 3) connected with the same iPad and a WIFI-connection in the PE hall permitted presentation of the video clips on a large monitor (Samsung, 32 inch) during DI. The other three iPads were used by three student-observers to identify shots on basket and evaluate their appropriateness. To this end, they used a tag panel on an iPad developed with the Dartfish EasyTag application (Dartfish, 2010). Dartfish EasyTag enables the construction of a tag panel with buttons that represent predefined events in a match. It has been shown previously that the tag panel is a reliable tool when the provided events are sufficiently distinctive, and - if included - subsequent judgments or evaluations are binary (Koekoek et al., 2018). For the current study, the panel permitted tagging a shot on basket, followed - if a shot was identified - by a judgement whether or not the shot was appropriate. Each identification and judgment were timestamped. The student video-tagger stood and the three student-observers were seated behind the line during the game (see Figure 6.1). 

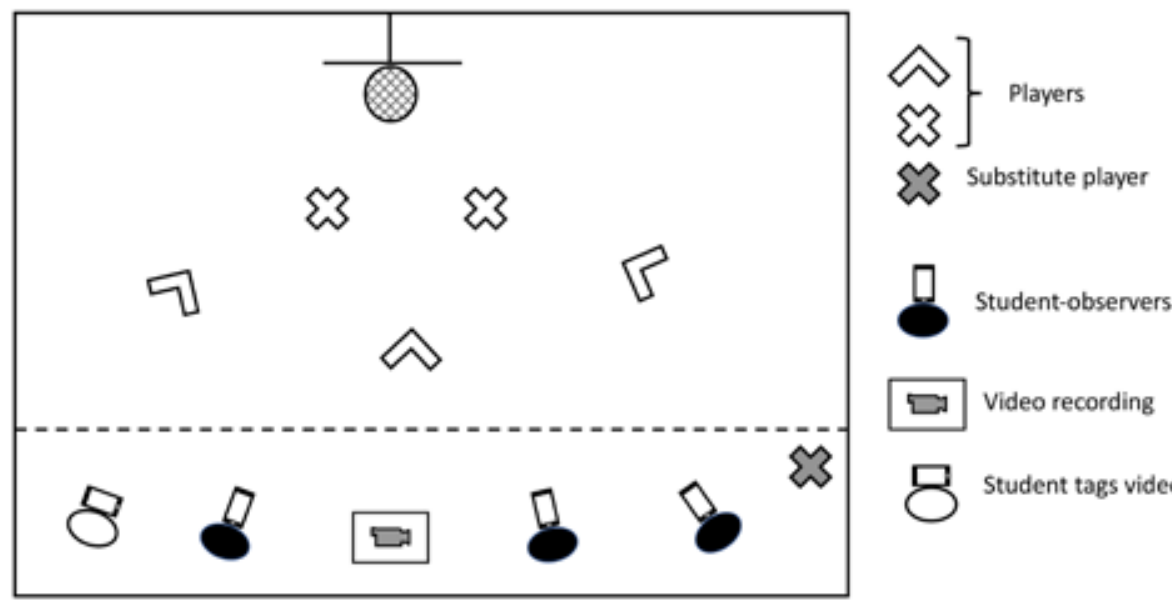

$\sqcup$ Video recording

$\bigcirc$ Student tags videos

Figure 6.1 Set-up for the video DI group.

Lesson unit basketball 3 vs 2

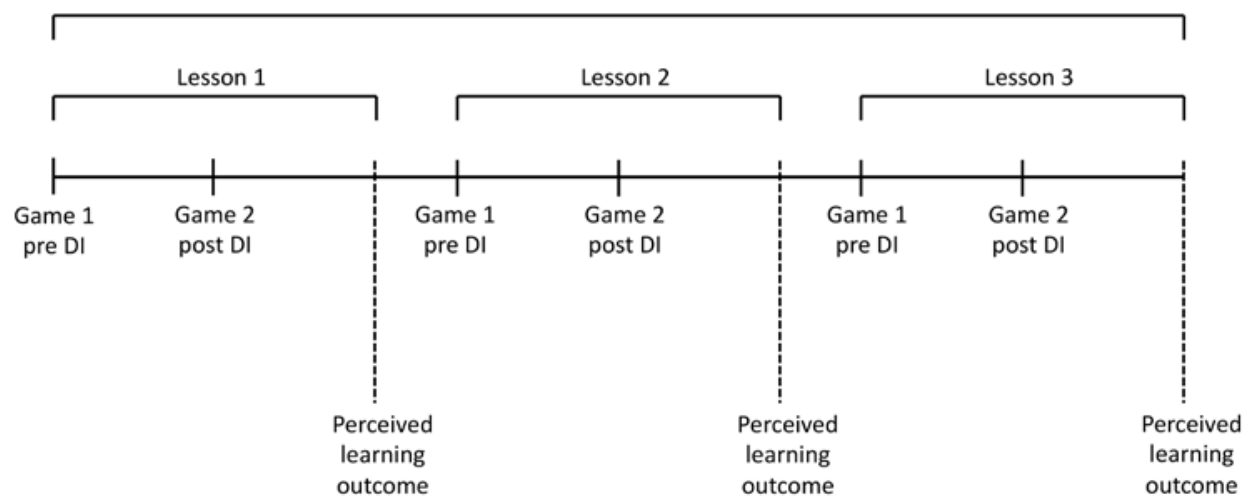

Figure 6.2 Timeline of study procedures and the data collection events.

\section{Design, procedure and data collection}

Figure 6.2 shows the timeline of the study procedures and data collection. The study was conducted in two groups from two classes, which consisted of 10 students each. The two groups participated in a small-sided 3 versus 2 basketball game across three 
subsequent PE lessons (Koekoek, Dokman, \& Walinga, 2014). The participants had little to no experience with basketball in small-sided game situations. Yet, they all had previously received three lessons which addressed acquisition of basic basketball skills, such as shooting on the basket, passing and dribbling. The participants also had no previous experience in using video-tagging. The remaining students of the class participated in small-sided PE activities on the other half of the PE hall.

The learning objective was for students to recognize and make appropriate decisions with respect to shooting on the basket. In line with a social constructivist learning perspective, students were not instructed about the situations that did or did not afford shooting. They together had to construct this meaning during the lessons. For each lesson, the same procedures for instructions and measurements were followed. The two experienced teacher-researchers (JK and WW) gave instructions to the students regarding the purpose and rules of the small-sided game, the different roles (i.e., player, video-tagging and observer) and the DI. The teacher-researchers assigned student roles and moderated the discussions during the DI.

The two groups differed in the manner in which the DI was facilitated. In each of three PE lessons, two games were played. The DI took place immediately after the first game. In the video group, the DI was enriched with video recordings of the game (see also Harvey \& Gittins, 2014), while in the verbal group, the DI was entirely verbal. The DIs functioned (and were moderated) to stimulate debate around making decisions regarding the appropriateness of a shot on basket (e.g., relative to the distance on the basket or the degree of defense), collaboration between teammates, and more generally, to enhance students' understanding of team tactics and strategies (Koekoek, Walinga, \& Van Hilvoorde, 2017). In the video group one student was assigned the role of video-tagging and selecting tagged game situations for reviewing and discussing in the DI. After each 5-minute-game, the student videotagger selected video clips, which were presented on the monitor as input for the DI session. The DI in the video group involved a series of didactical procedures and questions (see Table 6.1). The verbal group followed an identical procedure as the video group, but without input of video footage. Because there was no student videotagger in this verbal group, two of the students served as a substitute player (rather than one as in the video group). 


\section{Data collection}

To explore the agreement and accuracy of students' perceptions, three students of both the video group and verbal group were randomly assigned to the role of observer. The student-observers were instructed to observe the game play and tag each shot on the basket and judge whether the decision to shoot was appropriate or inappropriate using the Dartfish tag panel on the iPad. No further explication of appropriateness was given. The three student-observers of both groups only tagged: they neither participated in the game, nor were their tags used in the DI. However, these student-observers did participate in the DIs.

At the end of each lesson all students were individually interviewed by one of the teacher-researchers and asked what they thought they had learned regarding shooting on the basket from playing the small-sided games and participating in the DI session, respectively. In lesson 1 and 2, the students did this in response to a single question: "What can you tell about the difference between an appropriate and inappropriate shot on the basket?" At the end of lesson 3, students were asked: "What did you learn in tactical terms about the shot on the basket?"

Table 6.1 Didactical procedure and example questions of the debates sessions for the video group.

\begin{tabular}{|c|c|c|}
\hline STEPS & DIDACTICAL PROCEDURE & $\begin{array}{l}\text { EXAMPLES OF QUESTIONS FOR THE TEACHER/ } \\
\text { RESEARCHER }\end{array}$ \\
\hline 1 & $\begin{array}{l}\text { During the game: The student video-tagger uses } \\
\text { VideoTagger and judges tactical events during a game }\end{array}$ & $\begin{array}{l}\text { "When observing the first game, please make a judgement } \\
\text { of all the shots on the basket you see and press the button } \\
\text { if each shot on the basket is (1) appropriate or } \\
\text { (2) inappropriate made by the player." }\end{array}$ \\
\hline 2 & $\begin{array}{l}\text { After the first game of five minutes play: The teacher } \\
\text { asks the student video-tagger to explain the tagged } \\
\text { video clips }\end{array}$ & $\begin{array}{l}\text { "Can you explain one of your tagged video clips, especially } \\
\text { why you think it is an appropriate or inappropriate chosen } \\
\text { shot?" }\end{array}$ \\
\hline 3 & $\begin{array}{l}\text { Both the players and student-observers are watching } \\
\text { together several video clips on the video screen }\end{array}$ & $\begin{array}{l}\text { "We are going to watch the inappropriate chosen shots } \\
\text { according to the judgement of the student video-tagger." }\end{array}$ \\
\hline 4 & $\begin{array}{l}\text { DI: Both players and student-observers exchange ideas } \\
\text { and interpret the video clips content. They are allowed } \\
\text { to react to the student video-tagger's choices }\end{array}$ & $\begin{array}{l}\text { "Can you explain what you think about the shot on the } \\
\text { basket, and please try to formulate a reason that underpins } \\
\text { your opinion?" }\end{array}$ \\
\hline 5 & $\begin{array}{l}\text { After the DI session the teacher makes some } \\
\text { concluding remarks and formulates a learning question } \\
\text { for the group }\end{array}$ & $\begin{array}{l}\text { "Do I draw the right conclusion if I say that it is important to } \\
\text { shoot on the basket when you are in a position in the field } \\
\text { with a big chance to score?" }\end{array}$ \\
\hline 6 & Starting the second game of five minutes play & - \\
\hline
\end{tabular}




\section{Data analysis}

First, to assess the agreement between students' perceptions, the output of the tag panels for the three student-observers of both groups were event (and time) synchronized. Next, for each of three pairs of student-observers the number of agreements and disagreements were calculated (i.e., students 1 and 2, students 1 and 3 , and students 2 and 3 ). An agreement was defined as both observers identifying the shot and both judging it as either appropriate or inappropriate. A disagreement was defined as only one of two observers identifying the shot and/or one observer judging the shot as appropriate and the other as inappropriate. Finally, a series of Chi-square analyses was performed to examine whether the distribution of the total number of agreements and disagreements (i.e., the sum for the three pairs of student-observers of one group) differed between groups, games and across lessons.

Second, the accuracy of the students' perception was assessed. To this end, first the recordings of the games (made by the video camera on the tripod) were watched offline and scored by an expert game teacher. The expert identified all (attempted) shots on basket and evaluated whether or not these shots were appropriate. For this purpose,'appropriate' was defined relative to the distance to basket the ball was shot, the presence of a teammate who was better positioned to shoot, and the presence of an opponent, who could defend or interfere the shots on the basket. Next and similar to the agreement analysis, the number of agreements and disagreements between each student-observer of the two groups and the expert teacher were determined, followed by a series of Chi-square analyses to examine whether the distribution of the total number of agreements and disagreements (i.e., the sum for the three pairs of student-observers in one group) differed between groups, games and across lessons.

Third, the student answers regarding the question on perceived learning outcome were transcribed. These answers were categorized into emergent themes for each of the 10 players of both groups over three lessons with the use of a constant comparative analysis (Charmaz, 2006). Subsequently, the consistency of the responses among students, and the sort of outcome (i.e., how answers changed over sessions) between students and between sessions were analyzed. 


\section{Results}

\section{Agreement of students' perceptions}

Figure 6.3 shows the total number of agreements and disagreements among the three student-observer pairs for the video group and the verbal group across the three lessons. The percentage of agreements for the separate games ranged between $42 \%$ and $75 \%$ with an average accuracy of $58 \%$ for the video group and $63 \%$ for the verbal group. Overall, the agreements in identifying shots on basket and judging whether the shot was appropriate or not were relatively low in both groups. There were also no significant changes within and across lessons. This was confirmed with a series of $X^{2}$-analyses assessing a change in the distribution of the number of agreements and disagreements within and between lessons for each group ( $X^{\prime \prime} s<2.9, p^{\prime} s>$.09). However, one exception was revealed: in the first lesson of the verbal DI guided group, the number of agreements significantly increased after the DI $\left(X^{2}(1)=6.04, p=0.014\right.$, see Figure 6.3, bottom row, left panel). Finally, also a series of $X^{2}$-analyses assessing distribution of the number of agreements and disagreements in each game between the two groups did not reveal significant differences $\left(X^{2} s<1.63, p^{\prime} s>0.20\right)$. 

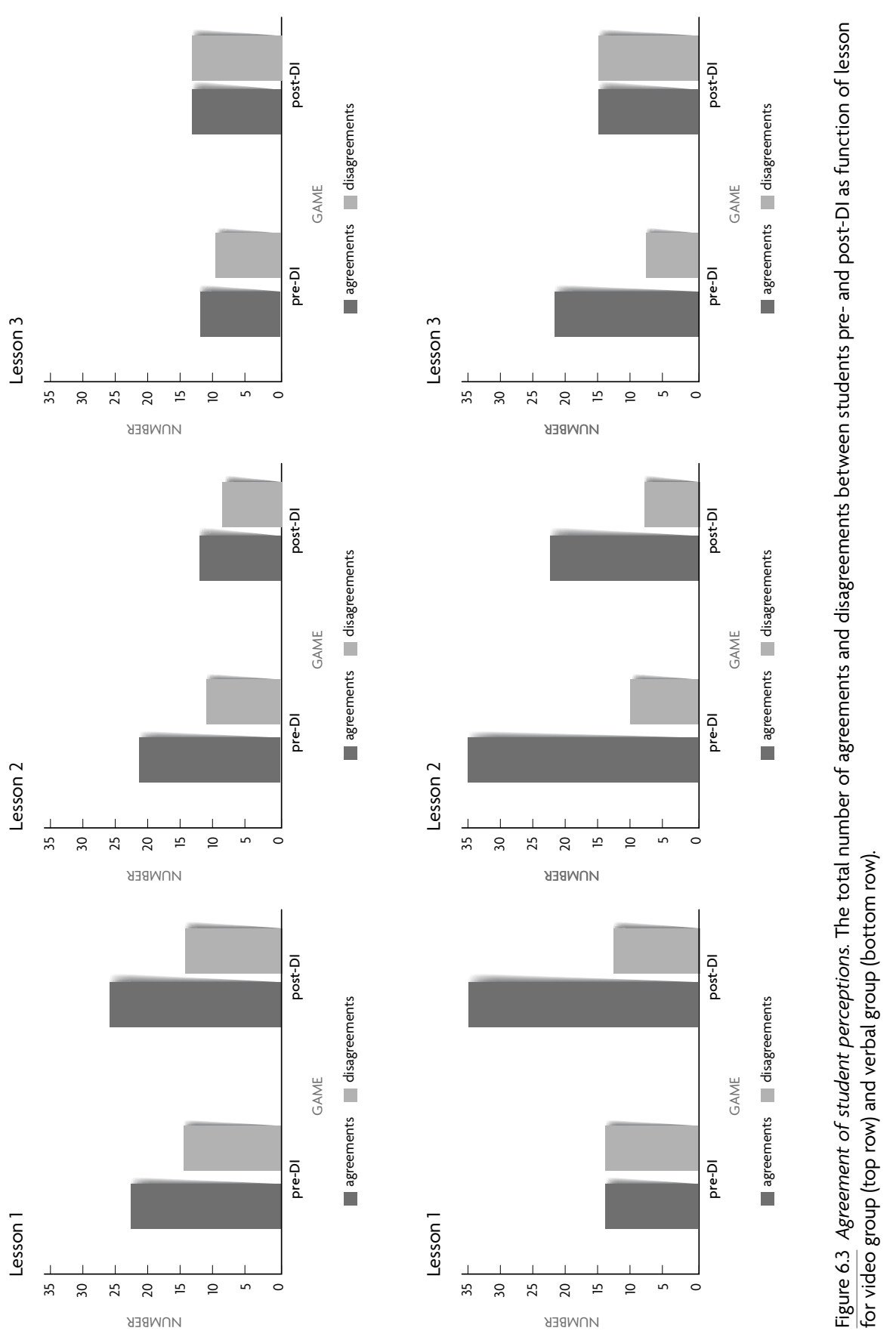

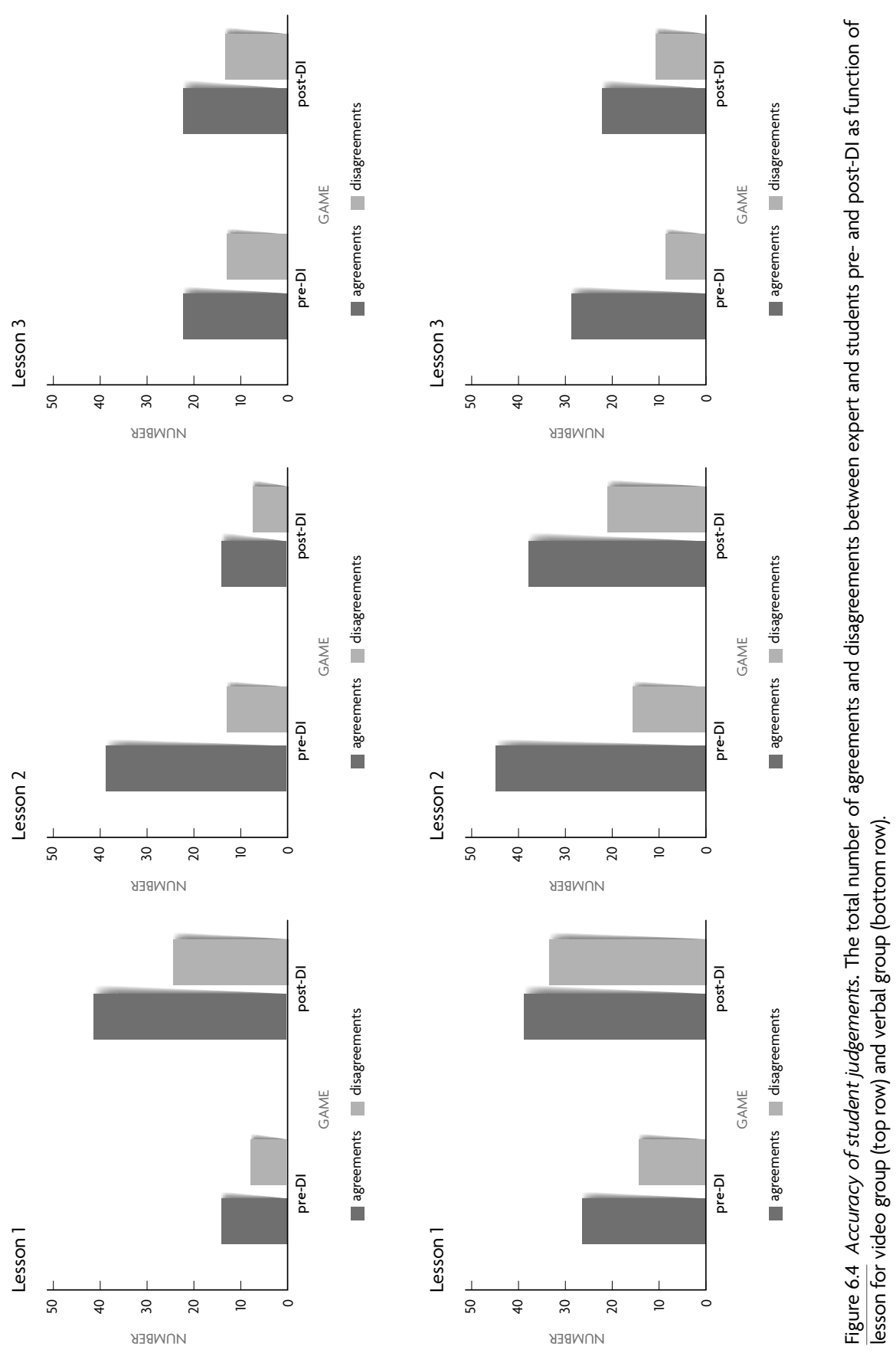


\section{Accuracy of student judgements}

Figure 6.4 presents the accuracy of the student-observers' judgments. Accuracy was measured as the total number of agreements and disagreements between the expert game teacher-researcher and the student-observers. The percentage of agreements for the separate games ranged between $53 \%$ and $76 \%$ with an average accuracy of $65 \%$ for the video group and $66 \%$ for the verbal group. There were also no apparent changes in accuracy. For both groups, there were no significant changes in distribution between pre-DI to post-DI $\left(X^{\prime \prime} s<1.2, p^{\prime} s>.26\right)$ and between lessons $\left(X^{2} s<4.4, p^{\prime} s>11\right)$. Finally, also the distribution of the number of agreements and disagreements in each game between the two groups did not reveal significant differences $\left(X^{\prime \prime} s<1.53, p^{\prime} s>\right.$.23).

\section{Students' perceived learning outcome}

The students in both the video group and the verbal group responded individually to the question what they can tell about the difference between an appropriate and inappropriate shot (i.e.,lesson 1 and 2 ) and what they did learn regarding the tactical aspects of shooting on the basket (lesson 3). Appendix 9 presents example responses of both groups. As can be seen many of the responses refer to specific elements of game play, such as tactical decisions, positions on court, position of opponents, and position of teammates. In general, the students provided straightforward answers. They typically used one full sentence to express their thoughts regarding shooting at the basket. Some students expressed their thoughts with only one or two words.

The responses of the students showed a clear difference between both groups in what they perceived as the critical aspect for defining a shot as appropriate. Notably, the verbal group showed a larger variety in their responses after each lesson while students' answers in the video group showed more consistency. Many students in the verbal group also reported more (than one) tactical aspects as learning outcomes after lesson 3. Finally, a few students responded that they had not only learned about when a shot on basket is appropriate, but that they also had acquired other aspects related to basketball, such as the technical performance of shooting, even though this was not introduced in the DI by the teacher-researchers. In both groups, the learning objective 'shooting at the basket' was often reproduced in the students' answers, which they linked to different tactical aspects. Four themes emerged in the students' responses: 'free or undefended shot on target', 'distance to target', 'focus of attention', and 'teammates' actions'. 
The answers of students in the video group were mainly related to the theme 'free or undefended shot on target'. They considered that a free shot would include several preconditions such as shooting without being defended too closely and looking for teammates who are in a better position. For example, one student answered: "An appropriate shot on the basket is when there are no players standing around me", while a second student explained: "[A shot on basket that is not appropriate] is when you shoot while there are too many defenders. You have to be in a free position." These preconditions were particularly manifest in the responses after the first and second lesson. Almost all students in the video group defined this as the central learning outcome after the third lesson. One student responded in a way that allowed no alternatives: "I only shoot on the basket when I am in a free position." Another student also considered the future outcomes: "I learned to shoot on the basket when nobody from the other team is standing near the basket." This student did include the situation which may occur after a shot missed the basket. In this answer a free shot on the basket also means that there would be time for a second attempt.

In the verbal group, students particularly answered in terms that are related to the theme 'distance to target'. For example, one student explained: "[It is not appropriate to shoot] when you aim on the basket too far from the basket." In fact, many students estimated the appropriate distance from the basket as a distance that was within their capability of throwing. For example, one student responded: "It is better to avoid shooting at the basket [from a position] that is too far." Another student in the verbal group explained after the first lesson what she thought an inappropriate shot on the basket means: "[inappropriate] is when [the shot] is too far from the basket or too close. The shot should be from a distance that is reasonable. Actually, I know in that case that I can reach the basket [boarding]." After the third lesson she explained that the distance to the basket was still important, but in her judgement about shooting at the basket she also considered her own capabilities: "[I will shoot on the basket] when I think I can reach the basket."

In both groups, the students also articulated other aspects in their judgement of shooting distance such as the throwing technique and their ability to create space. These aspects were related to the themes 'focus of attention' and 'teammates' actions'. Especially, in the video group, several students responded that it is important to watch and pay direct attention to what occurs in the game in deciding whether or not to shoot. For example, one student answered after the second lesson: 
"[I will shoot on the basket] when there are not many other children around me", suggesting that this student's decision to shoot at the basket did consider the presence of other students, but irrespective of whether they were opponents or teammates. After the third lesson she gave an answer that suggested she had shifted her focus somewhat: "It is important to watch where I can have a better position in the field, and look after [the position of both] defenders and teammates." Students also responded with technical issues when judging the shot on basket. For example: "A good shot is often successful when you use two hands."

\section{Discussion}

The central purpose of this study was to explore how mutual agreement and accuracy of student perceptions of tactical aspects of a basketball game situation and student perceived learning outcomes are influenced by using a debate of ideas (DI) setting that is enriched with video footage from digital tagging. The results of this study showed that the degree of agreement and accuracy among student-observers varied considerably in identifying and judging tactical situations in basketball. Yet, there were neither systematic nor significant changes across lessons or between groups. The perceived learning outcomes in the video guided group were more consistent and showed a greater emphasis on contextual aspects (e.g., teammates and opponents) in making decisions regarding the appropriateness of a shot on the basket.

The present findings thus indicate that a DI setting does not necessarily imply that observers develop a stronger agreement on what they perceive and how they judge this. This was also true when the DI was enriched with video footage. Possibly, the classmates might have brought up a large diversity of tactical solutions in the group discussions, revealing an increasing number of possible decision-making options for the individual student. Interestingly, although agreements did not differ between the two groups, the differences in perceived learning outcomes do suggest that tactical discussions enriched with video may have promoted diversity in the groups' perspectives of the tactical options available - or at least a difference in the options that were considered most relevant. Namely, the video guided debates seem to stimulate students to focus on 'free or undefended shot on target', while the verbal group more often articulated tactical aspects with respect to 'distance to 
target'. Although these differences in learning outcomes can also be attributed to factors other than the use of digital video, it does suggest that using digital tools is not simply neutral. When incorporating digital tools, it is also required to consider perceptual and cognitive backgrounds of students ( $O^{\prime}$ Donoghue, 2016; Walinga, Koekoek, \& Van Hilvoorde, 2017). In this respect, students should be enabled to practice using the tag panel and provide them sufficient time to learn what is, in fact, a dual task involving both observing and tagging.

Also, with respect to student-observer accuracy in identifying and judging shootings at the basket, there was not a simple line of progression following a DI or across lessons. In other words, the DIs did not improve the accuracy of tactical understanding by students, also not when it was enriched with video footage. Again, it cannot be ruled out that a DI, irrespective of whether or not it is streamlined with video, generates a larger variety of tactical options, rather than narrowing down the options to one single correct solution. Here, an important issue for consideration - also for research - is when to introduce a DI within or across a lesson. For example, dealing with different interpretations and a variety of tactical options may have different effects and benefits for student learning, depending on whether they are beginner learners or whether they are more competent learners that tend to reenact a preferred solution (Walinga, Consten, Van Driel, \& Van der Kamp, 2018).

Nevertheless, it is important to emphasize that the perceived learning outcomes were in line with the central purpose of a game-based approach such as TGfU (Harvey \& Jarrett, 2014). Namely, these students' perceptions included processes of decision-making that are learner centered. This is pertinent, because the teachers did not explicitly guide them toward these outcomes. These findings are in line with the aims of a social constructivist situated learning perspective, in which learning arises from the circumstances in a particular time and place, rather than being prescribed by a teacher only (Kirk \& Macdonald, 1998; Wallian \& Chang, 2007). This was especially present in the primary focus on team tactics by students rather than only on individual's techniques or capabilities. This underlines that gamebased approaches with DI promote relational and communication skills and shared understandings to judge about tactical situations (Ronglan \& Ertesvåg, 2015). In this respect, it is pertinent that the perceived learning outcome of students who watched video footage selected by an observer showed more consistency across students and lessons than in the verbal guided group. That is, many students in the video guided group articulated similar tactical intentions (especially, 'free or undefended shot 
on target'), while the students in the verbal guided group tended to show a greater variety in their answers. This finding suggests that enriching DI with video footage enhanced the shared understanding of a complex tactical situation, and likely increased focus towards the position of teammates and opponents. In contrast, the topic 'distance to the basket', that was discussed by the verbal DI group, suggests that these students much more limited their explanations to their individual capability. Thus, these students may have relied more on personal views and capacities in order to review tactical choices and positions in the field, while the context (i.e., the role of teammates and opponents) received less attention. Discussions in debates without the use of videos could therefore limit the situatedness of tactical options that students develop. A student-controlled video debate may create more degrees of freedom to develop contextual interpretations.

The particular contextual interpretations of students' perceptions in the video guided debates can be a pitfall for teachers. The different perceptions and understandings that students bring into the discussion may - seemingly - interfere with the teacher's learning objective. Therefore, a decisive role is assigned to the teacher's pedagogical skills when introducing video guided debates. Indeed, Palao, Hastie, Cruz and Ortega (2015) stressed that effective, interactive video guidance requires complex teaching skills. For example, teachers must observe tactical events in the game and determine the frequency and timing of DI. At the same time, teachers must moderate the contribution of different students into the discussions. Hence, a pertinent first step in future research on student-centered video guided DI is to investigate the teacher skills needed to manage and optimize the pedagogical conditions of DI. Therefore, it would be valuable to explore how the different teaching skills required for an optimal video guided debates setting may foster or perhaps obstruct student learning processes. Such insights may contribute to new knowledge and understanding regarding the incorporation of digital observation tools in game-based pedagogies (Memmert et al.,2015).

This discussion can be concluded with a reflection on how the current insights may contribute to the development of innovative digital pedagogies. In the present study, the digital tagging applications fostered the game teaching practice. In other words, the digital observation tool in this study was not merely used as a research instrument, but it was integrated in teaching in order to collect the data in this study. This method provided the opportunity to explore new procedures and teaching methodologies to support students in self-regulating their learning processes. 
To achieve this end, the researchers have been endeavored to organize this study in a representative physical education setting. Yet, this research is not without limitations. Since the study involved only a subgroup of students within one class, the PE teachers could not be fully involved; they were teaching the remaining students. In particular, some may stress the importance of PE teachers to guide the DIs, because they are more aware of the social context and their students' concerns and needs (e.g.,preferences for working with peers, work attitudes in groups, friendships, see Koekoek \& Knoppers, 2015). This knowledge may increase productivity of social interactions during DI. In this respect, $\mathrm{PE}$ teachers can benefit even more from the findings in this study if they intend to use an action research approach in which they learn themselves to collect data, to handle the technology, and to understand the pedagogical didactical procedures and requirements (e.g., Keegan, 2016).

Another limitation of this study is the extent to which these results can be generalized to other contexts. The PE classroom situation is often dynamic and unique. Even one basketball game may differ because student motivations may change, their tactical and technical backgrounds differ, and so on. This variability can influence the dynamics of the social interactions during DI. Although this study did try to ensure some standardization across lessons by keeping the students in the same roles, it did strive to maintain representativeness with respect to the PE context. Consequently, the data were not collected with the purpose to determine whether video guided DI would work in different contexts. In addition, the high and intensive collaboration that was needed between researchers, teachers and students during the sessions, considerably constrained the sample size. Hence, the present observations need further corroboration. However, the mixed methods did put the student observations and perceived learning outcomes into perspective. For instance, although students from the video guided DI group showed more consistency in perceptions of what they tactically learned, the findings in this study did not indicate that video guided debates achieve higher agreements and accurate judgements. These perhaps paradoxical observations warrant further investigation. In our opinion, in future research a more detailed qualitative assessment of the dynamics of the discussions between students during DI with video guidance could be of more interest for PE teachers than replicating this study with a larger sample size - although this is not without interest either. 


\section{Conclusion}

The debate of ideas in a pedagogical game setting generated a variety of meanings about tactical situations among students, irrespective of the debate being enriched by digital video. That is, student agreement and accuracy of their perception of tactical situation was not differently influenced by DIs that were video or verbally guided. However, the student-centered debates supplemented with video did enhance the consistency of students' shared understanding of tactical learning objectives of games compared to verbal guided DI.

\section{Disclosure statement}

No potential conflict of interest was reported by the authors. 


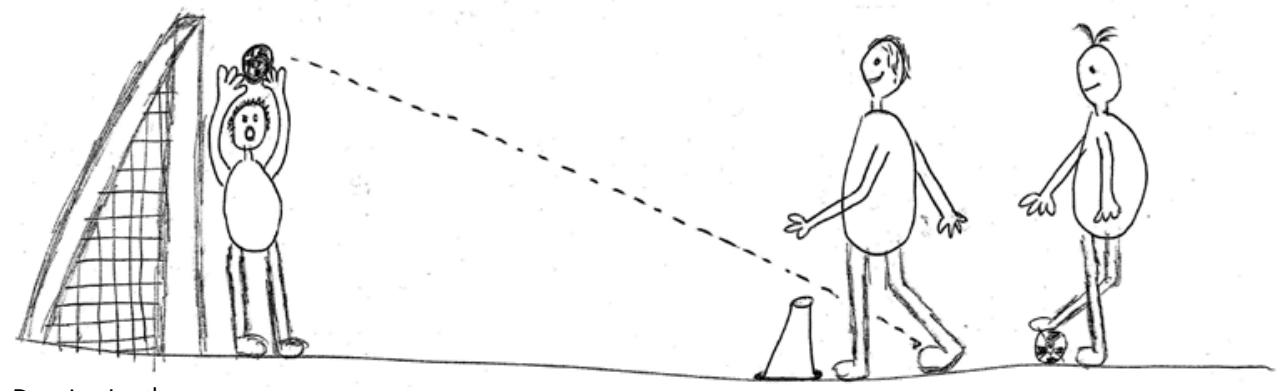

Drawing Jenthe. 


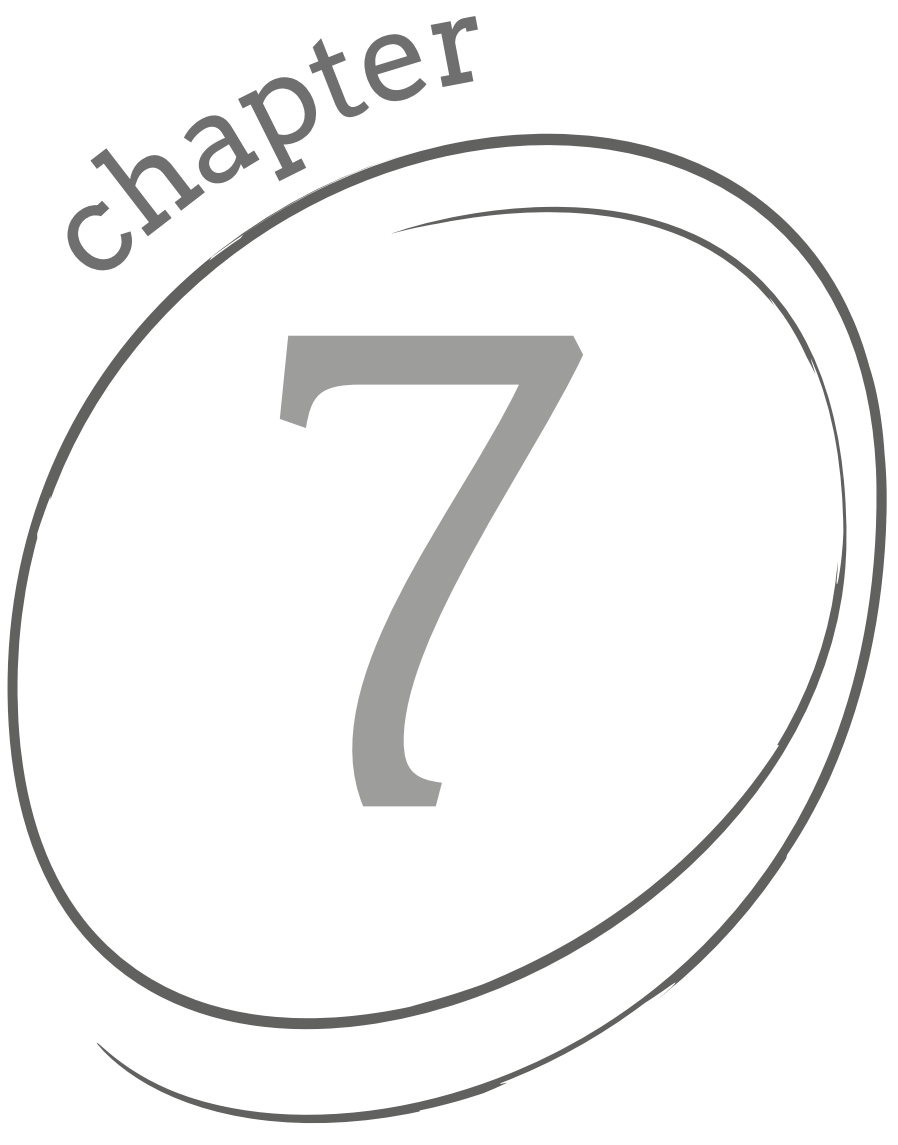

154 


\section{Aligning digital video technology with game pedagogy in physical education}

\section{Abstract}

The rapid development of digital technology has expanded the prospects and promises for its application in physical education programs. Physical educators are becoming increasingly interested in technology but often remain inadequately equipped to effectively integrate these technological resources in their daily practice, and/or lack the practical knowledge about the potential of these digital resources. For example, various commercial digital applications (apps) for gamebased teaching are available to support instruction and feedback, such as video analysis apps. But these promising technological innovations are sometimes applied incorrectly or may even overtake the teaching focus at the expense of the pedagogical and didactical aims. The purpose of this article is to describe the process of innovating, introducing and developing a digital tagging application for teaching tactical awareness in sport games. This case study illustrates how physical educators implemented a video analysis app to provide feedback and develop student tactical awareness in games. It demonstrates how innovative digital resources can be implemented in physical education, while supporting the central tenets of gamebased approaches to teaching games.

Published as:

Koekoek, J., Van der Mars, H., Van der Kamp, J., Walinga, W., \& Van Hilvoorde, I. (2018). Aligning digital video technology with game pedagogy in physical education. Journal of Physical Education, Recreation \& Dance, 89(1), 12-22. 
There is a growing interest among physical educators relative to incorporating digital technology in their teaching (Juniu, 2011; Pyle \& Esslinger, 2014; Thomas \& Stratton, 2006). In part, this willingness is a consequence of digital technology's already formidable impact on how children (and adults!) today experience games, sports and other physical activities. The use of smartphones, tablets, applications (apps), video feedback, serious (educational) games (Michael \& Chen, 2006), and YouTube has contributed greatly to these developments. Student learning, teachers' daily instructional practices, and preservice preparation programs are all affected by the ever-increasing sophistication of technology tools. Digital technologies influence how children and youth come in contact with sport, how they shape their own "sport identity" (Pot, Schenk, \& Van Hilvoorde, 2014), how they acquire movement skills, and how they perceive and evaluate their movement skills on video recordings (Palao, Hastie,Cruz, \& Ortega,2015). The use of digital technology in physical education differs fundamentally from its use in other school subjects. This is because the learning process in the psychomotor domain is directly observable and public (i.e., it is there to see for both peers and the teacher). Thus, digital technology can be utilized to help bring the learning process to life for the learner (Casey \& Jones, 2011). However, what remains unclear is how, when and by whom technological apps such as digital video analysis could best be used.

This article is directed at physical education professionals, physical education teacher education (PETE) faculty, and sport pedagogy researchers alike, and it will focus on how digital technology can be used to develop students' awareness of tactics in game-based lessons. For example, teachers can use video-based feedback to enrich the way they teach game pedagogy. In particular, the analysis of video footage showing tactical aspects of the game may foster higher levels of insightful tactical play and greater participation by students (Harvey \& Gittins, 2014). This "videoedited game analysis" is a typical feature of post-game performance evaluations in competitive sport. However, in the physical education teaching context, where time is a precious commodity, video-based feedback is not very commonplace due to the time needed to set up the multiple pieces of equipment (Tearle \& Golder, 2008). Despite its potential, these and other logistical barriers may make teachers less receptive toward the use of technological resources (Pyle \& Esslinger, 2014).

Moreover, students' tactical learning may be facilitated by giving them a video analysis assignment as homework. One caveat is that such assignments require even more time (e.g., video editing) to prepare the assignment. The actual use of 
video analysis requires that the perceived practical limitations are solved (e.g., short preparation and editing times to produce appropriate video clips) and organizational questions are answered (e.g., which camera and software are needed, how to make the clips instantaneously accessible for instruction, how to minimize the class time needed for its use, which steps to take in applying the video clips in practice with students). When teachers recognize the ease of use and how it genuinely benefits student learning, it will become more likely that they will want to employ new technologies (Tannehill, Van der Mars, \& MacPhail,2015).

One important requirement for digital technology to be integrated seamlessly within game-based physical education lessons is that the video recordings related to the intended learning focus are immediately accessible. To accomplish this, a process called 'tagging' is available. Tagging refers to marking relevant events in the video recordings in 'real time' as opposed to technologies where key events are selected 'offline', after the recording has been completed (i.e., after the class is over). Tagging thus provides the teacher immediate access to the video footage that is deemed relevant to share with students. Students themselves can also use the tagging feature to select key events during the playing of the game. This may help support the development of the students' ability to recognize key events in a game, and it provides the opportunity to introduce other didactical tools such as 'debate of ideas' and self-regulation (Koekoek \& Walinga, 2014). Since most teachers have to split their attention among different situations and different groups of students, providing students with a focused tagging assignment affords them the opportunity to work independently during the lesson (i.e., without direct supervision).

The functions and features of video analysis apps are not always immediately appropriate for the physical education context. Therefore, digital video technology should be adjusted to the demands of physical educators' pedagogy (Weir \& Connor, 2009). This article will describe the process of innovating, introducing and developing a digital tagging application toward developing students' tactical awareness in playing sport games. Additionally, it will describe how physical educators can be supported in adopting digital video technology during physical education class. Some physical educators may be quite tech savvy and see technology's value and potential. However, not every physical educator can be expected to adopt innovative technology prima facie and become an "early adopter" (cf. Rogers, 2003). The adoption and integration of digital technology can be successful only if it is fused with teachers' pedagogical aims and didactic know-how. 
Important for physical educators' acceptance and use of technology is knowing how to navigate the technological possibilities. Specific to game-based approaches (GBAs) to teaching sport games, physical education's digitization thus raises several practical and research questions. How, for example, can the use of digital instruction and analytical video technology:

- Impact student game play performance?

- Aid teachers in their teaching and curriculum/program design and organization?

- Help students analyze their own movement performance on video?

- Help select and show the better performance examples to learners?

- Influence different types of feedback to be used?

- Help develop tactical game-play performance (e.g., better decision-making and tactical moves)?

- Help develop learner autonomy and self-management?

With the increasing expectation that physical educators should infuse technology in their daily work, their professional input is crucial (National Association for Sport and Physical Education [NASPE],2008). Certainly, not every technological innovation is necessarily suitable or applicable to the physical educators' workplace context. Moreover, thoughtless use thereof may well take away from students' learning opportunities by reducing physical activity time and/or practice opportunities. Rather, the key to using the right digital technology in the right way and at the right time is for physical educators to be more than just facilitators of learning. That is, they should be deliberate and parsimonious when considering the 'which', 'why' and 'how' of digital technology. Successful innovation depends on the integration of technological, pedagogical and content knowledge (TPACK; Koehler \& Mishra, 2009). Based on the work of Shulman (1987), TPACK reflects the integration of subject-specific pedagogical content knowledge (PCK) and technological knowledge (TK), with the latter being the new knowledge domain. This TPACK can emerge only when teachers can fuse (meld) these three knowledge domains. An important goal of TPACK is to challenge teacher preparation programs and sport pedagogy researchers to consider the role of teachers' practical knowledge and how they use that when deciding whether, in what way, and in what instances to use specific technologies in their lessons (Koehler \& Mishra,2009). 


\section{Frameworks for the role of technology in game-based}

\section{approaches}

Today, physical educators who employ GBAs to teaching sport games (e.g., Teaching Games for Understanding [TGFU], play practice) can draw on an emerging evidence base that also has support in the motor learning literature (Chow et al.,2007; Davids, Button, \& Bennett, 2008; Tan, Chow, \& Davids, 2012). Before discussing the potential of digital technology within GBAs, it is important to highlight one of its central features: its focus on having learners develop better decision-making skills during actual game play (e.g., Bunker \& Thorpe, 1986; Griffin, Brooker, \& Patton, 2005; Kirk \& MacPhail, 2002; Koekoek, Walinga, \& Dokman, 2009; Launder \& Piltz, 2013). For example, a basketball player must choose whether to shoot, pass to a teammate, drive to the basket, or continue to dribble to maintain ball possession; tennis players must decide which shot to use and where to place the shot given the context at that moment; baserunners in softball must determine whether or not to take the extra base. Decision-making lies at the heart of every action players take in game play and, thus, should be a central focus of the teaching-learning process within game contexts (e.g., Light, Harvey, \& Mouchet, 2014). This perspective is also supported by current theoretical frameworks about learning to play and practice (Chow et al., 2007; Gréhaigne, Godbout, \& Bouthier, 2001; Harvey \& Jarrett, 2014).

\section{Digital video-based analysis for developing tactical}

\section{decision-making}

One of the key principles of GBAs is that teachers create game conditions that are developmentally appropriate through deliberate game modifications for the number of players, field/court dimensions and equipment, player restrictions, scoring rules, and so forth. Its central purpose is to help students develop better insight into the tactical aspects of the game, together with learning to execute the techniques (i.e., controlling the object such as a ball or a shuttle), also referred to as "game sense" (e.g., Launder \& Piltz, 2013; Light, 2013). Student game sense emerges when they start coming up with better solutions to the two main questions: (1) What should I do?; and (2) How do I do it? (Bunker \& Thorpe, 1986; Griffin \& Patton, 2005). There is evidence that the learners' perceptions, conceptions of game play, fondness 
(or 'liking') of the activity, and social interactions influence the solutions they devise (e.g., Light, 2006; Koekoek \& Knoppers, 2015; Pope, 2005). Thus, since learning to make better decisions during (modified) game play is a complex process, it should be primarily student-driven rather than teacher-driven. This does not diminish the role of the teacher in any way, who must still design the right modified game contexts with a clear purpose (what Launder and Piltz [2013] refer to as "shaping play"), and monitor how students respond to that specific game context. Within that context individual students (but also the teammates) learn through self-organization based on the actions of teammates and opponents (Richardson, Sheehy, \& Hopper, 2013).

A form of game analysis that can complement and support the pedagogy of tactical decision-making is for players to be able to view their own and others' game-play actions on digital video (e.g., Harvey \& Gittins, 2014). Game video review has long been an integral part of preparation for subsequent games at the higher level of sport competition (e.g., high school, college and professional sport teams). Video review can also help teachers who seek to develop students' game sense, and it can support teachers' verbal instructions. By watching short videos together with teammates and conducting brief discussions around the tactical decisions made, student decision-making can be made more explicit and meaningful. Therefore, teachers can use the "debate of ideas" dialogue (Gréhaigne, Richard, \& Griffin, 2005) for developing students' tactical understanding (e.g., Storey \& Butler, 2010). The debate of ideas approach can be best viewed as a group discussion in which perspectives and opinions from players and the teacher are interchanged. This exchange can lead to new insights for students, thereby improving their tactical knowledge and awareness and increasing their versatility as players.

Before teachers introduce a debate setting and combine this with digital tagging assignments, players need time to get used to the game. The learning process starts with playing the (modified) game, where students get the opportunity to explore the tactical possibilities and demands presented by the teacher. Students need time to get used to the rules, their teammates, and the aim of different playing roles in the game. After a few matches of at least five to ten minutes each (and usually during a timeout or in between two matches), the teacher starts facilitating the group discussion between the observers (i.e., non-playing students) and players through open-ended tactics-focused questions (e.g., Harvey \& Light, 2015). Such a group discussion could last up to five minutes, depending on the students' attention capacity. The intended goal is for a team to develop a consensus on possible solutions 
to the tactical problem presented in the game. The debate of ideas is a didactic tool that can be supported by digital tagging procedures and digital video analysis. Teachers are able to connect students' perceptions about game-play performance to the intended learning focus of the game through the use of the right questions and prompts (e.g., Harvey \& Light, 2015). By using video-game footage teachers also can better align and focus the attention of students (Ste-Marie et al.,2012). Moreover, through video playback students can see themselves and others perform, even without the teacher verbally sharing his or her intention.

\section{Real-time tagging of game play as a learning tool}

Table 7.1 includes a series of steps and accompanying questions for teachers to consider when assisting students in learning to tag tactical situations while playing invasion games, such as basketball or soccer. In step 1 teachers design a game form that includes contextual modifications (e.g., equipment, team size, play space, rules, scoring) that are appropriate for the lesson's objectives and that allow players to practice the designated tactical moves (Koekoek, Dokman, \& Walinga, 2014). For example, a basketball game ( 3 vs. 3 ) on a half court supports the offensive players to learn when to try to score or to pass, and for off-the-ball players to take position in the court in order to receive the ball during offensive play. When it appears that players have difficulties deciding when to try to score on the basket, the teacher can modify the game into a power-play situation ( 3 vs. 2) to give the attacking team more passing choices and scoring opportunities. Such a modification is deliberate, as it intends to create an imbalance between the offensive and defensive teams (Travassos, Vilar, Araújo, \& McGarry, 2014).

In step 2 the teacher creates a rubric or guideline to define what key events are. Based on his or her observations of game play, a learning objective moves students forward in their development as skillful players. In the basketball example players in the offensive role may learn when and how to pass the ball to teammates when they find free space and/or take a position near the basket. Based on how the students respond in the game, teachers can then make further adjustments in the game's design (what Launder and Piltz [2013] refer to as "refining play"), thereby creating more authentic learning conditions. That is, the learning process can be focused on students' decision-making and their tactical play opportunities (Koekoek, Dokman, et al.,2014). 
Table 7.1 How to apply digital video analysis in education settings?

\begin{tabular}{|c|c|c|c|c|}
\hline STEP & DIDACTICAL PROCESS & PLAYERS & QUESTIONS TO BE ANSWERED & $\begin{array}{l}\text { EXAMPLE IN A MODIFIED } \\
\text { SOCCER GAME }\end{array}$ \\
\hline 1 & $\begin{array}{l}\text { a. Determine balance of play } \\
\text { b. Play the game and make } \\
\text { any necessary adjustments } \\
\text { to ensure balance of play }\end{array}$ & $\begin{array}{l}\text { Teacher or } \\
\text { student- } \\
\text { observer }\end{array}$ & $\begin{array}{l}\text { Which "tagpanels" on balance of play } \\
\text { provide reliable information?* }\end{array}$ & $\begin{array}{l}\text { - The teacher organizes } \\
\text { several matches with } \\
\text { different circumstances (team } \\
\text { compositions, field sizes, } \\
\text { adapted rules, etc.) } \\
\text { - Matches last at least } 5 \text { minutes }\end{array}$ \\
\hline 2 & $\begin{array}{l}\text { Present one or more } \\
\text { learning goals within the } \\
\text { game }\end{array}$ & $\begin{array}{l}\text { Teacher } \\
\text { working } \\
\text { with both } \\
\text { players and } \\
\text { observers }\end{array}$ & $\begin{array}{l}\text { - What learning goals are appropriate for } \\
\text { both players and observers? } \\
\text { - How can the learning goal(s) be made } \\
\text { more explicit through the use of digital } \\
\text { media? } \\
\text { - What is the students' reaction and } \\
\text { receptiveness to the use of video } \\
\text { records within the lesson? }\end{array}$ & $\begin{array}{l}\text { The forwards learn to choose } \\
\text { their position towards each } \\
\text { other (and the defenders) in } \\
\text { such a way that they can keep } \\
\text { possession of the ball }\end{array}$ \\
\hline 3 & $\begin{array}{l}\text { Propose students a tag } \\
\text { observation task }\end{array}$ & $\begin{array}{l}\text { Student- } \\
\text { observer }\end{array}$ & $\begin{array}{l}\text { - Which "game events" can students } \\
\text { realistically observe and capture "tag" } \\
\text { when observing the game? } \\
\text { - How many unique "game events" can } \\
\text { students capture with a tag panel? }\end{array}$ & $\begin{array}{l}\text { Students need to push the } \\
\text { button when they see a player } \\
\text { taking the right position }\end{array}$ \\
\hline 4 & $\begin{array}{l}\text { Play the game, with } \\
\text { observers engaging in } \\
\text { "tagging" }\end{array}$ & $\begin{array}{l}\text { Student } \\
\text { players }\end{array}$ & $\begin{array}{l}\text { - What are the students' experiences } \\
\text { with tagging a game? } \\
\text { - Which device can best support the } \\
\text { tagging task? } \\
\text { - What are the optimal tag panels for a } \\
\text { game in terms of the type and number } \\
\text { of events to be tagged? } \\
\text { - Which camera set-up works the best } \\
\text { to capture all game action? } \\
\text { - To what extent does varying the } \\
\text { camera location add to the quality of } \\
\text { the students' tagging? }\end{array}$ & $\begin{array}{l}\text { - The student-observer has only } \\
\text { one event to tag } \\
\text { - The teacher uses a WIFI action } \\
\text { camera that is positioned from } \\
\text { above so that the whole field is } \\
\text { visible and all the players can be } \\
\text { recorded }\end{array}$ \\
\hline 5 & $\begin{array}{l}\text { Compile/collect the "tags" } \\
\text { recorded by student- } \\
\text { observers }\end{array}$ & Teacher & $\begin{array}{l}\text { - How can student-generated tags be } \\
\text { made accessible with ease and in a } \\
\text { speedy fashion? } \\
\text { - How will tagged game events be } \\
\text { organized for subsequent review by het } \\
\text { student players? } \\
\text { - How can individual students' opinions } \\
\text { about the game events result in a } \\
\text { commonly agreed upon tactical plan of } \\
\text { action in subsequent game play? }\end{array}$ & $\begin{array}{l}\text { - The student-observer shows } \\
\text { the tag recordings to the players } \\
\text { - These clips are watched } \\
\text { by both the players and the } \\
\text { teacher } \\
\text { - With the 'play all' function, all } \\
\text { the clips are directly available } \\
\text { - Players of one or both teams } \\
\text { are watching the clips that } \\
\text { lasted } 3 \text { minutes }\end{array}$ \\
\hline 6 & $\begin{array}{l}\text { Ask the question: } \\
\text { Why did the student- } \\
\text { observer choose the "tag" } \\
\text { the specific key moments in } \\
\text { the game? }\end{array}$ & $\begin{array}{l}\text { Student- } \\
\text { observer }\end{array}$ & $\begin{array}{l}\text { What type of questions will direct } \\
\text { students to focus on tactical dimensions } \\
\text { of play? }\end{array}$ & $\begin{array}{l}\text { The teacher asks the player: } \\
\text { Why do you think the observer } \\
\text { has tagged these clips in } \\
\text { particular? }\end{array}$ \\
\hline 7 & $\begin{array}{l}\text { Conduct a time-out to have } \\
\text { a "debate of ideas" }\end{array}$ & $\begin{array}{l}\text { Student } \\
\text { players, } \\
\text { student- } \\
\text { observer, } \\
\text { and } \\
\text { teacher }\end{array}$ & $\begin{array}{l}\text { How can the teacher shape/direct the } \\
\text { debate of ideas? }\end{array}$ & $\begin{array}{l}\text { - The players give a few } \\
\text { responses to the teacher's } \\
\text { question } \\
\text { - The teacher facilitates } \\
\text { discussions and tries to direct } \\
\text { the discussion to one or two } \\
\text { plans }\end{array}$ \\
\hline
\end{tabular}




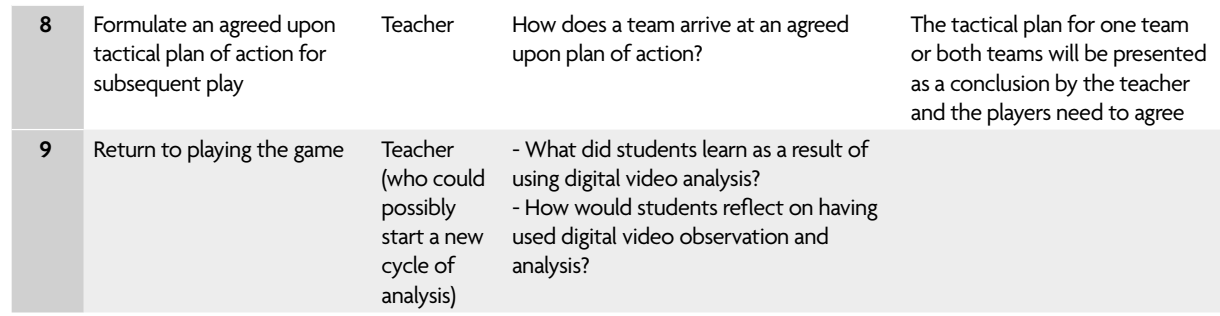

* The strength of the attack and defense of both teams by counting the percentage of scorings with respect to the amount of ball possessions of the attack (Koekoek, Dokman, \& Walinga, 2014).

In steps 3, 4 and 5 'tagging' takes on a prominent role. The modified game is video recorded, and key events are tagged in real time and are thus immediately available for analysis by the teacher. Not only the teacher, but also one or two students can take the role of observer (tagger) while eight to ten students are playing. The games consist of a maximum of eight players (e.g., 4 vs. 4 ) in order to achieve optimal learning and observing opportunities. Especially with students who have never analyzed tactics before, it is important to keep team sizes small. With the number of players in the teams increasing, it is getting more and more difficult for the observer to distinguish different phases and tactics in the game. It is therefore important that teachers are mindful of the following questions: (1) Can students successfully complete assigned tagging tasks?; (2) What do students themselves actually observe within the game that they view as pertinent when given a focused tagging task?; and (3) What types of tagging tasks are more appropriate, especially in the early stages of learning?

Returning to the basketball game, teachers should consider what the best instruction is for the students in identifying the passing of balls to teammates. Furthermore, the teacher should make sure that the observation assignment corresponds to the students' skill levels - for instance, whether or not they are able to analyze game tactics involving multiple perspectives, such as identifying the roles of offensive and defensive players at the same time. An appropriate tagging assignment ensures that the teacher's goals are aligned with the students' observation capacities.

Steps 6 to 9 emphasize the process of tactical group discussions with the students in a 'debate of ideas' session with video. Teachers need to support the observers in explaining their video tags to the group and moderate the discussion 
between observers and players. It is important that the presented video clips work as a clue to enhance tactical awareness and the agreement between players in tactical strategies.

Tablet computers equipped with cameras can produce relatively good digital video footage. There are now several examples of simple software (or apps) for game analysis that allow for tagging key game events (i.e., to mark or record) that can be retrieved and watched immediately after recording - for example, the VideoTagger (costs \$10.15 in the iTunes App Store; Robinson, 2014) and Dartfish EasyTag (costs $\$ 6.20$ in the iTunes App Store; Dartfish,2017). Both apps are compatible with iOS and Android. The Dartfish EasyTag app allows users to develop 'tag panels'. Tag panels are like a digital keyboard that a user can customize.

For example,tag panels can be created with separate tag buttons for game events such as ball possession, shot attempts, passes or turnovers. When a student who is assigned the role of observer identifies a turnover and hits the corresponding button, a 'tag' is registered immediately along with its time of occurrence. This type of information provides insight into the observation and analysis skills of the student. Moreover, it can provide the basis for subsequent assessments and discussions (i.e., 'debate of ideas') among students (and teachers) about decisions made by the players (e.g., Koekoek, Van Hilvoorde, Van der Kamp, \& Walinga, 2014). The next section shares some results of students' tagging behavior that have also become the basis for new approaches to game didactics and have provided direction for the development of a new video analysis app.

\section{Perceptions and tagging behavior of students in}

\section{basketball}

Before attempting to bring together the components of TK and PCK, the authors sought to answer a number of conditional questions related to students' observational capabilities using digital technology: (1) What types of and how many game-play dimensions can students observe simultaneously?; (2) How reliable are their observations (i.e., what would be the level of agreement between three studentobservers when asked to identify the same game-play events?); and (3) How can user-friendliness of the video analysis app be improved? 
The research project focused specifically on the perceptions and the tagging actions of 13-14-year-old students during a modified basketball game. Three students were given an observation task and were instructed to 'tag' three events (shots, dribbles and rebounds). To this end, a Dartfish tag panel of three buttons was used. Students were asked to watch a game for five minutes and press the appropriate buttons each time one of the three events occurred. The mean percentages of agreement among students in five separate groups are shown in Figure 7.1.

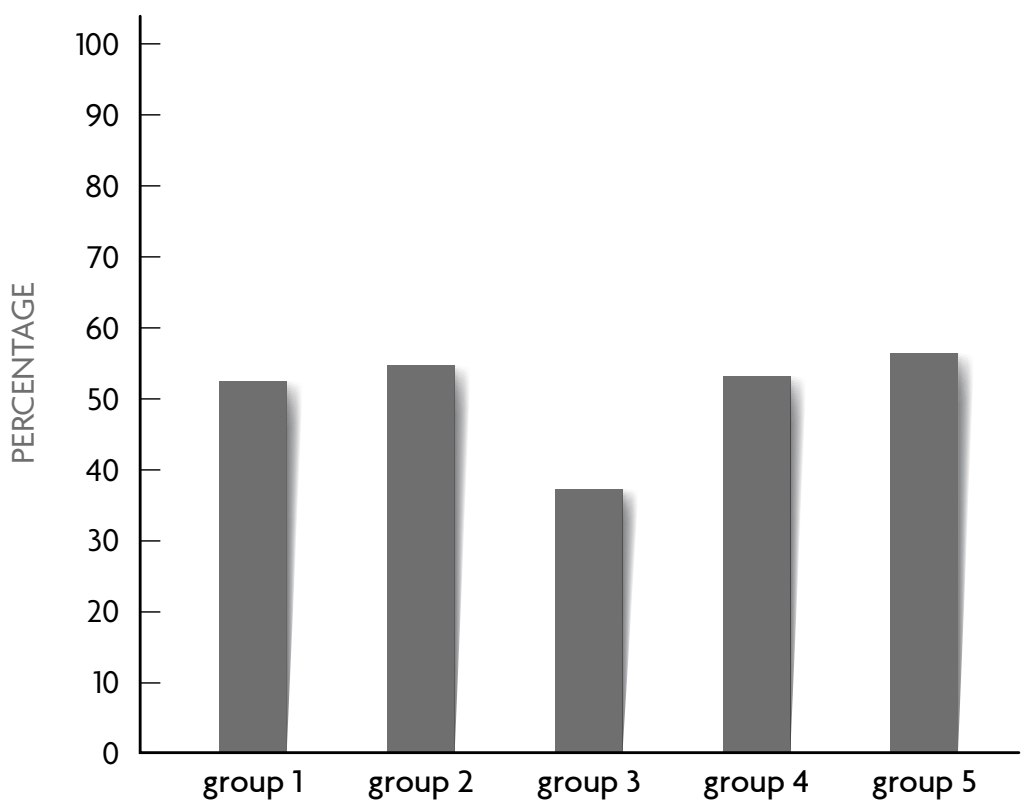

Figure 7.1 Student-observers' mean agreement percentages on tagged shooting, dribbling, and rebounding events across groups.

Taken as a group, the average percentage of agreement for identifying an event was approximately $50 \%$. That is, in almost half of the events students categorized an event (i.e.,'tagged') differently than one of their peers. This shows that, when asked to focus on multiple events of game play, students' game observation skills likely lack reliability, at least when they begin with tagging. And although the agreement improved by about $10 \%$ when asked to focus on one event only, students still 
tended to fail capturing key game events. It is also notable that reliability differed between events: students identified dribbles and rebounds much less frequently than the attempted shots, resulting in lower agreement percentages for dribbles and rebounds. The authors concluded from this that students need a reasonable amount of time to practice and would benefit from tagging one relatively frequent event only.

While this remains unstudied, the repeated use of tagging tasks (or other observation assignments) during various activities in physical education lessons may well contribute to students' reliability and accuracy in tagging. In addition, dedicated practice in tagging should focus on the dual task aspects of tagging. That is, it should incorporate practicing the motor component (e.g., as in blind typing, to push the correct button the student must know where the button is without looking) concurrently with watching the game. Another option for teachers is to have student-observers work in pairs. This allows the students to separate the motor and watching components. In addition, students can discuss what events to pay attention to and tag.

The pilot study also included interviews with the student-observers and players. They were asked whether the use of video-based game analysis added anything to their learning. The students especially valued reviewing the videos, because it helped them to learn from their mistakes. They also indicated that they preferred the teacher to be part of the review together with a small group of peers. The teacher could be the moderator in selecting appropriate images and leading the discussions while watching clips. The authors concluded that students' active engagement in game analysis is a potentially valuable tool. However, teachers need to be mindful of differences in observational capacities and the ability to recognize key events that students bring to the class.

\section{The technological development of video analysis for}

\section{the ipad}

Some teachers and coaches may already have some experience using game analysis and recognize the capabilities of video analysis applicationssuch as Dartfish EasyTag and VideoTagger. In the aforementioned pilot studies, these digital applications were used and tested to determine their practical application and students' 
observational capabilities and reliability in the physical education teaching context. These apps showed several limitations in user-friendliness for the PE context, such as the amount of time needed to select tagged video clips and accessibility to a clear dashboard, but also the availability of specific features (e.g., drawing, slow-motion play). Based on the insights gained from these pilot projects and with collaboration from a software company, the authors developed Video-Catch, a new video-analysis application (costs $\$ 6.45$ in the iTunes App Store; AppBakkers BV, 2017). Figure 7.2a shows the iPad-based opening screen, including four tag buttons.

In using Video-Catch, the user can customize the analysis focus by defining each tag button based on the technical and/or tactical focus of the lesson (e.g., ground strokes, passing, guarding/marking, off-the-ball positioning/movement, support). For each individual tag button, the duration of the footage of the event that is selected and stored can be set in advance within a bandwidth (the number of seconds) before and after the button is pressed (Figure 7.2b). The game can be recorded using the 'record' button, but only the game events captured with the tag buttons are stored. An uncluttered dashboard (Figure 7.2c) allows for quick retrieval and playback of clips. In play mode users can employ slow motion, can freeze the image, and can use a multicolored free-hand drawing tool (Figure 7.2d). In addition to using the iPad camera, Video-Catch can be linked to an action camera (e.g., Sony) using its WIFI signal. With that set-up, the signal from the action camera can be picked up by the iPad, and observers can tag key events.

\section{New knowledge by merging technology and didactics}

The use of VideoTagger, Dartfish EasyTag, and the subsequent development of the Video-Catch app have provided initial insight into how digital video technology can be infused into the physical education context when using GBAs to teach sport games. The didactic game structure supports the construction of a lesson plan, as shown in Figure 7.3. Didactics in GBAs can be broadly classified into three cyclical steps: (1) making direct game adjustments; (2) conducting a "game balance analysis"; and (3) providing tactical learning aids. In the first step the teacher presents a game design focused on achieving a balanced team composition, such as field, equipment and rules modifications. Beyond student enjoyment in being able to play, the goal is for the modified game design to be deliberate and directly linked to the goal of the lesson. 


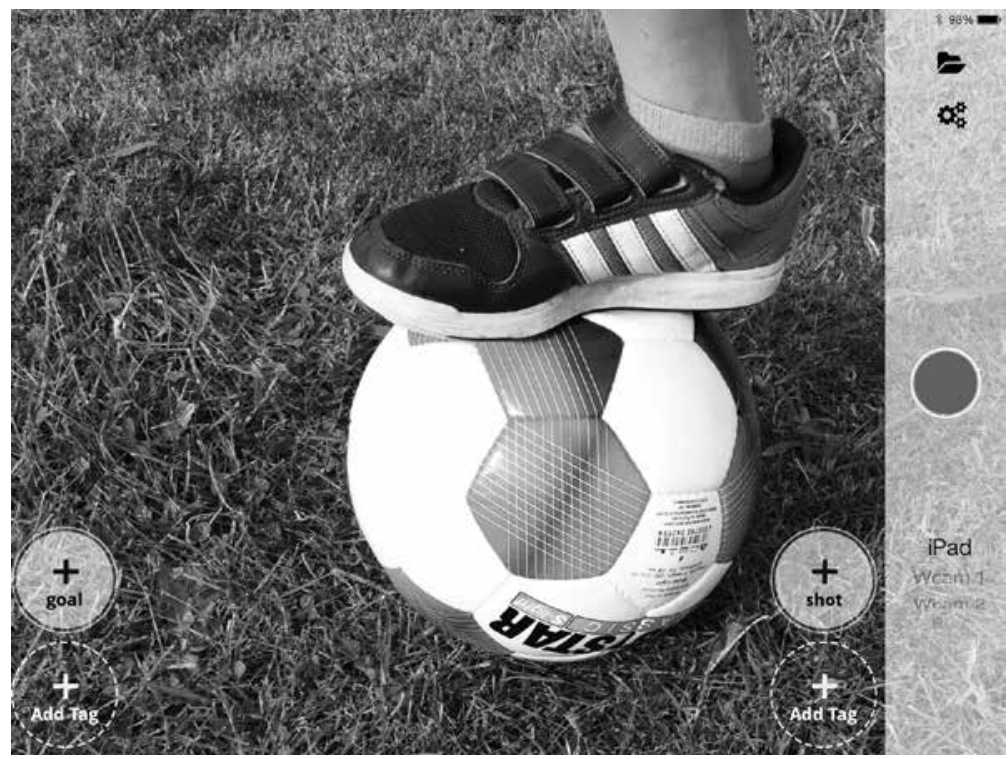

Figure 7.2a Video-Catch opening screen with four tag buttons.

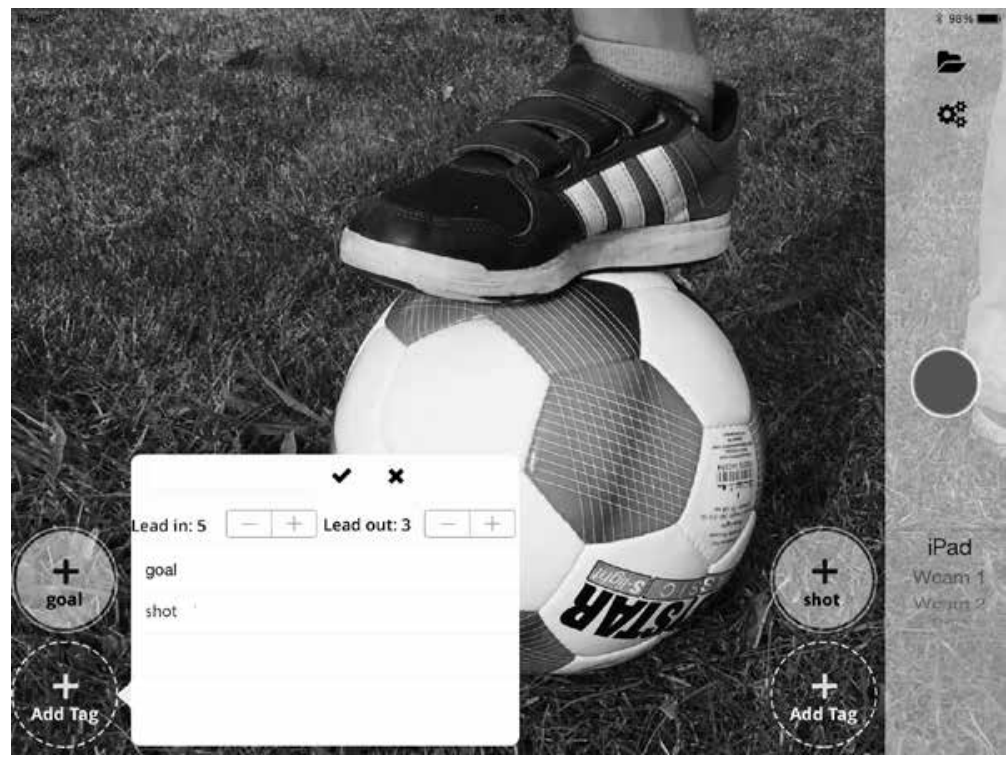

Figure 7.2b Setting up the duration and bandwidth of an event that is being stored. 


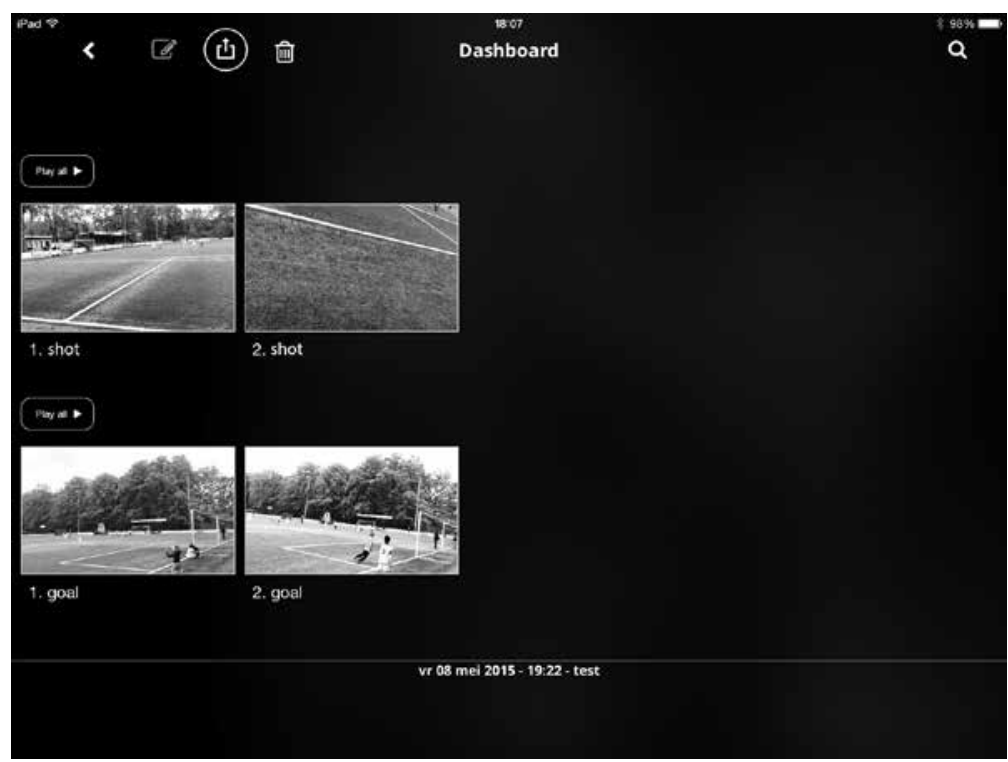

Figure 7.2c Dashboard sorted by tags for quick playback of video clips.

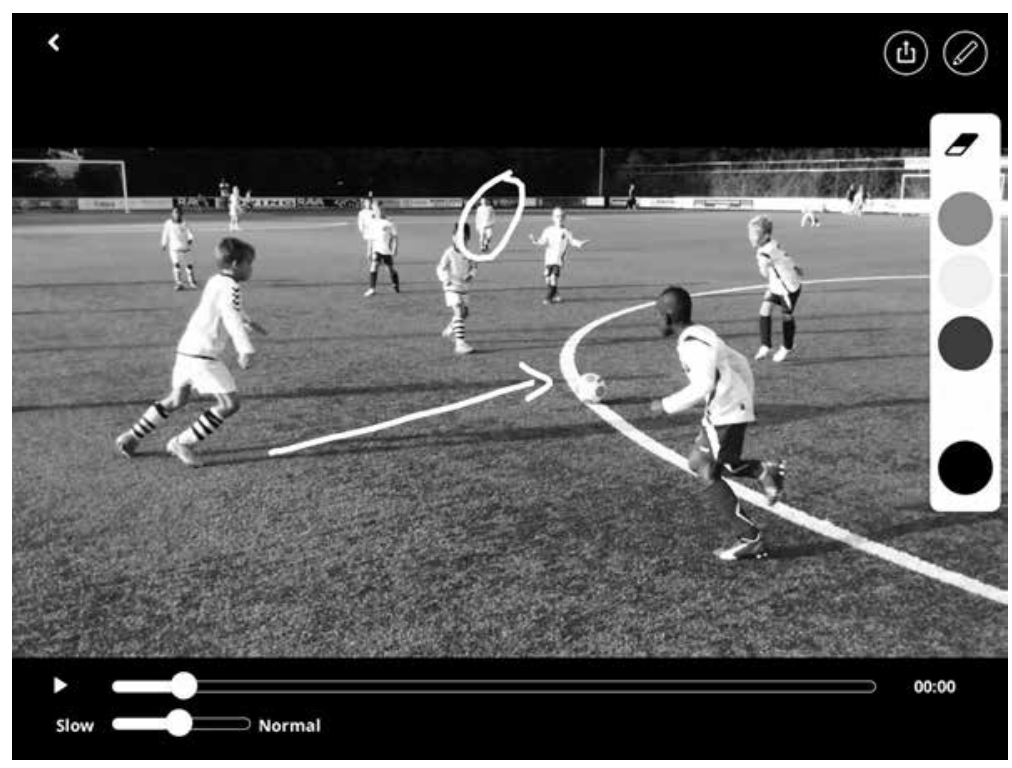

Figure 7.2d A multi-colored "free-hand draw tool". 


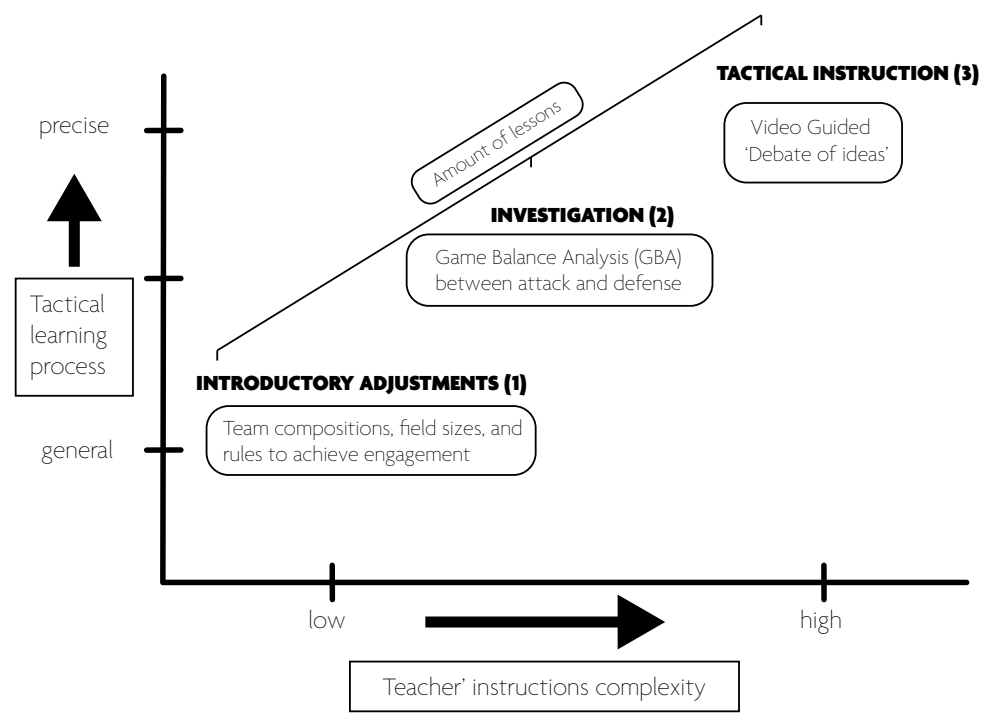

Figure 7.3 Didactic structure of a lesson plan by using video analysis in game-centered teaching.

A game balance analysis allows the teacher to determine the quality learning of the game by judging how well both teams' offense and defense are in balance (step 2; Koekoek, Van der Kamp, Walinga, \& Van Hilvoorde, 2014). Well-designed games are those with an even balance between the offense and defense. Balanced game play reflects a learning-rich game design. Conversely, if one of the teams is too dominant, learning opportunities are diminished.

When game scores become too lopsided (i.e., unbalanced offense and defense), the aforementioned step 2 is triggered through further game-design adjustments, as well as the employment of the debate of ideas (i.e., brief question and answer-focused timeouts). The goal for the teacher istoprovide learning support to a team or individual students. It is especially here that the use of video analysis can become meaningful to students. From a didactical perspective, infusing a meaningful selection of captured video images within a debate of ideas dialogue among or with students is perhaps also a more complex task for teachers. That is, it requires a seamless interplay between teachers' knowledge (and application) of tactical learning objectives, the use of digital technology, and the collection of relevant images (via instant tagging) directly into the lesson, and then leading focused discussions with the students. 
It is important to consider when it would be the right time and place to use digital apps like Video-Catch. The use of this cognitive learning aid is more appropriate later in sport game units when teachers seek to enhance play (see also Launder \& Piltz,2013). At the outset of a sport games unit students start learning about the game by developing a more general idea of the technical and tactical demands of the game (e.g., how to kick, shoot and pass; game rules, tactical problems to be solved). Only after several lessons will it make sense for teachers to employ the third step in the process by introducing the debate of ideas along with meaningful analysis of tagged video images, and to zoom in on the tactical aspects of game play.

It is in this third stage that teachers can support student learning by drawing their attention to specific game actions through the review and replay of captured video segments. The premise here is that providing teaching support on the tactical aspects of the game is easier when students see images of themselves and can reflect on them through brief discussions with their teacher. The captured video footage not only provides tangible feedback on what happened, but also encourages reflection about what is possible in the game tactically. Thus, the information garnered from Video-Catch, in combination with the use of the debate of ideas tool, places the teacher in a stronger position to support learning. As part of these brief debate of ideas discussions, the authors recommended that teachers make use of a "praise-prompt-challenge" approach (Koekoek \& Walinga, 2014):

A. Giving Praise (Compliments). Recording the game on digital video and tagging key moments of play enable teachers to compliment and reinforce students' actions during game play through positive feedback. The focus should be on reinforcing those actions that enhance the level of game play, rather than some arbitrary and rote form of praise. In particular, lower-skilled (or inexperienced) students have been shown to benefit from this type of teacher support.

B. Giving Prompts (Suggestions). Beyond merely observing the students' actions during game play, the tagging of key moments in the game is a way of helping teachers to focus on what prompts to use during the subsequent debate of ideas discussions. Teachers can now support their prompt (i.e., suggestion) through a replay of the captured video segment. Video analysis typically is chosen for a message that focuses on the execution of individual techniques (e.g., the execution of a backhand ground stroke in a racquet game). However, it can also be used to highlight students' tactical actions. Thus the key is to balance 
the technical focus with a focus on the contextual aspects that may influence students' actions (e.g., getting students to see the consequences of inaction or avoiding actions, such as a failure to get back to a central court position in a netcourt game or a pitcher not backing up the third baseman on a throw from the outfield).

C. Asking the Right Questions (Support Learning). Apps such as Video-Catch play an important role in framing questions that teachers want students to consider during the debate of ideas and when playing the game. It is here that students can be given ownership by being asked to serve as videotaggers (as opposed to the teacher) to capture key moments in the game. These can then be reviewed and discussed within their own teams. This will help individual players and/or a whole team to develop further as players.

\section{Implications for teachers, PETE faculty, and sport}

\section{pedagogy scholars}

Tannehill et al. (2015) noted that educators will generally respond differently to new developments on the technology front. Specific to the digital video technology presented in this article, infusing technology into daily instructional practices requires keen insight and decision-making to determine the true return of investment. Teachers will need to determine the cost and the time needed to learn to use the tool effectively during instruction. They also need to gauge whether or how the technology features enhance their own instruction and impact students' learning experiences.

PETE faculty may require professional development as well in order to effectively make the case for PETE majors to apply this technology and demonstrate the use thereof. Sport pedagogy researchers (especially those whose research focuses on the use of GBAs) should analyze the impact of digital video technology as presented here on student learning, as well as on teachers' instructional processes. Researchers interested in studying the use of such technologies not only should focus on how the combination of these technological and pedagogical innovations can actually foster student learning in game play contexts; they should also focus on developing a greater understanding of the teachers' use of technology in physical education as a central area of inquiry within this area (Mumtaz, 2000). 


\section{Conclusion}

This article described the process of innovating, introducing and developing a digital tagging application that can be combined with game didactic strategies for teaching tactical awareness in sport games. The development and amalgamation of both offers new insights into the appropriate time and place for using digital technology when using a GBA to teach sport games. Moreover, the technology was customized specifically for use in the PE context. As is the case with many other choices that teachers must make relative to instructional strategies, everyone should decide whether it is justified and useful to employ the digital technology presented here.

The essence of physical education remains to develop skillful movers, first and foremost. Within that context teachers typically instruct through verbal directions and instructions (e.g., prompts, feedback, questioning). The use of tagged video images that are immediately accessible can help students as they confront their own (and their teammates') actions in the immediate game context. The move toward incorporating digital video technology into GBAs within physical education is still in its infancy. However, the rich potential of technologies such as Video-Catch in supporting the development of skillful play among students deserves further exploration, experimentation and study.

New digital technologies will undoubtedly continue to emerge, and technology will likely continue to make further inroads into (physical) education. Thus, it may not be too far off to envision physical educators providing an iPad to each team in class with software such as Video-Catch already loaded. Moreover, students themselves will no doubt come to school with greater knowledge in how to use electronic tablets and the like. Especially in the case of sport education, students are afforded the opportunity to spend more time learning a sport activity, and they are expected to be more self-directed (Siedentop, Hastie, \& Van der Mars, 2011). Teachers might choose to dedicate class time to present a module on the use of the digital technology and the tagging process aimed at supporting game-play development. Sinelnikov (2012) already pointed to the potential value of using iPads in the context of sport education in support of learning to fulfill the various non-playing roles (e.g., coach, manager, statistician). The use of digital technology, along with tagging, constitutes a natural extension that can potentially support the development of competent players.

For more specific information (i.e., manual) about the Video-Catch software, please contact the lead author. 


\section{Part IV General Discussion}


Chapter 8

Discussion and conclusion 


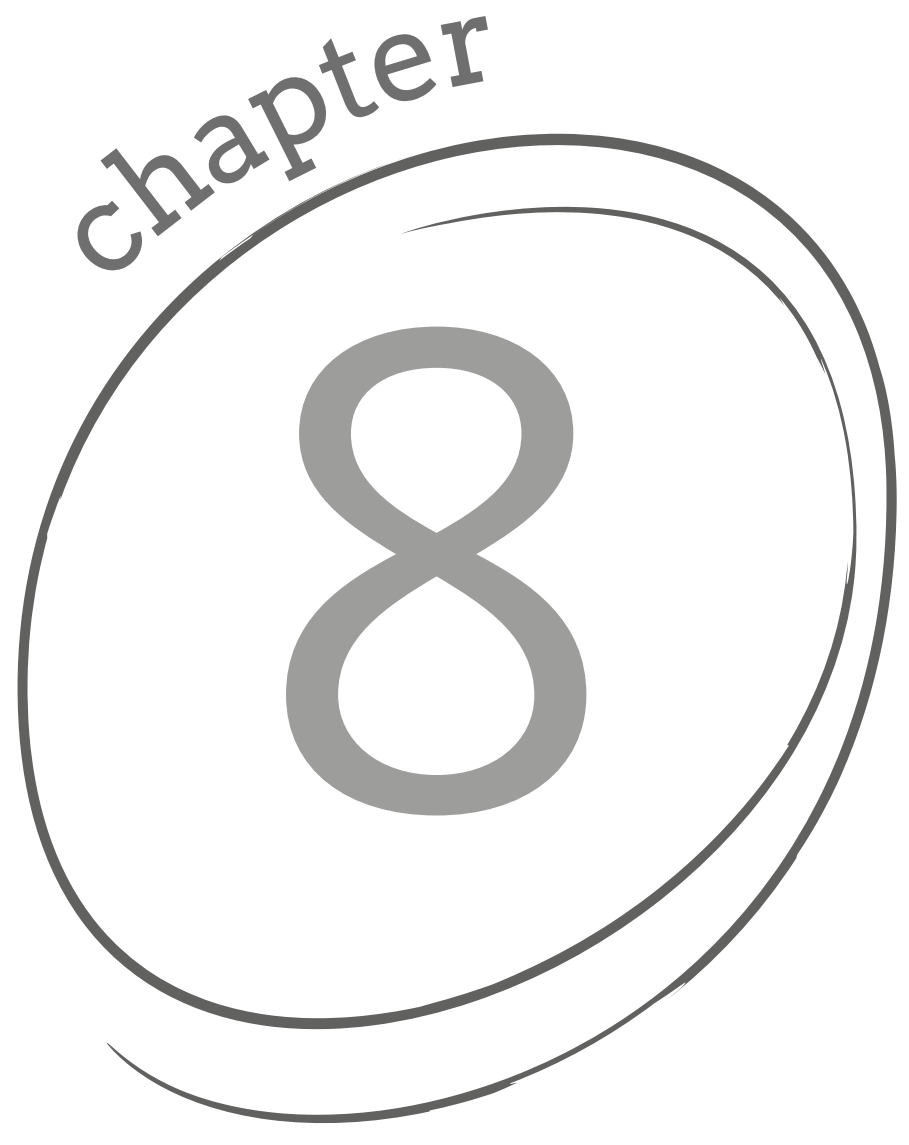

(176) 


\section{Discussion and conclusion}

In the general introduction (Chapter 1), I described my personal history with PE and sports during my youth. I reflected on my experiences with PE and I explained that I was not specifically aware of why, what, or how I learned during these lessons. This included my not being able to recall any awareness of how my enjoyment and skill development was informed by interactions with others during class. I felt competent and physically literate. My exploration of horizontal or peer interactions adds to the available knowledge and understanding of learning processes during task-related student peer interactions within PE in schools. In Chapter 2, I located current global thinking about the purpose of $\mathrm{PE}$ and described how Dutch PE is grounded in this thinking. Specifically, the chapter describes the context that drives curriculum initiatives in Dutch PE. These initiatives often include a focus on collaboration and assumptions about what that might produce.

The aim of this dissertation is to explore student perceptions of what they think about their learning processes in conjunction with collaboration during PE lessons. Since these perceptions are based on interactions that occur in $\mathrm{PE}$, my research projects focused on social constructions by students of their informal and formal learning. The central research question of this dissertation is: How do formal and informal task-related peer interactions constitute the PE curriculum? In Part II and III of this dissertation, I described several empirical studies that answer the following sub questions:

- How do children describe their learning experiences in physical education (Chapter 3)?

- What are children's perceptions of collaboration, group formations and friendships in a modified baseball game (Chapter 4)?

- How do gender constructions shape the way children form groups and how do they think these groups inform their learning (Chapter 5)?

- How do children perceive tactical elements in a game-based setting with video after a debate of ideas (Chapter 6)?

- How are student perceptions of tactical elements shaped by teacher use of a pedagogical tool that promotes task-related interactions within a game-based curriculum (Chapter 7)? 
In this Discussion chapter, I first briefly summarize the answers to the sub questions of the empirical studies from Part II (Chapters 3-5). Subsequently, I summarize the answers to the sub questions of Part III (Chapters 6 and 7). I then answer the central research question. I situate these findings in the research literature in my answers to the main question of this dissertation. This means I discuss the findings in light of what is congruent, dissimilar and new. In the second part of the remaining chapter, I reflect on the possible implications of these findings for the practice of $\mathrm{PE}$ teaching and PETE faculties.

\section{Summary of findings from the empirical studies}

\section{How do children describe their learning experiences in physical education?}

The findings of perceptions of learning processes in Chapter 3 revealed insights in how students experienced task-related learning situations in PE. In general, the participants showed limited ability in explaining their thoughts and feelings in their participation of PElessons. The results indicated that they constructed their learning in terms of concrete results such as gaining knowledge of rules or regulations in a movement activity. They articulated that such knowledge and understanding is part of what has to be learned in PE. Relatively few constructions of learning processes contained information describing exploration, communication, or negotiation in dealing with the task or with others. The students seemed to be limited by their vocabularies when trying to express their experiences of participation in a learning situation.

The results of Chapter 3 also indicated that students thought peers and the composition of work groups significantly influenced their learning. They constructed working together with friends during physical education classes as a very important element that shapes social processes in groups. The results revealed meanings they gave to experiences that might have influenced their learning. The meanings they assigned to the learning situation were related to their ideas about the teacher, their expectations of work group compositions, and how they perceived the role of friends. The amount of effort students wanted to put into collaboration played an important role in their meaning-making in assigned activities during a lesson. 


\section{How do children perceive collaboration, group formations, and friendships in a modified baseball game?}

The findings of Chapter 4 suggested that, similar to those participating in the previous project (Chapter 3), students primarily associated PE classes and playing games with having fun. These youngsters constructed that $P E$ as a place where they can hang out together. This perspective informed how they thought they could positively engage with others and participate in PE. The findings revealed what peer interactions meant for these children when collaborating during PE activities. These insights based on input from peers about their task-related interactions in playing a modified baseball game, revealed different dynamics that influenced the opinions of seventh and eighth graders about working together.

These dynamics are related to the input of peers based on formal and informal task-related interactions. Similar to findings in Chapter 3, I found that interactions with peers and friends informed these learning processes. This finding echoes those found in previous research in both PE (Hills, 2007) and music education (Miell \& MacDonald, 2000; MacDonald, Miell, \& Mitchell, 2002). The finding suggests that friendship relations contribute to positive task-related interactions. Music education research gives a possible explanation for this contribution. For example, Burland and Davidson (2001) suggested that groups consisting of friends may result in positive learning outcomes, because friends spend a lot of time together. This means they may have developed ways of working together and sharing ideas resulting in a higher quality of collaboration.

I also found (in Chapter 4) that student constructions showed contradictions in the preferences these students had for work group compositions. Friendships were perceived to have both positive and negative effects in a PE class when skills were taught within a modified game setting. This finding is in line with Beni, Fletcher and Ní Chróinín (2017), who reviewed studies that include meaning-making in PE. Beni et al. found that students themselves saw both the positive and negatives effects of working together with friends. The conversations in Chapter 4 revealed that these children changed their preferences as they gained more information about the demands and goals of the game and as their skills improved. 


\section{How do gender constructions based on processes of categorizations shape the way children form groups and how do they think these groups inform their learning?}

The results of the study in Chapter 5 revealed insights into the complexity of meanings students gave to task-related interactions in $\mathrm{PE}$, especially to group work and group compositions. The focus of the study was to explore how students made sense of the social construction of groups. The main finding from this chapter revealed that students created an implicit curriculum when engaged in task-related interactions in PE. Such curriculum consisted of social interactions in which students coded gender in their conversations by using words that are seemingly gender neutral. For example, friendships and classmates are seemingly neutral words that both boys and girls used. However, they used these words to refer to same gender groups. Their interactions were shaped by stereotypical gendered meanings they assigned to ability, attitudes, and expectations.

Table 8.1 consists of a summary of the main findings of Chapters 3-5 regarding informal task-related interactions.

Table 8.1 Summary of the empirical findings of Chapters 3-5.

\begin{tabular}{|c|c|c|c|}
\hline CHAPTER & $\begin{array}{l}\text { STUDENT CONSTRUCTION OF THE } \\
\text { LEARNING CONTEXT }\end{array}$ & $\begin{array}{l}\text { STUDENT PREFERENCE FOR TASK- } \\
\text { RELATED INTERACTIONS }\end{array}$ & $\begin{array}{l}\text { STUDENT EXPECTATIONS } \\
\text { AND DESIRES }\end{array}$ \\
\hline 3 & $\begin{array}{l}\text { Limited vocabulary to describe learning } \\
\text { processes }\end{array}$ & Friends constructed as fun & $\begin{array}{l}\text { Active involvement of } \\
\text { classmates } \\
\text { Having fun }\end{array}$ \\
\hline \multirow{2}{*}{4} & Within comfort zone & Peers with complementary skills & $\begin{array}{l}\text { Satisfactory performance } \\
\text { Active involvement of } \\
\text { classmates }\end{array}$ \\
\hline & Outside comfort zone (new tasks) & Friendships & $\begin{array}{l}\text { Enjoying/having fun } \\
\text { Support during participation }\end{array}$ \\
\hline & Group work & $\begin{array}{l}\text { Friends or classmates constructed as } \\
\text { same gender }\end{array}$ & $\begin{array}{l}\text { Receiving positive feedback } \\
\text { No laughing at mistakes }\end{array}$ \\
\hline 5 & $\begin{array}{l}\text { Group compositions } \\
\text { Same gender classmates constructed as } \\
\text { a static category }\end{array}$ & Same gender classmates & $\begin{array}{l}\text { Learning opportunities } \\
\text { Feelings of safety } \\
\text { Working hard, being serious, } \\
\text { and having fun }\end{array}$ \\
\hline
\end{tabular}




\section{How do children perceive tactical elements in a game-based setting with video after a debate of ideas?}

Chapter 6 described the students work in a TGfU setting and their structured debate sessions in between two basketball matches. During these debates, the teacherresearchers stimulated interactions and discussions between students. The results showed that their mutual agreement and accuracy in judging a tactical situation did not improve after these discussions. The findings suggested that the task-related interactions on the basis of discussions, whether or not they were streamlined with video, may have generated a large variety of tactical options. In other words, discussions and debates between students did not automatically lead to one single correct solution. However, the perceived learning outcome of students, who watched video footage, showed more consistency across students than in the verbally guided group. The quality of the horizontal interactions of the participants who worked in a formal model-based curriculum setting (TGfU) being supported by video footage, could have been improved as a result of the structured debate sessions. This finding indicates that those participating in the structured debate sessions may have become more involved with the focus on the position of teammates and opponents, in contrast to those students who did not watch videos and also showed a greater variety in answers. This could mean that the enrichment of debates with video footage may have enhanced the shared understanding of a complex tactical situation. When students engaged in formal task-related interactions such as 'debate of ideas' sessions, especially when using video footage, they were directed to focus on specific and detailed tactical situations in game-based settings.

\section{How are student perceptions of tactical elements shaped by teacher use of a pedagogical tool that promotes task-related interactions within a game-based curriculum?}

Chapter 7 presents the processes that may follow from these perceptions of tactical elements when teachers implement a pedagogical tool. Specifically, Chapter 7 refers to processes that promote task-related interactions within a game-based curriculum. The chapter suggests that observation tasks (e.g., digital tagging) and 'debate of ideas' sessions by students could be combined and may serve as a possible method for the analysis of video images of tactical situations. The results suggested that teachers must create several conditions to enable students to achieve quality interactions with their peers. The chapter suggests for example, that teachers/ 
researchers need to examine the observational capacities of students (such as their ability to observe a certain number of events), but also the composition of the groups (both in numbers and makeup), and what kind of opinions students bring into the discussions. The didactic structure presented in Figure 7.3 of Chapter 7 showed that the makeup of groups is one of the conditional factors that can contribute to the implementation of structured and formal interactions in lesson plans.

\section{Reviewing the central research question}

Student constructions with respect to formal and informal task-related interactions in PE were inductively explored. The overall outcome that emerged from the various results in the empirical studies in this dissertation suggests that informal task-related interactions create an informal curriculum that is based on the fear of being mocked, on gender categorizations, and on wanting to have fun. The ambiguity in these social constructions of learning tasks in PE lessons (e.g.,working together,assigned group work, debates/discussions) shaped the informal and formal curriculum in which they were situated. The findings in the empirical chapters suggest that peers influenced each other's preferences during group work, their thoughts about working together in specific work group compositions, and also their own expectations of learning outcomes and those of others. These task-related aspects refer to the social construction of working with others.

The results in this dissertation contribute to insights in dynamics that partly determine social constructions during PE classes. The findings are in line with PEliterature regarding ongoing reciprocity or horizontal task-related interactions in PE (e.g.,Beni et al.,2017; Casey,2017; Cox,Duncheon, \& McDavid,2009; Darnis \& Lafont, 2013; Domville, Watson, Richardson, \& Graves, 2019). These studies in general show that students value peer relationships and peer interactions during PE lessons. The valuing of peer interactions seems to have both negative and positive consequences for those involved in PE classes. For instance, Domville et al. (2019) found that peer interactions influenced enjoyment in PE when students had arguments, or when they considered the makeup of teams to be unfair. This finding is congruent with my findings about the dynamics in horizontal task-related interactions. Namely, peer interactions created meanings about groups and peers and a variety of preferences for group compositions. The review of Beni et al. (2017) that focused on meaningmaking in PE showed that student constructions of their preferences depended 
on their reflections about the quality of their own participation, ability, learning, achievement, and social/emotional well-being. In the next sections, I discuss the possible sources and frameworks that may explain the ambiguity and contextual processes of such horizontal interactions in $\mathrm{PE}$.

\section{Ambiguity of interactions within PE lessons}

In the studies comprising this dissertation, the preferences that the participants had for the composition of work groups provided me with additional insights into children's desire to have a choice and enjoyment in PE. Similarly, Domville et al. (2019) found individual preference to be an important factor that may influence enjoyment during PE. Preference in this situation refers to choices of students for certain sports and activities during PE. In the previous chapters I revealed how students also had preferences in working with their peers and in groups. These preferences may also have shaped expectations of others during group work. One such expectation was the desire to have fun in PE. The teenagers that I interviewed (Chapters 3-5) showed ambiguous considerations in their constructions of the desire of having fun and enjoyment in PE. Having fun in PE depended largely on how participants thought about the members of the group and how groups would work.

The way students constructed 'working together' and 'group compositions' provided explanations for why and when students varied in the meanings, they attached to these processes during PE lessons. One of the mediating factors was the construction of friendships during group work. Only a few studies have pointed to the dynamics of friendships as shaping horizontal interactions in PE classes (e.g., Cox et al., 2009; Hills, 2007). The findings in this dissertation revealed an additional perspective. The participants demonstrated ambiguous thoughts towards the role that friends play during PE. This suggests that children made sense of friendship relations not in a static way, but rather contextualized the meaning of friendship in relation to learning and the goal of an assignment. Friendships were valued in certain work groups during PE, but not in all work group situations. More specifically, the role of friendship in these PE classes was dependent on whether the emphasis in the task was on learning or performing, and on individual or team performance. Students may therefore initially have preferred to work with friends to enhance their enjoyment of the activity. When the nature and goal of an activity changed, 
their preference also changed. For example, when playing a baseball activity in pairs (see Chapter 4), students initially may have seen their friends as preferred partners. When teachers emphasized the learning objectives and required specific performance outcomes, children chose other (more competitive and skilled) peers than the classmates constructed as friends. A tension may have existed between their choice for feelings of comfort in being with friends, especially when these children lacked confidence in their own skill level, and wanting to be with highly skilled players to ensure what they saw as a good performance. This finding suggests that friendships could limit individual progress in PE but could also provide comfort and enjoyment during the learning of skills.

This finding extends scholarly explorations of the role of friendships in PE settings (Cox et al., 2009; Hills, 2007). The student perceptions of relatedness during PE in a quantitative study by Cox et al. (2009) showed that the acceptance of peers seemed to be more important than friendships in PE classes. Cox et al. found that sixth to eighth graders valued a general degree of acceptance by peers, because that acceptance may create more opportunities to interact with friends, and also provides opportunities for developing other relationships (e.g., with peers whose performance complements their own performance). The results of my research also demonstrated this process and showed how children negotiated their perspectives about friendships in PE. Namely, they seem to have negotiated the group composition, the learning objectives, and their expectations of others in order to construct their thinking about how they learn during PE. Subsequently, they may have seen other peers as more appropriate for collaboration than those they constructed as friends (not only for their comfort, but also sometimes because friendships distract from their learning).

This ambiguity is also in line with findings of Hills (2007) who explored the decisive influence of friendships in team games of 12- and 13-year-old girls in PE. Groups of girls were observed during game situations such as in basketball. The girls used passing the ball to teammates as a way to reinforce friendships. Consequently, passing to others seemed to work as a mechanism that contributed to the inclusion and exclusion of peers in the group. In addition to the findings of Hills, the teenagers' perceptions in this dissertation (see Chapter 5) showed that feelings of being excluded may be due to friendships relations, constructed as a result of gender categorizations. In other words, being excluded through not receiving passes or 
by passing balls to others were seemingly based on gendered constructions. Thus, students in Hill's study constructed preferences that informed their passes to peers.

The use of social constructivist theory may help to explain some of these results. In the next paragraph, I reflect on how these findings may expand the use of a social constructivist learning perspective.

\section{Contribution to social constructivist learning}

Social constructivist theories assume that when communication plays an important role in knowledge acquisition, social interactions are part of learning processes. Traditional perspectives on social constructivism highlight the decisive influence of the learner in what is learned during educational processes and how this learning unfolds. Social constructivism considers learning to be an active process that is directed by the learner. Vygotsky (1978) emphasized that social relations are fundamental for the way learners construct their knowledge. For example, language is originally a result of knowledge and assumptions that are developed through interactions and communication in the world (Davydov \& Kerr, 1995). The perceptions of students of interactions with their peers in learning assigned tasks in this dissertation revealed that how they perceived the learning context was related to others (see Chapters 4 and 5). These perceptions may have shaped their learning context and influenced their affective behaviors toward PE.

The findings in the foregoing studies suggest that the aforementioned perspective of a social constructivist framework regarding the position of the learner needs further consideration. Namely, the use of this framework means the individual learner is presumed to have a rather autonomous and subjectivist position in how and what is learned in educational settings. However, the framework and results of the various studies comprising this dissertation suggest that learning processes are also influenced by other factors such as the context, student expectations and preferences. Furthermore, learning is also shaped by habits, teaching rituals in the classroom, as well as cultural and historical experiences. For instance, whether or not children may know how to play soccer is also partly determined by the cultural context and the traditions in which they live (determined by the dominant sports in the country, their neighborhood, sports club etc.). Thus, a social constructivist perspective in PE could frame learning processes as being embedded within the 
relation between the learner and his/her environment in which students make constructions and give meaning to their experiences.

Two tenets of social constructivism about development and interactions as posited by Vygotsky (1978) may in part explain the overall results. Vygotsky argued that social and cultural realities play a role in learning considered as zones of development. The zone of actual development includes the current knowledge of the learner, but in particular the ability to acquire new insights in problem solving (i.e., finding solutions independent of others). In PE this could be, for example, searching for strategical solutions during game play. The zone of proximal development can be defined as "the difference between that which a learner can do independently and that which can be achieved with support of a more significant other" (Adams, 2006 , p. 252). For example, questioning approaches such as 'debate of ideas' may give the teachers the opportunity to bring the learners within their zone of proximal development (Harvey \& Light, 2015).

Since task-related interactions for PE are specific and constantly in flux, children's position towards the zones of development may also change. For instance, those participants who saw their peers as a source of distraction from their own learning in group work, may have felt constrained in engaging in interactions with others within the particular learning situation. According to them learning did not emerge, possibly because they did not perceive 'the others' as sufficiently knowledgeable. It can be assumed that they limited their interactions with others in the group because they saw them as not possessing sufficient knowledge or skill. This could mean that the skills and understanding of these students within the learning situation were outside their zone of proximal development, due to interactions with their peers. Developmental and age levels of the participants in this study may have informed this possibility as well. Possibly too, their insights of the knowledge skills of their peers may also change as they age. Obviously, longitudinal studies are needed to explore the perceptions of the children about their interactions with peers.

Horizontal interactions in PE are unavoidable and undeniable. The use of Vygotsky's zones of development, requires the zone of proximal development of each student to be aligned with appropriate task-related interactions. Teachers need to modify their instructions in assigned learning tasks to children's skill level to be congruent with this alignment. When students work together with peers within their comfort zone, this learning may not be automatically similar to their zone of proximal development. Namely, some of these youngsters may have had 
other reasons to participate (such as being required to do so, wanting to have fun or hanging out) rather than working to attain the next step or level in a learning situation. In contrast, students may work with peers who may have appropriate skills to achieve the performance tasks presented by the teacher, but the group may perceive failure for various reasons when trying to achieve the learning objectives. For example, some students may not value the collaboration, because they do not want to show their skills in public, do not like the activity, or show their failures to those peers who do not belong to the group of classmates that they saw as friends or being the same gender. These reasons the children gave may have informed the position of children with respect to their zone of proximal development.

Although these social constructivist learning processes are specific and related to the context of PE, similar processes also can be found in other contexts such as music education (Olsson, 2007) and sports clubs (see for example, a pilot study described in Appendix1). Such findings suggest that besides social interactions, other elements such as the 'perceived context' could influence the learning processes of adolescents. This means that horizontal interactions as part of social constructivism also are part of what has been called the concept of situated learning. This concept will be discussed in the next paragraphs.

\section{Task-related interactions are fluid and situated}

A recurrent issue that emerged from the various studies is that horizontal interactions, seen through the eyes of students, constantly changed their constructions of working on tasks in groups. This tension that emerged from the findings of Chapters 3-6 is inconsistent with the dynamics of friendship relations during collaborative work that have been found in music lessons (Miell \& MacDonald, 2000). Miell and MacDonald discovered that working together in pairs of friends positively influenced verbal and musical exchange during collaborative work. Collaboration between 11-year-old friends resulted in positive and quality interactions. These children could rely on previous experiences, anticipate effectively when sharing ideas, and work with greater efficiency by assigning each other specific roles and tasks. However, MacDonald, Miell and Mitchell (2002) found that pairs of friends did not result in a higher music composition performance than collaboration between pairs of non-friends. These studies showed that collaborative 
work with friends within music education lessons revealed different and contrasting results. Such findings seems to be similar to what I found in the empirical studies.

Although the participants in Chapters 4 and 5 initially preferred to work with friends, their constructions also contained ambiguous choices. The fluidity of collaboration in PE was reflected in the different and contradictory opinions the students had regarding the role and meaning of friendships in PE. For example, they recognized that in PE the nature and goals of the activity partly determined whether or not they thought the interactions would lead to positive outcome during group processes. Depending on the goals of the activity students may have had other preferences and expectations for the task to be mastered. For example, when the goal was on achievement and skill performance the children preferred to work with other classmates (than those constructed as friends). This means they then preferred peers who were seen as having a higher skill level. This finding reflects an emphasis in PE in which physical capability and achievement have a high social status and may be part of the functional curriculum for children at this age (Casey, 2017). Therefore, it can be argued that dependent on how teachers construct the learning context (whether or not it is linked with achievement), the expectations of students may shape their perceptions of collaboration and the task.

The insights in task-related interactions that have emerged in this dissertation contribute to understandings of how different constructions of a task can be explained. Since these interactions constantly changed due to expectations of peers, groupings and working attitudes, task-related interactions are not fixed processes, but fluid and contextual. This finding can be explained as situated learning, a concept that lies beyond the tenets of many social constructivist theories, but congruent with the premise that the learner constructs knowledge on the basis of social interactions.

Situated learning is a conceptual framework about learning that emphasizes the relation between an individual, an activity, and the environment (Kirk \& MacDonald, 1998; Lave \& Wenger,1991; Rovegno, 2006). Lave and Wenger (1991) have expanded the concept of the situatedness of learning processes. They contended that learning must be understood as a result of a range of contextual processes in which human beings participate and act. Congruent with the notion of situated learning developed by Kirk and MacDonald, student perceptions of task-related interactions in PE as described in this dissertation, highlighted the tension between different choices and preferences for work groups. These choices for working together with others 
that I found in Chapter 4 depended on how students perceived their skill level compared to their peers. Specifically, the judgements of peers about skill levels of others seemed to have been an influencing factor, because these students do not want to be seen as the weakest player in the group. The ambiguity in student choices showed the fluidity of task-related interactions with respect to their preferences for working with friends on one hand, and highly skilled classmates on the other.

The public character of PE may also influence the situatedness of the context. The uniqueness of PEmay shape learning that goes beyond group work. The findings in this dissertation revealed insights into the public and collaborative nature of performances in PE. Although both music and PE require public performance, their context perceived by students differs in several ways. The embodied presence that is required in PEcould be assigned more importance by participants than when they must perform and play together in a music setting. The body is currently highly valued in Western society (Van Amsterdam,2014). As Chapter 2 suggests, PE is often assumed to be the place where the body is to be disciplined by and into various norms such as those pertaining to health. Research (Beni et al., 2017; Domville et al., 2019) has shown however, that learning skills in PE is not equally valued by all students in PE classes. Girls and boys, for example, may experience PE lessons differently as the literature cited in Chapter 5 indicates. These differences in perceptions illustrate that student expectations of peers during PE are part of the situatedness in learning processes.

Teachers and peers may have explicit and implicit expectations of girls that could marginalize their performances in PE. Those girls participating in the studies in this dissertation seemingly wanted to be with friends and sought comfort when required to work in groups. Similarly, several boys who participated in the studies also articulated that their reasons for choosing peers for collaboration went beyond improving performance. This notion highlights the situatedness of expectations during group work. However, it raises the question whether the participants in this dissertation actually valued improving their performance and positive collaboration in PE lessons. I did not focus on the importance students attached to working collaboratively in PE. Future research could explore relationships between desired group composition and the importance assigned to learning a specific skill or (publicly) performing in PE.

The role of the sport context related to PE in schools is another aspect that could have informed the findings. Children may experience PE as strongly related 
to sports. Chapter 2 describes how this is the case in several countries in Europe. In most of the studies in this dissertation the participants had PE lessons that were based on adapted, small-sided activities (see Chapter 2 regarding TGfU, and movement education). These activities presented by the teachers were grounded in a perspective that criticizes traditional sport conventions that seem to value performance and highly skilled performers (Harvey \& Jarrett, 2014). However, many Dutch children are members of sports clubs (Van der Poel, Hoeijmakers, Pulles, \& Tiesssen-Raaphorst, 2018). The findings in this dissertation (including those related to gender and performance) could have been in part developed at the sports club. The grounding of teaching in anti-traditional sport conventions does not automatically mean that children can erase experiences they may have had in sports club contexts. For example, these children may not have been selected for specific (high performance) teams, may have been found inadequate, laughed at, or praised for their performance in sport. Regardless of such experiences, it can be assumed that if most children are involved in a sports club, then they may have been socialized in wanting to perform well. Their experiences of group work at sports clubs may lead to different and dynamic constructions and expectations for group work in PE classes. ${ }^{7}$ Yet, $\mathrm{PE}$ is a site where everyone is involved, not just the children from the sports club, so this may produce heterogeneity and situatedness in the results. When teachers implement a game-based approach children may bring different sport cultural perspectives into their horizontal interactions. A future study in which children are asked to describe and compare their experiences in sport and PE could expand insight into the dynamics of situated learning in collaborative work.

In the previous sections, I elaborated on social constructivism (including zones of actual and proximal development) and situated learning as frameworks that may explain the ambiguity of children's perceptions about task-related interactions in PE (Chapters 3-5). The concept of affordances could provide a bridge to explain the results of the studies focusing on collaboration as part of the formal curriculum (Chapters 6-7), and the relationship with the perceptions obtained in the informal curriculum (Chapters 3-5). The relationship between affordances and task-related interactions in PE are discussed in the next section. 


\section{Social interactions as an affordance}

The situatedness of task-related interactions may occur on the basis of affordances (Gibson, 1977; 1979). From the perspective of the ecological approach of Gibson (1977), affordances can be understood as opportunities or possibilities for action. These opportunities originate in the relation between the learner's capabilities and what the learning environment affords. Rovegno (2006) described affordance as "... the possible use, meaning, or function of something in the environment in relation to the individual's capabilities, goals, and intentions" (p. 263). For example, students learn and become influenced by the opportunities that they have been afforded when participating in an educational learning setting. When students play a game, the constitution of the learning situation affords learners different solutions depending on their action capabilities (Withagen \& Van der Kamp, 2010). Gamebased learning situations afford students different opportunities determined by the context of the game. For example, as the results described in Chapters 3-5 suggested, the makeup of teams may influence the group when students have expectations of peers and groupings. These expectations can be seen as social affordances that played an important role in the desired group formations.

Rietveld and Kiverstein (2014) argued that affordances can be understood in ways that go beyond a sole focus on motor abilities. This broader understanding of affordances also includes the situated context. The individual (performer), the task and the environment serve as constraints and enablers (Renshaw, Chow, Davids, \& Hammond, 2010). Task constraints (e.g., boundary playing areas, adapted rules, equipment, number of players) and environmental constraints (e.g., peer groups, social norms, cultural expectations) may influence student learning (Chow, Davids, Button, Shuttleworth, Renshaw, \& Araújo, 2007; Davids, Button, \& Bennet, 2008). The quality of relationships that students perceive is partly based on what they afford in a collaboration. Students can afford both positive and negative experiences based on the constitution of the groups in which they practice the skill or assignment. The children participating in Chapters 3-5 therefore functioned as peer constrained and enabled achievements.

Based on the finding of the studies described in this dissertation, I suggest that task-related interactions grounded in student expectations of peers need to be considered as a possible affordance influencing a learning situation. For example, when peers work together on tasks, the expectations of the group members can be considered as 'opportunities (or limitations) for action'. The composition of a group 
may constrain what individuals bring and expect of the performance, or efforts of others. Throughout the assignment, these expectations of peers may determine what actually occurs in work groups. For example, peers can make decisions during a game that afford opportunities for collaboration and communication. However, they could also distract other members when they are not able to make a contribution in tactical discussions.

Thus, task-related interactions between peers not only serve as an enabler of performance as Chapters 3-5 suggest, but can be also seen as a constraint that influences the quality of the learning context. Ovens and Godber (2013) connect the idea of constraints to affordance networks. Affordance networks are social structures based on the connections between individuals and "exist as a result of friendships, common interest, or through a relationship of beliefs, knowledge or prestige" (p. 56). These affordance networks, based on connections between individuals, are influenced by social interactions. The way individuals interact in a social context provides an affordance for learning within a social network.

The critical perspective on the working attitudes of group members that has been perceived by peers interviewed in Chapter 4, may show how such perceptions can work as an affordance during these processes. The participants were able to articulate their expectations for their peers in collaborative efforts. Here, it can be suggested that when peers afford a positive working attitude to group members, ongoing reciprocity may occur, that is, their peers may respond in a similar manner. Barker and Quennerstedt (2015) investigated power relations during group work in PE. The researchers explored cultural norms in PE classes and the related social actions students used during group work (e.g., following, contradicting, ignoring). The researchers found that the combination of these actions shaped the behaviors of group members when working together. The study of Barker and Quennerstedt showed that interactions afforded student actions and cooperation between peers. Group members contributed to the performance when they demonstrated an action, explained a strategy or manipulated others in the group in order to achieve good results. But the researchers also found that less visible social actions such as listening, being quiet or being in-active, also contributed to group performance. This finding is in contrast with the argument voiced by participants in this dissertation, that inactivity and perceived working attitude may distract from the quality of group work during PE (Chapters 3 and 4). In other words, perceptions of a negative working attitude afforded negative collaboration. The type of task (dance and fitness) and the 
age of the participants in the study of Barker and Quennerstedt might explain the difference with regard to the findings in my studies.

The strong influence of peers as described in Chapters 3 to 5 may also explain the results that emerged in Chapter 6. Participants in the study of Chapter 6 played basketball on small-sided courts, which was a fairly new experience for them. These students did not receive any instructions about possible solutions that could contribute to realizing the learning objective of the lessons. The relative inability of students to judge a situation in basketball suggest that the quality of processes of collaboration during debate sessions was low. Students may have considered the new, unfamiliar learning situation and task-related interactions as a setting that was beyond their comfort zone. Their preferences for peers (i.e., friends, see Chapter 4) and expectations of work groups may have worked as an affordance that explains the large variety and limited agreement in their judgements of a tactical situation in basketball. These results suggest that teachers continually need to evaluate and experiment with different approaches to attaining objectives that constitute the formal curriculum. The results of the studies in this dissertation suggest that students responses to tasks involving peers emerge from the conditions comprising the context (situated learning) and affordances.

\section{Limitations}

Qualitative research methods such as interviews and observations are often used to explore children's perceptions in PE (see for example, Burrows, Eves, \& Cooper, 1999; Carlson,1995; Sanders \& Graham, 1995). A pitfall is that researchers, especially those who also work as teachers, may use their own interpretations of what children perceive in learning (Easton, McComish, \& Greenberg, 2000). In this case, I also had to deal with the complexity of interviewing youngsters in school settings. I tried to circumvent this by using various methodologies (see Chapter 3). I used a grounded theory approach to explore, in different phases, the appropriateness of several qualitative methods in order to reflect on whether or not children are able to express their thoughts and feelings. Chapter 3 provided insights into different methodological issues regarding the way students expressed themselves about learning skills in physical education. In addition, these students articulated thoughts about what learning skills are involved in $\mathrm{PE}$, which also provided some pedagogical implications. The data showed that the use of focus group interviews in 
combination with draw and write/tell procedures were more successful in obtaining information about children's perceptions than individual interviews or draw and write techniques alone. This combined approach to focus group interviews may have reduced the role of the researcher as interpreter in the discussions. I used these qualitative methods in Chapters 4 and 5.

Moreover, I acknowledge possible difficulties with the line by line coding procedures (Allan, 2003). The different schools and PE settings may have caused confusions during the analysis processes of collected interview data. For example, in one study (Chapter 5) the same interview topics were used for different classes and schools. Although these schools had similar PE curricula, the PE classes and dynamics are always unique for each context (e.g., group sizes, equipment, gym, rituals). Although I attempted to explore congruent learning contexts as much as possible, I do acknowledge possible differences when making constant comparisons of interview data. Memo writing was used to address this complexity that supported the iterative processes of the data collection and analyses in order to understand possible differences between contexts.

In Chapter 6, I used a mixed method approach to explore student perceptions about tactical events in a game. Several limitations regarding this methodology are already described in this chapter. The data collection took place directly in the PE classroom with the aim to approximate the context of regular PE lessons and achieve a high degree of representativeness as much as possible. Digital video tagging was used to explore the appropriateness of this approach in gathering student perceptions. I acknowledge the relatively low number of participants in the quantitative part of the study, which made it difficult to generalize these effects to a larger group. The aim of the methodology in Chapter 6 was not to generalize regarding both methodological procedures, but to increase the reliability of possible differences between two student groups who worked with different pedagogical tools resulting in a form of triangulation. Further research may focus on finding ways to explore what students actually say and how they interact during debates of ideas sessions. For example, the communication processes between students during debate sessions could be audio recorded. Such method may inform how children react to each other and negotiate meanings of possible strategical solutions.

Another limitation in the empirical studies could be located in the meanings these middle schoolers articulated during the focus group interviews. For instance, in the interviews used in Chapters 3,4 and 5, students described difficulties they had 
with group members when working together in groups. Some of them explained that the quality of the learning outcome decreased, especially when they had to work together with specific children (i.e., those seen as embodying the same gender or as lacking a 'serious' attitude towards the task). Although these children explained the possible negative outcomes of a work group, I did not explore whether or not these outcomes actually reflected decreased quality of performance. The student or group learning outcomes were not measured since the central aim of this entire dissertation project was to explore the underlying dynamics of group work in PE. Future research could include both participant views, as well as the results of group learning outcomes in order to determine whether or not their perspectives are congruent.

Similarly, children in the Chapters 4 and 5 indicated that they wanted to work together with friends and have fun instead of performing well in the group. However, I did not explore the reasons and motivations these children attributed to participation in PE. An understanding of what youngsters value in PE may give teachers a cue for ways to organize PE lessons and assign group compositions. The findings raised new questions regarding task-related interactions. For instance, why do children change their attitudes towards group work when they make categorizations of their peers? Why do they think their performance will decrease when they work in certain group compositions? What occurs during task-related interactions such as debates, and how can physical educators guide the dynamics that are part of these discussions? In the next section, I reflect on the findings and the implications of my studies by attempting to link the empirical evidence with the practice of $\mathrm{PE}$ and future directions of development for teacher educators and researchers.

\section{Future directions}

In this dissertation, students described in various ways their thoughts about what they learn in PE lessons. The results have shown that task-related peer interactions influence student preferences such as their expectations of peers during collaborative work. These interactions shaped both the informal and formal curriculum. These findings suggest that although learning objectives for PE may look transparent, operable, and applicable for seamless use in a quality $\mathrm{PE}$ curriculum, other dynamics may also occur and influence teaching goals when 
children come together in PE classes. Informal and formal curricula contain aspects and processes that are fluid and contextual. The context of PE lessons is unavoidably a site for peer interactions.

Social interactions during PEclasses are therefore considered to be a permanent aspect of Dutch standards in the future (Curriculum.nu, 2019). This means that collaboration and communication by students with their peers continues to be important in PE lessons. According to Curriculum.nu (2019) this means that students:

\section{... become aware of their role and behavior and those of others during movement activities. They learn to work with and accept their own abilities and those of their peers.}

This standard says little about the pedagogical skills teachers should use in their lessons. Based on the findings of the research described in this dissertation, I contend that children need to be taught to interact in ways that do justice to differences in ways of doing and being in the group. Consequently, teachers need to find appropriate solutions to manage this challenge. Teaching PE with an explicit and substantial attention for social interactions in lessons implies that teachers acquire several didactical skills to enable them to prepare lessons, teach movement activities (e.g., classroom management, communication with students, observing, giving prompts etc.), and evaluate lessons. These need to be part of the pre-service curriculum.

The results of the various chapters as well as the scholarly literature strongly suggest that the makeup of groups or teams is a crucial aspect dependent on the classroom climate, the relationships between students, and the previous experiences the teacher had with the class. Thus, teachers can consider beforehand which students may work together and what kind of dynamics during classes can be expected. In their lesson planning teachers need to reflect on the nature of the desired or needed group composition as it pertains to the kind of movement activities being taught and what the class needs. For example, are these activities introduced for the first time, do they consist of competitive elements, or is differentiation by skill level needed?

Depending on the answers to these questions, teachers can use different procedures in the forming of groups to achieve the needed collaboration. For 
example, instead of assigning numbers to students (e.g., by counting 1, 2, 3 etc.) that result in groups that are created randomly, teachers may deliberately assign students to specific groups. Children (and pre-service teachers) need to be taught possible ways of constituting a group and giving voice to all. This means that students could also have a free choice for choosing peers with whom they want to work. Since teachers direct and choose the method, they also should acknowledge student input even though this may undermine their feelings of authority in class.

Another possible application of the results of my studies for PE teaching practice is the kind of interactions required of students and their role in determining the nature of these processes during a lesson. Although most preferences and expectations of children are often not explicitly stated, teachers may require students to explain and express their thoughts and feelings about collaborative work. In other words, in some situations teachers may give students space and time in order to reflect on their implicit meanings. This information can be used in such way that necessary adjustments can be made in order to achieve a rich learning environment. For example, students could have discussions during basketball activities. These debates could be an opportunity for students to express their thoughts about interactions with classmates during collaboration (e.g., how to attack, defend or when shooting etc.). Therefore, students (and teachers) need to acquire skills that enable them to critically reflect on their experiences in groups. Moreover, this also requires learning to engage in ongoing reciprocity, by seeing and accepting their classmates' needs. This also means teachers need (to learn) to facilitate a positive atmosphere in which preferences and expectations can be shared in a safe manner.

Since PE is a place where students often interact, it is crucial that teachers find ways that enable students to express their concerns and desires. Teachers need to be aware of which children in the group have a decisive influence by being too normative or controlling in what is desirable behavior (e.g., having chats, playing for enjoyment or performance etc.). Pedagogical tools that enable teachers to see these dynamic processes that occur during workgroup interactions would need to be integrated and incorporated in pre-service and in-service instruction/courses (see for example, Dokman, Van Beusekom, Oldeboom, \& Pepping-Poot, 2018).

PE teachers may also use a didactical observation model for PE that takes into account student interactions (Walinga \& Koekoek, in press). This model includes a focus on possibilities for organizing and planning lessons. Teachers are invited to 
analyze the constitution of the learning situation and how collaboration between peers could be organized. This tool requires teachers to analyze the learning situation and determine whether or not this situation consists of well-defined rules and an appropriate regulation of processes. In such an environment children may feel safe and know exactly what is expected from them and what they can expect from their teacher and their peers.

Another element that requires attention in the observation model of Walinga and Koekoek is the level of communication in class (including interactions). Interactions between peers are often differentiated due to incompatibility between student interests and that of the teacher. This means that teachers must (learn to) recognize how/when students provide space for others (e.g., by giving suggestions, solutions, or taking initiatives etc.) and how that is related to the space these classmates give to them.

The PE curriculum and PE professional development in the Netherlands seem to be moving towards a closer synthesis between what children experience outside school, in their neighborhood and in sports clubs (Van Berkel \& Hazelebach, 2016). PE teachers have become more involved in these contexts, especially in neighborhood and club sports. Although physical education takes place in a context where children experience participation rather differently than in sport, the growing attention for social aspects in PE may also be of interest for these other related contexts in which children are physically active. Claringbould, Knoppers and Jacobs (2015) for example, explored how young athletes experienced their relationship with their coach at the sports club. The athletes in this study became aware of the informal rules that coaches expected regarding performance and winning instead of having fun. This finding but also other factors (e.g., race, gender) suggest that a hidden curriculum may be part of sports clubs as well (see for example, Harrison Jr., Azzarito, \& Burden Jr., 2004; Larneby, 2016).

Nevertheless, a focus on peer interactions in the context of youth sport needs to go beyond sport pedagogical methods and interventions. The study presented in Appendix 1 may function as an example of how my research methodology also could be used by sport coaches at sports clubs. The paper demonstrates the recognition of eliciting perceptions of players regarding their experiences of practices. The study shows how perceptions of these processes during practices may inform the development of didactical tools that enable coaches to create rich 
learning environments for players. By conducting similar research methods - as in Chapters 3-5 - in other contexts scholars and educators could learn more about what learning environment for children can be afforded when children work with peers, teachers or coaches.

The social dynamic between peers in PE classrooms that I have shown in my dissertation also emphasizes that researchers and teachers need to take a critical position towards the application of teaching or coaching methods. Fixed pedagogical models are characterized by pre-structured lesson plans with defined activities, well-designed organizational structures, and standard teaching instructions functioning as normative solutions for seemingly general recognizable issues in the classroom. The results show a fluidity in processes during interactions suggesting that clear-defined, so called fixed pedagogical strategies may not contribute much to effective implementation in PE teaching and PETE faculties. Pre-service teachers may initially benefit from this knowledge that exists in pedagogy books or has been learned during PE didactical courses. Yet, when they come as teacher into the classroom and meet the students, the situated context and its dynamic processes require more than a "one-size-fits-all" pedagogy ${ }^{8}$. Peer interactions in PE also require the use of interventions that are contextual. Future research is needed that explores how teachers can be best prepared in their teaching and which didactical tools can be created and applied that support them to guide these dynamics in student learning processes.

The incorporation of PE pedagogy is however, often a pluriform endeavor and influenced by different contemporary theoretical (educational) approaches (e.g., Biesta, 2015; Whitehead, 2010), prevailing policy goals (see for example Plezier in Bewegen, Nederlandse Sportraad et al., 2018), technological influences (e.g., Van Hilvoorde \& Kleinpaste, 2014; Koekoek \& Van Hilvoorde, 2018), and/ or timely empirical evidence from motor learning literature (e.g., the role of implicit and explicit learning methods, Van der Kamp et al., 2015). Such pluriform and multidisciplinary perspectives characterize the complexity of focusing on pedagogy and didactics of $\mathrm{PE}$ as a subject of inquiry in the Netherlands. I therefore framed my dissertation within a variety of theoretical and pedagogical models (e.g., social constructivism, nonlinear pedagogy, physical literacy, situated learning, TPACK, TGfU). Since research on PE pedagogy in the Netherlands is relatively scarce, my dissertation may function as an example of how an evidence-informed multidisciplinary research perspective can be used. PE research that strongly 
focuses on didactical issues needs to have a decisive place in universities and PETE faculties in the future. Specifically, I propose a paradigm of PE research that includes empirical exploration, but also translates theory into practice in order to contribute to a pedagogy for PE. PE scholars, lecturers and teachers should be encouraged to embrace evidence-informed practices and stimulated to include the perceptions of the learner in order to achieve sustainable quality PE.

\section{Notes Chapter 8}

7. An examination of other possible influences of preferences for peers in group works such as the possibility of the presence of competitive components in the general school curriculum is beyond the scope of this dissertation.

8. I acknowledge that peer interactions can also include bullying and practices of exclusion and that specific ways in which the PE class may be a medium for such practices and/or in which this occurs during interactions in PE have been identified (see for example, Benn \& Pfister, 2013; Li, Li, Zhao, \& Li, 2017; O'Connor \& Graber, 2014). This is a topic that goes beyond the scope of this dissertation although it does need serious attention. 


\section{References}

Abbott, A., Collins, D., Martindale, R.J., \& Sowerby, K. (2002). Talent identification and development: An academic review. Edinburgh: Sport Scotland.

Adams, P. (2006). Exploring social constructivism: Theories and practicalities. Education, 34(3),243-257.

Adams, P. (2008). Considering 'best practice': The social construction of teacher activity and pupil learning as performance. Cambridge Journal of Education,38(3),375-392.

Allan, G. (2003). A critique of using grounded theory as a research method. Electronic Journal of Business Research Methods,2(1),1-10.

Almond, L. (2015). Rethinking teaching games for understanding. Ágora para la ef y el Deporte,17,15-25.

Amara, S., Mkaouer, B., Nassib, S.H., Chaaben, H., Hachana, Y., \& Salah, F.Z.B. (2015). Effect of video modeling process on teaching/learning hurdle clearance situations on physical education students. Advances in Physical Education, 5(04), 225-233.

Angell, C., Alexander, J., \& Hunt, J.A. (2015). 'Draw, write and tell': A literature review and methodological development on the 'draw and write' research method. Journal of Early Childhood Research,13(1),17-28.

Anguera, M.T., Camerino, O., \& Castañer, M. (2012). Mixed methods procedures and designs for research on sport, physical education and dance. In O. Camerino, M. Castañer, \& T.M. Anguera,(Eds.), Mixed methods research in the movement sciences: Case studies in sport, physical education and dance (pp. 97-135). London: Routledge.

Annerstedt,C. (2008). Physical education in Scandinavia with a focus on Sweden: A comparative perspective. Physical Education and Sport Pedagogy, 13(4),303-318.

AppBakkers BV. (2017). Video-catch (version 0.1) [iPad software application]. Retrieved from http://itunes. apple.com

Azzarito, L., \& Ennis, C.D. (2003). A sense of connection: Toward social constructivist physical education. Sport, Education and Society, 8(2), 179-197.

Azzarito, L., \& Solmon, M. (2009). An investigation of students' embodied discourses in physical education: A gender project. Journal of Teaching in Physical Education,28,173-191.

Azzarito, L., Solmon, M.A., \& Harrison Jr, L. (2006). "... If I had a choice, I would...." A feminist poststructuralist perspective on girls in physical education. Research Quarterly for Exercise and Sport,77(2),222-239.

Baarda, D.B., De Goede, M.P.M., \& Van der Meer-Middelburg, A.G.E. (2000). Basisboek open interviewen [Basics of open interviewing]. Houten: Stenfert Kroese.

Bain, L.L. (1975). The hidden curriculum in physical education. Quest,24(1), 92-101.

Bailey, R. (2006). Physical education and sport in schools: A review of benefits and outcomes. Journal of School Health, 76(8),397-401.

Balyi, I. (2004). Long-term athlete development: Trainability in childhood and adolescence. Windows of opportunity, Optimal trainability. Victoria: National Coaching Institute, British Columbia \& Advanced Training and Performance Ltd.

Bandura, A. (1997). Self-efficacy: The exercise of control. New York: Freeman and Co.

Barker, D., \& Rossi, A. (2011). Understanding teachers: The potential and possibility of discourse analysis. Sport, Education and Society, 16(2),139-158.

Barker, D., Quennerstedt, M., \& Annerstedt, C. (2015). Inter-student interactions and student learning in health and physical education: A post-Vygotskian analysis. Physical Education and Sport Pedagogy, 20(4), 409-426.

Barker, D., Wallhead, T., \& Quennerstedt, M. (2017). Student learning through interaction in physical education. European Physical Education Review,23(3),273-278. doi:10.1177/1356336X16640235 
Barnett, L., Stodden, D., Cohen, K.E., Smith, J.J., Lubans, D.R., Lenoir, M., [...] Morgan, P.J. (2016). Fundamental movement skills: An important focus. Journal of Teaching in Physical Education,35(3),219-225. doi:http:// dx.doi.org/10.1123/jtpe.2014-0209

Baron, A.S., Schmader, T., Cvencek, D., \& Meltzoff, A.N. (2014). The gendered self-concept: How implicit gender stereotypes and attitudes shape self-definition. In P.J. Leman \& H.R. Tenebaum (Eds.), Gender and Development (pp. 109-132). East Sussex: Psychology Press.

Beni,S., Fletcher, T., \& Ní Chróinín, D. (2017). Meaningful experiences in physical education and youth sport: A review of the literature, Quest, 69(3),291-312, DOI: 10.1080/00336297.2016.1224192.

Benn, T., \& Pfister, G. (2013). Meeting needs of Muslim girls in school sport: Case studies exploring cultural and religious diversity. European journal of sport science, 13(5), 567-574.

Biesta, G. (2009). Good education in an age of measurement: On the need to reconnect with the question of purpose in education. Educational Assessment, Evaluation and Accountability (formerly: Journal of Personnel Evaluation in Education),21(1),33-46.

Biesta, G.J.J. (2015). What is education for? On good education, teacher judgement, and educational professionalism. European Journal of Education, 5O(1),75-87.

Biesta, G.J.J. (2015). Good education in an age of measurement: Ethics, politics, democracy. Boulder, Co: Paradigm Publishers.

Bland, D. (2012). Analysing children's drawings: Applied imagination. International Journal of Research \& Method in Education, 35(3), 235-242.

Blomqvist, M., Luhtanen, P., \& Laakso, L. (2001). Comparison of two types of instruction in badminton. European Journal of Physical Education, 6(2),139-155.

Boghossian, P. (2006). Behaviorism, constructivism, and Socratic pedagogy. Educational Philosophy and Theory, 38(6), 713-722.

Braun, V. \& Clarke, V. (2006). Using thematic analysis in psychology. Qualitative Research in Psychology, $3(2), 77-101$.

Bunker, B., \& Thorpe, R. (1986). The curriculum model. In R. Thorpe, D. Bunker, \& L. Almond (Eds.), Rethinking games teaching (pp. 7-10). Loughborough, England: University of Technology, Department of Physical Education and Sports Science.

Burland, K., \& Davidson, J.W. (2001). Investigating social processes in group musical composition. Research Studies in Music Education, 16(1), 46-56.

Burrows, C., Eves, F., \& Cooper,D. (1999). Children's perceptions of exercise -are children mini-adults? Health Education, 99(2), 61-69.

Butler, J. (2006). Curriculum constructions of ability: Enhancing learning through Teaching Games for Understanding (TGfU) as a curriculum model. Sport, Education and Society, 11(3), 243-258.

Capel, S. (2007). Moving beyond physical education subject knowledge to develop knowledgeable teachers of the subject. The Curriculum Journal,18(4),493-507.

Cardinal, B.J., Yan, Z., \& Cardinal, M.K. (2013). Negative experiences in physical education and sport: How much do they affect physical activity participation later in life? Journal of Physical Education, Recreation \& Dance, 84(3), 49-53.

Carlson, T.B. (1995). We hate gym: Student alienation from physical education. Journal of Teaching in Physical Education, 14(4), 467-477.

Carr,S., \& Weigand,D.A. (2001). Parental, peer, teacher and sporting hero influence on the goal orientations of children in physical education. European Physical Education Review, 7(3),305-328.

Casey,A. (2017). Student interactions in the hidden curriculum. European Physical Education Review,23(3), 366-371.

Casey, A., \& Goodyear, V.A. (2015). Can cooperative learning achieve the four learning outcomes of physical education? A review of literature. Quest, 67(1),56-72. 
Casey, A., Goodyear, V.A., \& Armour, K.M. (2017). Rethinking the relationship between pedagogy, technology and learning in health and physical education. Sport, Education and Society,22(2),288-304.

Casey, A., Hill, J., \& Goodyear, V.A. (2014). "PE doesn't stand for physical education. It stands for public embarrassment": Voicing experiences and proffering solutions to girls' disengagement in physical education. In S.B. Barnard Flory,A. Tischler,\& S. Sanders (Eds.), Sociocultural issues in physical education: Case studies for teachers (pp. 37-53). Maryland (US): Roman \& Littlefield.

Casey, A., \& Jones, B. (2011). Using digital technology to enhance student engagement in physical education. Asia-Pacific Journal of Health, Sport and Physical Education,2,51-66.

Chang, C.W., Wallian, N., Nachon, M., \& Gréhaigne, J.F. (2006). Pratiques langagières et strategies d'action: vers une approche sémio-constructiviste du basket-ball à Taiwan [Language productions and action strategies: Towards a semio constructivist approach of basketball in Taiwan]. Staps, 72(2), 63-77.

Charmaz, K. (2006). Constructing grounded theory: A practical guide through qualitative analysis. London: Sage Publications Ltd.

Chen, A., \& Darst, PW. (2002). Individual and situational interest: The role of gender and skill. Contemporary Educational Psychology,27,250-269.

Chow, J.Y., Davids, K., Button, C., Shuttleworth, R., Renshaw, I., \& Araújo, D. (2007). The role of nonlinear pedagogy in physical education. Review of Educational Research,77(3), 251-278.

CITO (2008). Balans van het bewegingsonderwijs aan het einde van de basisschool 3. PPON-reeks nummer 38 [Balance sheet of physical education at the end of elementary education]. Arnhem: CITO.

Clément-Guillotin, C., Cambon, L., Chalabaev, A., Radel, R., Michel, S., \& Fontayne, P. (2013). Social value and asymmetry of gender and sex categories in physical education. European Review of Applied Psychology, 3,75-85.

Cole,M., \& Wertsch,J.V. (1996). Beyond the individual-social antinomy in discussions of Piaget and Vygotsky. Human Development, 39(5), 250-256.

Constantinou, P., Manson, M., \& Silverman, S. (2009). Female students' perceptions about gender-role stereotypes and their influence on attitude toward physical education. Physical Educator, 66(2), 85-96.

Cothran, D.J. (2017). Designing effective programs: Creating curriculum to enhance student learning. In C.D. Ennis (Ed), Routledge handbook of physical education pedagogies (pp. 57-71). London: Routledge.

Cothran, D.J., \& Hodges Kulinna, P. (2006). Student's perspectives on direct, peer, and inquiry teaching strategies. Journal of Teaching in Physical Education,25(2), 166-181.

Cox, A., Duncheon, N., \& McDavid, L. (2009). Peers and teachers as sources of relatedness perceptions, motivation, and affective responses in physical education. Research Quarterly for Exercise and Sport, $80(4), 765-773$.

Crotty, M. (1998). The foundations of social research: Meaning and perspective in the research process. St Leonards, NSW: Allen and Unwin.

Curriculum.nu (2019). Voorstellen voor het leergebied Bewegen \& Sport [Proposals for the area of Movement and Sport]. Retrieved from: https://www.curriculum.nu/voorstellen/bewegen-sport/.

Darbyshire, P., MacDougall, C., \& Schiller, W. (2005). Multiple methods in qualitative research with children: More insight or just more? Qualitative Research,5(4),417-436.

Darnis, F., \& Lafont, L. (2015). Cooperative learning and dyadic interactions: Two modes of knowledge construction in socio-constructivist settings for team-sport teaching. Physical Education and Sport Pedagogy, 20(5), 459-473.

Dartfish (2010). Dartfish EasyTag (version 1.3) [iPad application software]. Retrieved from http://itunes. apple.com.

Dartfish (2017). Dartfish EasyTag (version 2.1) [iPad application software]. Retrieved from http://itunes. apple.com. 
Davids, K., Button, C., \& Bennett, S. (2008). Dynamics of skill acquisition. A constraints-led approach. Champaign, IL: Human Kinetics.

Davis, B., \& Sumara, D. (2002). Constructivist discourses and the field of education: Problems and possibilities. Educational Theory, 52(4), 409-428.

Davydov, V.V., translated by Kerr, S.T. (1995). The influence of L.S. Vygotsky on educational theory, research, and practice. Educational Researcher,24,12-21.

Dekkers, W.J. (1995). FJJ Buytendijk's concept of an anthropological physiology. Theoretical Medicine, 16(1), 15-39.

Dokman, I., Van Beusekom, R., Oldeboom, B., \& Pepping-Poot, A. (2018). Ik in de wij [Me in de we]. Lelystad: Lving.

Domville, M., Watson, P.M., Richardson, D., \& Graves, L.E.F. (2019). Children's perceptions of factors that influence PE enjoyment: A qualitative investigation. Physical Education and Sport Pedagogy,24(3), 207219.

Doozan,A.,\& Bae,M. (2016). Teaching physical literacy to promote healthy lives: TGfU and related approaches. The Physical Educator, 73(3), 471-487.

Dudley, D., Okely, A., Pearson, P., \& Cotton, W. (2011). A systematic review of the effectiveness of physical education and school sport interventions targeting physical activity, movement skills and enjoyment of physical activity. European Physical Education Review, 17(3),353-378.

Dyson, B. (1995). Students' voices in two alternative elementary physical education programs. Journal of Teaching in Physical Education, 14,394-407.

Dyson, B. (2005). Integrating cooperative learning and tactical games models: Focusing on social interactions and decision making. Teaching games for understanding: Theory, research, and practice, 149-168.

Dyson, B. (2006). Students' perspectives of physical education. In D. Kirk, D. Macdonald, \& M. O'Sullivan (Eds.), The handbook of physical education (pp. 326-346). London: Sage Publications.

Dyson, B., \& Casey, A. (2012). Cooperative learning as a pedagogical model in physical education. In B. Dyson \& A. Casey (Eds.). Cooperative learning in physical education: A research-based approach (pp. 1-12). London: Routledge.

Dyson, B., Griffin, L.L., \& Hastie, P. (2004). Sport education, tactical games, and cooperative learning: Theoretical and pedagogical considerations. Quest,56(2),226-240.

Easton, K.L., McComish, J.F., \& Greenberg, R. (2000). Avoiding common pitfalls in qualitative data collection and transcription. Qualitative Health Research, 10(5),703-707.

Evans, J., \& Penney, D. (2008). Levels on the playing field: The social construction of physical 'ability' in the physical education curriculum. Physical Education and Sport Pedagogy, 1,31-47.

Faulkner, R (2003). Group composing: Pupil perceptions from a social psychology study. Music Education Research, 5(2), 101-124.

Fisette, J.L. (2013). 'Are you listening?': Adolescent girls voice how they negotiate self-identified barriers to their success and survival in physical education. Physical Education and Sport Pedagogy,18,184-203.

Fitzpatrick, K., \& Enright, E. (2017). Gender, sexuality and physical education. In C. Ennis (Ed.), Routledge handbook of physical education pedagogies (pp. 319-331). New York: Routledge.

Flintoff,A., \& Dowling, F. (2019). 'I just treat them all the same, really': Teachers, whiteness and (anti)racism in physical education. Sport, Education and Society,24(2),121-133.

Flintoff, A., \& Fitzgerald, H. (2012). Theorizing difference and (in)equality in physical education, youth sport and health. In F. Dowling, H. Fitzgerald, \& A. Flintoff (Eds.), Equity and difference in physical education, youth sport and health. A narrative approach (pp. 11-36). London: Routledge, Taylor \& Francis.

Flintoff, A., Fitzgerald, H., \& Scraton, S. (2008). The challenges of intersectionality: Researching difference in physical education. International Studies in Sociology of Education,2,73-85. 
Forrest, G.J. (2014). Questions and answers: Understanding the connection between questioning and knowledge in game-centred approaches. In R.L. Light,J. Quay, S. Harvey \& A. Mooney (Eds.), Contemporary developments in games teaching (pp. 167-177). Abingdon, United Kingdom: Routledge.

Gainsburg, J. (2009). Creating effective video to promote student-centered teaching. Teacher Education Quarterly,36(2), 163-178.

Gibbone, A., Rukavina, P., \& Silverman, S. (2010). Technology integration in secondary physical education: Teachers' attitudes and practice. Journal of Educational Technology Development and Exchange, 3(1), 27-42.

Giblin, S., Collins, D., \& Button, C. (2014). Physical literacy: Importance, assessment and future directions. Sports Medicine, 44(9), 1177-1184.

Gibson, J.J. (1977). The theory of affordances. In R.E. Shaw \& J. Bransford (Eds.), Perceiving, Acting, and Knowing. Hillsdale, NJ: Lawrence Erlbaum Associates.

Gibson, J.J. (1979). The ecological approach to visual perception. Boston, MA: Houghton Mifflin.

Glaser, B.G. \& Strauss, A.L. (1967). The discovery of grounded theory: Strategies for qualitative research. New York: Aldine de Gruyter.

Glatthorn,A. (2000). Aligning the curriculum. In A. Glatthorn, The principal as curriculum leader: Shaping what is taught \& tested, Thousand Oaks, California: Corwin Press.

Gordijn, C.C.F. (1961). Bewegingsonderwijs [Movement Education]. Baarn: Bosch \& Keuning.

Gorely, T., Holroyd, R., \& Kirk, D. (2003). Muscularity, the habitus and the social construction of gender: Towards a gender-relevant physical education. British Journal of Sociology of Education,24,429-448.

Grahn, K., \& Torell, V.B. (2015). Negotiations of gender discourse: Experiences of co-education in a Swedish sports initiative for children. Sport in Society, 19, 1186-1201.

Gréhaigne J.F., Godbout, P., \& Bouthier,D. (2001). The teaching and learning of decision making in team sports, Quest, 53(1),59-76.

Gréhaigne, J.F., Richard, J.F., \& Griffin, L.L. (2005). Teaching and learning team sports and games. London: Routledge.

Gréhaigne, J.F., Wallian, N., \& Godbout, P. (2005). Tactical-decision learning model and students' practices. Physical Education \& Sport Pedagogy, 10(3),255-269.

Grenier, M. (2006). A social constructionist perspective of teaching and learning in inclusive physical education. Adapted Physical Activity Quarterly,23,245-260.

Griffin, L.L., Brooker, R., \& Patton, K. (2005). Working towards legitimacy: Two decades of teaching games for understanding. Physical Education \& Sport Pedagogy, 10(3), 213-223.

Griffin, L.L., \& Patton, K. (2005). Two decades of teaching games for understanding: Looking at the past, present, and future. In L.L. Griffin and J.I. Butler (Eds.), Teaching games for understanding. Theory, research and practice (pp. 1-17). Champaign, IL: Human Kinetics.

Groves, S., \& Laws, C. (2000). Children's experiences of physical education. European Journal of Physical Education, 5,19-27.

Guest, G., Bunce, A., \& Johnson, L. (2006). How many interviews are enough? Field Methods, 18(1),59-82.

Guest, G., Namey, E., \& McKenna, K. (2017). How many focus groups are enough? Building an evidence base for nonprobability sample sizes. Field Methods,29,3-22.

Hamre, B.K., Pianta, R.C., Downer, J.T., DeCoster, J., Mashburn, A.J., Jones, S.M., [...] \& Brackett, M.A. (2013). Teaching through interactions: Testing a developmental framework of teacher effectiveness in over 4,000 classrooms. The Elementary School Journal,113(4), 461-487.

Hardman, K., Murphy, C., Routen, A.C., \& Tones, S. (2013). World-wide survey of school physical education. Paris: UNESCO.

Harrington, W.J. (2016). Collaborative learning among high school students in a chamber music setting. Dissertation. Boston: Boston University. 
Harrison Jr., L., Azzarito, L., \& Burden Jr., J. (2004). Perceptions of athletic superiority: A view from the other side. Race Ethnicity and Education, 7(2), 149-166.

Harvey, S., Cope, E., \& Jones, R. (2016). Developing questioning in game-centered approaches. Journal of Physical Education, Recreation \& Dance, 87(3),28-35.

Harvey, S., \& Gittins, C. (2014). Effects of integrating video-based feedback into a Teaching Games for Understanding soccer unit. Agora Para la Educación Física y el Deporte,16,271-290.

Harvey, S., \& Jarrett, K. (2014). A review of the game-centred approaches to teaching and coaching literature since 2006. Physical Education and Sport Pedagogy, 19(3), 278-300.

Harvey, S., \& Light, R.L. (2015). Questioning for learning in game-based approaches to teaching and coaching. Asia-Pacific Journal of Health, Sport and Physical Education, 6(2), 175-190.

Hassandra, M., Goudas, M., \& Chroni, S. (2003). Examining factors associated with intrinsic motivation in physical education: A qualitative approach. Psychology of Sport and Exercise, 4,211-223.

Heij, P. (2006). Grondslagen van 'verantwoord' bewegingsonderwijs - Filosofische en pedagogische doordenking van relationeel gefundeerd bewegingsonderwijs [Principles of 'a justified' physical education - Philosophical and pedagogical reflection on relationally based physical education]. Budel: Damon.

Hills, L. (2007). Friendship, physicality, and physical education: An exploration of the social and embodied dynamics of girls' physical education experiences. Sport, Education and Society, 12(3), 317-336.

Hills, L.A., \& Croston, A. (2012). 'It should be better all together': Exploring strategies for 'undoing' gender in coeducational physical education. Sport, Education and Society, 17(5), 591-605.

Hume,C., Salmon, J., \& Ball,K. (2005). Children's perceptions of their home and neighborhood environments, and their association with objectively measured physical activity: A qualitative and quantitative study. Health Education Research,20(1), 1-13.

Inspectie van het Onderwijs (2018). Peiling bewegingsonderwijs einde basis- en speciaal basisonderwijs 2016-2017 [Assessing PE at the end of primary school]. Utrecht: Inspectie van het Onderwijs.

Jacobs, F., Knoppers, A., \& Webb, L. (2013). Making sense of teaching social and moral skills in physical education. Physical Education \& Sport Pedagogy, 18(1), 1-14.

Jourand, C., Adé, D., Sève, C., Komar, J., \& Thouvarecq, R. (2018). Dynamics of student interactions: An empirical study of orienteering lessons in physical education. Physical Education and Sport Pedagogy, 23(2), 134-149.

Jung, J., Ressler, J., \& Linder, A. (2018). Exploring the hidden curriculum in physical education. Advances in Physical Education, 8(2), 253-262.

Juniu, S. (2011). Pedagogical uses of technology in physical education. Journal of Physical Education, Recreation \& Dance, 82(9), 41-49.

Jurbala, P. (2015). What is physical literacy, really? Quest, 67(4),367-383.

Keegan, R. (2016). Action research as an agent for enhancing teaching and learning in physical education: A physical education teacher's perspective. Physical Educator,73(2), 255-284.

Kendrick, M., \& McKay, R. (2004). Drawings as an alternative way of understanding young children's constructions of literacy. Journal of Early Childhood Literacy,4,109-128.

Kerry, D.S., \& Armour, K.M. (2000). Sport sciences and the promise of phenomenology: Philosophy, method, and insight. Quest, 52(1), 1-17.

Kim, B. (2010). Social constructivism. In M. Orey (Ed.), Emerging perspectives on learning, teaching, and technology (pp. 55-61).

Kirk, D. (1992). Physical education, discourse, and ideology: Bringing the hidden curriculum into view. Quest, 44(1),35-56.

Kirk, D. (2005). Physical education, youth sport and lifelong participation: The importance of early learning experiences. European Physical Education Review, 11(3), 239-255. 
Kirk, D. (2009). Physical education futures. London: Routledge.

Kirk, D., \& Kinchin, G. (2003). Situated learning as a theoretical framework for sport education. European Physical Education Review, 9(3), 221-235.

Kirk, D., \& Macdonald, D. (1998). Situated learning in physical education. Journal of Teaching in Physical Education, 17(3),376-387.

Kirk, D., \& MacPhail, A. (2002). Teaching games for understanding and situated learning: Rethinking the Bunker-Thorpe model. Journal of Teaching in Physical Education,21(2), 177-192.

Knol, F. (2012). Statusontwikkeling van wijken in Nederland 1998-2010 [Social economic status of districts in the Netherlands 1998-2010]. Den Haag: Sociaal en Cultureel Planbureau.

Koehler, M.J., \& Mishra, P. (2009). What is technological pedagogical content knowledge? Contemporary Issues in Technology and Teacher Education, 9,60-70.

Koekoek, J., Dokman, I., \& Walinga, W. (2014). Sportspelen [Sport Games]. Den Haag: Boom Lemma.

Koekoek, J., \& Knoppers, A. (2015). The role of perceptions of friendships and peers in learning skills in physical education. Physical Education and Sport Pedagogy,20(3),231-249.

Koekoek, J., Knoppers, A., \& Stegeman, H. (2009). How do children think they learn skills in physical education? Journal of Teaching in Physical Education,28(3),310-332.

Koekoek, J., Van der Mars, H., Van der Kamp, J., Walinga, W., \& Van Hilvoorde, I. (2018). Aligning digital video technology with game pedagogy in physical education. Journal of Physical Education, Recreation \& Dance, 89(1), 12-22.

Koekoek, J., \& Van Hilvoorde, I. (Eds.) (2018). Digital technology in physical education: Global perspectives. London: Routledge.

Koekoek, J., Van Hilvoorde, I., Van der Kamp, J., \& Walinga, W. (2014, February). Accuracy and reliability of tagging and video feedback to enhance tactical knowledge: Students' perspectives within a TGfU basketball setting. Poster presented at the AIESEP TGfU symposium, University of Auckland, New Zealand.

Koekoek, J., Van der Kamp, J., Walinga, W., \& Van Hilvoorde, I. (2014). Dutch elite youth soccer players perceptions of a TGfU-modified game practice. Agora para la educación física y el deporte,16,232-254.

Koekoek, J., \& Walinga, W. (2014). TGfU in Dutch PE: Integrating methodical notions with digital observation tools. Paper presented at the AIESEP World Congress TGfU symposium, 9th February, Auckland, University of Auckland, New Zealand.

Koekoek, J., Walinga, W., \& Dokman, I. (2009). Understanding baseball in physical education: A methodical approach to enhance learning based on game-like situations. In T. Hopper, J. Butler \& B. Storey (Eds.), TGfU...simply good pedagogy: Understanding a complex challenge (pp. 115-126). Canada: PHE Canada.

Koekoek, J.,Walinga,W., \& Van Hilvoorde, I.M. (2017). Improving game based pedagogy by technology. Game balance analysis and digital video tagging within a TGfU setting. In A. Bund, \& C. Scheuer (Eds.), Changes in childhood and adolescence: Current challenges for physical education, Proceedings of the 12th FIEP European Congress (pp. 160-161). Berlin: Logos Verlag.

Kok, M., \& Van der Kamp, J. (2018). Adopting self-controlled video-feedback in physical education. A way to unite self regulation skills, motivational beliefs, and motor skill learning. In J. Koekoek \& I. Van Hilvoorde (Eds.), Digital technology in physical education: Global perspectives (pp. 32-47). London: Routledge Taylor \& Francis Group.

Krueger, R.A., \& Casey, M.A. (2000). Focus groups. A practical guide for applied research. Thousand Oaks, CA: Sage Publications, Inc.

Larneby, M. (2016). Transcending gender hierarchies? Young people and floorball in Swedish school sport. Sport in Society, 19(8-9), 1202-1213.

Launder, A.G., \& Piltz, W. (2013). Play practice: Engaging and developing skilled players from beginner to elite. Champaign, IL: Human Kinetics. 
Lave, J. (1991). Situating learning in communities of practice. Perspectives on socially shared cognition, 2, 63-82.

Lave, J., \& Wenger, E. (1991). Situated learning: Legitimate peripheral participation (Vol. 521423740). Cambridge: Cambridge university press.

Laws, C., \& Fisher, R. (1999). Pupils' interpretations of physical education. In C.A. Hardy \& M. Mawer (Eds.), Learning and teaching in physical education (pp. 23-37). New York: Routledge Falmer.

Li, W., Lee, A., \& Solmon, M. (2007). The role of perceptions of task difficulty in relation to self-perceptions of ability, intrinsic value, attainment value, and performance. European Physical Education Review, 13, 301-318.

Li, H., Li, W., Zhao, Q., \& Li, M. (2017). Including overweight and obese students in physical education: An urgent need and effective teaching strategies. Journal of Physical Education, Recreation \& Dance,88(5), 33-38.

Light, R. (2006). Accessing the inner world of children: The use of student drawings in research on children's experiences of game sense. In R. Light (Ed.), Proceedings for the Asia Pacific Conference on Teaching Sport and Physical Education for Understanding (pp. 72-83). Sydney, Australia: University of Sydney.

Light, R. (2008). Complex learning theory-its epistemology and its assumptions about learning: Implications for physical education. Journal of Teaching in Physical Education,27(1),21-37.

Light, R. (2009). Understanding and enhancing learning in TGfU through complex learning theory. In T. Hopper, J. Butler \& B. Storey (Eds.), TGfU...Simply good pedagogy: understanding a complex challenge (pp. 23-34). Canada: PHE Canada.

Light, R. (2013). Game sense: Pedagogy for performance, participation and enjoyment. London: Routledge.

Light, R., \& Fawns, R. (2001). The thinking body: Constructivist approaches to games teaching in physical education. Critical Studies in Education, 42(2),69-87.

Light, R., \& Fawns, R. (2003). Knowing the game: Integrating speech and action in games teaching through TGfU. Quest, 55(2), 161-176.

Light, R., Harvey, S., \& Mouchet, A. (2014). Improving "at-action" decision-making in team sports through a holistic coaching approach. Sport, Education and Society, 19,258-275.

Liu, C.H., \& Matthews, R. (2005). Vygotsky's philosophy: Constructivism and its criticisms examined. International Education Journal, 6(3),386-399.

Lomax, H.J. (2012). Shifting the focus: Children's image-making practices and their implications for analysis. International Journal of Research \& Method in Education,35(3),227-234.

Luke, I., \& Hardy, C.A. (1999). Pupils' meta-cognition and learning. In C.A. Hardy \& M. Mawer (Eds.), Learning and teaching in physical education (pp. 38-58). New York: Routledge Falmer.

Lupton, D. (2015). Data assemblages, sentient schools and digitised health and physical education (response to Gard). Sport, Education and Society,20(1),122-132.

MacDonald, R.A.R., \& Miell, D. (2000). Creativity and music education: The impact of social variables. International Journal of Music Education, 36,58-68.

MacDonald, R.A.R., Miell, D., \& Mitchell, L. (2002). An investigation of children's musical collaborations: The effect of friendship and age. Psychology of Music,30(2), 148-163.

Macgregor, A.S.T., Currie, C.E., \& Wetton, N. (1998). Eliciting the views of children about health in schools through the use of the draw and write technique. Health Promotion International, 13(4),307-318.

MacPhail, A. (2001). Nominal group technique: A useful method for working with young people. British Educational Research Journal,27,161-170.

MacPhail, A., Kinchin, G., \& Kirk, D. (2003). Students' conceptions of sport and sport education. European Physical Education Review, 9(3),285-299.

MacPhail, A., Kirk, D., \& Eley, D. (2003). Listening to young people's voices: Youth sports leaders' advice on facilitating participation in sport. European Physical Education Review,9,57-73. 
MacPhail, A., Kirk, D., \& Griffin, L. (2008). Throwing and catching as relational skills in game play: Situated learning in a modified game unit. Journal of Teaching in Physical Education,27(1), 100-115.

MacPhail, A., Kirk, D., \& Kinchin, G. (2004). Sport education: Promoting team affiliation through physical education. Journal of Teaching in Physical Education,23(2),106-122.

Mandigo, J., Francis, N., Lodewyk, K., \& Lopez, R. (2009). Physical literacy for educators. Physical and Health Education Journal, 75(3), 27-30.

Martin, P.Y. (2003). "Said and done" versus "saying and doing". Gendering practices, practicing gender at work. Gender \& Society, 17,342-366.

Martin, P.Y. (2006). Practicing gender at work: Further thoughts on reflexivity, Gender, Work and Organization, 13,254-276.

Matsumoto, N. (2018). What students learn at netball game play? Students' conception in children's drawings. Poster presentation at AIESEP,World Congress 2018,25-28 July, University of Edinburgh (UK).

McKenzie, T.L., \& Lounsbery, M.A. (2009). School physical education: The pill not taken. American Journal of Lifestyle Medicine,3(3),219-225.

Memmert, D. et al. (2015). Top 10 research questions related to Teaching Games for Understanding. Research Quarterly for Exercise and Sport, 86(4),347-359.

Merleau-Ponty, M. (1962). Phenomenology of perception. London and New York: Routledge.

Michael, D., \& Chen, S. (2006). Serious games: Games that educate, train, and inform. Stamford, CT: Thomson Course Technology PTR.

Miell, D., \& MacDonald, R. (2000). Children's creative collaborations: The importance of friendship when working together on a musical composition. Social Development, 9(3),348-369.

Mitchell, F., Gray, S., \& Inchley, J. (2015). 'This choice thing really works...' Changes in experiences and engagement of adolescent girls in physical education classes, during a school-based physical activity program. Physical Education and Sport Pedagogy,20,593-611.

Mitchell,S.A., Oslin, J.L., \& Griffin, L.L. (2013). Teaching sport concepts and skills: A tactical games approach for ages 7 to 18 . Champaign, IL: Human Kinetics.

Mogashoa, T. (2014). Applicability of constructivist theory in qualitative educational research. American International Journal of Contemporary Research,4(7),51-59.

Mooij, C., Van Berkel, M. \& Hazelebach, C. (2004). Basisdocument bewegingsonderwijs. Leerlijnen, tussendoelen en methodisch didactische uitwerkingen [Foundational document for physical education. Learning categories, goals and methodical and didactic descriptions]. Zeist: Jan Luiting Fonds.

Morgan, D.L. (1997). Focus groups as qualitative research. Thousand Oaks: Sage Publications, Inc.

Mulvihill, C., Rivers, K., \& Aggleton, P. (2000). A qualitative study investigating the views of primary-age children and parents on physical activity. Health Education Journal,59(2),166-179.

Mumtaz, S. (2000). Factors affecting teachers' use of information and communications technology: A review of the literature. Journal of Information Technology for Teacher Education, 9, 319-342.

Munk, M., \& Agergaard, S. (2018). Listening to students' silences - a case study examining students' participation and non-participation in physical education. Physical Education and Sport Pedagogy,23(4), 371-386.

National Association for Sport and Physical Education (2008). National standards for initial physical education teacher education. Reston, VA: Author.

Nederlandse Sportraad, Onderwijsraad en Raad voor Volksgezondheid en Samenleving (2018). Plezier in bewegen. Een oproep tot dagelijks twee keer een half uur sporten en bewegen in het onderwijs [Enjoying movement: A call for physical activity twice a day]. Den Haag: Nederlandse Sportraad.

Netherlands Code of Conduct for Research Integrity (2018). doi:10.17026/dans-2cj-nvwu.

Ningthoujam, R. (2016). Construction and importance of video based analyses teaching in physical education by use of window live movie maker. Video Journal of Education and Pedagogy, 1(1),1-14. 
NOC*NSF (2011). Meerjaren Opleidingsprogramma [Multiyear educational program]. Retrieved from http://www.nocnsf.nl/cms/showpage.aspx?id=7642.

Novak, D., Antala, B., \& Knjaz, D. (2016). Physical education and new technologies. Zagreb: Croatian Kinesiology Association.

Nugent, P., \& Faucette, N. (1995). Marginalized voices: Constructions of and responses to physical education and grading practices by students categorized as gifted or learning disabled. Journal of Teaching in Physical Education, 14,418-430.

Nutt,G., \& Clarke,G. (2002). The hidden curriculum and the changing nature of teachers' work. Sociology of Sport and Physical Education: An Introduction, 148.

O'Donoghue, P.G. (2016). Using technology to evaluate game play for beginners and proficient players that encompasses game-play evaluation. Research Quarterly for Exercise and Sport,87(1),S6-S7.

O'Loughlin,J.,Chróinín,D.N.,\& O'Grady,D. (2013). Digital video: The impact on children's learning experiences in primary physical education. European Physical Education Review, 19(2),165-182.

Olsson, B. (2007). Social issues in music education. In L. Bresler (Ed.), The international handbook of research on arts education (pp. 989-1006). Dordrecht: Springer.

Onwuegbuzie, A.J., \& Leech, N.L. (2004). Enhancing the interpretation of significant findings: The role of mixed methods research. The Qualitative Report, 9(4),770-792.

Oslin, J., \& Mitchell, S. (2006). Game-centered approaches to teaching physical education. In D. Kirk, D. Macdonald \& M. O'Sullivan (Eds.), The handbook of physical education (pp. 627-651). London, England: Sage Publications.

O'Connor, J.A., \& Graber, K.C. (2014). Sixth-grade physical education: An acculturation of bullying and fear. Research Quarterly for Exercise and Sport,85(3),398-408.

O'Sullivan, M., Bush, K., \& Gehring, M. (2002). Gender equity and physical education: A USA perspective. In D. Penney (Ed), Gender and physical education: Contemporary issues and future directions (pp. 163189). London: Routledge.

Ovens, A., Hopper, T., \& Butler, J. (Eds.) (2013). Complexity thinking in physical education: Reframing curriculum, pedagogy, and research. London: Routledge.

Ovens, A., \& Godber, K. (2013). Affordance networks and the complexity of learning. In A. Ovens, T. Hopper, \& J. Butler (Eds.). Complexity thinking in physical education: Reframing curriculum, pedagogy and research (pp. 55-66). London: Routledge.

Palao, J.M., Hastie, P.A., Cruz, P.G., \& Ortega, E. (2015). The impact of video technology on student performance in physical education. Technology, Pedagogy and Education,24(1),51-63.

Pearson, P.J., \& Webb, P. (2009). Improving the quality of games teaching to promote physical activity. In T.F. Cuddihy \& E. Brymer (Eds.), Creating active futures, Proceedings of the 26th ACHPER International Conference, Queensland University of Technology, 7-10 July 2009,443-450.

Penney, D. (2003). Sport education and situated learning: Problematizing the potential. European Physical Education Review, 9(3),301-308.

Piaget, J. (1964). Part I: Cognitive development in children: Piaget development and learning. Journal of Research in Science Teaching,2(3), 176-186.

Portman, P.A. (1995). Who is having fun in physical education classes? Experiences of sixth-grade students in elementary and middle schools. Journal of Teaching in Physical Education, 14,445-453.

Pope, C.C. (2005). Once more with feeling: Affect and playing with the TGfU model. Physical Education \& Sport Pedagogy, 10(3), 271-286.

Pot, N.,Schenk, N., \& Van Hilvoorde, I. (2014). School sports and identity formation: Socialisation or selection? European Journal of Sport Science, 14(5), 484-491.

Pot,N.,Van Hilvoorde, I.,Afonso, J., Koekoek, J., \& Almond,L. (2017). Meaningful movement behaviour involves more than the learning of fundamental movement skills. International Sports Studies,39(2), 5-20. 
Powell, K.C., \& Kalina, C.J. (2009). Cognitive and social constructivism: Developing tools for an effective classroom. Education, 130(2), 241-250.

Pyle, B., \& Esslinger, K. (2014). Utilizing technology in physical education: Addressing the obstacles of integration. Delta Kappa Gamma Bulletin, 80,35-39.

Qi, J., \& Wang, L. (2018). Social interaction between students with and without disabilities in general physical education: A Chinese perspective. Physical Education and Sport Pedagogy, 23(6), 575-591.

Quennerstedt, M., Annerstedt, C., Barker, D., Karlefors, I., Larsson, H., Redelius, K., \& Öhman, M. (2014). What did they learn in school today? A method for exploring aspects of learning in physical education. European Physical Education Review,20(2), 282-302.

Quennerstedt, M., Öhman, M., \& Armour, K. (2014). Sport and exercise pedagogy and questions about learning. Sport, Education and Society, 19,885-898.

Ratliffe, T., Imwold, C., \& Conkell,C. (1994). Children's views of their third grade physical education class. The Physical Educator,51,106-111.

Rich, P.J., \& Hannafin, M. (2009). Video annotation tools: Technologies to scaffold, structure, and transform teacher reflection. Journal of Teacher Education, 60(1),52-67.

Richard,J.F.,\&Wallian, N. (2005). Emphasizing student engagement in the construction of game performance. In L.L. Griffin and J.I. Butler (Eds.), Teaching games for understanding. Theory, research and practice (pp. 19-32). Champaign, IL: Human Kinetics.

Richardson, K.P., Sheehy, D., \& Hopper, T. (2013). Modification by adaptation: Proposing another pedagogical principle for TGfU. In A. Ovens, T. Hopper, \& J. Butler (Eds.), Complexity thinking in physical education (pp. 181-193). Oxon, UK: Routledge.

Rietveld, E., \& Kiverstein, J. (2014). A rich landscape of affordances. Ecological Psychology, 26(4),325-352.

Rink, J.E. (2001). Investigating the assumptions of pedagogy. Journal of Teaching in Physical Education, 20(2), 112-128.

Rink, J.E. (2003). Effective instruction in physical education. In S. Silverman and C. Ennis (Eds.), Student learning in physical education: Applying research to enhance instruction (pp. 165-186). Champaign, IL: Human Kinetics.

Renshaw, I., Chow, J.Y., Davids, K., \& Hammond, J. (2010). A constraints-led perspective to understanding skill acquisition and game play: A basis for integration of motor learning theory and physical education praxis? Physical Education and Sport Pedagogy, 15(2),117-137.

Robinson, J. (2014). Video Tagger (version 1.3) [iPad software application]. Retrieved from http://itunes.apple. com.

Rogers, E.M. (2003). Diffusion of innovations (5th ed.). New York, NY: Free Press.

Ronglan, L.T., \& Ertesvåg, V. (2015). Becoming a team player? Learning outcomes from implementing a teambased TGfU unit in high school. Journal of Physical Education,2(1), 51-70.

Rønholt, H. (2002). 'It's only the sissies...': Analysis of teaching and learning processes in physical education: A contribution to the hidden curriculum. Sport, Education and Society, 7(1),25-36.

Rovegno, I. (2006). Situated perspectives on learning. In D. Kirk, D. Macdonald \& M. O'Sullivan (Eds.), The handbook of physical education (pp. 262-274). London: Sage Publications.

Rovegno,I. \& Dolly, J.P.(2006). Constructivist perspectives on learning. In D. Kirk,D. Macdonald \& M. O'Sullivan (Eds.), The handbook of physical education (pp. 242-261). London: Sage Publications.

Rovegno, I., Nevett, M., Brock, S., \& Babiarz, M. (2001). Chapter 7: Teaching and learning basic invasion-game tactics in 4th grade: A descriptive study from situated and constraints theoretical perspectives. Journal of Teaching in Physical Education,20(4),370-388.

Rubin, K.H., Bukowski, W., \& Parker, J. (2006). Peer interactions, relationships, and groups. In N. Eisenberg (Ed.), Handbook of child psychology (6th edition): Social, emotional, and personality development. (pp. 571-645). New York: Wiley. 
Sanders, S., \& Graham, G. (1995). Kindergarten children's initial experiences in physical education: The relentless persistence for play clashes with the zone of acceptable responses. Journal of Teaching in Physical Education, 14,372-383.

Sani, M.H.M., \& Khan, T.K.A. (2017). Modeling technique: The effect on rugby sport performance. International Journal of Academic Research in Business and Social Sciences, 7(10), 419-425.

Shulman, L. (1987). Knowledge and teaching: Foundations of the new reform. Harvard Educational Review, $57,1-23$.

Siedentop, D., Hastie, P., \& Van der Mars, H. (2011). Complete guide to sport education (2nd ed.). Champaign, IL: Human Kinetics.

Sinelnikov, O.A. (2012). Using the iPad in a sport education season. Journal of Physical Education, Recreation \& Dance, 83(1),39-45.

Singleton, E. (2009). From command to constructivism: Canadian secondary school physical education curriculum and Teaching Games for Understanding. Curriculum Inquiry, 39(2), 321-342.

Slagt, N. (2018). 'Sorry, maar ik kan vandaag écht niet meedoen...' Vervreemding van het bewegingsonderwijs bij adolescente meisjes in Nederland ['I'm sorry, but I can't participate today'. Alienation from physical education of adolescent girls in the Netherlands]. Master thesis. Zwolle: Hogeschool Windesheim.

Smith, A., \& Parr, M. (2007). Young people's views on the nature and purposes of physical education: A sociological analysis. Sport, Education and Society, 12(1),37-58.

Smith, B., \& Sparkes, A.C. (2005). Analyzing talk in qualitative inquiry: Exploring possibilities, problems, and tensions. Quest, $57,213-242$.

Smyth, R. (2011). Enhancing learner-learner interaction using video communications in higher education: Implications from theorising about a new model. British Journal of Educational Technology, 42(1), 113127.

Society of Health and Physical Educators (2014). National standards \& grade-level outcomes for K-12 physical education. Champaign, IL: Human Kinetics.

Solmon, M.A. (2003). Student issues in physical education classes: Attitudes, cognition, and motivation. In S. Silverman \& C. Ennis (Eds.), Student learning in physical education: Applying research to enhance instruction (pp. 147-164). Champaign, IL: Human Kinetics.

Solmon, M. (2006). Learner cognition. In D. Kirk, D. Macdonald, \& M. O'Sullivan (Eds.), The handbook of physical education (pp. 226-241). London: Routledge.

Solmon, M.A. (2014). Physical education, sports, and gender in schools. Advances in Child Development and Behavior, 47,117-150.

Solmon, M. (2017). Student cognition. Understanding how students learn in physical education. In C.D. Ennis (Ed.), Routledge handbook of physical education pedagogies (pp. 489-502). London: Routledge.

Solmon, M.A., \& Carter, J.A. (1995). Kindergarten and first-grade students' perceptions of physical education in one teacher's classes. The Elementary School Journal,95(4),355-365.

Spencer-Cavaliere, N., \& Rintoul, M.A. (2012). Alienation in physical education from the perspectives of children. Journal of Teaching in Physical Education, 31(4),344-361.

Steenbergen, J. (2017). Physical Literacy - verkenning naar het wat, wie en hoe... [Physical literacy, explorative study of the what, who, and how]. Nijmegen: Kennispraktijk.

Steenbergen, J. et al. (2018). 'Physical Literacy': Bouwstenen voor een leven lang bewegen van jong tot oud [Physical Literacy: Building blocks for long life participation from early years to older age]. Ede: Kenniscentrum Sport.

Stegeman, H. (2004). Kwaliteit van lichamelijke opvoeding [Quality in physical education]. In R. Kunnen (Ed.) Sport in beweging: Transformatie, betekenis en kwaliteit [Sport on the move: Transformation, 
constructions and quality] (pp. 95-110). 's Hertogenbosch/Nieuwegein: Mulier Instituut/Arko Sports Media.

Ste-Marie, D.M., Law, B., Rymal, A.M., Jenny, O., Hall, C., \& McCullagh, P. (2012). Observation interventions for motor skill learning and performance: An applied model for the use of observation. International Review of Sport and Exercise Psychology, 5, 145-176.

Stewart, D.W.,Shamdasani, P.N., \& Rook, D.W. (2007). Focus groups. Theory and practice (2nd ed.). Thousand Oaks, CA: Sage Publications, Inc.

Stolz, S.A. (2015). Embodied learning. Educational Philosophy and Theory, 47(5), 474-487.

Stolz, S., \& Pill, S. (2014). Teaching games and sport for understanding: Exploring and reconsidering its relevance in physical education. European Physical Education Review, 20(1), 36-71, http://dx.doi. org/10.1177/1356336X13496001.

Storey, B., \& Butler, J. (2010). Ecological thinking and TGfU: Understanding games as complex adaptive systems. In J.I. Butler \& L.L. Griffin (Eds.), More teaching games for understanding: Moving globally (pp. 139-154). Champaign, IL: Human Kinetics.

SueSee, B., Pill, S., \& Edwards, K. (2016). Reconciling approaches - a game centred approach to sport teaching and Mosston's spectrum of teaching styles. European Journal of Physical Education and Sport Science, 2(4), 69-96.

Tamboer, J.W.I. (1992). Sport and motor actions. Journal of the Philosophy of Sport, 19(1),31-45.

Tan, C.W.K., Chow, J.Y., \& Davids, K. (2012). "How does TGfU work?": Examining the relationship between learning design in TGfU and a nonlinear pedagogy. Physical Education and Sport Pedagogy, 17,331-348.

Tannehill, D., Van der Mars, H., \& MacPhail, A. (2015). Building effective physical education programs. Sudbury, MA: Jones \& Bartlett.

Taylor, M., Ntoumanis, N., \& Smith, B. (2009). The social context as a determinant of teacher motivational strategies in physical education. Psychology of Sport \& Exercise, 10(2), 235-243.

Tearle,P.,\& Golder, G. (2008). The use of ICT in the teaching and learning of physical education in compulsory education: How do we prepare the workforce of the future? European Journal of Teacher Education, 31, 55-72.

Ten Brinke, G., Brouwer, B., Houthoff, D., Massink, M., Mooij, C., Mossel, G. van, Swinkels, E., \& Zonnenberg, A. (2007). Basisdocument bewegingsonderwijs voor de onderbouw in het voortgezet onderwijs [Foundational document for physical education in the first two years of secondary school]. Zeist, The Netherlands: Jan Luiting Fonds.

Thomas, A., \& Stratton, G. (2006). What we are really doing with ICT in physical education: A national audit of equipment, use, teacher attitudes, support, and training. British Journal of Educational Technology, $37,617-632$.

Tinning, R. (2012). The idea of physical education: A memetic perspective. Physical Education \& Sport Pedagogy, 17(2), 115-126.

Travassos, B., Vilar, L., Araújo, D., \& McGarry, T. (2014). Tactical performance changes with equal vs unequal numbers of players in small-sided football games. International Journal of Performance Analysis in Sport, 14,594-605.

Van Amsterdam, N. (2014). AbNormAll Bodies. Gender, dis/ability and health in sport, physical education and beyond (Doctoral dissertation, Utrecht University).

Van Amsterdam, N., Knoppers, A., Claringbould, I., \& Jongmans, M. (2012). 'It's just the way it is...' or not? How physical education teachers categorise and normalise differences. Gender and Education,24(7),783-798.

Van Berkel, M., \& Hazelebach, C. (Eds.) (2016). Werkboek voor de buurtsportcoach [Handbook for neighborhood sport coaches]. Nieuwegein: Jan Luiting Fonds. 
Van der Kamp, J., Duivenvoorden, J. Kok, M., \& Van Hilvoorde, I. (2015). Motor skill learning in groups: Some proposals for applying implicit learning and self-controlled feedback. Revista Internacional de Ciencias del Deporte,39(11),33-47.

Van der Poel,H.,Hoeijmakers, R.,Pulles,I.,\& Tiesssen-Raaphorst,A. (2018). Rapportage sport 2018. Den Haag: SCP.

Van Doodewaard, C., \& Knoppers, A. (2018). Perceived differences and preferred norms: Dutch physical educators constructing gendered ethnicity. Gender and Education, 30(2),187-204.

Van Hilvoorde, I. (2008). Fitness: The early (Dutch) roots of a modern industry. The International Journal of the History of Sport, 25(10), 1306-1325.

VanHilvoorde,I.,\&Kleinpaste,J.(Eds.)(2014).Vantikkennaartaggen.Digitaliseringvanbewegingsonderwijs en sport [From tagging to digital tagging: Digital technologies in PE and Sports]. Deventer: daM uitgeverij.

Van Hilvoorde, I., \& Koekoek, J. (2018). Next generation PE: Thoughtful integration of digital technologies. In J. Koekoek \& I. Van Hilvoorde (Eds.). Digital technology in physical education: Global perspectives (pp. 17-32). London: Routledge.

Van Hilvoorde, I., Vorstenbosch, J., \& Devisch, I. (2010). Philosophy of sport in Belgium and the Netherlands; History and characteristics. Journal of the Philosophy of Sport, 37(2), 225-236.

Van Maarseveen, M.J., Oudejans, R.R., \& Savelsbergh, G.J. (2018). Self-controlled video feedback on tactical skills for soccer teams results in more active involvement of players. Human Movement Science, 57, 194-204.

Vašičková, J. (2016). Physical literacy in the Czech Republic. Olomouc: Palacký University Olomouc.

Von Glasersfeld, E. (1990). An exposition of constructivism: Why some like it radical. In R.B. Davis, C.A. Maher, \& N. Noddings (Eds.), Constructivist views on the teaching and learning of mathematics, Journal for Research in Mathematics Education Monograph, 4 (pp. 19-29).

Voogt, J., \& Roblin, N.P. (2012). A comparative analysis of international frameworks for 21st century competences: Implications for national curriculum policies. Journal of Curriculum Studies, 44(3), 299321.

Vygotsky, L.S. (1978). Mind in society. The development of higher psychological processes. Cambridge, MA: Harvard University Press.

Walinga, G., \& Koekoek, J. (in press). Coachen met loopt't lukt't leeft't 2.0 [Coaching with fix fit fun 2.0]. Zeist: Jan Luiting Fonds.

Walinga, W., Koekoek, J., \& Van Hilvoorde, I. (2017). Video guided debate of ideas to enhance student's tactical knowledge in a modified (TGfU) basketball game. In A. Bund \& C. Scheuer (Eds.), Changes in childhood and adolescence: Current challenges for physical education (pp. 269-270), Proceedings of the 12th FIEP European Congress, dd. 13-16 September 2017, Luxembourg. Berlin: Logos Verlag.

Walinga, W., Consten, A., Van Driel, G., \& Van der Kamp, J. (2018). Using digital technology in physical education tailored to students' learning phase. In J. Koekoek \& I. van Hilvoorde (Eds.), Digital technology in physical education: Global perspectives (pp. 181-203). London: Routledge.

Wallian, N., \& Chang, C.W. (2007). Language, thinking and action: Towards a semio-constructivist approach in physical education. Physical Education and Sport Pedagogy, 12(3),289-311.

Ward, P., \& Lee, M. (2005). Peer-assisted learning in physical education: A review of theory and research. Journal of Teaching in Physical Education,24(3),205-225.

Webster,C.A. (2017). Student attitudes and perspectives. In C.D. Ennis (Ed.), Routledge Handbook of Physical Education Pedagogies (pp. 518-529). New York, NY: Routledge.

Weir, T., \& Connor, S. (2009). The use of digital video in physical education. Technology, Pedagogy and Education, 18(2), 155-171.

Weiss, M.R., Smith, A.L., \& Theeboom, M. (1996). "That's what friends are for": Children's and teenagers' perceptions of peer relationships in the sport domain. Journal of Sport \& Exercise,18(4),347-379. 
Weiss, M.R., \& Stuntz, C.P. (2004). A little friendly competition: Peer relationships and psychosocial development in youth sport and physical activity contexts. In M.R. Weiss (Ed.), Developmental sport and exercise psychology: A lifespan perspective (pp. 165-196). Morgantown, WV: Fitness Information Technology.

West, C., \& Zimmerman, D.H. (1987). Doing gender. Gender and Society,1,125-151.

Whitehead, M. (2001). The concept of physical literacy. European Journal of Physical Education, 6(2), 127-138.

Whitehead, M. (Ed.) (2010). Physical literacy: Throughout the lifecourse. London: Routledge.

Williams, A., \& Bedward, J. (2002). Understanding girls' experience of physical education: Relational analysis and situated learning. In: D. Penney (Ed.), Gender and physical education: Contemporary issues and future directions (pp. 146-159). London: Routledge.

Williams, A., Bedward, J., \& Woodhouse, J. (2000). An inclusive national curriculum? The experience of adolescent girls. European Journal of Physical Education, 5, 4-18.

Withagen, R., \& Van der Kamp, J. (2010). Towards a new ecological conception of perceptual information: Lessons from a developmental systems perspective. Human Movement Science,29(1),149-163.

With-Nielsen, N., \& Pfister, G. (2011). Gender constructions and negotiations in physical education: Case studies. Sport, Education \& Society, 16,645-664.

Wilson, M. (2002). Six views of embodied cognition. Psychonomic Bulletin \& Review, 9(4), 625-636.

Wright, J. (1996). The construction of complementarity in physical education. Gender and Education, 8(1), 61-80.

Wright, J. (1997). The construction of gendered contexts in single sex and co-educational physical education lessons. Sport, Education and Society,2,55-72.

Wright, J. \& Forrest, G. (2007). A social semiotic analysis of knowledge construction and games centred approaches to teaching. Physical Education and Sport Pedagogy, 12(3), 273-287.

Young, R.A., \& Collin, A. (2004). Introduction: Constructivism and social constructionism in the career field. Journal of Vocational Behavior, 64(3),373-388.

Yousef, A.M.F., Chatti, M.A., \& Schroeder, U. (2014). Video-based learning: a critical analysis of the research published in 2003-2013 and future visions. In eLmL 2014, The Sixth International Conference on Mobile, Hybrid, and On-line Learning (pp. 112-119).

Zerai,Z. (2018). Verbalization and learning in handball. Advances in Physical Education, 8,7-19.

Zosuls, K.M., Martin, C.L., Ruble, D.N., Miller,C.F. Gaertner, B.M. England, D.E., \& Hill,A.P. (2011). 'It's not that we hate you': Understanding children's gender attitudes and expectancies about peer relationships. British Journal of Developmental Psychology,29,288-304. 


\section{Samenvatting in het Nederlands (Summary in Dutch)}

\section{Een verkenning van taakgerelateerde interacties tussen leerlingen in het bewegingsonderwijs}

Voor leerlingen die in het bewegingsonderwijs positieve ervaringen opdoen, is de kans groter dat zij later blijvend, zelfstandig, verantwoord en perspectiefrijk deelnemen aan sport en bewegen. Het tegenovergestelde is ook mogelijk op het moment dat negatieve ervaringen leiden tot een afkeer van lessen bewegingsonderwijs. De kans is dan aanwezig dat op latere leeftijd de behoefte en het plezier aan sport en bewegen vermindert. Positieve leerervaringen zijn daarom van cruciaal belang voor het ontwikkelen van een positieve beweegidentiteit, wat weer leidt tot een meervoudige deelnamebekwaamheid.

Bewegingsonderwijs is een vakgebied waar veel ruimte is voor interacties. Onderzoek toont aan dat docent-leerlinginteracties onmiskenbare dynamiek toevoegen aan het functionele curriculum zonder dat leerkrachten zich daar bewust van zijn. Dit onzichtbare aspect wordt ook wel het 'verborgen curriculum' genoemd. Tussen leerlingen onderling vinden echter ook interacties plaats. Dit gebeurt zowel in informele situaties, bijvoorbeeld tijdens deelname aan bewegingsactiviteiten, als in formele situaties, zoals tijdens geplande en gestructureerde discussies tussen leerlingen over spelstrategieën. Er is nog relatief weinig onderzoek gedaan naar hoe deze interacties de ervaringen van leerlingen mede vormgeven en hoe zij denken dat deze interacties hun leerprocessen beïnvloeden. Interacties tussen leerlingen kunnen dus ook een verborgen curriculum creëren.

In dit onderzoek verken ik deze ervaringen van leerlingen over interacties met andere leerlingen in taakgerelateerde informele en formele situaties. Ik ga in deze verkenning uit van de aanname dat leren betrekking heeft op persoonlijke 
ervaringen en afhankelijk is van contextuele factoren. Mijn focus ligt dus op de betekenissen die leerlingen met elkaar construeren over en tijdens hun taak en niet op de leeruitkomsten.

De centrale onderzoeksvraag in dit proefschrift is: Hoe beïnvloeden informele en formele taakgerelateerde interacties tussen leerlingen een curriculum in het bewegingsonderwijs? Voor de beantwoording van deze centrale vraag is het proefschrift opgesplitst in vier delen. In deel 1 wordt een inleiding gegeven op het onderzoek, inclusief een theoretische onderbouwing (hoofdstuk 1). Vervolgens wordt de context van bewegingsonderwijs in Nederland beschreven waar de verschillende onderzoeken zijn uitgevoerd (hoofdstuk 2). In deel 2 worden de percepties van leerlingen van informele taakgerelateerde interacties onderzocht en worden de volgende deelvragen beantwoord:

- Hoe beschrijven leerlingen hun leerervaringen in bewegingsonderwijs (hoofdstuk 3)?

-Wat zijn de percepties van leerlingen ten aanzien van samenwerken, groepssamenstellingen en vriendschapsrelaties in een aangepast softbalspel (hoofdstuk 4)?

- Hoe vormen genderconstructies de keuzes van leerlingen in het samenstellen van groepen en daarmee hun leren (hoofdstuk 5)?

Deel 3 van dit proefschrift heeft betrekking op onderzoek naar formele taakgerelateerde interacties. De volgende deelvragen worden beantwoord:

- Hoe nemen leerlingen tactische elementen waar in een spelgecentreerde setting met video op basis van een 'debate of ideas' (hoofdstuk 6)?

- Hoe worden percepties van leerlingen gevormd in het gebruikvan een didactische tool die taakgerelateerde interacties stimuleert in een spelgecentreerd curriculum (hoofdstuk 7)?

Deel 4 bestaat uit de beantwoording van de centrale onderzoeksvraag en een discussie van de implicaties van de bevindingen.

In hoofdstuk 1 wordt het theoretisch kader van sociaal constructivisme uitgewerkt, wat als basis dient voor alle hoofdstukken. Een van de grondleggers van deze 
leertheorie is Vygotsky, die ervan uitgaat dat het leerproces een actief proces is van kennisverwerving, waarbij de kennis ontstaat en gedeeld wordt met anderen. Dit uitgangspunt geeft sturing aan de beantwoording van de onderzoeksvragen, waarbij ik ook gebruikmaak van andere concepten als 'situated learning' en 'affordances'.

Hoofdstuk 2 start met een beschrijving van het concept 'physical literacy' (PL) zoals het in Nederland en in een aantal andere Europese landen wordt gebruikt. PL wordt beschreven als de motivatie en het vertrouwen om eigen motorische mogelijkheden verder te ontwikkelen en het bezit van competentie en kennis om blijvend te kunnen deelnemen aan sport en bewegen. PL wordt in toenemende mate verbonden met de praktijk van het bewegingsonderwijs. Onder invloed van personalistisch denken ontstaat er een herwaardering van PL en wordt de nadruk gelegd op een aantal invloedrijke ontwikkelingen. Deze ontwikkelingen gaan over de groeiende weerstand tegen onderwijssystemen die het accent leggen op louter kwantificeerbare leeruitkomsten, de rol van digitale technologie en de nadruk op

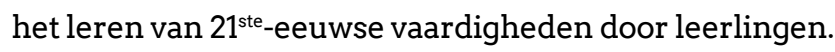

Uitgangspunten van PL zijn nauw verbonden met de algemene doelstelling en pijlers van het Nederlandse bewegingsonderwijs. Deze pijlers hebben betrekking op het 'bewegen regelen,' 'bewegen verbeteren', en 'bewegen beleven'. Iedere afzonderlijke pijler wordt in dit hoofdstuk beschreven en verbonden met de uitgangspunten van PL. Het is daarmee een voorbeeld van een Europese oriëntatie op het vakgebied, die wordt gekenmerkt door betekenisvol bewegingsonderwijs en door het werken aan en behalen van persoonlijke doelen. PL focust meer op plezier in bewegen en het ontwikkelen van een beweegidentiteit en staat veelal haaks op het louter leren van fundamentele beweegvaardigheden.

In hoofdstuk 3 is een verkenning gedaan naar verschillende kwalitatieve methodieken waarmee leerlingen hun ervaringen, gedachten en gevoelens kunnen uitdrukken over het leren van een taak in het bewegingsonderwijs. Het onderzoek is in drie fasen uitgevoerd en bestond uit het toepassen van verschillende onderzoeksinstrumenten, zoals semigestructureerde een-op-eeninterviews, focusgroepen en teken- en schrijfopdrachten. De tekenopdracht is een tool waarmee leerlingen kunnen nadenken over hun ervaringen en de onderzoeker vervolgens in een focusgroep een start kan maken met het gesprek tussen leerlingen over die ervaringen. De inmenging van ideeën van de moderator wordt hiermee geminimaliseerd. De resultaten gaven aan dat een combinatie 
van de 'draw, write, \& tell'-methodiek, gecombineerd met focusgroepen, leidt tot rijkere data dan wanneer alleen individuele interviews of tekenopdrachten worden gebruikt. Uit de gesprekken met de leerlingen blijkt dat ze geen duidelijk beeld hebben van het leerproces en daar ook weinig over kunnen reproduceren. Het samenwerken met anderen in de les vinden ze daarnaast belangrijk. Vooral spreken deze leerlingen over vriendschappen die ervoor zorgen dat in de groep een sfeer van vertrouwdheid ontstaat tijdens het leren van nieuwe opdrachten.

Het onderzoek in hoofdstuk 4 bouwt voort op deze bevindingen en zoomt verder in op de perspectieven van brugklasleerlingen uit één klas over lessen softbal. Daaruit blijkt dat deze leerlingen hun peers zien als een belangrijk onderdeel van de leersituatie. Zij geven aan dat een softbalactiviteit bij uitstek een situatie is waar ruimte is voor interacties met anderen. Samenwerken en interacties met anderen vormen volgens hen een belangrijke voorwaarde waardoor in een les of groep kan worden geleerd. Deze leerlingen werken bij voorkeur samen met vrienden, zoals ook bleek uit de resultaten in het onderzoek van hoofdstuk 3. Er is echter in dit onderzoek een gevarieerder beeld ontstaan over hoe leerlingen denken over de rol van deze vriendschappen tijdens gymlessen. De kinderen bepalen graag zelf de groepssamenstelling.Vriendschapsrelaties geven de leerlingen de mogelijkheid om met elkaar te spreken, elkaar te helpen en dienen als buffer voor negatieve reacties van andere leerlingen over hun prestaties. Deze vriendschapsrelaties vormen vaak een comfortzone voor de leerlingen tijdens bewegingssituaties. Toch hebben ze niet altijd de voorkeur voor samenwerking met vrienden. Vriendschappen kunnen voor een negatieve samenwerking vormen, wanneer de leerlingen voelen dat ze worden uitgelachen, te veel kletsen of plagen. Leerlingen maken daarnaast constructies van wat andere leerlingen over hun prestaties denken. Die gedachten leiden soms tot mindere prestaties, maar tonen vooral aan dat leerlingen zich zorgen maken over de houding van hun medeleerlingen.

Uit deze studie blijkt dat interacties met anderen in de les leiden tot verwachtingen van klasgenoten en voorkeuren voor samenwerkingsverbanden. De lessen softbal worden niet alleen beschouwd als een plek om plezier te beleven. Leerlingen geven ook aan dat ze zo goed mogelijk willen presteren. In dat geval zijn vrienden niet altijd geschikte klasgenoten om mee samen te werken. In eerste instantie kiezen kinderen bij voorkeur voor groepen waarin vrienden zitten om plezier in de les te beleven. Maar zodra de bekendheid met de activiteit en het doel dat de leerkracht stelt duidelijk is, verandert ook hun voorkeur. Ze willen dan vooral 
ook samenwerken met leerlingen (niet-vrienden) die complementair zijn aan hun eigen bewegingsvaardigheden.

In hoofdstuk 5 analyseer ik de perspectieven van leerlingen over hun voorkeur voor groepswerk met vrienden (maar ook met andere klasgenoten) in bewegingsonderwijs. De vraag die ik in dit onderzoek stel, is hoe genderconstructies werken met betrekking tot de voorkeur van leerlingen voor taakgerelateerde interacties en groepen. Voor hen blijkt de vraag 'Met wie werk ik samen in de groep?' centraal te staan. Leerlingen gebruiken genderneutrale woorden, zoals vrienden of klasgenoten, om deze vraag te beantwoorden. Maar in deze woorden zijn constructies van gender zichtbaar die zijn gebaseerd op hun voorkeuren. Deze vrienden zijn kinderen van dezelfde gender. Jongens werken over het algemeen graag met elkaar samen en datzelfde geldt voor meisjes. Die voorkeuren gaan over een serieuze werkhouding, waarbij ze verwachten dat leerlingen een positieve bijdrage leveren in de samenwerking. Deze verwachtingen zijn impliciet en vinden leerlingen vooral terug wanneer ze met vrienden samenwerken. De voorkeuren voor deze groepssamenstellingen liggen ten grondslag aan de behoefte aan plezier in bewegen tijdens de les en aan het daarmee voorkomen van vervelende ervaringen tijdens het bewegen, zoals in het geval van blunders of motorisch onvermogen.

In hoofdstuk 6 worden de verplichte interacties tussen leerlingen in een formele setting onderzocht. Leerlingen hebben deelgenomen aan debate of ideassessies, verdeeld over meerdere basketballessen. Een debate of ideas is een gestructureerde discussie en uitwisseling tussen leerlingen die plaatsvindt na afloop van een partijspel. Deze discussies gaan over de strategie in een specifieke spelsituatie. Het doel is dat leerlingen met elkaar tot nieuwe inzichten komen die ze kunnen gebruiken voor de volgende partij. In het onderzoek is gekeken in hoeverre leerlingen in het beoordelen van deze situaties onderling overeenstemmen en hoe accuraat zij de spelsituaties beoordelen. Daarnaast is vastgelegd wat leerlingen denken datze hebben geleerd over die specifieke spelsituatie. Data zijn verzameldvan een groep leerlingen waarbij de discussies zijn gecombineerd met door een leerling geselecteerde videobeelden en een groep leerlingen die enkel verbale discussies voerden in de periode tussen twee basketbalpartijen. Uit de resultaten blijkt dat in beide groepen leerling-overeenstemming en accuraatheid relatief laag waren. Dit suggereert dat in een formele onderwijssetting gedurende een lessenreeks met discussies en interacties tussen leerlingen over een gelijksoortige spelsituatie 
veel verschillende en uiteenlopende meningen en perspectieven bestaan. Alleen de leerlingen uit de groep die videobeelden bekeken tijdens de discussies reproduceerden meer overeenkomsten in hun antwoorden dan de groep met enkel verbale uitwisselingen. Het gebruik van videomateriaal tijdens een 'debate' leidt mogelijk tot potentieel hogere overeenkomsten tussen leerlingen in het bepalen van gezamenlijke strategische vervolgen in spelsituaties. Deze bevindingen en de percepties die zijn gevonden in de studies in deel 2 van deze dissertatie vormen een belangrijke bron voor de incorporatie van digitale technologie.

Hoofdstuk 7 focust op de mogelijke consequenties van de conclusies uit eerdere hoofdstukken voor het inrichten van een formeel curriculum in de praktijk. Als voorbeeld wordt het proces van innovatie, introductie en ontwikkeling van een instrument voor het digitaal 'taggen' van spelsituaties beschreven. Met dit instrument kan een leerling op een eenvoudige manier tijdens een partijspel situaties markeren en direct geselecteerde videobeelden beschikbaar maken, om daarmee vervolgens discussies te voeren met medeleerlingen. Het onderzoek naar het gebruik van digitaal 'taggen' in combinatie met het voeren van discussies over spelsituaties tussen leerlingen geeft mogelijkinzichten in hoe kinderen spelsituaties observeren, welke groepssamenstelling (teams) geschikt is voor interactie en wat verwachtingen en keuzes daarin zijn van leerlingen.

In hoofdstuk 8 blik ik terug op de resultaten die zijn beschreven in deel 2 en 3 van dit proefschrift. Uit mijn onderzoek is gebleken dat informele taakgerelateerde interacties tussen leerlingen een informeel, impliciet curriculum kunnen creëren tijdens lessen bewegingsonderwijs. Een dergelijk curriculum werd gevormd door percepties en verwachtingen van leerlingen die wilden voorkomen dat ze afgaan tijdens bewegingsactiviteiten, maar ook omdat ze gendercategorieën maakten en plezier wilden hebben en maken tijdens de les. Deze sociale constructies werden gekenmerkt door de opvattingen van leerlingen die meededen in deze onderzoeken over samenwerken, groepsopdrachten en gestructureerde discussies. Deze leerlingen beïnvloedden elkaars voorkeuren in het uitvoeren van groepsopdrachten, maar ook hun ideeën over samenwerken met klasgenoten in verschillende samenstellingen.

De sociale interacties in de lessen bewegingsonderwijs werden gekenmerkt door de voorkeuren van leerlingen voor plezierbeleving en/of het leveren van prestaties tijdens de lessen. De verwachtingen van de leerlingen van de leersituatie bepaalde 
mede wat hun voorkeuren waren om dat samen te doen met bepaalde klasgenoten of vrienden. Ook de leerdoelen en de bekendheid met de taak speelden een rol in de voorkeuren van de leerlingen. De resultaten suggereerden dat vrienden mogelijk een veilige omgeving creëren, waardoor leerlingen bereid zijn hun eigen mogelijk falen te laten zien in het openbaar. Als ze echter zelf betere prestaties willen leveren, zijn ze mogelijk meer geneigd samenwerking te zoeken met andere leerlingen.

Deze bevindingen worden in dit hoofdstukgeplaatst binnen de theorie van sociaal constructivistisch leren. Deze theorie veronderstelt onder andere dat docenten rekening moeten houden met de invloed van taakgerelateerde interacties tussen leerlingen en hun zone van naaste ontwikkeling. De zone van naaste ontwikkeling heeft betrekking op de potentiële leermogelijkheden van leerlingen wanneer ze hulp krijgen van anderen. Mijn onderzoek laat zien dat wanneer leerlingen met andere leerlingen samenwerken, er niet automatisch sprake is van een zone van naaste ontwikkeling. Het blijkt dat docenten rekening moeten houden met keuzes en verwachtingen van leerlingen die 'social affordances' worden genoemd. Docenten kunnen de leersituatie beïnvloeden door onder andere tegemoet te komen aan deze social affordances, waardoor een betekenisvolle leersituatie kan ontstaan. Deze situatie wordt mede bepaald door het publieke karakter van lessen bewegingsonderwijs en de sportieve achtergrond of sportervaringen van de leerlingen.

Samenvattend kan worden gezegd dat de bevindingen van dit onderzoek naar sociale interacties in lessen bewegingsonderwijs illustreren dat docenten niet onproblematisch kunnen werken volgens vastomlijnde, pedagogisch-didactische curriculummodellen waarin het lessenplan en de bewegingsactiviteiten vooraf zijn uitgeschreven. Tijdens de les is ook sprake van andere dynamieken waar in dat soort methodieken meestal geen antwoorden voor zijn. Niet alleen leerkrachten maar ook leerlingen creëren een verborgen curriculum. De bevindingen uit dit proefschrift geven aan dat voor het formuleren van leerdoelen voor bewegingsonderwijs ook rekening moet worden gehouden met de vaak verborgen dynamiek tussen leerlingen in bewegingssituaties. 


\section{Dankwoord (Acknowledgements)}

Een doorsnee promotietraject duurt meestal lang en kost relatief veel tijd. Dat was in mijn geval niet anders, het is een aanzienlijke tijd geleden dat ikvan start ging. Toch is het verloop van mijn studie niet helemaal vergelijkbaar met dat van een gemiddelde promotie. Zo hebben twee kinderen mijn grote gezin gecomplementeerd en is er een keer verhuisd. Ook heb ik samen met collega's tussentijds mooie boeken gepubliceerd en hebben we interessante onderzoeksprojecten uitgevoerd. Bovendien heb ik in het werk naast mijn promotie diverse functies bekleed. Binnen Windesheim heb ik op verschillende plekken gewerkt, gehopt van Calo naar het Domein, weer terug en weer terug. Genoeg 'life events' die een promotie normaal gesproken op verschillende momenten zouden kunnen tackelen. Maar ze hebben de periode voor mij juist heel waardevol en betekenisvol gemaakt. Ik zou het op deze manier zo weer doen, want ik heb enorm genoten van de afgelopen jaren. Al ging dat soms ook gepaard met teleurstellingen, stevige werkdruk, momenten van impasse of ingewikkelde keuzes voor aandacht tussen bijvoorbeeld het lesgeven of het onderzoek en schrijven.

Ik voel me hoe dan ook vooral een bevoorrecht mens. Bijvoorbeeld vanwege de verkregen kans om op mooie en interessante plekken te komen en daar nieuwe mensen uit ons vakgebied te ontmoeten. Mijn werkplek was bovendien dikwijls niet alleen de Calo of de zolder thuis. Zo heb ik een tijdje aan dit proefschrift mogen schrijven in The Source in Denver, Colorado (VS). Een inspirerende omgeving om afgezonderd te kunnen schrijven, net als de bibliotheek van The University of Auckland (Nieuw-Zeeland), al was het in beide gevallen alleen al vanwege het gevoel van luxe om ongestoord en anoniem in een onbekende omgeving te kunnen werken. Dat voorrecht voel ik ook in de steun van een grote groep mensen die mij op verschillende manieren hebben geholpen. In het bijzonder wil ik hier enkele mensen noemen, met de kans er een aantal te zullen vergeten. Ik wil daarom met de totstandkoming van dit proefschrift bij voorbaat de vele mensen bedanken 
die gedurende het promotietraject met mij hebben samengewerkt en vooral mij hebben gesteund en ondersteund waar nodig.

Bovenal spreek ik mijn waardering uit voor mijn begeleidingsteam. Allereerst ben ik mijn promotor Annelies Knoppers veel dank verschuldigd. Annelies, ik heb ontzettend veel van je geleerd en ik heb bewondering voor je manier van begeleiden. Je hebt een onnavolgbare toewijding voor de wetenschap. Met tomeloze kracht en inzet heb je mij in zo'n beetje alles voor de promotie geholpen. Van het uitvoeren van het onderzoek, het leren schrijven van papers, een verweer opstellen naar reviewers tot aan het begrijpen van mijn gedachten, zowel tijdens discussies als op papier. En dit altijd met een positieve insteek en via enthousiaste aanmoediging. Ik heb dat begrepen als 'Ik promoveer, maar we doen het samen' en dat zal me altijd bijblijven. Met respect voor mijn situatie en werkzaamheden in Zwolle heb je geduld getoond, mij vrijheid gegeven in mijn ontwikkeling of keuzes. En soms heb je me een spiegel voorgehouden. Je bent een inspirator voor het vak. Nooit ging ik met tegenzin via de Oudegracht van station Utrecht naar de USBO, wanneer ik een afspraak met je had. Een heerlijke wandeling waarmee de Oudegracht mede door jouw inbreng voor mij een plek is geworden van inspiratie en uitzichten op een vervolgstap, nieuw plan of idee.

Mijn copromotor Ivo van Hilvoorde wil ik eveneens bedanken voor zijn rol in en waardevolle bijdrage aan het promotietraject. Ivo, je hebt tijdens mijn promotieweg meegekeken vanuit een overkoepelende visie op bewegen en bewegingsonderwijs. Je kritisch constructieve houding ten aanzien van wetenschappelijke concepten en theoretische frameworks hebben het proefschrift voor een groot deel gemaakt zoals het nu is. Ik waardeer dat je in alle stadia van de promotie het onderzoek hebt onderworpen aan gezonde 'academische twijfel'. Ik ben het met je eens dat de discussie niet is gestold maar verder gaat, ondanks dat het proefschrift is geschreven. Van jou heb ik geleerd dat er altijd weer vervolgvragen zijn, maar dat je ook moet stilstaan bij de actuele meerwaarde van de verkregen kennis voor de praktijk. Je feedback is altijd eerlijk en oprecht geweest en met jouw opmerking in teksten als "Ik begrijp dit niet", was voor mij duidelijk dat er soms aan een paragraaf (of concept) nog flink moest worden gesleuteld. Mede door jou heb ik de kans gekregen mijzelf in de kenniskring van het lectoraat Bewegen, School \& Sport te ontwikkelen tot de docent en onderzoeker die ik nu ben. Ik hoop dat we 
nog een tijdje zo doorgaan en samen mogen werken aan nieuwe projecten, alsmede nieuwe boeken, hoofdstukken en een 'bunch of papers' mogen schrijven. Dat is vooral aangenaam als we dit kunnen blijven combineren met af en toe een sportief uitstapje. Zoals mountainbiken in de Schoorlse Duinen of de wat hoger gelegen Rocky Mountains, padel spelen in Spanje, tjoekbal in Leeds, of voetbal en petanque tijdens de master-startdag.

Copromotor Noortje van Amsterdam wil ik bedanken voor haar inzet en betrokkenheid in het proces. Noortje, je bent relatief laat ingestapt in de begeleiding, maar niet minder toegewijd. Je hebt je ogenschijnlijk vrij eenvoudig ingelezen in de materie van mijn onderzoek en afgestemd op de inhoud van de vele conceptteksten die in korte tijd bij je langskwamen. Je expertise en zinvolle feedback hebben een positieve bijdrage geleverd aan de inhoud van het onderzoek. Menigmaal heb ik jouw wetenschappelijke achtergrond en kennis gebruikt ter inspiratie voor mijn schrijven.

Mijn dank gaat ook uit naar Harry Stegeman. Harry, als voormalig lector van Hogeschool Windesheim ben je de initiator geweest in het laten starten van mijn promotie. Je aanmoediging bijna dertien jaar geleden betaalt zich dan toch eindelijk uit. Na jouw periode bij Windesheim kwam ik je soms nog tegen in het land en moest ik mij steeds bij je 'verantwoorden' over de voortgang. Maar nu is het dan eindelijk zo ver. Fijn dat je ook als coauteur van de eerste publicatie jouw aandeel hebt gehad. Voor mij breekt mogelijk de tijd aan dat ik ook over rivieren in de omgeving van Zwolle kan gaan schrijven. Maar misschien stel ik dat nog even uit.

Ik wil daarnaast graag de collega's bedanken die hebben meegewerkt als coauteur aan de verschillende hoofdstukken van het proefschrift, namelijk Wytse Walinga (MSc), dr. John van der Kamp,prof. dr. Hans van der Mars en dr. Niek Pot. Jullie kennis, inbreng en fijne manier van samenwerken zijn voor mij zeer waardevol geweest. John, je bent scherp en complementair in het begrijpen van 'onze' weerbarstige praktijkwereld en gedachtegoed. Je bent voor mij een fijne collega om te werken aan nieuwe ideeën en voorstellen voor ons vak. Je hoort er wat mij betreft helemaal bij en je bent de rapste die ik ken in het geven van feedback. Hans, het is me een waar genoegen dat we elkaar hebben mogen ontmoeten en vervolgens zijn gaan samenwerken, ondanks dat Arizona niet echt heel dicht bij Zwolle ligt. Wat mij 
betreft houden we het contact zo lang het kan nog in stand. Niek, je werkt niet meer op de Calo, maar gedurende die periode heb ik genoten van onze samenwerking en kijk ik met veel genoegen terug op de mooie belevenissen tijdens congressen en meetings. Mede dankzij jou begeven we ons nu moeiteloos in de wereld van physical literacy. Bijzondere dank gaat uit naar vriend, paranimf en 'room mate' Wytse. Dank voor al je betrokkenheid, zowel inhoudelijk als op betrekkingsniveau. Vooral je inspiratie, creatieve geest en mogelijkheid tot (humoristisch) klankborden is onmisbaar in alles wat we samen doen in ons leven en voor het vak. Soms relativeren we met ons werk ons bestaansrecht, maar uiteindelijk doen we het ook voor de kinderen die leren bewegen. Mooi dat je met mij spelend op reis wilde gaan. Als het aan mij ligt, blijven we samen nog langer onderweg met nieuwe plannen en mooie producten. Dan dromen we hartelijk verder over megalomane successen en nemen anders ook gerust genoegen met het kleine en waardevolle dat we hebben om ons heen.

De leescommissie bestaande uit prof. dr. Maarten van Bottenburg, prof. dr. Mariëtte de Haan, prof. dr. Kristine de Martelaer, dr. Frans Prins, prof. dr. Marc Theeboom en de overige leden van de oppositie wil ik graag bedanken voor het lezen en beoordelen van het manuscript. Ik ben jullie zeer erkentelijk voor de beschikbaar gestelde tijd en deskundigheid.

Mijn collega's van de Calo en de collega's van het lectoraat Betekenisvol bewegen van het domein BEvan Hogeschool Windesheim ben ik dankbaar in de wijze waarop ik mijn kennis mocht delen. Uiteraard ook mijn leidinggevenden die er nu en in de afgelopen jaren zijn geweest: Robert Agelink, Jan Doelman, Bram Donkers, Cees Klaassen, Bert Meijer en Henk van der Palen. Met geduld en facilitering hebben jullie op je eigen manier mij de ruimte gegeven om de promotie te doen slagen. Mijn kamergenoten die ik hiervoor nog niet heb genoemd, Corina van Doodewaard, Biek Leissner, Nienke van der Meij en Nicolette Schipper-van Veldhoven, dank ik voor de waardevolle uitwisselingen en samenwerkingsmomenten ten gunste van het mooie onderwijs en onderzoek in de bachelor en master van de Calo. Vriend, oud-kamergenoot en collega Arnold Consten, dank voor alle momenten dat werk even niet belangrijk is maar juist de ontspanning en de relativering. Met onze gezamenlijke momenten van observatie, cabaret en lach houden we ons beiden altijd op de been. 
In de start van de promotie heb ik mijn ideeën in een klankbordgroepje mogen delen met (ex-)collega's Tejo van den Berg, Karel Verweij, Gert van Driel en Chris Hazelebach. Door jullie heb ik toen al veel beter leren inzien dat een eigen algemeen idee over leren niet hetzelfde is als de manier waarop kinderen daar betekenis aan geven. Karel, jouw didactische kennis over groeperingvormen in gymlessen is goud waard. Hopelijk kunnen we daar samen nog eens iets moois van maken. Gert, we zijn samen gestart in de kenniskring en hebben dezelfde fascinatie en interesse voor het leerproces van kinderen. Je hebt me vanaf het begin al aangemoedigd om te gaan starten met de promotie. En het is mooi gelukt dat je aan het eind van het traject ook nog steeds actief betrokken bent geweest. Dank voor al je inzet in de laatste fase, wat ervoor heeft gezorgd dat het proefschrift is gepubliceerd. Chris, bedankt voor al het moois wat we samen hebben beleefd en hebben meegemaakt. Voor mij ben je de inspirator en goeroe van het bewegingsonderwijs. Ik ben ervan overtuigd dat jij dit type onderzoek voor het vak bewegingsonderwijs omarmt en ik ben trots dat de kennis die is opgeborreld uit de verschillende hoofdstukken nauw samenhangt met jouw oorspronkelijke en innovatieve ideeën over didactiek, methodiek en leren bewegen.

Ook wil ik graag nog enkele collega's en organisaties bedanken die in andere verbanden met mij samenwerken of indirect betrokken zijn geweest. Ivo Dokman voor je kennis over groepsdynamica, klasse spel en sportspelen, maar vooral ook voor de gezellige Leuvense workshops. Fijn dat we blijven samenwerken aan een mooie videoanalysetool voor het onderwijs. Stefan Luchtenberg en Dennis Rosink van PEC Zwolle: het ontdekkend leren voetballen voor jeugdvoetballers en het onderzoek is mede door jullie geslaagd.

I would also like to thank my colleagues who collaborated with me within the several international networks. From the Teaching Games network, I thank dr. David Gutierrez diaz Del Campo, dr. Tim Hopper, and dr. Dennis Slade. Furthermore, thanks to dr. Bambang Abduljabar for his invitations to collaborate with me and the very nice discussions we have together, dr. Mauro André for working together with me regarding our master study trip, Margot Bowes for her support during my stay in Auckland, and dr. Margaret Whitehead for the opportunity to publish our chapter in her book and her inspiring way in promoting physical literacy across the world. 
Alle docenten bewegingsonderwijs in het veld en de studenten van de Calo die in dit onderzoek met mij hebben samengewerkt, dank ik voor hun medewerking aan de organisatie en uitvoering van het onderzoek op de verschillende scholen. En natuurlijk gaat mijn speciale waardering uit naar alle kinderen die hebben meegewerkt. Jullie tekeningen en discussies hebben zinvol bijgedragen aan nieuwe kennis waarmee docenten in de toekomst beter toegerust zijn op het geven van lessen bewegingsonderwijs. Medewerkers van Jan Luiting Fonds en Arko Sports Media dank ikvoor hun inzet en de gegeven mogelijkheid om dit boek uit te brengen. Ik werk graag verder samen met jullie aan een vervolgboek over dit onderwerp.

Geen promotie zonder een goede privéomgeving. Dank aan alle teamgenoten van meerdere voetbalteams voor de gegeven gelegenheid om speels te ontspannen. Mark en Kevin, dank voor jullie vriendschap en ontspanning van het samen fietsen en het soms mogen beklimmen van de hoogste cols in Europa. Natuurlijk met mij achteraan in het peloton. Want dat moet altijd iemand zijn, die ook minder traint; fijn dat ik jullie daarmee een goed gevoel kon geven. Door onze vriendschap stond de promotie eens een keer niet op de voorgrond. Ik hoop dat we nog vele jaren mogen genieten van de fietstripjes samen met onze gezinnen.

Mijn ouders, pa en ma, jullie staan aan de basis van alles wat ik heb gedaan en heb bereikt. Ik heb altijd in vrijheid en met geboden ruimte mijn studies kunnen doen en me kunnen ontwikkelen tot degene die ik nu ben. Jullie hebben belangstelling getoond, altijd klaargestaan en op verschillende momenten in het leven onbaatzuchtig hulp geboden. $\mathrm{Ma}$, voor je betrokkenheid op mijn gezondheid en welzijn en je moeite soms oppasoma te zijn helemaal vanuit Houten. Pa, voor je kijk op wat je van je leven maakt en wat je via doorzetten ervan wilt en kunt maken. Mooi dat je mijn vaste bezoeker en reviewer bent geworden van onze kennis-events en bijzonder dat je mij als paranimf tijdens de verdediging wilt bijstaan. Zus Carola, we doen allebei iets heel anders, maar het is altijd fijn en gezellig als we met de kinderen op visite zijn. Mooi om op latere leeftijd te zien, al zal je dat niet denken, dat we toch in bepaalde eigenschappen veel gemeenschappelijks hebben.

Thijmen, Babeth, Alyke en Jenthe. Jullie zijn dit niet gewend van mij te horen, maar jullie zijn mijn geluk en energie waar ik voor leef. Wat is en was het een mooie tijd waarin ik jullie het afgelopen decennium heb zien opgroeien en mogen meemaken. 
"Wanneer is je boekje klaar?" - deze vraag kwam regelmatig terug. Maar met jullie geduld, geloof in de positieve afloop en jullie levendige optimisme is het ook gelukt om als gezin naast mijn promotie veel samen te doen en de dagen te vieren met onze Jip, samen te reizen en van het leven te genieten in gezondheid en welzijn. Dat houden we natuurlijk zo. Ik ben trots op hoe jullie het samen met elkaar doen. Al is dat soms wel eens pittig, toch krijgen we het steeds weer voor elkaar. Ieder op jullie eigen manier hebben jullie spelen, bewegen en bewogen worden meegenomen in jullie levens. Ik ben enorm trots op jullie.

En dan tot slot, my loving lady. Lieve Pauline, uiteindelijk is er maar een die echt naast me staat en die echt weet wie ik ben en door wie ik meer weet over wie ik zelf ben. Natuurlijk zeg ik het te weinig, maar je bent mijn geluk. Je geeft me alle steun, je bent mijn levensmaat, mijn opvang voor alle tegenslag, maar vooral ook mijn klankbord voor alle gebeurtenissen in mijn leven. Laten we nog lang met elkaar lachen, boeiende gesprekken hebben, nabij zijn en elkaars ideeën en interesses met elkaar delen. Boven alles dank voor dat je mijn grote levensliefde mag zijn. 


\section{Curriculum vitae}

Jeroen Koekoek was born on the fourth of July 1973 in Zwolle, the Netherlands. In 1991, he graduated from high school in Nieuwegein. From 1991-1995 he studied physical education teacher at PETE faculty Calo, Windesheim University in Zwolle. From 1995-1999, he studied Human Movement Sciences at VU University. During that period, he also worked as PE teacher in primary and secondary schools in Rotterdam, Amsterdam, and Utrecht. After 10 years of working as PE teacher in a primary school in Utrecht, Jeroen started to work as teacher educator PE and Health in primary education for pre-service teachers at PABO Inholland University of Applied Sciences in Rotterdam.

In 2001, Jeroen returned to PETE faculty Calo, Zwolle (Windesheim University of Applied Sciences) as teacher educator giving games-teaching courses. After a few years he also worked as researcher in the lectorate 'Bewegen en Gedragsbeïnvloeding'. Currently, Jeroen works as Associate Lector Physical Education \& Sport Pedagogy in the lectorate 'Human Movement, School, \& Sports'. In addition, he teaches the courses Designing pedagogical interventions, and New technologies in the master PE \& Sport Pedagogy, and games-teaching in the bachelor of PETE.

His research interests are in the areas of game-based approaches and teacher education related to game pedagogy. Jeroen is member of the International Advisory Board (IAB) of the Teaching Games for Understanding - Special Interest Group (TGfU-SIG) representing the Netherlands. He is involved in several research projects regarding digital technology pedagogy. Currently, he is working on the Smart Sports Exercises project, a multidisciplinary, ZonMw funded project, that aims to improve volleyball practices through the use of interaction technology. Jeroen contributed to several books and papers on physical education and sport with a focus on teaching and learning. Jeroen is co-editor of Routledge's book published in 2018 about international perspectives on digital technology in physical education. 


\section{Peer reviewed papers}

Koekoek, J., Knoppers, A., \& Stegeman, H. (2009). How do children think they learn skills in physical education? Journal of Teaching in Physical Education,28,310-332.

Koekoek, J., Van der Kamp, J., Walinga, W., \& Van Hilvoorde, I. (2014). Dutch elite youth soccer players' perceptions of a TGfU-modified game practice. Ágora para la Educación Física y el Deporte,16 (3),232-254.

Koekoek, J., \& Knoppers, A. (2015). The role of perceptions of friendships and peers in learning skills in physical education. Physical Education and Sport Pedagogy, 20(3), 231-249.

Pot, N., Van Hilvoorde, I., Afonso, J., Koekoek, J., \& Almond, L. (2017). Meaningful movement behavior involves more than the learning of fundamental movement skills. International Sports Studies,39(2), 5-20.

Koekoek, J., Van der Mars, H., Van der Kamp, J., Walinga, W., \& Van Hilvoorde, I. (2018). Aligning digital video technology with game pedagogy in physical education. Journal of Physical Education, Recreation \& Dance,89(1), 12-22.

Koekoek, J., Van der Kamp, J., Walinga, W., \& Van Hilvoorde, I. (2019). Exploring students' perceptions of video-guided debates in a game-based basketball setting. Physical Education and Sport Pedagogy,24(5),519-533.

Koekoek, J., \& Knoppers, A. (2019). Gender categorizations during group work in physical education. Journal of Teaching in Physical Education,39(2),196-205.

\section{Books}

Mooij, C., et al. (2004). Basisdocument bewegingsonderwijs voor het basisonderwijs. Zeist: Jan Luiting Fonds. (co-author)

Koekoek, J., Dokman, I., \& Walinga, W. (2014). Sportspelen. Den Haag: Boom|Lemma. (co-author) 
Walinga, W., Koekoek, J., Luchtenberg, S., \& Rosink, D. (2017). Ontdekkend leren voetballen [Discovery Learning in Youth Soccer]. Deventer: daM Uitgeverij. (coauthor)

Koekoek, J., \& Van Hilvoorde, I. (2018). Digital Technology in Physical Education: Global Perspectives. London: Routledge. (co-editor en co-author)

\section{Chapters in books/abstracts}

Koekoek, J. (2007). Zelf waargenomen competentie in het bewegingsonderwijs. Over de competentiebeleving van kinderen in bewegingssituaties. In: G. van Driel \& P. Heij, Reeks Gordijnlezingen (2), De geboren aanpasser. De Meern: 't Web.

Koekoek, J., Walinga, W., \& Dokman, I. (2009). Understanding baseball in physical education: A methodical approach to enhance learning based on game-like situations. In T. Hopper, J. Butler, \& B. Storey, TGfU...simply good pedagogy: Understanding a complex challenge (pp.115-129.) Canada: PHE.

Koekoek, J., \& Walinga, W. (2014). Nut en noodzaak van taggen in sportspelen. In I. Van Hilvoorde \& J. Kleinpaste (Eds.), Van tikken naar taggen. Digitalisering van bewegingsonderwijs en sport (pp 43-61). Deventer: ...daM uitgeverij.

Koekoek, J., \& Hazelebach, C. (2016). Spelonderwijs en de aandacht voor zwakke en goede leerlingen. In C. Van Doodewaard \& L. Duteweerd (Eds.), MRT in perspectief. Remediërend bewegingsonderwijs. Nijverdal: Hetweb.

Van Hilvoorde, I., \& Koekoek, J. (2017). Digital technology in physical education: Global perspectives (abstract). In A. Bund \& C. Scheuer (Eds.), Changes in childhood and adolescence: Current challenges for physical education, Proceedings of the 12th FIEP European Congress, dd. 13-16 September 2017, Luxembourg. Berlin: Logos Verlag.

Koekoek, J., Walinga, W., \& Van Hilvoorde, I. (2017). Improving game based pedagogy by technology. Game balance analysis and digital video tagging within a TGfU setting. (abstract). In A. Bund \& C. Scheuer (Eds.), Changes in childhood and adolescence: Current challenges for physical education (pp. 160-161), Proceedings 
of the 12th FIEP European Congress, dd. 13-16 September 2017, Luxembourg. Berlin: Logos Verlag.

Walinga, W., Koekoek, J., \& Van Hilvoorde, I. (2017). Video guided debate of ideas to enhance student's tactical knowledge in a modified (TGfU) basketball game (abstract). In A. Bund \& C. Scheuer (Eds.), Changes in childhood and adolescence: Current challenges for physical education (pp. 269-270). Proceedings of the 12th FIEP European Congress, dd. 13-16 September 2017, Luxembourg. Berlin: Logos Verlag.

Van Hilvoorde, I., \& Koekoek, J. (2018). Next generation PE: Thoughtful integration of digital technology. In J. Koekoek \& I. Van Hilvoorde (Eds.). Digital technology in physical education: Global perspectives. London: Routledge.

Van Hilvoorde, I., \& Koekoek, J. (2018). Digital technologies: A challenge for physical education. In C. Scheuer, A. Bund, \& M. Holzweg (Eds.), Changes in childhood and adolescence: Current challenges for physical education (pp. 54-63). Berlin: Logos Verlag.

Koekoek, J., Pot, N., Walinga, W., \& Van Hilvoorde, I. (2019). Perspectives on physical literacy in continental Europe. In M. Whitehead (Ed.), Physical literacy across the world (pp. 143-155). London: Routledge.

\section{Conference contributions and workshops (international)}

Koekoek, J., \& Van Driel, G. (2006). Construction of learning tasks in movement education. Oral presentation during the AIESEP World Congress in Jyväskylä (Finland); July 2006.

Koekoek, J., Knoppers, A, \& Stegeman, H. (2008). Seeing skills through the eyes of elementary school students: Research methods, poster presentation during the 4th TGfU-conference, May 2008, Vancouver (Canada).

Koekoek, J., \& Ten Brinke, G. (2008). TGfU in soft and baseball, practical session during the 4th AIESEP-TGfU conference, May 2008 in Vancouver (Canada). 
Koekoek, J., Knoppers, A., \& Stegeman, H. (2009). From a child's perspective: The social context of $P E$ and learning in a TGfU baseball unit, poster presentation during the AIESEP seminar, May 2009 in Besançon (France).

Koekoek, J., Knoppers, A., \& Stegeman, H. (2010). Understanding games: Peer influence and gender differences in learning baseball, during the AIESEP-TGfU symposium, October 2010 in La Coruna (Spain).

Koekoek, J., Knoppers, A., \& Stegeman, H. (2011). Children's perceptions of learning tasks in physical education: a grounded theory approach [Percepciones de los Ninos de las Tareas de Aprendizaje en la Educacion Fisica: Un acercamiento a la Teoria Basada en la Evidencia] poster presentation during the ISSA World Congress, July 2011 in Havana (Cuba).

Koekoek, J., \& Walinga, W. (2012). Sportspelen en betekenisvol leren. Practical session, Katholieke Universiteit Leuven (KUL) en Katholieke Hogeschool Leuven (KHL), Belgium, June 2012.

Koekoek, J., \& Knoppers, A. (2012). Learning modified games through children's eyes: Perceptions of teaching methods and teacher influence, poster presentation during the 5th TGfU conference, July 2012 in Loughborough (England). Award: 'Best poster presentation'.

Koekoek, J., \& Walinga, W. (2013). Sportspelen en betekenisvol leren. Practical session. Katholieke Hogeschool Leuven (KHL), Belgium, June 18th 2013.

Koekoek, J., \& Walinga, W. (2014). European Handball. Practical session for PE teachers at Massey University, Palmerston North, New Zealand, February 7th 2014.

Koekoek, J., Van Hilvoorde, I., Van der Kamp, J., \& Walinga, W. (2014). Accuracy and reliability of tagging and video feedback to enhance tactical knowledge: Student's perspectives within a TGfU Basketball setting. Practical session during the AIESEPTGfU Symposium February 9th; University of Auckland, Auckland, New Zealand. 
Koekoek, J., Van Hilvoorde, I., Van der Kamp, J., \& Walinga, W. (2014). TGfU in Dutch $P E$ : Integrating methodical notions with digital observation tools. Practical session during the AIESEP-TGfU Symposium February 9th; University of Auckland, Auckland, New Zealand.

Koekoek, J., Van Hilvoorde, I., Van der Kamp, J., Knoppers, A., \& Walinga, W. (2014). A grounded theory analysis of children's perceptions of learning tasks in physical education. Oral presentation during the AIESEP World Congress February 2014; University of Auckland, Auckland, New Zealand.

Koekoek, J., Van Hilvoorde, I., Van der Kamp, J., Knoppers, A., \& Walinga, W. (2014). Consulting children's thoughts about their learning experiences in PE: Analysis of the draw, write and tell method. Poster presentation during the AIESEP World Congress February 2014; University of Auckland, Auckland, New Zealand (Award: 2nd price, best poster presentation).

Koekoek, J., \& Walinga, W. (2014). Sport games. A game centered approach for instruction and curriculum development. 2-day didactic course and workshops on teaching games for understanding, professional development physical education teachers, 13th and 14th October; FPOK Universitas Pendidikan Indonesia; Bandung, Indonesia.

Koekoek, J. (2014). A game centered approach for instruction and curriculum development in physical education and sport. Keynote speaker International Conference on Sport and Physical Education, Improving quality of life through sport and physical education; 15th and 16th October, 2014. FPOK Universitas Pendidikan Indonesia; Bandung, Indonesia.

Koekoek, J., \& Walinga, W. (2015). Digitalisering in sportspelen; Practical workshop, June 2015, Katholieke Universiteit Leuven; Faculteit Bewegingswetenschappen.

Van Hilvoorde, I., \& Koekoek, J. (2016). Digital technology in the PE classroom: The need for a clear pedagogical view. Oral presentation 2016 AIESEP Conference, Blazing New Trails: Future Directions for Sport Pedagogy and Physical Activity; 8-11 June; University of Wyoming, Laremie, USA. 
Koekoek, J., Van der Kamp, J., Walinga, W., \& Van Hilvoorde, I. (2016). Understanding students' ability to perform a digital tagging task within a TGfU basketball setting; poster presentation during the AIESEP Conference, Blazing New Trails: Future Directions for Sport Pedagogy and Physical Activity; 8-11 June; University of Wyoming, Laremie, USA. (Award: 2nd price, best poster presentation).

Koekoek, J., \& Walinga, W. (2016). Handbal vanuit een game centered approach; Practical workshop, Belgium, June 2016, Katholieke Universiteit Leuven; Faculteit Bewegings- en Revalidatiewetenschappen.

Koekoek, J. (2016). From movement concept to pedagogy. Implementing TGfUpedagogy to enhance student learning. Guest lecture, 18th July, FPOK Universitas Pendidikan Indonesia; Bandung, Indonesia.

Koekoek, J. (2016). TGfU concepts for elite youth team sports performance. Conference on high skilled sport performance; 23rd August; Invited presentation for the West Java Sport Committee; Bandung, Indonesia.

Koekoek, J., Agelink, R., \& Schipper-van Veldhoven, N. (2016). Outline applied research and innovation. Invited by Faculty of Health and Sport Sciences, Tsukuba University, Tsukuba, Japan.

Koekoek, J., \& Van der Kamp, J., \& Van Hilvoorde, I. (2017). Digital technology in the physical education classroom. From research to pedagogy. Masterclass presentation for the regional department of Castilla La Mancha (physical educators and staff),21st March 2017, Universidad Castilla La Mancha, Toledo, Spain.

Koekoek, J., Dokman, I., \& Walinga, W. (2017). Spelenderwijs leren handballen: Oog voor content, competentie en groepsdynamiek. Practical session, dd. 19-20 March 2017, Faculteit Bewegings- en Revalidatiewetenschappen, KU Leuven, Leuven, Belgium.

Koekoek, J., Pot, N., \& Van Hilvoorde, I. (2017). Digital applications Video-catch and Game Balance Analysis. Invited presentation at the University of Sheffield, dd. 27 June 2017, Sheffield, UK. 
Pot, N., Van Hilvoorde, I., \& Koekoek, J. (2017). Physical literacy in the Netherlands. Presentation during the International Physical Literacy Association (IPLA) symposium dd. 28-29 June 2017, Liverpool, UK.

Koekoek, J., \& Walinga, W. (2017). Game based pedagogy through the use of technology. Presentation during visit of Japanese scholars from Fukuoka University and Toin Yokohama University 31st August 2017, Windesheim University of Applied Sciences.

Koekoek, J., Walinga, W., \& Van Hilvoorde, I. (2017). Improving game based pedagogy by technology. Game balance analysis and digital video tagging within a TGfU setting. Oral presentation during the 12th FIEP European Congress, dd. 1316 September 2017, Luxembourg.

Walinga, W., Koekoek, J., \& Van Hilvoorde, I. (2017). Video guided debate of ideas to enhance student's tactical knowledge in a modified (TGfU) basketball game. Poster presentation during the 12th FIEP European Congress, dd. 13-16 September 2017, Luxembourg.

Koekoek, J., \& Kleinpaste, J. (2018). Game balance analysis within TGfU invasion games to foster PETE student's teaching skills. Practical workshop during the AIESEP TGfU Symposium, dd. 26 July 2018, University of Edinburgh (UK, Scotland).

Koekoek, J. (2018). (1) Formative assessment for tactical learning. Using VideoCatch for iPad. (2) Designing rich learning environments in PE. Using game balance analysis for iPad. Showcase during the AIESEP specialist seminar "Future directions in PE assessment", dd. 18-20 October 2018, Fontys University of Applied Sciences, Eindhoven, The Netherlands.

Postma, D., Van Delden, R., Walinga, W., Koekoek, J., Van Beijnum, B.J, Salim, F.A., ... \& Reidsma, D. (2019, October). Towards Smart Sports Exercises: First designs. In Extended abstracts of the annual symposium on computer-human interaction in play companion extended abstracts (pp. 619-630). ACM. 


\section{Publications (national)}

Van Driel, G., \& Koekoek, J. (2005). Constructie van leertaken in het bewegingsonderwijs (1), Lichamelijke Opvoeding,5,9-14.

Van Driel, G., \& Koekoek, J. (2006). Constructie van leertaken in het bewegingsonderwijs (2), Lichamelijke Opvoeding, 14,33-35.

Van Driel, G., Koekoek, J., \& Stegeman, H. (2007). Constructie van leertaken in het bewegingsonderwijs (3), Lichamelijke Opvoeding, 1,46-48.

Koekoek, J. (2007). Attractief handbal spelen (1). Lichamelijke Opvoeding, 6,28-30.

Koekoek, J. (2007). Attractief handbal spelen (2). Lichamelijke Opvoeding, 7,24-27.

Koekoek, J., \& Walinga, W. (2007). Attractief handbal spelen (3). Lichamelijke Opvoeding, 8,20-23.

Van Hilvoorde, I.M., Dumasy, E., Hoogendam, A., Kleinpaste, J., Koekoek, J., Pot, J.N., Van Doodewaard, C., \& Van Muijen, H. (2011). Onderzoek naar 'School, Bewegen \& Sport'. Lichamelijke Opvoeding,2, 8-11.

Koekoek, J., Walinga, W., \& Dokman, I. (2013a). Sportspelen. Fundament voor het ontwerpen van leerrijke spelsituaties (1). Lichamelijke Opvoeding, 1,22-24.

Koekoek, J., Walinga, W., \& Dokman, I. (2013b). Sportspelen. Fundament voor het ontwerpen van leerrijke spelsituaties (2). Lichamelijke Opvoeding,2,20-23.

Koekoek, J., Walinga, W., \& Dokman, I. (2013c). Sportspelen. Fundament voor het ontwerpen van leerrijke spelsituaties (3). Lichamelijke Opvoeding, 6,34-36.

Koekoek, J., Walinga, W., \& Dokman, I. (2013d). Sportspelen. Fundament voor het ontwerpen van leerrijke spelsituaties (4). Lichamelijke Opvoeding, 9,14-17.

Koekoek, J., Walinga, W., \& Van Hilvoorde, I. (2013). Digitale spelanalyse in het bewegingsonderwijs. Lichamelijke Opvoeding, 8,16-18. 
Koekoek, J., Walinga, W., \& Van Hilvoorde, I. (2015). Spelanalyse met Video-catch voor de iPad. Een combinatie van digitale techniek, vakinhoud en didactiek in het spelonderwijs. Lichamelijke Opvoeding, 6,16-18.

Treub, J., \& Koekoek, J. (2019). Student designed games als models-based practice. Lichamelijke Opvoeding,3,9-11.

Van Hilvoorde, I., Koekoek, J., \& Walinga, W. (2019). De internationale aantrekkingskracht van Physical Literacy. Lichamelijke Opvoeding, 8,11-13.

\section{Public press}

Koekoek, J., \& Walinga, W. (2013). In de praktijk van de gymles; interview met radio 1, Lunch! NCRV; dd. 8-11-2013:

http://www.radio1.nl/item/168298In\%20de\%20Praktijk\%20van\%20de\%20gymles. html

Van Hilvoorde, I., Koekoek, J., \& Kleinpaste, J. (2014). Groeiende invloed van digitalisering op het (leren) bewegen. Column in SportknowhowXL; dd. 14-01-2014: http://www.sportknowhowxl.nl/alleen-op-de-wereld/8722

Van Hilvoorde, I., Koekoek, J., \& Kleinpaste, J. (2015). De gymzaal bedreigd als wifivrij reservaat. Column in SportknowhowXL; dd. 03-03-2015:

http://www.sportknowhowxl.nl/nieuws-en-achtergronden/open-podium/ item/97365/

Koekoek, J., Van der kamp, J., \& Van Hilvoorde, I. (2017). La Tribuna; Monroy, J. Experienca Danesa Deporte Con Nuevas Technolgías. Digital technology in the physical education classroom. From research to pedagogy. Masterclass presentation for the regional department of Castilla La Mancha (physical educators and staff), March 21,2017,Universidad Castilla La Mancha, Toledo, Spain.

Koekoek, J., Walinga, W., \& Van Hilvoorde I. (2017); Jeugdvoetballers hebben baat bij experimenteren en ontdekken. Column SportknowhowXL; dd. 16-05-2017:

http://www.sportknowhowxl.nl/nieuws-en-achtergronden/column-xl/item/109449/ 
Koekoek, J. (2017). Ontdekkend leren in jeugdvoetbal. Interview with BNR nieuwsradio, dd. 07-06-2017.

Koekoek, J. (2017). De jeugdtrainer moet meer zijn mond houden en spelers hun gang laten gaan, interview met RTV Oost, dd. 07-06-2017:

http://test2.rtvoost.nl/tag/Windesheim/270182/de-jeugdtrainer-moet-meer-zijnmond-houden-en-spelers-hun-gang-laten-gaan?o=1

Weelink,G. (2018). Ontdekkend leren voetballen (1,2 en 3), interview and elaboration of the book 'ontdekkend leren voetballen' [Discovery learning in soccer] in magazine De Voetbaltrainer.

https://www.voetbaltrainer.nl/magazine/voetbaltrainer-236/

Steenbergen, P. (2019). Videovloer brengt sporter en coach verder. Interview with De Stentor, dd. 25-04-2019. 


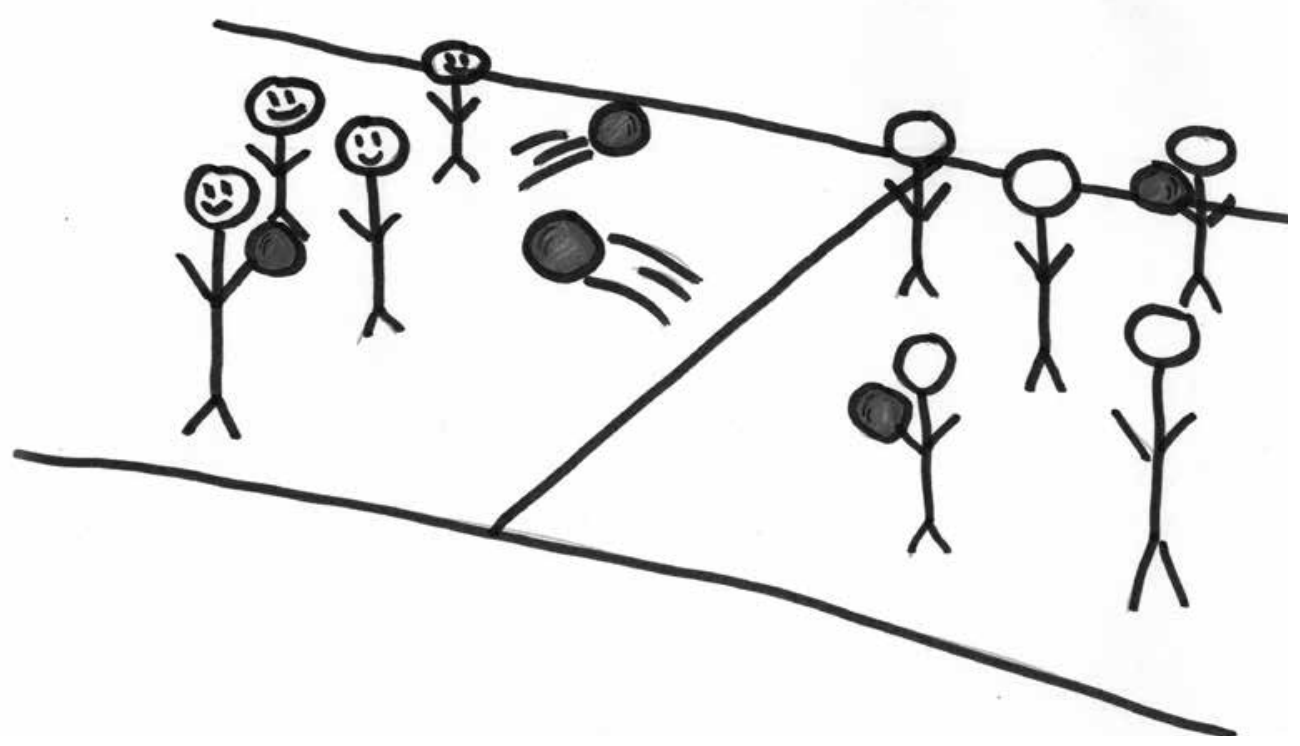

Drawing Alyke. 
Appendices 


\section{Appendix 1}

Dutch elite youth soccer players' perceptions of a TGfU-modified game practice

\section{Appendix 2}

Co-auteursverklaring hoofdstuk 2

\section{Appendix 3}

Co-auteursverklaring hoofdstuk 3

\section{Appendix 4}

Co-auteursverklaring hoofdstuk 4

\section{Appendix 5}

Co-auteursverklaring hoofdstuk 5

\section{Appendix 6}

Co-auteursverklaring hoofdstuk 6

\section{Appendix 7}

Co-auteursverklaring hoofdstuk 7

\section{Appendix 8A and 8B}

Topics, sample questions, and interview schedule (Chapter 3)

\section{Appendix 9}

Examples of student answers to the single question (Chapter 6) 


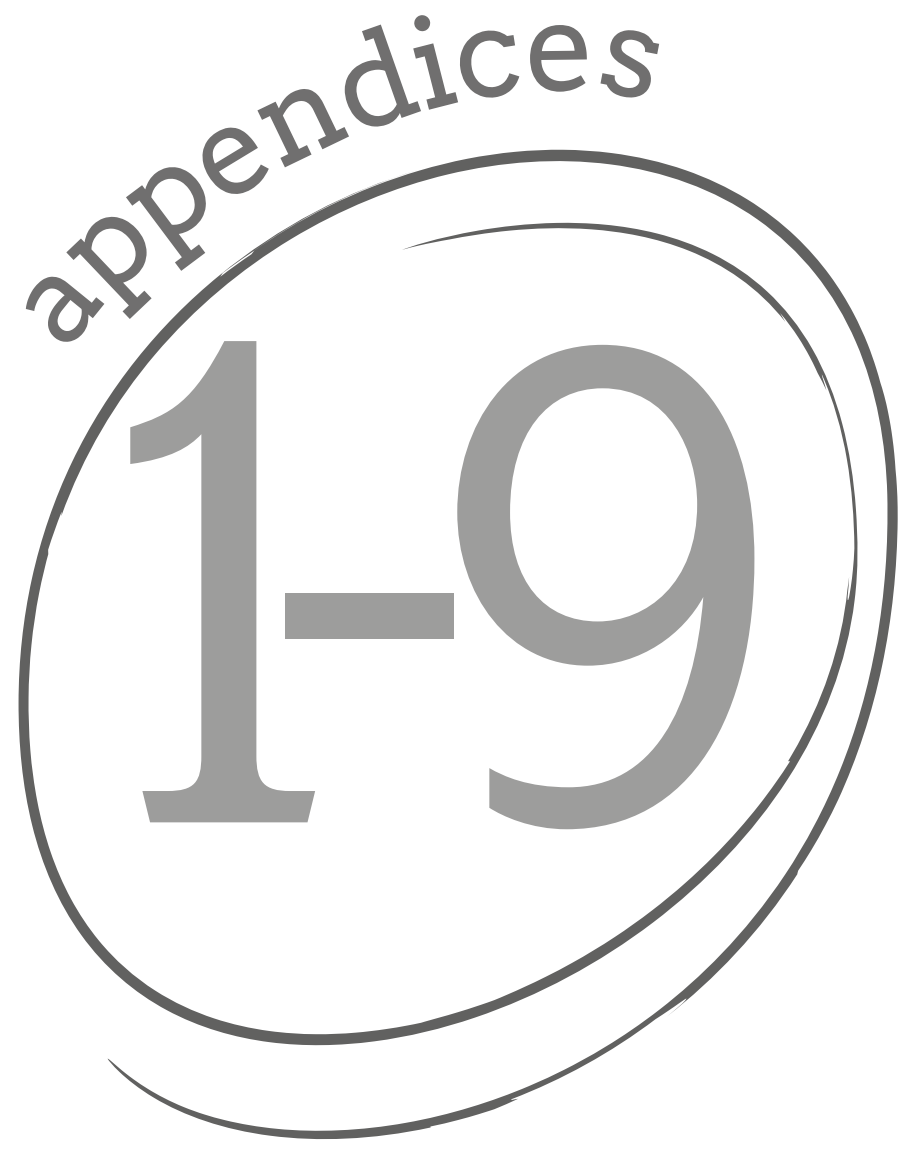

244 


\section{Appendix 1 \\ Dutch elite youth soccer players' perceptions of a TGfU-modified game practice}

\section{Abstract}

A game-based approach in physical education and sport settings focuses on the players' learning of tactical decision-making. TGfU pedagogical principles provide teachers and coaches method to structure their players' decision-making practices by reducing the demands of a complex game. The purposes of this study were (1) to examine youth elite soccer players' perceptions of practicing in a small-sided game; and (2) to describe the process of implementation of a pedagogical intervention tool (Game Balance Analysis, GBA) and how it provides guidelines for the design of modified game practices. Two Dutch coaches and youth elite soccer players ( $N=17$ ) of one team participated in the study. The draw, write, and tell method was used to elicit players' perceptions of learning of tactical decision-making. During one soccer season, GBA was used to design learning objectives, playing scenarios, and constraints in small-sided games. The results showed that the players were fully aware of what tactically can be learned in small-sided games, but they also had contradictory perspectives to what they think that is important to learn.

\section{Abstract}

El enfoque basado en el juego en Educación Física y en contextos deportivos se centra en el aprendizaje de la toma de decisión por parte de los jugadores. Los principios pedagógicos del modelo TGFU aportan a docentes y entrenadores las claves para estructurar las prácticas de toma decisión a partir de la reducción de la complejidad de los juegos. Los objetivos del presente estudio fueron: (1) examinar 
las percepciones de jóvenes jugadores de fútbol de nivel élite,sobre sus experiencias en la práctica de juegos reducidos y (2) describir el proceso de implementación de una herramienta de intervención pedagógica (Game Balance Analysis, GBA) y las directrices aportadas a partir del uso de esta herramienta para el diseño de sesiones de entrenamiento mediante juegos modificados. Dos entrenadores holandeses y jóvenes futbolistas de nivel élite $(N=17)$ de un mismo equipo participaron en el estudio. El método de dibujar, escribir y contar se utilizó para obtener las percepciones de aprendizaje de toma de decisiones tácticas de los jugadores. Durante una temporada, la GBA se utilizó para diseñar los objetivos de aprendizaje, los escenarios de juego, y las características de los juegos reducidos. Los resultados mostraron que los jugadores eran plenamente conscientes de lo que tácticamente se puede aprender en juegos reducidos, pero también mostraron puntos de vista contradictorios sobre lo que ellos piensan que es importante aprender.

Published as:

Koekoek, J., Van der Kamp, J., Walinga, W., \& Van Hilvoorde, I. (2014). Dutch elite youth soccer players' perceptions of a TGfU-modified game practice. Ágora para la Educación Física y el Deporte,16(3),232-254. 


\section{Introduction}

In the last 10 years, there has been a mounting interest in nonlinear pedagogical approaches to enhance learning games in physical education (PE) and sport, in particular with regard to tactical decision-making (e.g., Chow et al., 2007; Davids, Button, \& Bennet, 2008). An important reason for this increasing awareness is that nonlinear pedagogical approaches emphasize that learners should search or explore solutions themselves, rather than teachers or coaches being overly prescriptive about what and how they must learn. Evidently, nonlinear pedagogy is becoming more relevant because it enhances intrinsic motivation and results of meaningful improvements in tactical skills (Renshaw, Oldham, \& Bawden, 2012; Tan, Chow, \& Davids, 2012). The nonlinear pedagogical approach provides insights that support teachers and coaches in how game practices can be structured for acquisition of tactical skills (Gréhaigne, Bouthier, \& David, 1997; Renshaw, Chow, Davids, \& Hammond,2010). It helps teachers and coaches to choose and use relevant pedagogical tools that, from a methodological viewpoint, contribute to curriculum development, adapted lesson plans, and long-term improvement of tactical complexity (Tan et al.,2012).

One nonlinear pedagogical tool is to tinker the practice constraints. In this constraints-led approach the acquisition of tactical skills is conceived as arising from the (interactive) influences of individual, environmental, and task constraints on the game (Davids et al., 2008, p. 114). This provides many ideas for designing rich learning environments in PE lessons and sport practices for manipulating constraints (e.g., adjustments in task, rules, field size and equipment) that benefits tactical learning. Yet, there is a paucity of research that examines how manipulating these constraints can channel tactical learning without the teacher or coach being prescriptive. It is therefore difficult for practitioners to translate the theoretical nonlinear pedagogical concepts into actual game practice, because there is a lack of knowledge about their application in the gym or on the playing field.

One possible application is the Teaching Games for Understanding (TGfU) model. TGfU provides operable concepts for developing game settings that are adapted to the players' learning needs (Bunker \& Thorpe,1986; Kirk \& MacPhail, 2002; Oslin \& Mitchell,2006). One key aspect is the design of well-structured games (often reduced in game complexity) in which players have considerable opportunities of making appropriate decisions (Harvey \& Jarret,2013; Oslin \& Mitchell,2006). In general,TGfU settings centralize decision-making learning by using pedagogical principles such 
as game sampling (i.e.,transfer of learning across games), representation (i.e.,playing games with a comparable tactical structure), exaggeration (i.e.,practice adjustments that emphasize a tactical problem), and tactical complexity (Griffin \& Patton, 2005). Because of its focus on the learners' needs, it is important that teachers and coaches are aware of the learners' personal reference models (Gréhaigne, Richard, \& Griffin, 2005).These include motivation, affect, and tactical knowledge. Accordingly, tactical decision-making in small-sided games (by which the complexity of the regular game is reduced) entails asking players to make appropriate action choices by focusing on both (1) what to do; and (2) how to do this in the game situation. Consequently, learners become fully engaged in solving tactical problems instead of focusing only on the learning of techniques or motor skills. The TGfU pedagogical principles, such as small-sided games, provide learners a more constrained workspace for exploring tactical solutions in the game (Richardson, Sheehy, \& Hopper, 2013). However, it is pertinent to also assess the learners' perception of the learning process, because their experiences may be a crucial aspect for achieving positive learning outcomes. Hence, this issue is important if players' perceptions (i.e., what they think and feel about their learning) influence this process as well (Koekoek \& Knoppers, 2013). This presumes that players' perceptions in game learning are an invaluable source of information that could have consequences for the designing of the learning environments. We therefore address players' perceptions and specifically focus on players' views and voices in a team sport and how they influence the learning of tactical skills.

\section{The role of players' perceptions in learning tactical skills}

For severalyears, an important role has been given to players' perceptions of learning in PE and sports with a focus on engagement, meanings, and authenticity (Dyson, 2006; O'Sullivan \& MacPhail,2010). Particularly, the meanings of players about their own learning are preferentially and widely valued as an important indication for arranging effective learning environments (Brooker \& Macdonald, 1999; Koekoek, Knoppers, \& Stegeman,2009; Lee,2010; Rikard \& Banville,2006). For example, Strean and Holt (2000) asked youth soccer and hockey players as well as their coaches what they thought about the practices. The coaches had a preference for teaching isolated techniques instead of improving players' tactical understanding. The players, however, wanted to have fun by playing games instead of performing drills. 
The authors emphasized the discourse of coaches who think their players need to learn technical skills (e.g., to improve their confidence) rather than give them space to learn in game contexts. The study also suggested that a TGfU approach may help children to become more involved in the game and increase feelings of control. Rather than a focus on drills, providing children the opportunity to restructure games may optimize the balance between motivational challenge and skill learning.

Only a few studies within the field of game-centered approaches have paid attention to the role of children's perceptions in learning. Pope (2005) found that feelings and emotions may shape decision-making skills. He contended that learning is guided by these affective elements, and that they often pilot the learner's decisions. It follows that in designing practice, children need to have a voice in participating, making decisions, and the possibility of learning from tactical views of the game by themselves. Perceptions of peers and social interactions also play a decisive role in learning games. Koekoekand Knoppers (2013) found that perceptions of children, who learned a modified baseball game in PE, changed through influences within the social context that depended on the composition of teams, the presence of recognizable performance goals in the game, and with whom they wanted to play. In a similar study, Light (2006) stimulated dialogue between children about their learning experiences by using drawings. This showed that the children perceived and valued interactions as an important part of learning. Although these aforementioned studies demonstrate the important influence of the social context, the learning objectives, and feelings of involvement, still relatively little is known about its role in TGfU modified game settings. The current investigation, therefore, aims to increase the knowledge base to better explain how players perceive learning in modified game settings and how this affects learning of tactical decision-making.

From this perspective, it is important that learning needs and perceptions of players guide the design of rich learning environments. Accordingly, in modifying game structures coaches need to be creative in adjusting constraints that match the player's perceptions and tactical skill levels. Game Balance Analysis (GBA), which is fully consistent with a TGfU approach, is proposed as an appropriate pedagogical tool to achieve this. In GBA, the teacher or coach must modify a game such that it (1) provides insights in game play; (2) is appropriate to adjust game constraints; and (3) supports in adapting games to the players' tactical skill levels (Koekoek, Dokman, \& Walinga, 2014). Through exaggeration of the game, particular tactical problems during play are emphasized, while the complexity of the game gradually increases. 
This aspect is useful in game-centered approaches because it ensures that coaches modify the games according to the players' need in learning to make decisions. However, a difficulty in adjusting game forms is that coaches tend to make tactical instructions very prescriptive. These tactical instructions are often not aligned with the player's individual capacity. For example, the modification of small-sided soccer games (e.g., overload 3 vs. 2) would not automatically enhance the tactical skills of all players (Holt, Ward, \& Wallhead, 2006). Hence, the purpose of this study was (1) to explore youth elite soccer players' perceptions of practicing in a modified game (i.e., when they learn tactical skills); and (2) to describe how GBA provides guidelines for the design and implementation of modified game practices that take the players' learning needs into account. In particular, our exploration focuses on players' observations of how they think they learn decision-making skills. Furthermore, we describe the process of experimenting with game constraints and gathering tactical learning objectives using GBA. Hence, these insights might expose trends in game practice modifications and accompanying instructions. As noted earlier, the nonlinear pedagogy approach assumes a learner centered position in the acquisition of tactical skills. Consequently, through adjusting game constraints tactical learning occurs rather through self-organization and independent from the coach's verbal instructions.

\section{Methodology}

\section{Context of the study}

Most of the Dutch professional soccer clubs in the Netherlands have established a youth academy. PEC Zwolle is a professional soccer club that currently plays in the first national league ("Eredivisie"). The main purpose of the PEC Zwolle Youth Academy is to prepare young boys for being professional soccer players. Through facilitating practice and by working with high-skilled coaches, these players develop a broad spectrum of skills they will need as a professional player. Since an important goal of the club is to play soccer with a recognizable style, players are taught defensive and offensive game concepts that fit the club's playing philosophy.

The Youth Academy has nine youth soccer teams with children between seven and 18 years. At the age of seven, children are selected from the regional partner soccer clubs or through regional youth tournaments to participate at one club practice 
session each week. After the children are nine years of age, they are selected and actually start playing until they are 18-19 years old. Once selected and 12 years old, the children take lessons at the same secondary school. This school facilitates an adapted educational program that supports talented players in organizing their busy life. They adjust school schedules to fit soccer practice and matches. Furthermore, the school lessons are tailor-made to the players cognitive learning capacities. The staff of the Youth Academy monitors players' development on more than only soccer skills. Their support fits with a broader pedagogical perspective and ensures that the children are balanced with respect to school work and performance, soccer practice and matches, and physical load, and the private situation at home. Each youth team has a staff that consists of two coaches supplemented with a physiotherapist, a team manager, and a team assistant.

\section{Participants}

Children of one youth team $(N=17)$ participated in the study. They (boys, aged 1112) played in the Dutch D-category and are club members for one to three years. At this age, the Academy increasingly emphasizes the development of players' tactical skills. Because these players already played a few years at the club, they were capable of telling in some depth about their learning experiences and feelings, and distinguish changes in game structure and concepts in the practice sessions during the season. Two soccer coaches of the Youth Academy of PECZwolle participated and were member of the project group. These coaches had several years of experience as a coach of (professional) soccer youth teams.

\section{Procedure}

The project group was composed of two researchers and two coaches of the Youth Academy. This group worked together and organized meetings (approximately one meeting a week) to develop new ideas for game practices. Additionally, observations of practices and informal talks with the players, coaches, and staff members were used to support the innovations in game design.

The research included one soccer season plus a preparation period of four months. In its first stage, the two coaches were introduced to several concepts of game-centered approaches in the context of PE and sport. They also practiced with using the GBA tool to design games. In other words, the coaches were encouraged to change their custom habits in the way they structured games during practice. 


\section{Game Balance Analysis (GBA)}

GBA consists of four steps that enable coaches to adjust and design several varieties of the game (Koekoek et al., 2014). Moreover, GBA allow us to describe the process of implementation of small modified games in the curriculum of the Academy. The four steps are as follows:

Step 1. Adjusting team compositions, field sizes, and rules to achieve engagement. Coaches need to adjust the composition of teams to have similar skill levels as much as possible. At the start, the coach wants players to be engaged in the learning situation and prevent that they show a lack of motivation. For example, if a power play (overload) situation is practiced, the coach forms two equal teams and should choose the accompanying player (who plays with both teams when attacking) to have a skill level that complements the performances of the team. It is important that the introductory game meets the standards of the tactical skill levels of most of the involved players. To achieve this, the coach focuses on adjusting rules, field size, and equipment.

The central aim of this first step is initiating the game. Both teams should have the opportunity to explore several strategies and find as many tactical solutions as possible. This exploration phase is mandatory when introducing a completely new (modified) game, so that players are able to investigate the possible "degrees of freedom" (exploring the scope of playing strategies). At the start of the game, the coach ensures that they have chosen a good team position in the field and clarifies the game concept. Players need to understand the aim of the game and take position in the field that is appropriate to their current decision-making skills. For example, the position of the midfield player compared to a winger requires different tactical skills.

\section{Step 2. Investigating GBA between attack and defense.}

The second step begins after playing a few small matches, once players get used to the rules, field sizes, the possible tactical strategies, and skill levels of their team members. Evidently, a variety of these aspects may influence how the game is played. It is assumed that when making adjustments to the game, the coach takes these aspects into account. Coaches then investigate the strength of the attack and defense of the teams by counting the percentage of scores with respect to the amount of ball possessions of the attack (see Table 1). With the help of this ratio, game practices can 
be analyzed in terms of the potential amount of opportunities for learning for the players. The observation procedure starts with two sessions of 10 ball possessions (attempts).

Table 1 Game Balance Analysis (GBA). Relation between the amount of scores and conclusions for the game balance and subsequent game design.

\begin{tabular}{|c|c|c|}
\hline $\begin{array}{l}\text { AMOUNT OF SCORES FROM NUMBER } \\
\text { ATTEMPTS (BALL POSSESSIONS) }\end{array}$ & CONCLUSION & CONSEQUENCE \\
\hline 4 OR 5 OUT OF 10 & Equal game balance & $\begin{array}{l}\text { Both attack and defense roles have } \\
\text { many chances to learn }\end{array}$ \\
\hline $\begin{array}{l}2 \text { OR } 3 \text { OUT OF } 10 \text { AND } 6 \text { OR } 7 \text { OUT } \\
\text { OF } 10\end{array}$ & Small imbalance & $\begin{array}{l}\text { It is possible that over a period of time } \\
\text { one of the two roles leads to a decrease } \\
\text { in play motivation of players }\end{array}$ \\
\hline $\begin{array}{l}0 \text { OR } 1 \text { OUT OF } 10 \text { AND } 8,9 \text { OR } 10 \text { OUT } \\
\text { OF } 10\end{array}$ & Imbalance & $\begin{array}{l}\text { There is a unilateral power of one the } \\
\text { two roles (attack or defense). This } \\
\text { situation leads to a frustrated learning } \\
\text { situation. The attack or defense is too } \\
\text { strong within the game and the game } \\
\text { contains few learning opportunities }\end{array}$ \\
\hline
\end{tabular}

Step 3. Consequences of GBA for each phase in the game.

In the third step, the coach identifies the phase of the game (building up the attack, creating scoring chances, or utilizing scoring chances) in which the game's (im)balance occurs. In order to have an effective transfer to game design, it is necessary to draw a conclusion for GBA with respect to one of the three phases in the game. In this investigation, game design represents the balance outcome and justifies the direction of adjusting the game.

Step 4. Concluding and determining follow up (game design).

Both the game (im)balance conclusion and the particular phase of the game determine the coach's pedagogical interventions. If the coach accomplishes game balance, the game is well-organized and achieves rich learning environment standards. Moreover, the coach does not need to make extensive adjustments to the game. The game provides enough learning opportunities, while over a period of time, the coach searches for a small imbalance game situation for one of both teams in order to give a chance to recover the game to a balanced situation. Through continuously manipulating these balances, the game maintains a rich learning environment. 
In a small imbalance situation, the game can be defined as near-optimally organized. This means that players need some support without the coach modifying the rules, field sizes, or equipment. The chosen interventions focus on either individual or group tactical instructions with the purpose of recovering the game balance. Importantly, both the game balance and the small imbalance situations require adjustments. However, these interventions focus on the team strategy with verbal instructions, giving compliments, or asking questions. If there is a large difference between players' skill levels within teams, the coach should focus on the players' individual learning. Instructions consist of (1) decisive decision-making skills in the game focusing on time, space, pass, and run directions; (2) exploring and assigning tactical solutions; and (3) focusing on technical skills.

By contrast, if there is strictly an imbalance in power of either the attacking or defending team, the game is defined as a non-learning or poor-learning game situation. Modification and adjustments of the game structure is required (e.g., field and goal sizes, playing rules, number of players, equipment).

\section{Eliciting players' perceptions with the draw, write, and tell method}

We used a draw, write, and tell method to assess players' perceptions of learning. Several studies have indicated that the use of focus groups in combination with draw and write/tell techniques provides relevant, authentic information about children's learning experiences (MacPhail, Kinchin, \& Kirk, 2003; Koekoek et al., 2009). Although a single analysis of drawings also provides significant information about children's perceptions, we did not analyze these data. Instead, children's drawings in the current study were used as a cue for them to express thoughts and feelings and to stimulate meaningful dialogue among them (Bland,2012; Darbyshire, MacDougall, \& Schiller, 2005; Koekoek \& Knoppers, 2013; Light, 2006).

We conducted the draw, write, and tell method after the second half of the season. From the start of the soccer season these players had several experiences with playing in small-sided games. The players were asked to draw pictures about their practices and what they thought they learned in general. Thus, they were not specifically asked to draw pictures of small-sided games. Directly after making the drawings, the players participated in a focus group. To elicit the perceptions of all players of the team, four focus groups were organized consisting of three or four players. The focus groups enabled the players to exchange a great variety of practice experiences. First, each player individually explained his drawing, and subsequently, 
a group discussion wasstarted about one of these players' drawings. Two experienced moderators participated in the focus group. The group discussions were structured by the following topics: (1) the players' learning experiences; (2) what they think (in terms of motivation) about playing in small-sided games; and (3) what they think about the game practice and the coach's instructions. The focus group sessions lasted between 30 and 45 minutes.

\section{Data analysis}

We structured the implementation of game design by using video clips of practices and matches. For each game form, we determined children's learning opportunities on the basis of GBA results. The videos structured the process of assigning learning objectives in the real game ("match-like") and the development of small-sided game modifications. Methodical steps in this game design were marked with the use of fieldnotes. The meetings with the coaches were used to discuss the scope of these steps, and the consequences for developing self-regulated learning interventions, learning objectives, and individual skill levels.

We analyzed the interview data from a constructionist discourse analysis perspective (Barker \& Rossi, 2011). According to Barker and Rossi (2011, p. 143), "discourse analysis consists of elements that emphasize individuals' constructions of their world through the use of language in relation to others." The focus group discussions were audio recorded and transcribed. The data were analyzed with the constant comparative method (Charmaz, 2006; Glaser \& Strauss, 1967). After each focus group, line-by-line coding was used to identify both implicit concerns and explicit statements (Charmaz, 2006). Together with written memos these codes were combined and analyzed. This method enables researchers to develop and refine theoretical categories and themes during an iterative process. The following themes emerged from the data: (1) perceptions of performance and objectives in the game; (2) the coach's role in facilitating learning during practice; and (3) perceptions of practicing a small-sided game as a place for learning. 


\section{Results}

\section{Implementing GBA for game design}

Determining team functions and tasks. Discussions with trainers and staff before they implemented GBA showed the different team functions identified in matches and in the development and modification of small-sided games in practices (see Table 2).

Table 2 Summary of team functions with the associated team tasks that are used at the Youth Academy.

\begin{tabular}{|l|l|}
\hline TEAM FUNCTION & \multicolumn{1}{c}{ TEAM TASKS } \\
\hline 1. ATTACKING & $\begin{array}{l}\text { - Building up the attack through passing between players } \\
\text { - Utilizing scoring chances }\end{array}$ \\
\hline 2. DEFENDING & $\begin{array}{l}\text { - Disturbing teamwork of the opposite team that try to make } \\
\text { effective passing combinations } \\
\text { - Trying to avoid or holding goals }\end{array}$ \\
\hline $\begin{array}{l}\text { 3. CHANGE OVER FROM ATTACK TO DEFENSE AND VICE } \\
\text { VERSA }\end{array}$ & $\begin{array}{l}\text { - Trying to make a fast change while preventing mistakes } \\
\text { - Trying to make a change with as many players as possible in } \\
\text { the team by making clear agreements }\end{array}$ \\
\hline
\end{tabular}

Since the classification of team functions and accompanying team tasks may help the coaches to design practices, we used this format as a frame of reference for the construction of learning objectives and skill levels in small-sided games. By observing practice sessions, we identified a starting point for modifying the working method of the Youth Academy. A central recurrent theme during these practices was how players learned that each team position implies a set of rules according to which to play the game. At each position in the team, a player must learn these rules with an eye for playing the match. Each practice consisted of several activities such as warming up, enhancing technical skills, strength, velocity, and developing tactical awareness through small-sided games. Most importantly (for the current purposes), at the end of each practice, a game (e.g., 9 vs. 9 instead of small-sided) is played that imitates the 'Saturday'-match, during which players practice according to the tactical agreements associated with their team position. The coaches called this part of practice 'applied practice'. 'Applied practice' was typically characterized by a prescriptive way of enhancing awareness of the team goals and appropriate tactical solutions. The learning of the team goals played an important role in match preparation. Prior to the implementation of GBA, the coaches judged the learning of tactical skills as the central learning objective for practice. This first evaluation 
of the practice sessions also showed a connection was lacking between what had to be learned during the other parts of practices and the 'applied practice'. 'Applied practice' turned out to have learning objectives that limited the amount of solutions that players have available to solve a problem in the game. In other words, players were unable to explore new opportunities in the game. The degree of freedom to find tactical answers in the game was strongly limited by the set of rules imposed by the coach. Hence, the construction and design of practice was relatively coachdirected, even though the Academy aims to develop independent players with high awareness of the decisions they make. Hence, the coach-directed approaches typically used were not in accordance with the club's policy. On the basis of these observations, the project group started to introduce GBA to design small-sided games for learning tactical skills.

Introducing GBA: Objectives and design from application back to exploration. The 'applied practice' was analyzed relative to team functions and team tasks. Several general objectives in these games were recognized as potential ingredients for developing a small-sided game (see Table 3).

Table 3 General learning objectives of playing a game of 3 against 1 with one goalkeeper.

\begin{tabular}{|c|c|}
\hline PHASE OF THE GAME & GENERAL LEARNING OBJECTIVES \\
\hline 1. BUILDING UP THE ATTACK & $\begin{array}{l}\text { - Passing and receiving the ball with a light resistance of defense play } \\
\text { - Developing awareness of the position of opponent players (in front or beside) } \\
\text { - Taking an effective position in the field in order to receive the ball from team } \\
\text { members } \\
\text { - The central attacking player takes position 'behind the ball' in order to receive it when } \\
\text { the player with the ball is under pressure }\end{array}$ \\
\hline 2. CREATING CHANCES TO SCORE & $\begin{array}{l}\text { - Receiving the ball at a position from which it is likely to score } \\
\text { - 'Making space' and passing along the opponent } \\
\text { - Dribbling in the direction of the goal in order to score or trying to attract defenders } \\
\text { and making space for other attacking players } \\
\text { - Translocate the attack zone in the game by changing the side of attacking and } \\
\text { unexpectedly pass to another team member }\end{array}$ \\
\hline 3. UTILIZING A SCORING CHANCE & $\begin{array}{l}\text { - Shooting at the goal from a position from which it is highly likely to score } \\
\text { - Making an appropriate decision between shooting on the goal or continuing the } \\
\text { attack } \\
\text { - Using space and time for technique selection that optimizes the likelihood to scoring }\end{array}$ \\
\hline
\end{tabular}

Taking the perspective of the team task 'building the attack', we adopted the scenarios that can occur in match play and designed a new small-sided game (see Figure 1). This game included the same tactical learning goals as in the games that 
were played in the 'applied practice'. However, the focus of the small-sided game is on players' exploration of tactical opportunities to enhance tactical creativity instead of following the coaches' prescribed learning objectives and rules.

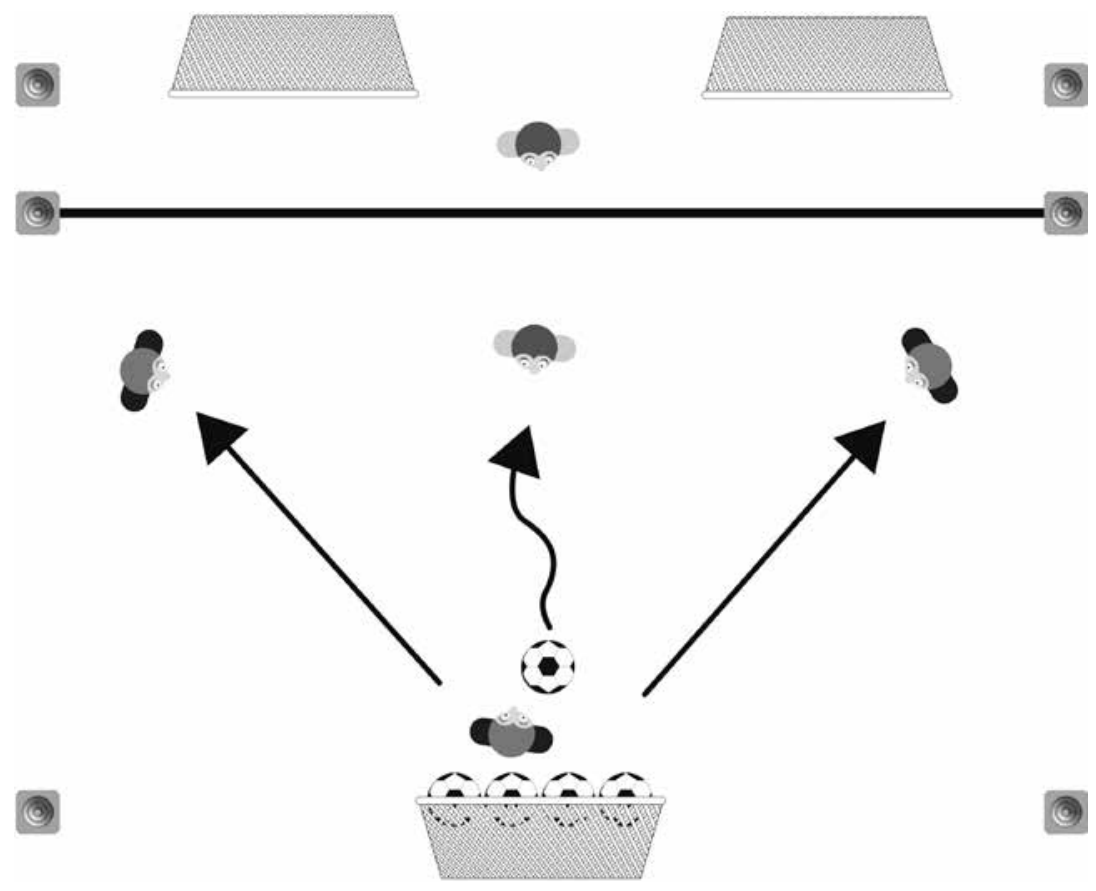

Figure 1 Design of the small-sided game 3 against 1 with one goalkeeper (edited from Koekoek et al., 2014).

This simplified game (played on a field measuring 25 by 20 meters) has been modified without erasing the central characteristics of soccer (except the offside rule). This small-sided game incorporates the learning of rules that coaches typically practiced in 'applied practice', but with a greater amount of players. The aim of the game is that three attackers have five attempts to try to score in one of the two small goals. The defender tries to disturb the attack or steal the ball, while one goalkeeper behind the line tries to prevent a score. When both the defender and the goalkeeper intercept the ball they get one chance (one attack) to score on the (bigger) goal. In this game, attacking players encounter different decision-making situations that correspond to the learning objectives. For example, players have to decide whether they must dribble, pass along the defender, or pass the ball to team 
members. Furthermore, the task of the central attacker is to stay in position in order to always be able to receive the ball from the wing players. He also changes the direction of the attack zone when needed.

Video analysis of several practices and discussions of the 3-1-1 game revealed playing scenarios that frequently occurred during the game (see Table 4). Both results of GBA and the scenarios provided guidelines for making adjustments in the game. For example, adjusting the field width and number of small goals (exaggeration) can influence both the GBA results and the tactical skill level of players. The process of designing a new game form began when most of the scenarios were no longer present in the 3-1-1 version. The next step was using GBA in a small-sided game with four attackers, two defenders, and two goalkeepers (4-2-2).

Table 4 Playing scenarios in the 3-1-1 game in order to make modifications.

PLAYING SCENARIOS FOR IMPROVEMENT AND DESIGN (3-1-1 SMALL-SIDED GAME)

An attacking player with the ball focuses too much on his own action instead of taking the other team members' opportunities into account.

2. Passing and receiving the ball between players takes too much time. It takes too long for scoring goals.

3. Players who take too much time when having ball possession lose the ball to the defender.

4. Attacking players pass the ball through the air instead of passing the ball on the ground.

5. Attacking players take position too close to each other. The defender has a chance to intercept the ball or pressures the attackers into giving a wrong pass.

6. The central player ' 1 ' runs too far into the direction of the goals. The defender has chances to make effective passing screens.

7. Both wing players fail to make any decisions after receiving the ball.

8. The defender runs to the player with the ball but is frequently too late. He has little chance to intercept the ball or to disturb the attack.

\section{Players' perceptions of learning in a small-sided game}

Perceptions of performance and objectives in the game.

The players were able to give complex and rich details of their opportunities for learning in the game during practice. In particular, the players reproduced tactical team tasks and functions of several positions mirrored from the adapted game as needed for the match they play on Saturdays. Furthermore, they showed a strong tactical awareness of how they could practice the game in relation to what they think they learned, what they were supposed to learn, and to what degree they achieved these goals. Most of the players had positive experiences with playing in the small- 
sided games. They recognized that these games were good and appropriate for practice because they were comparable with a real match: "The game is similar with a match playing the ball on the midfield and passing to the center forward or wingers." Nevertheless, a few players criticized the game in regard to what they thought that could be learned from it:

Player 1: I like this game, but actually I think I don't learn anything. When we play three against two it would be more challenging for us. Player 2: Yes I think so, playing this game with an extra defender in the field would be more difficult.

Players had clear ideas on how to adjust the game into a rich learning environment. For example, they developed awareness about the significance of the amount of players. Furthermore, players also noticed that different functions in the game influenced their meanings:

This game is really nice but sometimes I don't like it. For example, if I have a bad day. As a defender, you constantly have to intercept balls and run through the field. Yes, being a defender is not always fun.

Players also used some details in the game and explained what they liked:

Player 1: [I like this game] simply because I have to play the ball around. Sometimes I suddenly have the ball in front of me.

Player 2: In this game, we constantly have to change position. I like this rule because then I can play in each position. 
One group discussed one of the adjustments of their coach. Children were asked how the game can change when the coach keeps score by counting the number of goals and attempts. This discussion showed how players changed their attitude:

Player 1: By keeping score, I play much more decent. I also have more focus on my shot on the goal. Most players want to score goals as many as possible, but then it doesn't work.

Interviewer: Would 5 scores within 5 attempts be feasible?

Player 2: 5 out of 5 is really overdone. Players would pass the ball and are then too rushed.

Interviewer: Ok, but what if your coach does not use this counting system?

Player 1: I think there will be too many shots on the goal. Yes, we have more trouble playing together and will not be careful when we pass balls.

Moreover, players also preferred to play the game as a match or at least at a higher complexity level:

Player 1: I don't like this game if we use the small goals. If we play this game we need to have large space between the players. Thus, with both a large field and more defenders the game becomes more difficult and attractive.

Interviewer: Why do you think with these adjustments this game would be more attractive?

Player 2: We can work together and give each other instructions.

Most of these conversations reflect what players thought what they could learn in the game and how it supported their learning for matches. This showed that the tactical goals of the adapted game (i.e., increase in tactical skills) were achieved, however, many players also indicated a preference for playing the game with more complexity (fewer options to score, more defenders etc.). 
The coach's role in facilitating learning during practice.

The players not only had clear opinions about the small-sided game and the benefits for tactical decision-making, but they were also aware of the coaches' role during the practice sessions. One player explained his drawing and said: "This player runs to the '10 position' so that we can block the attackers. My coach told me [this]. He explained all these things at the start of the season." During the conversations, many players mirrored the coach's behavior, his instructions, and how he responded to the decisions and actions players made during practice: "We often play small matches during practice. Our coach stops the game and explains what we can learn. A midfield player often does not know what he must do. But after practicing you get more information." These players were asked about the role of the coach in this situation and answered: "He shouts very loudly and said: Stop! Everyone must stand still. He then explains which options we have. He also gave us examples. And he tells a player on the sideline [of the field] what to do."

The players also discussed the explicit interventions the coach used during practice of the game. A number of players commented on the feedback they received about the way they play the game as a team. The coach provided them feedback through assigning a level of performance. For example, these players explained how the assignment of playing levels works as a pedagogical tool:

Player 1: [A 'level 3 game'] is when we have a fast ball circulation. We pass the ball very quickly and safely. Thus, we play the ball effectively. Interviewer: How do you know which level your team is playing? Player 1: While playing a game, the coach tells us what kind of performance level we have.

Player 2: Yes, he notices our level and explains how we have to play better. He doesn't explain these levels for each individual player. He makes a judgment for the team. 
Many players appreciated the coach's explicit judgment of team performance. These comments indicated that they clearly understood what their coach intended with assigning playing levels. Also in another focus group, some players articulated these performance requirements in detail:

Player 1: He [the coach] tells us that when we play a 'level 1 game', players need to get used to the game and watch how tactics work. A level 2 play situation consists of searching for solutions and doing things better. Level 3 is doing important things and knowing when.

Player 2: I think everyone has level 2.

Interviewer: Do you think that by yourself or did your coach tell you? Player 1: No, my coach didn't say that. But sometimes while playing the game he said, "This is really a 'level 3 play'."

Interviewer: Do you know what your coach means by this?

Yes [all the players said together]. It is when you pass the ball well or take initiative.

The players often identified the coaches' verbalization as the most important source of information. Even though the coach used many visual examples during practice, it was typically the coach's verbal explanations that the players considered. For example, a player explained his drawing:

Player: This [he points to his drawing] goalkeeper has got the ball. The other player passes the ball to the center back and he starts to dribble forwards with the ball. After this, he passes the ball to the midfielder, and so further on to the center forward or wingers. When I'm the center back, I have to dribble with the ball, and if I am the right fullback, then I have to keep the ball to the side to look after a wide playing field. Interviewer: How did you learn this?

Player: The coach told me. 
Obviously, although this player had detailed awareness of the tactical complexity of the game, on the whole he reproduced the coach's tactical intentions for the team. In most of the discussions, players talked about learning in terms of explicitly complying with the rules. In one discussion, players talked about passing straight balls:

Player 1: If we play a match [on Saturday], we are only allowed to make actions on the middle field or near the 'sixteen'.

Player 2: Yes, and my coach also tells me that, as a full back, I can dribble with the ball till the center line. And when I meet an opponent, then I have to pass the ball.

Player 3: And as a winger, you must try to get the ball in the area of the goal. Most of the time the coach wants us to take these actions.

Player 1: Actually, there is always a rule for everything and each position.

Interviewer: Are you able to make actions in the back positions?

Yes [all the players together].

Player 2: Yes, only if we search for space instead of staying with an opponent.

Player 3: Indeed, together with the midfielder. He must ask for the ball from the back.

In this discussion, the players show the tension available between adherence to made agreements and exploring ("doing") opportunities that arise during the game. Remarkably, these players articulated the rules as a set of open opportunities or choices to explore. However, they frequently answered these questions with "yes, but only...", indicating that the constraints were very strict within a small workspace to explore. The coach had a mandate on the degrees of freedom that had been assigned to exploring the rules.

Evidently, the last remarks show that players seem to have explicit awareness of many rules that exist during practices and matches. They explained that the coach wanted them to use and obey the rules. In general, the players perceived a comfortable situation in establishing such a learning environment. In addition, the players' comments show conformity with the way they think learning works 
in a soccer team. The next discussion also provides insight into how natural this apparently works:

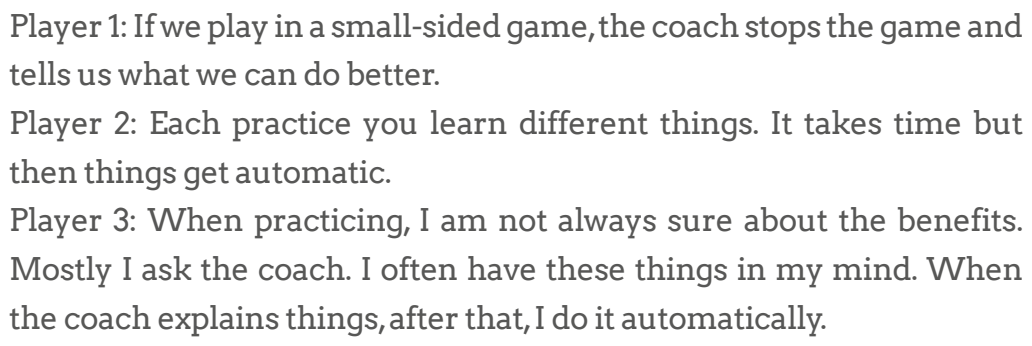

The players thus regulate an important part of their learning by themselves. Most of them reproduced important team positioning and rules with a reference to the coaches' instructions. These perceptions indicate a significant prescriptive contribution of the coaches, and their struggle to fully implement a learnercentered-approach. At the same time, a few players explained they had learned and understood tactics by experiencing them while playing. For a coach this may be a central aim: to get the players in a learning modus that induces them to develop creativity and the ability to think during the game. A discussion about receiving the ball in an "open" or "closed" position shows the players" perspectives on this:

\footnotetext{
Player 1: [In an "open" position] I can see what is happening around me.

Player 2: Yes. If someone is entering my back and I lose the ball, I know whether I have to bounce the ball or turn around and start to dribble. Interviewer: How did you learn this rule?

Player 1: It is an agreement.

Player 2: Yes, but it is understandable if you think logically.
}

The answer of the first player shows the coach's role in facilitating learning. The second response indicates that players are aware that they also should trust their own capabilities. This short conversation also suggests that the coach facilitates learning according to TGfU principles without being too prescriptive. In a similar discussion about receiving balls in an "open" position, players articulated that they trust their own capacity to learn from playing the game: 
Player 1: [Pointing to his drawing] This is a straight ball. If somebody gets between them, we lose the ball.

Interviewer: How do you know this?

Player 1: We learned this from our coach. Yes, but also by myself through trying and feeling during playing the game.

Player 2: Yes, I learned most of things here [at this club].

Player 3: Yes, me too. At the [soccer] club I was before I only learned basic things. Here [at this club] I learn to play soccer how it is supposed to be. Learning soccer to become a better player.

Perceptions of practicing a small-sided game as a place for learning.

In each discussion, the players were asked what they thought about learning technical and tactical skills during the small-sided games. Mostly, the players felt that they had possibilities to explore new things in the game. According to their comments, learning in the game also implies making mistakes: "I try to avoid making mistakes, but my coach says you have to make mistakes. Yes, that's true, you can learn from your mistakes. But in that case, he [the coach] wants us to get ball possession as quickly as possible." Although the players explained that they were allowed to make mistakes during practice and matches, the conversations also indicated that the opportunity their coach provided for this was framed within a set of rules. The question of whether they are allowed to experiment or try new things in the game was frequently answered as follows:

Player 1: Yes, we are allowed to experiment. [But] our coach does not like it if a player doesn't pass the ball but rather does things for himself. He also tells us that we have to keep ball possession. And if we make a move, he really doesn't like that.

Player 2: Yes, he shows us that he isn't satisfied.

Interviewer: But what if you think it's a good move?

Player 1: Then the coach starts shouting. It's part of the team and the club. It is normal for us. You can learn from these things.

Player 2: Sometimes, when we are in the changing room [after a match], he gets angry if we play poorly. Some players are starting to laugh after a match. Then he gets really angry. He says, "Well now 
you're laughing, but you don't need to. You have lost the match, you played as badly as I said."

Player 3: Yes indeed, the coach can be angry. Once, after a match, he said: "Well, if you don't play well, you're out. There are hundreds of other guys who can take your place."

Player 1: Yes, but this is also how a professional soccer club works.

Player 2: Yes, but sometimes he gets too angry.

This conversation provides insight into the club culture, the team, the way rules are implemented, and the behavior that is expected from the players. The players articulated the opportunities for learning by exploration during a game. Yet, their constructions of the underlying intention of the coach, and the way the players explained how they practiced indicated that these opportunities could often not be utilized.

In one discussion, the players could clearly remember an example of one of the coach's exercises and the opportunity for exploring tactical skills in a game:

Player 1: [The coach said:] "I only give one example and then you must find solutions for this as a team." Sometimes, a player asked him: "Wouldn't this [other tactical solution] work better?" We must figure out the tactical way by ourselves. And if we don't understand it, he gives us some possible solutions. Thus, through this, we learn and improve how to play well.

Player 2: Yes, we learn and understand, because through discovering things, we search for our own solutions.

Hence, the opportunity for experimenting during practice that players experience seems to be common sense. At the same time, the players were aware that their coaches put constraints on the opportunity for exploring tactical strategies. This shows the tension between (prescriptive) instruction (by the coach) and through players' self-initiatives. In this respect, the players used different wordings to explain what they meant by practicing a game. For instance, they referred to (1) "game-like"; (2) "match-like"; or (3) "technical practice". A few players distinguished between learning and practicing soccer. Specifically, they used these terms when discussing 
their perceptions of practice during small-sided games at the club and learning at home or on the street:

Player 1: At home I learn new tricks. If I take a ball by myself I can practice.

Interviewer: And learning tricks when playing the small-sided game? Player 1: We are not allowed during practice.

Player 2: Yes, we only need to focus on the practice.

Player 3: Yes, we do not have time for it. We have time before the practice starts.

Player 1: We have practice of one and a half hours, there is no time.

Remarkably, exploring things and learning new tricks does not belong to practice at the club because of the lack of time they experience during practice. This indicates that players differentiated between the status of practicing (the game of soccer) at the club and what they called "learning or acquiring" (ball) skills (tricks). The players pointed out that the context of their home situation and playing soccer on the street were the places for learning new skills:

Player 1: [We learn these skills] by practicing outside on the street.

Player 2: Yes, but also when we practice here [at the club].

Interviewer: What's the difference between practicing at the club and practice outside?

Player 3: Outside I try things. I try to perform them better.

Player 2: Sometimes I go back to my former soccer club. I'm better than these players. Then I try new things. At PEC Zwolle, I follow instructions during practice.

Player 1: When I play outside there are many players. So, it's difficult to pass the ball or make actions.

These playersexplained that it depended on the context in which they played whether or not they could learn soccer skills. These contexts (e.g., their neighborhood) were defined as particular opportunities to learn specific ball skills. They could also articulate the latitude of what they are allowed to practice during the small-sided games. The practices at the club consisted of many rules and instructions. Hence, 
when they played soccer on the street or with children with lower skills, they felt challenged and encouraged to explore and improve their motor skills, while during small-sided games learning focused on tactical decision-making. In summary, practicing soccer seems to be interpreted by players in many different ways. They considered the practices at the club more comparable to the preparation of a competitive or as academic achievement: "You have to learn during practice. The things we learn are necessary for [the match on] Saturday. Actually, practice could be compared with having a school test."

\section{Discussion}

The central aim of the current study was to examine youth elite soccer players' perceptions of practicing in a modified game. In particular, our exploration focused on the players' comments of how they think they learned tactical decision-making skills. Secondly, the study described the process of designing and developing small-sided games in order to give an idea about an actual process of implementing modified game practices with the use of GBA. Designing practices with the use of GBA is consistent with recent concepts of the nonlinear pedagogy approach (Renshaw et al., 2010; Tan et al., 2012). This approach holds that varying the constraints of the game will shape the decision-making skills. In TGfU settings, decision-making is the central aspect of tactical learning. Accordingly, if the game form is accurately adapted to the players' current tactical skill level, they become fully aware of what tactically can be learned in game situations (without the coach instructing them in detail).

The results indicated that youth elite soccer players indeed learned the tactical skills that coaches wanted them to learn. Although the process of game design provided players with the opportunity to explore tactical decisions by themselves, their perceptions also indicated that practice often was rather prescriptive. This finding shows the difficulty coaches had in changing their own habits, even when they intend to do so. It is important for coaches to recognize that young players are very capable of perceiving such tensions (the goals/rules of the coach vs. exploring solutions).

The results also revealed that the young players had explicit views about the small-sided games they played. They had ideas of what they had learned (in terms of games/matches), of what they were supposed to learn (with respect to the position 
in the field), and why the practice was designed in the way it was (also relative to other practices). This suggests that the small-sided games were suitable for making players (more) responsible for their own learning. The players defined the practices at the club as the place for tactical skill learning, while playing at home was the place for learning new technical skills. Furthermore, the interviews suggested that the players saw their coach not only as a facilitator or an important resource for tactical skill learning, but sometimes also as the person who - at the end of the day - determines the rules. They were very aware of the rules and tasks the coaches wanted them to learn for the 'Saturday match'. The players were able to concisely articulate what the game objectives were, and what kind of tactical skills are needed for an effective learning outcome. Although GBA provided guidelines for proposing and adjusting the constraints of the game, it does not generally produce self-determining decision makers and contribute to successful learning outcomes. Moreover, the players' perceptions suggested that their learning experiences may be a result of what 'significant others' (coaches) want to see that has to be learned in the game. When these players were asked whether they were able to experiment or learn new ball skills during practice, they saw other contexts (e.g.,neighborhood) rather than practice at the club as the appropriate place for learning. They learned different things (and had different intentions for learning) at the club and the street. They did not consider club practice sessions as a way for learning ball skills (even though improving ball skills is what they seemed to enjoy most). Rather club practice sessions primarily served for learning the tactics of soccer. Obviously, these findings are in contrast with the assumptions and goals in game-centered approaches. Hence, even when coaches implement a TGfU approach, such as when integrating modified games and pedagogical principles, this does not guarantee the development of self-regulated decision makers.

In this regard, one issue that the players raised concerns taking risks and making tactical mistakes during game play. This was considered to be an important part for learning in practice (as also emphasized by the coach). Nevertheless, it appeared that the players felt a limited degree of freedom for exploring and experimenting during game practice. The players, however, had different perceptions of this when talking about the small-sided game. For example, some players made sense of the fact that they had to adhere to agreements about the game in perspective of the coach and the other team members. They contended that each position in the field consisted of either defending or attacking playing rules. This shows that the adapted game 
form provoked explicit learning experiences (through agreements) rather than exploration and experimentation to find solutions themselves. This finding suggests that at an early stage, coaches must seek (even more) for a variety of constraints (e.g., requiring the number of goals to be scored, counting attempts, or using a timeslot to score a certain amount of goals) to inform their players with the kind of intention, or attitude, they may play the adapted game while being reserved on advising on the best solution. Perhaps, the coaches in the current study became impatient, because the imposed constraint did suffice in enforcing a solution upon the players (or insufficiently challenged them to search the solution). Therefore the workspace for exploring solutions might be too small. Coaches may face the challenge of limiting the players' workspace, but without becoming overly verbally prescriptive. On the other hand, this suggests that for the development of rich learning environments, the coach needs to reflect on how much tactical instructions and solutions are desirable relative to the objectives of implementing small-sided games. A coach should have confidence in players finding the solution on their own.

The context in which this study has been conducted can be defined as specific and unique. Although the group of participants consisted of an elite group of highly skilled soccer players, the results from this study provide relevant insights that may also be useful for amateur sports or PE. It shows that notwithstanding the intentions of coaches implementing TGfU/GBA, there is no guarantee that pedagogical aims are fully achieved. In addition, adapted games with a TGfU approach provide 'constraining structures' for all learners to understand tactical knowledge (Slade, Webb, \& Martin, 2013). Hence, learning design in TGfU means that games are adapted to the skill levels of the players.

In conclusion, the players' perception reveals potential pitfalls in designing games with the aim of achieving learner centered environments. The soccer coaches want players that have learned to act flexibly when they play similar but tactically more complex situations, but they also want to make sure that their players know the tactical rules. Therefore, practices should be arranged by taking into account both aspects. Curriculum development and construction of practice plans need to be considered within a continuum of learning tactical decision-making skills from prescriptive explicit instructions and agreements (perhaps as a direct preparation for the match on Saturdays), and, on the other hand, creating opportunities for the acquisition of long-term flexible tactical skills. 


\section{References}

Barker, D., \& Rossi, A. (2011). Understanding teachers: The potential and possibility of discourse analysis. Sport, Education and Society, 16,139-158.

Bland, D. (2012). Analysing children's drawings: applied imagination. International Journal of Research \& Method in Education, 3,235-242.

Brooker, R., \& Macdonald, D. (1999). Did we hear you ?: Issues of student voice in a curriculum innovation, Journal of Curriculum Studies, 31(1), 83-97.

Bunker, B., \& Thorpe, R. (1986). The curriculum model. In R. Thorpe, D. Bunker, \& L. Almond (Eds.), Rethinking games teaching (pp. 7-10). Loughborough, England: University of Technology, Department of Physical Education and Sports Science.

Chow, J.Y., Davids, K., Button, C., Shuttleworth, R., Renshaw, I., \& Araújo, D. (2007). The role of nonlinear pedagogy in physical education. Review of Educational Research,77,251-278.

Claringbould, I., Knoppers,A., \& Jacobs, F. (2015). Young athletes and their coaches: disciplinary processes and habitus development. Leisure Studies,34(3),319-334.

Darbyshire, P., MacDougall, C., \& Schiller, W. (2005). Multiple methods in qualitative research with children: More insight or just more? Qualitative Research,4,417-436.

Davids, K., Button, C., \& Bennet, S. (2008). Dynamics of skill acquisition. A constraints-led approach. Champaign, IL: Human Kinetics.

Charmaz, K. (2006). Constructing grounded theory: A practical guide through qualitative analysis. London, England: Sage Publications Ltd.

Dyson, B. (2006). Students' perspectives of physical education. In D. Kirk,D. Macdonald \& M. O'Sullivan (Eds.), The handbook of physical education (pp. 326-346). London: Sage Publications.

Glaser, B.G., \& Strauss, A.L. (1967). The discovery of grounded theory: Strategies for qualitative research. New York: Aldine de Gruyter.

Gréhaigne, J.F., Bouthier, D., \& David, D. (1997). Dynamic-system analysis of opponent relationships in collective actions in soccer, Journal of Sports Sciences, 15 (2), 137-149.

Gréhaigne, J.F., Richard, J.F., \& Griffin, L.L. (2005). Teaching and learning team sports and games. London: Routledge.

Griffin, L.L., \& Patton, K. (2005). Two decades of Teaching Games for Understanding: Looking at the past, present, and future. In L.L. Griffin and J.I. Butler (Eds.), Teaching Games for Understanding. Theory, research and practice (pp. 1-17). Champaign, IL: Human Kinetics.

Harvey, S., \& Jarrett, K. (2014). A review of the game-centred approaches to teaching and coaching literature since 2006. Physical Education and Sport Pedagogy, 19(3), 278-300.

Holt, J.E., Ward, P., \& Wallhead, T.L. (2006). The transfer of learning from play practices to game play in young adult soccer players, Physical Education and Sport Pedagogy, 11 (2),101-118.

Kirk, D., \& MacPhail, A. (2002). Teaching games for understanding and situated learning: Rethinking the Bunker-Thorpe model. Journal of Teaching in Physical Education,21,177-192.

Koekoek, J.H., Dokman, I., \& Walinga, W. (2014). Sportspelen. Betekenisvol leren in de onderbouw van het voortgezet onderwijs. [Teaching Sportgames. Learning games in the first two years of high school.] Den Haag: Boom Lemma uitgevers.

Koekoek, J., \& Knoppers, A. (2013). The role of perceptions of friendships and peers in learning skills in physical education, Physical Education and Sport Pedagogy. DOI: 10.1080/17408989.2013.837432.

Koekoek, J., Knoppers, A., \& Stegeman, H. (2009). How do children think they learn skills in physical education? Journal of Teaching in Physical Education,28,310-332.

Lee, J. (2010). Student's evolving meanings and experiences with physical activity and sport. In M. O'Sullivan \& A. MacPhail (Eds.), Young people's voices in physical education and youth sport (pp. 11-30), London: Routledge. 
Light, R. (2006). Accessing the inner world of children: The use of student drawings in research on children's experiences of game sense. In R. Light (Ed.), Proceedings for the Asia Pacific Conference on Teaching Sport and Physical Education for Understanding (pp. 72-83). Sydney, Australia: University of Sydney.

MacPhail, A., Kinchin, G., \& Kirk, D. (2003). Students' conceptions of sport and sport education. European Physical Education Review, 9,285-299.

Oslin, J., \& Mitchell, S. (2006). Game-centered approaches to teaching physical education. In D. Kirk, D. Macdonald \& M. O'Sullivan (Eds.), The handbook of physical education (pp. 627-651). London, England: Sage Publications.

O'Sullivan, M., \& MacPhail,A. (2010). Young people's voices in physical education and youth sport. London: Routledge.

Pope, C.C. (2005). Once more with feeling: Affect and playing with the TGfU model. Physical Education \& Sport Pedagogy, 3,271-286.

Renshaw, I., Chow, J.Y., Davids, K., \& Hammond, J. (2010). A constraints-led perspective to understanding skill acquisition and game play: a basis for integration of motor learning theory and physical education praxis?. Physical Education and Sport Pedagogy, 15(2),117-137.

Renshaw, I.,Oldham,A.R,. \& Bawden, M. (2012). Nonlinear pedagogy underpins intrinsic motivation in sports coaching. The Open Sports Sciences Journal,5,88-99.

Richardson, K.P., Sheehy, D., \& Hopper, T. (2013). Modification by adaptation: Proposing another pedagogical principle for TGfU. In: A. Ovens, T. Hopper, \& J. Butler (Eds.), Complexity thinking in physical education (pp. 181-193), London: Routledge.

Rikard, G.L., \& Banville, D. (2006). High school student attitudes about physical education. Sport, Education and Society, 11(4), 385-400.

Slade, D.G., Webb, L.A., \& Martin, A.J. (2013). Providing sufficient opportunity to learn: A response to Gréhaigne, Caty and Godbout. Physical Education and Sport Pedagogy, 20(1), 67-78. DOI 10.108/17408989.2013.798405.

Strean, W.B., \& Holt, N.L. (2000). Coaches', athletes', and parents' perceptions of fun in youth sports: Assumptions about learning and implications for practice. Avante-Ontario-, 6(3), 84-98.

Tan, C.W.K., Chow, J.Y., \& Davids, K. (2012). 'How does TGfU work?': Examining the relationship between learning design in TGfU and a nonlinear pedagogy. Physical Education and Sport Pedagogy, 17(4), 331348. 


\section{Appendix 2 Co-auteursverklaring hoofdstuk 2}

Co-auteursverklaring

In overeenstemming met het Promovendireglement kunnen gepubliceerde artikelen opgenomen worden in het proefschrift. Indien dergelijke delen van het proefschrift in samenwerking zijn ontwikkeld, moeten deze delen vergezeld gaan van een verklaring van elk van de auteurs aandeel in het werk van de student.

Artikel en proefschrift

Deze co-auteursverklaring heeft betrekking op het volgende artikel:

Perspectives on physical literacy in continental Europe

Gepubliceerd in het volgende tijdschrift of andersoortige publicatie:

Whitehead, M. (Ed.) (2019). Physical literacy across the world (pp. 143-155). London: Routledge.

Het artikel maakt deel uit van het proefschrift met de volgende titel:

Exploring task-related student peer interactions in physical education

Proefschrift ingediend ter verdediging van de graad door:

Jeroen Koekoek 
Omvang bijdrage

Jeroen Koekoek

(Naam promovendus)

Heeft op de volgende schaal bijgedragen aan het bovenstaande artikel met de omvang:

A. Heeft bijgedragen aan de samenwerking (0-33\%).

B. Heeft aanzienlijk bijgedragen (34-66\%)

C. Heeft overwegend zelfstandig de werkzaamheden verricht (67-100\%)

\section{C}

Mogelijke aanvullende opmerkingen over bijdrage:

Handtekeningen co-auteurs

\begin{tabular}{|l|l|l|l|}
\hline Datum & Naam & Functie & Handtekening \\
\hline 28-11-2019 & Niek Pot & Co-auteur & \\
\hline $28-11-2019$ & Wytse Walinga & Co-auteur & \\
\hline 28-11-2019 & Ivo van Hilvoorde & Co-promotor & \\
\hline
\end{tabular}

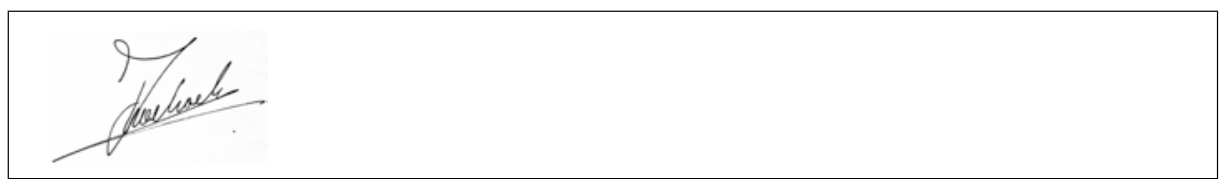

(handtekening promovendus) 


\section{Appendix 3 Co-auteursverklaring hoofdstuk 3}

Co-auteursverklaring

In overeenstemming met het Promovendireglement kunnen gepubliceerde artikelen opgenomen worden in het proefschrift. Indien dergelijke delen van het proefschrift in samenwerking zijn ontwikkeld, moeten deze delen vergezeld gaan van een verklaring van elk van de auteurs aandeel in het werk van de student.

Artikel en proefschrift

Deze co-auteursverklaring heeft betrekking op het volgende artikel: How do children think they learn skills in physical education?

Gepubliceerd in het volgende tijdschrift of andersoortige publicatie: Journal of Teaching in Physical Education

Het artikel maakt deel uit van het proefschrift met de volgende titel: Exploring task-related student peer interactions in physical education

Proefschrift ingediend ter verdediging van de graad door:

Jeroen Koekoek 
Omvang bijdrage

Jeroen Koekoek

(Naam promovendus)

Heeft op de volgende schaal bijgedragen aan het bovenstaande artikel met de omvang:

A. Heeft bijgedragen aan de samenwerking (0-33\%).

B. Heeft aanzienlijk bijgedragen (34-66\%)

C. Heeft overwegend zelfstandig de werkzaamheden verricht (67-100\%)

\section{C}

Mogelijke aanvullende opmerkingen over bijdrage:

Handtekeningen co-auteurs

\begin{tabular}{|l|l|l|l|}
\hline Datum & Naam & Functie & Handtekening \\
\hline 28-11-2019 & $\begin{array}{l}\text { Annelies } \\
\text { Knoppers }\end{array}$ & 1e promotor & Ornpon \\
\hline 28-11-2019 & Harry Stegeman & Co-auteur & \\
\hline
\end{tabular}

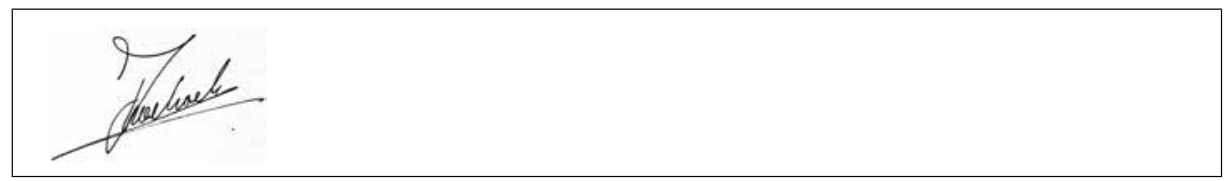

(handtekening promovendus) 


\section{Appendix 4 Co-auteursverklaring hoofdstuk 4}

Co-auteursverklaring

In overeenstemming met het Promovendireglement kunnen gepubliceerde artikelen opgenomen worden in het proefschrift. Indien dergelijke delen van het proefschrift in samenwerking zijn ontwikkeld, moeten deze delen vergezeld gaan van een verklaring van elk van de auteurs aandeel in het werk van de student.

Artikel en proefschrift

Deze co-auteursverklaring heeft betrekking op het volgende artikel:

The role of perceptions of friendships and peers in learning skills in physical education.

Gepubliceerd in het volgende tijdschrift of andersoortige publicatie:

Physical Education and Sport Pedagogy

Het artikel maakt deel uit van het proefschrift met de volgende titel:

Exploring task-related student peer interactions in physical education

Proefschrift ingediend ter verdediging van de graad door:

Jeroen Koekoek 
Omvang bijdrage

Jeroen Koekoek

(Naam promovendus)

Heeft op de volgende schaal bijgedragen aan het bovenstaande artikel met de omvang:

A. Heeft bijgedragen aan de samenwerking (0-33\%).

B. Heeft aanzienlijk bijgedragen (34-66\%)

C. Heeft overwegend zelfstandig de werkzaamheden verricht (67-100\%)

\section{C}

Mogelijke aanvullende opmerkingen over bijdrage:

Handtekeningen co-auteurs

\begin{tabular}{|l|l|l|l|}
\hline Datum & Naam & Functie & Handtekening \\
\hline 28-11-2019 & $\begin{array}{l}\text { Annelies } \\
\text { Knoppers }\end{array}$ & 1e promotor & Oetropos \\
\hline
\end{tabular}

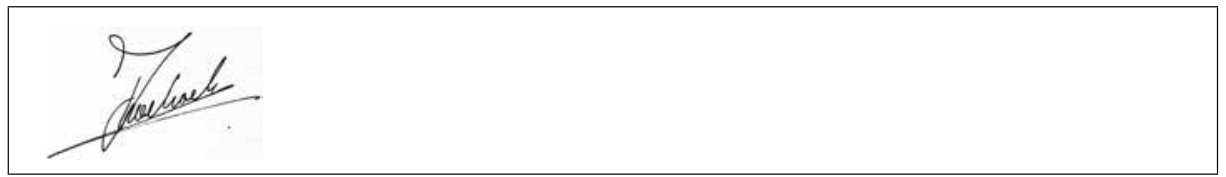

(handtekening promovendus) 


\section{Appendix 5 Co-auteursverklaring hoofdstuk 5}

Co-auteursverklaring

In overeenstemming met het Promovendireglement kunnen gepubliceerde artikelen opgenomen worden in het proefschrift. Indien dergelijke delen van het proefschrift in samenwerking zijn ontwikkeld, moeten deze delen vergezeld gaan van een verklaring van elk van de auteurs aandeel in het werk van de student.

Artikel en proefschrift

Deze co-auteursverklaring heeft betrekking op het volgende artikel:

Gender categorizations during group work in physical education

Gepubliceerd in het volgende tijdschrift of andersoortige publicatie: Journal of Teaching in Physical Education

Het artikel maakt deel uit van het proefschrift met de volgende titel: Exploring task-related student peer interactions in physical education

Proefschrift ingediend ter verdediging van de graad door:

Jeroen Koekoek 
Omvang bijdrage

Jeroen Koekoek

(Naam promovendus)

Heeft op de volgende schaal bijgedragen aan het bovenstaande artikel met de omvang:

A. Heeft bijgedragen aan de samenwerking (0-33\%).

B. Heeft aanzienlijk bijgedragen (34-66\%)

C. Heeft overwegend zelfstandig de werkzaamheden verricht (67-100\%)

\section{C}

Mogelijke aanvullende opmerkingen over bijdrage:

Handtekeningen co-auteurs

\begin{tabular}{|l|l|l|l|}
\hline Datum & Naam & Functie & Handtekening \\
\hline 28-11-2019 & $\begin{array}{l}\text { Annelies } \\
\text { Knoppers }\end{array}$ & 1e promotor & Oetropos \\
\hline
\end{tabular}

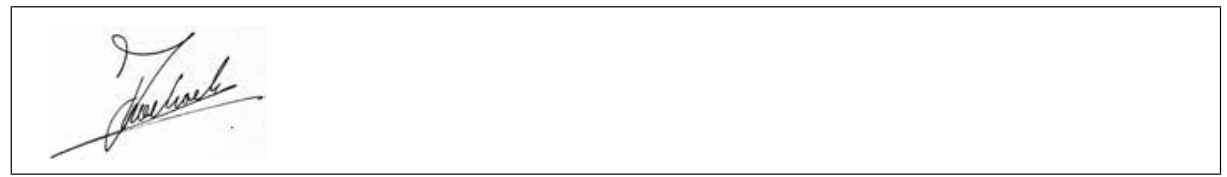

(handtekening promovendus) 


\section{Appendix 6 Co-auteursverklaring hoofdstuk 6}

Co-auteursverklaring

In overeenstemming met het Promovendireglement kunnen gepubliceerde artikelen opgenomen worden in het proefschrift. Indien dergelijke delen van het proefschrift in samenwerking zijn ontwikkeld, moeten deze delen vergezeld gaan van een verklaring van elk van de auteurs aandeel in het werk van de student.

Artikel en proefschrift

Deze co-auteursverklaring heeft betrekking op het volgende artikel:

Exploring students' perceptions of video-guided debates in a game-based basketball setting

Gepubliceerd in het volgende tijdschrift of andersoortige publicatie:

Physical Education and Sport Pedagogy

Het artikel maakt deel uit van het proefschrift met de volgende titel:

Exploring task-related student peer interactions in physical education

Proefschrift ingediend ter verdeiging van de graad door:

Jeroen Koekoek 
Omvang bijdrage

Jeroen Koekoek

(Naam promovendus)

Heeft op de volgende schaal bijgedragen aan het bovenstaande artikel met de omvang:

A. Heeft bijgedragen aan de samenwerking (0-33\%).

B. Heeft aanzienlijk bijgedragen (34-66\%)

C. Heeft overwegend zelfstandig de werkzaamheden verricht (67-100\%)

\section{C}

Mogelijke aanvullende opmerkingen over bijdrage:

Handtekeningen co-auteurs

\begin{tabular}{|l|l|l|l|}
\hline Datum & Naam & Functie & Handtekening \\
\hline 28-11-2019 & $\begin{array}{l}\text { John van der } \\
\text { Kamp }\end{array}$ & Co-auteur & \\
\hline $28-11-2019$ & Wytse Walinga & Co-auteur & \\
\hline $28-11-2019$ & Ivo van Hilvoorde & Co-promotor & \\
\hline
\end{tabular}

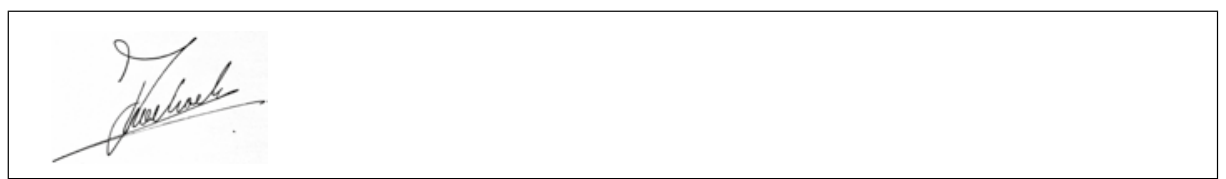

(handtekening promovendus) 


\section{Appendix 7 Co-auteursverklaring hoofdstuk 7}

Co-auteursverklaring

In overeenstemming met het Promovendireglement kunnen gepubliceerde artikelen opgenomen worden in het proefschrift. Indien dergelijke delen van het proefschrift in samenwerking zijn ontwikkeld, moeten deze delen vergezeld gaan van een verklaring van elk van de auteurs aandeel in het werk van de student.

Artikel en proefschrift

Deze co-auteursverklaring heeft betrekking op het volgende artikel:

Aligning digital video technology with game pedagogy in physical education

Gepubliceerd in het volgende tijdschrift of andersoortige publicatie:

Journal of Physical Education, Recreation \& Dance

Het artikel maakt deel uit van het proefschrift met de volgende titel:

Exploring task-related student peer interactions in physical education

Proefschrift ingediend ter verdediging van de graad door:

Jeroen Koekoek 
Omvang bijdrage

Jeroen Koekoek

(Naam promovendus)

Heeft op de volgende schaal bijgedragen aan het bovenstaande artikel met de omvang:

A. Heeft bijgedragen aan de samenwerking (0-33\%).

B. Heeft aanzienlijk bijgedragen (34-66\%)

C. Heeft overwegend zelfstandig de werkzaamheden verricht (67-100\%)

\section{C}

Mogelijke aanvullende opmerkingen over bijdrage:

Handtekeningen co-auteurs

\begin{tabular}{|l|l|l|l|}
\hline Datum & Naam & Functie & Handtekening \\
\hline 28-11-2019 & $\begin{array}{l}\text { Hans van der } \\
\text { Mars }\end{array}$ & Co-auteur & Co-auteur \\
\hline $28-11-2019$ & $\begin{array}{l}\text { John van der } \\
\text { Kamp }\end{array}$ & Co-auteur \\
\hline 28-11-2019 & Wytse Walinga \\
\hline 28-11-2019 & Ivo van Hilvoorde & Co-promotor & \\
\hline
\end{tabular}

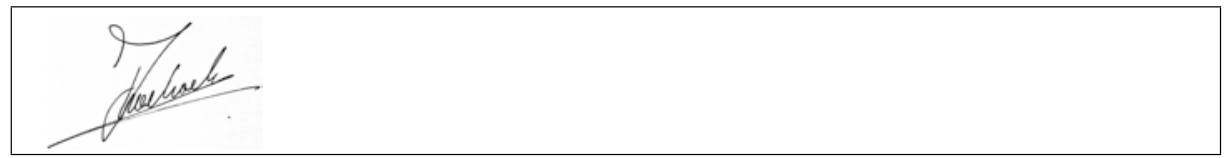

(handtekening promovendus) 


\section{Appendix $8 \mathrm{~A}$ and $8 \mathrm{~B}$ Topics, sample questions, and interview schedule (Chapter 3)}

\section{A: Topics for interviews and sample questions (phase 1)}

Motivation (importance and perceived competence)

1. Do you enjoy physical education classes? (Can you give examples of how you feel or what you think about them?)

2. Do you think physical education is important? (Explain why)

3. What do think about your own skill-level in physical education classes? (Explain this in relation to skill levels of other children; on what is this comparison based?)

Construction of knowledge as a result of active learning

1. Examples of learning experiences from physical education classes: what and how do you learn a task?

2. How do you know if you can learn something in a game or task? How do you know what part you have to learn?

3. What are your experiences when you do something that is just too easy or too difficult to learn? Describe (why, how and when).

Active learning and cooperating with others

4. What can you tell me about your class during physical education? How do you cooperate with others when you are trying to learn a task?

5. Do you prefer to work with certain children when you learning a task during physical education? (Explain) 
Information about and instructions from the teacher

1. What can you tell me about your physical education teacher?

2. Can you give examples of something you learned by the presence or intervention of your teacher? What happened and how did he/she try to teach you a task?

\section{B: Focus groups interview schedule and topics (phase 3)}

1. Conversation of the drawing: explanation of what is drawn, why and how.

2. Drawing: focus to the learning part. What do children think they have learned in the learning task?

3. Meanings of group compositions: meaning given to learning tasks in perspective of working with classmates, friends or participate in an annoying group.

4. Relationship between children's learning and teachers' efforts and intentions: experiences and expectations. 


\section{Appendix 9 Examples of student answers to the single question (Chapter 6)}

Examples of Student Answers to the Single Question After Each Basketball Lesson (Video and Verbal group).

\begin{tabular}{|c|c|c|c|c|}
\hline STUDENT & SEX & LESSON 1 & LESSON 2 & LESSON 3 \\
\hline & & $\begin{array}{l}\text { What can you tell about } \\
\text { the difference between an } \\
\text { appropriate or an inappropriate } \\
\text { chosen shot on the basket? }\end{array}$ & Same question as after lesson 1 & $\begin{array}{l}\text { What did you tactically learned } \\
\text { about the shot on the basket? }\end{array}$ \\
\hline 1. & $\mathbf{F}$ & $\begin{array}{l}\text { An appropriately chosen shot is } \\
\text { when you are in a free position } \\
\text { and passing the ball well } \\
\text { together } \\
\text { An inappropriately chosen shot } \\
\text { is when you play the ball only } \\
\text { by yourself }\end{array}$ & $\begin{array}{l}\text { An inappropriately chosen shot } \\
\text { is when you shoot too often } \\
\text { without having a free position }\end{array}$ & $\begin{array}{l}\text { Only shoot on the basket when I } \\
\text { am in a free position }\end{array}$ \\
\hline 2. & M & I have no idea & $\begin{array}{l}\text { An appropriately chosen shot } \\
\text { is when I have a free position } \\
\text { with enough space to shoot on } \\
\text { the basket }\end{array}$ & $\begin{array}{l}\text { Only shoot on the basket when I } \\
\text { am in a free position }\end{array}$ \\
\hline 3. & $\mathbf{F}$ & $\begin{array}{l}\text { An appropriately chosen shot } \\
\text { does have many chances on } \\
\text { success and a poor shot doesn't } \\
\text { An inappropriately chosen shot } \\
\text { is from a distance that is too far } \\
\text { or too close }\end{array}$ & $\begin{array}{l}\text { An appropriately chosen shot is } \\
\text { from the right distance to the } \\
\text { basket }\end{array}$ & $\begin{array}{l}\text { Not too far from the basket } \\
\text { If someone stays in front of you: } \\
\text { don't shoot! }\end{array}$ \\
\hline 4. & M & $\begin{array}{l}\text { An appropriately chosen shot } \\
\text { is if you wait not too long with } \\
\text { shooting on the basket }\end{array}$ & $\begin{array}{l}\text { When you aim on the basket } \\
\text { too far from the basket it is } \\
\text { inappropriately chosen }\end{array}$ & $\begin{array}{l}\text { Watching } \\
\text { If you can shoot then shoot! } \\
\text { Not too far or too close from } \\
\text { the basket }\end{array}$ \\
\hline
\end{tabular}





\section{Exploring task-related student peer interactions in physical education}

Physical education (PE) is often organized in coeducational settings where collaboration between pupils is a central aspect of teaching practice. The student interactions that evolve from this collaboration influence learning situations in PE classroom settings. However, scholars, educators and policy makers have largely neglected the role that the construction of task-related interactions by students in PE may inform learning. An investigation of the social context in PE can contribute to understandings of when and how these task-related peer interactions may occur. This book describes the content of instruction-based peer interactions, how students think about collaborative tasks and how they construct these processes in PE. Based on the findings of various empirical studies, the author discusses the possible sources and frameworks that may explain the ambiguity and contextual processes of peer interactions in PE. He locates notions of collaborative work in PE in theoretical frameworks such as social constructivism and situated learning and uses them to explain student perceptions about task-related interactions. The book elaborates on the findings and implications of the included studies by attempting to link empirical evidence with PE practices. For example, a few studies in the book inform PE teachers about how they can align digital video technology with formal student discussions during lessons that incorporate a game based approach such as Teaching Games for Understanding.

This book can be of interest to and useful for scholars and teacher educators as well as practitioners such as teachers and coaches who focus on pedagogies in the context of PE.

Jeroen Koekoek (1973) obtained his BA degree in Physical Education at CALO of Windesheim University of Applied Sciences in Zwolle, the Netherlands. Subsequently, he studied Human Movement Sciences at the VU Amsterdam. He conducted his $\mathrm{PhD}$ research at Utrecht University. Currently, Jeroen works as senior lecturer and researcher Physical Education and Sport Pedagogy in the research unit Human Movement, School \& Sports of Windesheim University of Applied Sciences.
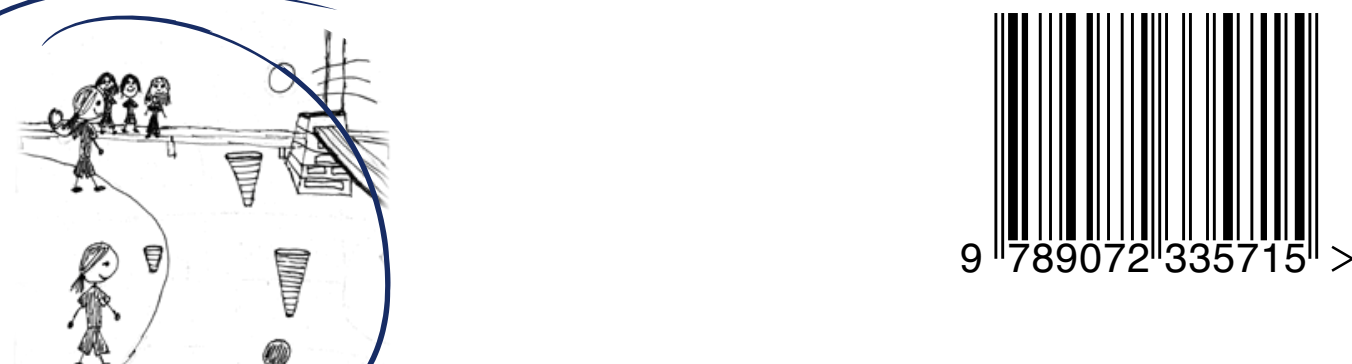